\title{
Picophytoplankton Photoacclimation and Mixing in the Surface Oceans
}

by

\section{Jeffrey A. Dusenberry}

\section{B.S., Environmental Engineering \\ Northwestern University, 1987}

\begin{abstract}
Submitted in Partial Fulfillment of the Requirements for the Degree of
\end{abstract}
Doctor of Philosophy

at the

Massachusetts Institute of Technology

and the

Woods Hole Oceanographic Institution

February 1995

(C) 1

1995 Massachusetts Institute of Technology

Woods Hole Oceanographic Institution

All Rights Reserved

Signature of Author
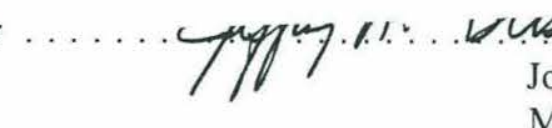

\footnotetext{
Joint Program in Biological Oceanography

Massachusetts Institute of Technology and

'oods Hole Oceanographic Institution
}

Certified by . C C

Sallie W. Chisholm, Professor

Department of Civil and Environmental Engineering

Massachusetts Institute of Technology

Thesis Advisor

Certified by $\ldots \ldots \ldots \ldots \ldots \ldots \ldots \ldots \ldots \ldots \ldots \ldots \ldots \ldots \ldots \ldots \ldots \ldots \ldots \ldots$

Robert J. Olson, Associate Scientist

Biology Department

Woods Hole Oceanographic Institution

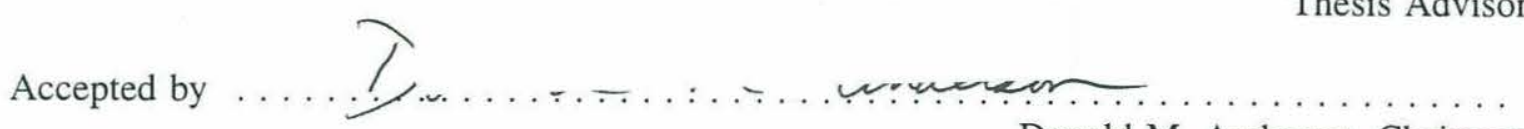

Donald M. Anderson, Chairman

Joint Committee in Biological Oceanography

MIT/WHOI Joint Program in Oceanography and Oceanographic Engineering 
To Mom:

Whose dedication, to life and to her children; whose courage and strength; and whose example continue to inspire 


\title{
Picophytoplankton Photoacclimation and Mixing in the Surface Oceans
}

by

\author{
Jeffrey A. Dusenberry
}

\begin{abstract}
Fluctuations in light intensity due to vertical mixing in the open ocean surface layer will affect phytoplankton physiology. Conversely, indicators of phytoplankton photoacclimation will be diagnostic of mixing processes if the appropriate kinetics are known. A combination of laboratory and field experimental work, field observations, and theoretical models were used to quantify the relationship between vertical mixing and photoacclimation in determining the time and space evolution of single cell optical properties for the photosynthetic picoplankton, Prochlorococcus spp. Diel time-series observations from the Sargasso Sea reveal patterns in single-cell fluorescence distributions within Prochlorococcus spp. populations which appear to correspond to decreasing mixing rates and photoacclimation during the day, and increased mixing at night. Reciprocal light shift experiments were used to quantify the photoacclimation kinetics for Prochlorococcus spp. fluorescence.

A laboratory continuous culture system was developed which could simulate the effects of mixing across a light gradient at the level of the individual cell. This system was operated at four different simulated diffusivities. Prochlorococcus marinus strain Med4 fluorescence distributions show distinct patterns in the mean and higher moments which are consistent with a simple quasi-steady turbulent diffusionphotoacclimation model. In both, daytime photoacclimation drove the development of a gradient in mean fluorescence, a decrease in variance overall, and skewing of distributions away from the boundaries. These results suggest that picophytoplankton single-cell fluorescence distributions could prove to be a useful diagnostic indicator of the mixing environment.
\end{abstract}

Thesis Advisor: Sallie W. Chisholm

Title: Professor

Thesis Advisor: Robert J. Olson

Title: Associate Scientist 


\section{Acknowledgments}

This project, in its existing scope, would have not been possible without the substantial support of many, many individuals. I have aknowledged many of these individuals in appropriate chapters in order to more directly recognize their specific contributions.

I thank the members of my thesis committee: Penny Chisholm, Rob Olson, Jim Price and John Waterbury, for their guidance and support throughout this project. Phil Gschwend generously agreed to chair my defense. My co-advisors, Penny Chisholm and Rob Olson, complemented each other well. From Penny I learned much about mentoring and politics. She was adamant in recognizing the value and quality of this work. Rob had a sharp eye and keen enthusiasm for some of the more "nittygritty" aspects of science. I appreciate his technical expertise and hands on knowledge.

The other members of the labs have been supportive as well, offering expertise, insight, and a helping hand: Ginger Armbrust, Kent Bares, Brian Binder, Raffaella Casotti, Michele DuRand, Liz Mann, Lisa Moore, Ena Urbach and Erik Zettler. I also thank the M.I.T. UROP program and the numerous UROPs who have participated in this work. In particular, Zack Johnson, my first UROP, through whom I learned a lot about teaching others and being a mentor. Like the rest of the known universe, I owe a debt of gratitude to Sheila Frankel, whose "behind the scenes" expertise and skills are unparalleled.

On a more personal note, I'd like to thank Roland and Jeff. I learned so much about life from both of them and enjoyed our times together. Despite the geographic, emotional and philosophical differences that separate us now, they will always remain special to me. 
I thank my family for their never ending emotional and financial support, even in the face of seemingly overwhelming odds ("another year? again?"). Especially Mom, who was always there for emotional support when most needed, always ready to listen to me complain, always ready to share my sorrows and my triumphs. She raised three children in face of strong odds, and instilled in me the courage and strength to pursue my ideals. These words are woefully inadequate to express my gratitude.

And, I'd like to thank the latest addition to my family, Ember ("Thesis? Ha! I say we play frisbee!"). She has brought joy, humor, patience and understanding into my life in a way no human ever could.

This project received primary financial support from the Office of Naval Research, with additional support from the National Science Foundation, the Environmental Protection Agency, Sea Grant, M.I.T. Sloan funds and M.I.T. Department of Civil and Environmental Engineering funds. I also wish to acknowledge support from a Rockwell Fellowship and a National Science Foundation Graduate Fellowship. 


\section{Table of Contents}

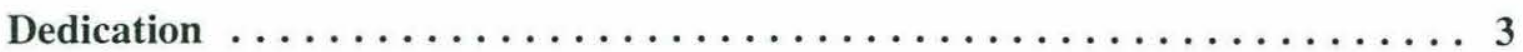

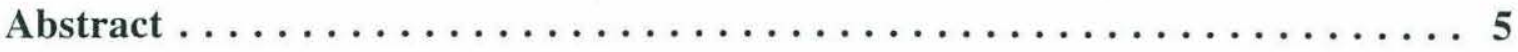

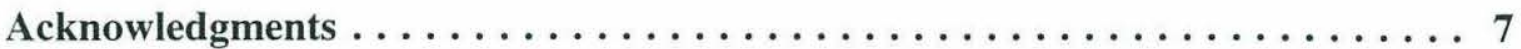

Table of Contents $\ldots \ldots \ldots \ldots \ldots \ldots \ldots \ldots \ldots \ldots \ldots \ldots$

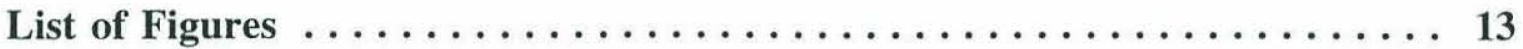

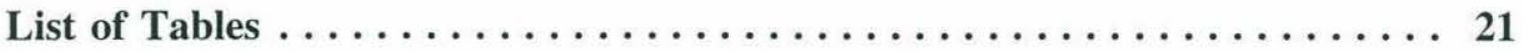

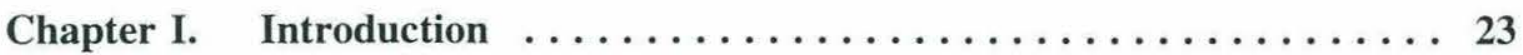

References ........................ 29

Chapter II. Field Observations of Picophytoplankton Single-Cell Optical Properties ....................... 31

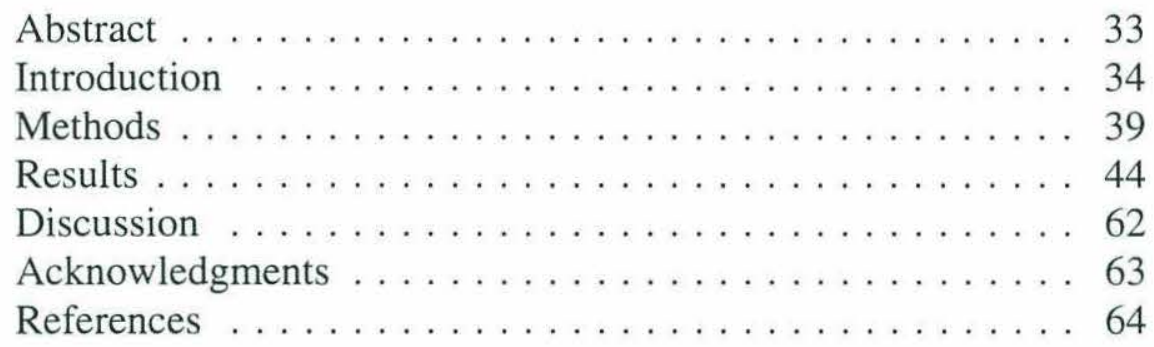

Chapter III. Photoacclimation in Photosynthetic Picoplankton and an Analysis of their Potential Use as Tracers for Vertical Mixing . . 67

Abstract ......................... 69

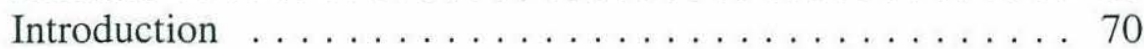

Methods ...................... 72

Results . . . . . . . . . . . . . . . . . 75

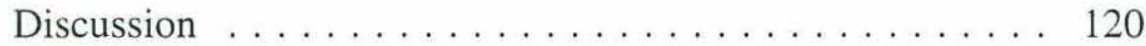

Acknowledgments ... . . . . . . . . . . . . . . . 124

References ....................... 125 
Chapter IV. Steady State Single-Cell Model Simulations of

Photoacclimation in a Vertically Mixed Layer . . . . . . . . . . 127

Abstract . . . . . . . . . . . . . . . . 129

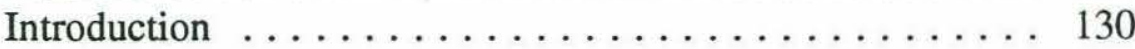

Model Assumptions . . . . . . . . . . . . . 132

Results ....................... 137

Discussion ....................... 152

Acknowledgments ................... 154

References .................... 155

Chapter V. Experimental Analysis of the Effects of Vertical Mixing on Picoplankton Fluorescence Distributions: A Calibration for Field Applications $\ldots \ldots \ldots \ldots \ldots \ldots \ldots \ldots \ldots \ldots \ldots \ldots$

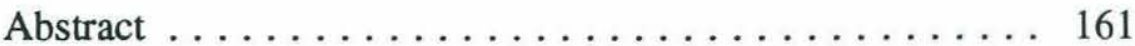

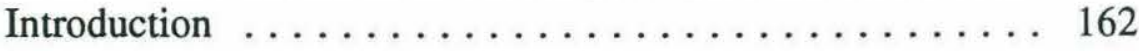

Mixostat Apparatus . . . . . . . . . . . . . . . . . 164

Methods ........................... 164

Results ...................... 170

Mixostat / Mixed Layer Model . . . . . . . . . . . . . 183

Model Assumptions:

Growth Model . . . . . . . . . . . . 192

Photoacclimation - Diffusion Model . . . . . . . . 194 Model Results:

Growth Model . . ............... 195

Photoacclimation - Diffusion Model ........ 202

Discussion ....................... 212

Acknowledgments . . . . . . . . . . . . . . . . . 214

References .................... 215

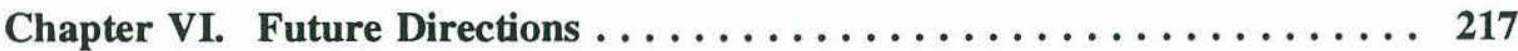

Field ....................... 219

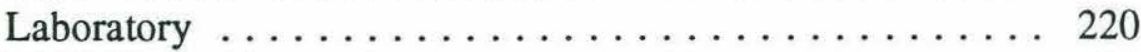

Modelling . . . . . . . . . . . . . . . 221

References ................... 223

Appendix A. Chapter II Ancillary Data $\ldots \ldots \ldots \ldots \ldots \ldots \ldots \ldots \ldots 225$ 
Appendix B. Use of Forward Angle Light Scatter as a Proxy for Size in Prochlorococcus marinus Strain Med4

Methods ........................ 235

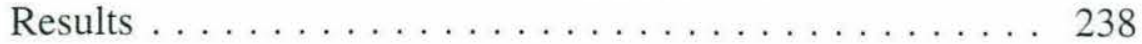

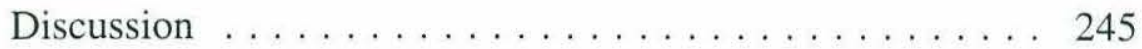

References .................. 260

Appendix C. Chapter III Ancillary Data $\ldots \ldots \ldots \ldots \ldots \ldots \ldots \ldots \ldots 261$

Appendix D. Chapter IV Numerical Algorithm .............. 267

Model Definition . . . . . . . . . . . . . . . . . . . 269

Boundary Conditions .................. 271

Matrix Formulation and Solution . . . . . . . . . 275

Appendix E. Chapter V Numerical Algorithm $\ldots \ldots \ldots \ldots \ldots \ldots \ldots 277$

Model Definition . . . . . . . . . . . . . . . . 279

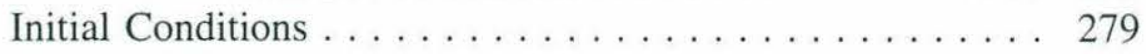

Temporal Propagation ................ 282

Reference ................... 286

Appendix F. Increasing the sensitivity of a FACScan flow cytometer to study oceanic picoplankton. (reprinted from Limnology and Oceanography) ........................ 287

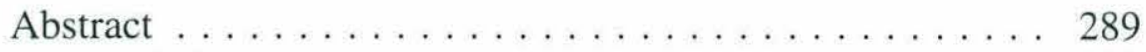

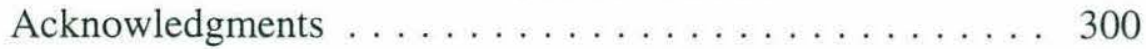

References ..................... 301 


\section{List of Figures}

\section{Chapter II. Field Observations of Picophytoplankton Single-Cell Optical Properties}

Figure 1. "Typical" flow cytometric scattergram of a surface sample from the Sargasso Sea. . . . . . . . . . . . . . . . . 37

Figure 2. Same samples presented in figure 1, replotted to show the $18^{\circ}$ rotation used to remove diel patterns due to growth and division from red fluorescence signals. . . . . . . . . . . . . . 43

Figure 3. Examples of frequency distributions with non-zero third and

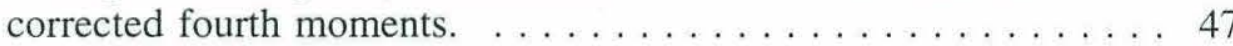

Figure 4. Density (sigma-t) contours of October 1989 Sargasso Sea timeseries.

Figure 5. Flow cytometric observations of Prochlorococcus spp. in the upper $50 \mathrm{~m}$ from the October 1989 Sargasso Sea time-series. . . . . . . . 51

Figure 6. Density (sigma-theta) contours during the January 1992 Sargasso

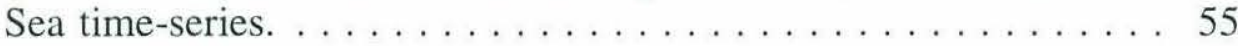

Figure 7. Flow cytometric observations of Prochlorococcus spp. in the upper $75 \mathrm{~m}$ from the January 1992 Sargasso Sea time-series. . . . . . . . 57

Figure 8. Prochlorococcus spp. normalized red fluorescence mean (a), variance (b), third moment (c), and corrected fourth moment (fourth moment less three times the standard deviation, s, to the fourth power) (d) for the October time-series. . . . . . . . . . . 59

Figure 9. Prochlorococcus spp. normalized red fluorescence mean (a), variance (b), third moment (c), and corrected fourth moment (fourth moment less three times the standard deviation, s, to the fourth power) (d) for the January time-series. . . . . . . . . . . 61

\section{Chapter III. Photoacclimation in Photosynthetic Picoplankton and an Analysis of their Potential Use as Tracers for Vertical Mixing}

Figure 1. Time-series measurements of mean forward angle light scatter for P. marinus strain Med4 during a laboratory reciprocal light shift 


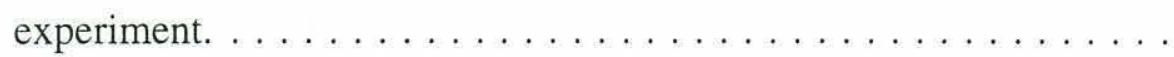

Figure 2. Time-series measurements of mean red fluorescence for $P$. marinus strain Med4 during the reciprocal light shift experiment presented

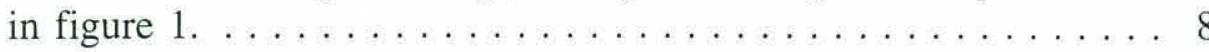

Figure 3. Time-series measurements of cell concentration for P. marinus strain Med4 during the reciprocal light shift experiment presented

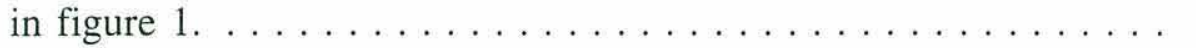

Figure 4. Correlation between mean red fluorescence and mean forward angle light scatter for the control (unshifted) cultures in the laboratory experiment shown in figures 1 and $2 . \ldots \ldots \ldots \ldots$

Figure 5. Time-series measurements of mean red fluorescence normalized to the cube root of the mean forward angle light scatter signal for $P$. marinus strain Med4 during the reciprocal light shift experiment

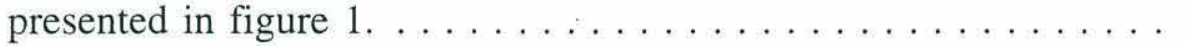

Figure 6. Time-series measurements of mean forward angle light scatter for Prochlorococcus spp. during a simulated in-situ reciprocal light shift experiment carried out during the October 1989 cruise to the Sargasso Sea. . . . . . . . . . . . . . . . . . 9

Figure 7. Time-series measurements of mean red fluorescence for Prochlorococcus spp. during the simulated in-situ reciprocal light shift experiment represented in figure $6 \ldots \ldots \ldots . \ldots 93$

Figure 8. Time-series measurements of cell concentration for Prochlorococcus spp. during the simulated in-situ reciprocal light shift experiment presented in figure $6 . \ldots \ldots \ldots \ldots . \ldots 95$

Figure 9. Time-series measurements of mean red fluorescence normalized to the cube root of the mean forward angle light scatter for Prochlorococcus spp. during the simulated in-situ reciprocal light shift experiment presented in figure $6 \ldots \ldots \ldots \ldots 7$

Figure 10. Time-series measurements of mean forward angle light scatter for Prochlorococcus spp. during a simulated in-situ reciprocal light shift experiment carried out during the July 1990 cruise to the Sargasso Sea.

Figure 11. Time-series measurements of mean red fluorescence for Prochlorococcus spp. during the simulated in-situ reciprocal light 
shift experiment represented in figure $10 \ldots \ldots \ldots \ldots \ldots \ldots$

Figure 12. Time-series measurements of cell concentration for Prochlorococcus spp. during the simulated in-situ reciprocal light shift experiment represented in figure $10 \ldots \ldots \ldots \ldots \ldots \ldots$

Figure 13. Time-series measurements of mean red fluorescence normalized to the cube root of the mean forward angle light scatter for Prochlorococcus spp. during the simulated in-situ reciprocal light shift experiment represented in figure $10 \ldots \ldots \ldots \ldots \ldots . .107$

Figure 14. Time-series measurements of mean forward angle light scatter for Prochlorococcus spp. during a simulated in-situ reciprocal light shift experiment carried out during the August 1991 cruise to the equatorial Pacific. .................... 11

Figure 15. Time-series measurements of cell concentration for Prochlorococcus spp. during the simulated in-situ reciprocal light shift experiment presented in figure $14 \ldots \ldots \ldots \ldots \ldots \ldots 113$

Figure 16. Time-series measurements of mean red fluorescence for Prochlorococcus spp. during the simulated in-situ reciprocal light shift experiment presented in figure $14 \ldots \ldots \ldots \ldots \ldots \ldots .115$

Figure 17. Time-series measurements of mean red fluorescence normalized to the square root of mean forward angle light scatter for Prochlorococcus spp. during the simulated in-situ reciprocal light shift experiment presented in figure $14 . \ldots \ldots \ldots \ldots \ldots \ldots .117$

Figure 18. Estimates of the fully acclimated values of normalized red fluorescence based on fits of the logistic model (Eq. 2) to the data presented in figures 5,9,13 and 17, plotted as a function of

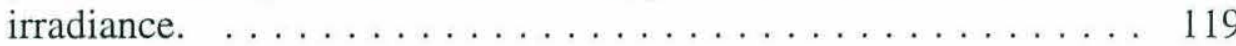

Figure 19. Estimates of the photoacclimation rate for normalized red fluorescence based on fits of the logistic model (Eq. 2) to the data presented in figures 5, 9, 13 and 17 , plotted as a function of

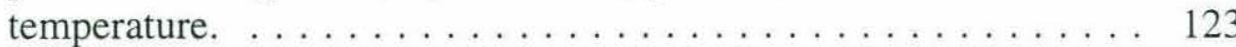

\section{Chapter IV. Steady State Single-Cell Model Simulations of Photoacclimation in a Vertically Mixed Layer}

Figure 1. Probability density of a photoacclimative parameter as a function 
of depth generated by the (a) first-order or (b) logistic

photoacclimation-diffusion model for a range of values of $\mathrm{K}_{\mathrm{v}} \gamma^{-1} \mathrm{~h}^{-2} .141$

Figure 2. Contours of mean photoacclimative parameter, $\Gamma$, as a function of depth (relative to the mixed layer depth) and $\mathrm{K}_{\mathrm{v}} \gamma^{-1} \mathrm{~h}^{-2}$ for the firstorder (a) and logistic (b) photoacclimation models.

Figure 3. Contours of the variance in the photoacclimative parameter, $\Gamma$, as a function of depth (relative to the mixed layer depth) and $\mathrm{K}_{\mathrm{v}} \gamma^{-1} \mathrm{~h}^{-2}$ for the first-order (a) and logistic (b) photoacclimation models. . 147

Figure 4. Contours of the third moment of the photoacclimative parameter, $\Gamma$, as a function of depth (relative to the mixed layer depth) and $\mathrm{K}_{\mathrm{v}} \gamma^{-1} \mathrm{~h}^{-2}$ for the first-order (a) and logistic (b) photoacclimation models. . . . . . . . . . . . . . . . . . . . . . . . 149

Figure 5. Contours of the fourth moment, less three times the standard deviation to the fourth power, of the photoacclimative parameter, $\Gamma$, as a function of depth (relative to the mixed layer depth) and $\mathrm{K}_{\mathrm{v}} \gamma^{-1} \mathrm{~h}^{-2}$ for the first-order (a) and logistic (b) photoacclimation

\section{Chapter V. Experimental Analysis of the Effects of Vertical Mixing on Picoplankton Fluorescence Distributions: A Calibration for Field Applications}

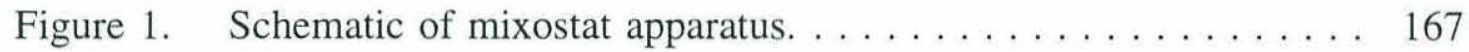

Figure 2. Time averaged cell concentrations for laboratory mixostat

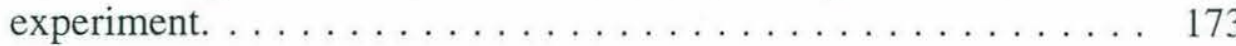

Figure 3. Time series observations of $P$. marinus optical properties in the mixostat apparatus operated at a simulated diffusivity of $40 \mathrm{~cm}^{2} \mathrm{~s}^{-1} .175$

Figure 4. Time series observations of $P$. marinus optical properties in the mixostat apparatus operated at a simulated diffusivity of $80 \mathrm{~cm}^{2} \mathrm{~s}^{-1} .177$

Figure 5. Time series observations of $P$. marinus optical properties in the mixostat apparatus operated at a simulated diffusivity of $300 \mathrm{~cm}^{2} \mathrm{~s}^{-1}$

Figure 6. Time series observations of $P$. marinus optical properties in the mixostat apparatus operated at a simulated diffusivity of 
Figure 7. Time-series contours of the mean and higher moments of normalized red fluorescence from the mixostat simulation operated at $40 \mathrm{~cm}^{2} \mathrm{~s}^{-1}$.

Figure 8. Time-series contours of the mean and higher moments of normalized red fluorescence from the mixostat simulation operated at $80 \mathrm{~cm}^{2} \mathrm{~s}^{-1}$

Figure 9. Time-series contours of the mean and higher moments of normalized red fluorescence from the mixostat simulation operated at $300 \mathrm{~cm}^{2} \mathrm{~s}^{-1}$.

Figure 10. Time-series contours of the mean and higher moments of normalized red fluorescence from the mixostat simulation operated at $600 \mathrm{~cm}^{2} \mathrm{~s}^{-1}$.

Figure 11. Cell concentrations predicted by the growth model _. . . . . . 197

Figure 12. Substrate (nitrogen) concentrations predicted by the growth model. 199

Figure 13. Growth rates predicted by the growth model. . . . . . . . . 201

Figure 14. Model simulations of the mean and higher moments of a photoacclimative property, $\Gamma$, in a mixed layer with a diffusivity of $40 \mathrm{~cm}^{2} \mathrm{~s}^{-1}$, and a photoacclimative rate, $\gamma$, of $3.5 \mathrm{~d}^{-1} \ldots \ldots \ldots 205$

Figure 15. Model simulations of the mean and higher moments of a photoacclimative property, $\Gamma$, in a mixed layer with a diffusivity of $80 \mathrm{~cm}^{2} \mathrm{~s}^{-1}$, and a photoacclimative rate, $\gamma$, of $3.5 \mathrm{~d}^{-1} \ldots \ldots \ldots 207$

Figure 16. Model simulations of the mean and higher moments of a photoacclimative property, $\Gamma$, in a mixed layer with a diffusivity of $300 \mathrm{~cm}^{2} \mathrm{~s}^{-1}$, and a photoacclimative rate, $\gamma$, of $3.5 \mathrm{~d}^{-1} \ldots \ldots \ldots 209$

Figure 17. Model simulations of the mean and higher moments of a photoacclimative property, $\Gamma$, in a mixed layer with a diffusivity of $600 \mathrm{~cm}^{2} \mathrm{~s}^{-1}$, and a photoacclimative rate, $\gamma$, of $3.5 \mathrm{~d}^{-1} \ldots \ldots \ldots 21$

\section{Appendix A. Chapter II Ancillary Data}

Figure 1. Density (sigma-theta) measurements from a time-series of profiles 
taken in the Sargasso Sea $\left(26^{\circ} 51^{\prime} \mathrm{N}, 67^{\circ} 44^{\prime} \mathrm{W}\right)$ in January 1992. . 229

Figure 2. Flow cytometric observations of Prochlorococcus spp. for the upper $50 \mathrm{~m}$ from the same time-series of figure 1 .

\section{Appendix B. Use of Forward Angle Light Scatter as a Proxy for Size in Prochlorococcus marinus Strain Med4}

Figure 1. Time-series measurements of cell concentration for P. marinus strain Med4 during the laboratory reciprocal light shift experiment discussed in Chapter III. . . . . . . . . . . . . . . . .

Figure 2. Time-series measurements of mean (geometric) forward angle light scatter for $P$. marinus strain Med4 during the laboratory reciprocal light shift experiment presented in figure $1 . \ldots \ldots \ldots \ldots$

Figure 3. Time-series measurements of (a) forward angle light scatter and (b) cell concentration for Prochlorococcus spp. during a simulated insitu reciprocal light shift experiment carried out during the October 1989 Sargasso Sea cruise. . . . . . . . . . . . . . . . . . . . . . . 247

Figure 4. Time-series measurements of (a) forward angle light scatter and (b) cell concentration for Synechococcus spp. during a simulated insitu reciprocal light shift experiment carried out during the October 1989 Sargasso Sea cruise. . . . . . . . . . . . . . . . . . . . . . . . . 249

Figure 5. Time-series measurements of (a) forward angle light scatter and (b) cell concentration for Prochlorococcus spp. during a simulated insitu reciprocal light shift experiment carried out during the July 1990 Sargasso Sea cruise. . . . . . . . . . . . . . . . . 25

Figure 6. Time-series measurements of (a) forward angle light scatter and (b) cell concentration for Synechococcus spp. during a simulated insitu reciprocal light shift experiment carried out during the July 1990 Sargasso Sea cruise. . . . . . . . . . . . . . . . . . . 253

Figure 7. Time-series measurements of (a) forward angle light scatter and (b) cell concentration for Prochlorococcus spp. during a simulated insitu reciprocal light shift experiment carried out during the August 1991 equatorial Pacific cruise. . . . . . . . . . . . . . . 255

Figure 8. Time-series measurements of (a) forward angle light scatter and (b) cell concentration for Synechococcus spp. during a simulated in- 
situ reciprocal light shift experiment carried out during the August 1991 equatorial Pacific cruise. . . . . . . . . . . . . . 257

\section{Appendix C. Chapter III Ancillary Data}

Figure 1. Time-series of mean red fluorescence normalized to the cube root of the mean forward angle light scatter signal for P. marinus strain Med4 during the laboratory based reciprocal light shift experiment presented in Chapter III (Chapter III, Fig. 1-5). . . . . . . . . . . 265

\section{Appendix D. Chapter IV Numerical Algorithm}

Figure 1. Definition schematic for the finite-difference approximation discussed in the text. . . . . . . . . . . . . . . . . . 273

\section{Appendix E. Chapter V Numerical Algorithm}

Figure 1. Definition schematic for the finite-difference approximation discussed in the text. . . . . . . . . . . . . . . . 281

\section{Appendix F. Increasing the sensitivity of a FACScan flow cytometer to study oceanic picoplankton. (reprinted from Limnology and Oceanography)}

Figure 1. Schematic of FACScan excitation optics before and after modifications.

Figure 2. Single-parameter histograms for red (chlorophyll) fluorescence for the same sample presented in Table 1. . . . . . . . . . . . 299 


\section{List of Tables}

Chapter II. Field Observations of Picophytoplankton Single-Cell Optical Properties

Table 1. Location and date of diel time-series observations carried out in the Sargasso Sea. . . . . . . . . . . . . . . . . . . 39

Chapter III. Photoacclimation in Photosynthetic Picoplankton and an Analysis of their Potential Use as Tracers for Vertical Mixing

Table 1. Cruises on which natural samples were incubated on deck under simulated in situ conditions. . . . . . . . . . . . . . . . . . . . 74

Appendix B. Use of Forward Angle Light Scatter as a Proxy for Size in Prochlorococcus marinus Strain Med4

Table 1. Growth rates estimated from time-series of on-deck bottle incubations for cruises discussed in Chapter III. . . . . . . . . . 245

Appendix F. Increasing the sensitivity of a FACScan flow cytometer to study oceanic picoplankton. (reprinted from Limnology and Oceanography)

Table 1. Results of flow cytometric analyses of a sample from $10 \mathrm{~m}$ in the Sargasso Sea, October 1989. . . . . . . . . . . . . . . . 300 
Chapter I

\section{Introduction}




\section{Introduction}

In 1953, Sverdrup published his ideas concerning the critical depth theory. By suggesting that mixing depth strongly influenced the physiology of cells by being the primary determinant of whether or not cells attained enough light to sustain net growth, he sought to explain when conditions would be suitable for phytoplankton blooms. His observations and ideas opened up the field of study of the effects of mixing on phytoplankton productivity and also physiology and ecology.

Phytoplankton are exposed to a constantly changing invironment in terms of their light intensities, and this affects their physiology in a variety of ways. I focus here on the picophytoplankton response to changes in light induced by vertical mixing. I approach this from the dual perspectives of how we can use field observations to further increase our understanding of mixing processes as seen by the picoplankton and to further our understanding of the physiology of the picophytoplankton as they respond to these changes. Ultimately, one hopes to explore how these processes together help define biomass distributions, ocean color, and productivity.

Mixing processes have long been hypothesized as important determinants of phytoplankton physiology and productivity, due primarily to the changing light levels resulting from vertical movement in the water column. Just as deeper mixed layers result in lower average light intensities experienced by the phytoplankton (Sverdrup, 1953), fluctuating light intensities attributed to turbulent diffusion, wave motions, Langmuir circulation, cloud cover, etc. have been more recently shown to affect productivity. However, while some investigators find increased productivity under 
fluctuating light intensities relative to static incubations (Marra, 1978; Walsh and Legendre, 1983; Mallin and Paerl, 1992), others find no effect (Gallegos and Platt, 1982; Yoder and Bishop, 1985) or decreased productivity resulting from fluctuations in light intensity (Randall and Day, 1987). Thus the mechanisms by which vertical mixing (and resultant changes in light intensity) affect productivity are still poorly understood.

Because phytoplankton absorb light energy that can enhance solar warming of the surface layer, they have been implicated in feedback loops, thus exerting some control over the physical dynamics (Simonot et al., 1988; Sathyendranath et al., 1991). Unfortunately these processes are even less well understood and studied than the effects of mixing on phytoplankton.

If mixing produces measurable and predictable effects on phytoplankton physiology, we should be able to use observations of phytoplankton physiology to infer mixing dynamics. This idea was one of the original motivations for pursuing this thesis research. I thus present here a framework for investigating the implications of vertical mixing on phytoplankton physiology and also the potential for the use of physiological properties measured at the individual cell level to infer mixing processes.

The chapters presented here could have been arranged in a variety of ways. I cross-reference between chapters and found it necessary to write each chapter as if they were a little more independent (and thus a little more redundant) than would usually be expected in a thesis. I decided to present field observations first (Chapter II) to give the reader a "feel" for the real world. I then present in Chapter III some 
rather simple laboratory and field experiments aimed at quantifying the kinetics of photoacclimation, a key component to relating vertical mixing to phytoplankton physiology. A simple model was developed of the relationship between photoacclimation and vertical mixing in determining the distributions of photo-reactive physiological properties at the single-cell level. The simplified stationary solution to this is presented in chapter IV, and gives the reader an idea of how the mean and higher moments of the distribution of a photoacclimative property will vary as a result of mixing rates. Moving back to the laboratory, I developed an apparatus which can simulate a random walk across a light gradient at the single cell level. Four investigations from this apparatus, representing four different mixing rates, and a corresponding time-dependent model are presented in Chapter V. Finally, Chapter VI suggests some avenues for future research and shows how the techniques developed here extend to other fields.

This project has involved a tremendous amount of observations from field time-series profiles and bottle experiments, not all of which was included here. Some of this supporting data and analyses are presented in the appendices. Also in the appendices are the numerical algorithms used in the model simulations in chapters III and IV (appendices D and E). In addition, a method for relating cell volume to forward angle light scatter measurements based primarily on observations of growth rates, is used to further understand some of the normalizations used for Prochlorococcus spp. populations. This method is outlined in Appendix B. Appendix F is a paper, coauthored with Sheila Frankel, which was published in Limnology and 
Oceanography which describes modifications to the FACScan flow cytometer which was the backbone of this thesis in terms of instrumentation. 


\section{References}

Gallegos, C. L. and T. Platt. 1982. Phytoplankton production and water motion in surface mixed layers. Deep-Sea Res. 29:65-76.

Mallin, M. A. and H. W. Paerl. 1992. Effects of variable irradiance on phytoplankton productivity in shallow estuaries. Limnol. Oceanogr. 37:54-62.

Marra, J. 1978. Phytoplankton photosynthetic response to vertical movement in a mixed layer. Mar. Biol. 46:203-208.

Randall, J. M. and J. W. Day. 1987. Effects of river discharge and vertical circulation on aquatic primary production in a turbid Louisiana (USA) estuary. Neth. J. Sea Res. 21:231-242.

Sathyendranath, S., A. D. Gouveia, S. R. Shetye, P. Ravindran and T. Platt. 1991. Biological control of surface temperature in the Arabian Sea. Nature. 349:54-56.

Simonot, J., Dollinger, E. and Le Treut, H. 1988. Thermodynamic-biological-optical coupling in the oceanic mixed layer. J. Geophys. Res. 93(C7):8193-8202.

Sverdrup, H. U. 1953. On conditions for the vernal blooming of phytoplankton. $J$. Cons. Explor. Mer. 18:287-295.

Walsh, P. and L. Legendre. 1983. Photosynthesis of natural phytoplankton under high frequency light fluctuations simulating those induced by sea surface waves. Limnol. Oceanogr. 28:688-697.

Yoder, J. A. and S. S. Bishop. 1985. Effects of mixing-induced irradiance fluctuations on photosynthesis of natural assemblages of coastal phytoplankton. Mar. Biol. 90:87-93. 


\section{Chapter II}

\section{Field Observations of Picophytoplankton Single-Cell Optical Properties}




\title{
Field Observations of Picophytoplankton Single-Cell Optical Properties
}

\begin{abstract}
Two diel time-series sampling schemes were undertaken to quantify the effects of changing mixing dynamics on picophytoplankton optical properties. Both timeseries show a shoaling of the mixed layer due to surface warming and a rain-formed mixed layer. These dynamics coupled with the diurnal cycle of solar irradiance, drove the development of a gradient in mean red fluorescence of Prochlorococcus spp. via photoacclimation. In addition, the distribution of fluorescence within field populations responds to changing mixing and photoacclimation dynamics, with photoacclimation in the absence of strong mixing generally resulting in reduced variance in fluorescence within sample populations. Nighttime mixing in the absence of photoacclimation reversed this process and resulted in increased variation of single-cell fluorescence. Both the effects of physical boundaries and hysteresis in photoacclimation appear to affect the third moment (skewness) of fluorescence, with boundaries causing optical properties to be skewed away from the boundary and hysteresis causing overall negative skewness. These observations show that the mean and variance, and possibly the higher moments, of single-cell optical properties reflect the physical dynamics, and should yield useful information regarding the light history of the population.
\end{abstract}




\section{Introduction}

Since phytoplankton respond physiologically to changes in light intensity, their physiological state is a function of their light history. The effects of light fluctuations have been historically investigated primarily in the context of the effects of vertical mixing (see Denman and Gargett, 1983 for review) on productivity (Marra, 1978a,b, 1980; Gallegos and Platt, 1982; Marra and Heinemann, 1982; Falkowski, 1983; Walsh and Legendre, 1983; Lewis et al., 1984; Yoder and Bishop, 1985; Savidge, 1988).

An important implication of this physiological response is the potential to use phytoplankton as tracers for mixing processes. The relationship between vertical mixing and phytoplankton physiology has been explored primarily using bulk water properties, including photosynthesis-irradiance relationships (Falkowski and Wirick, 1981; Lewis and Smith, 1983), carbon/chlorophyll ratios (Laws and Bannister, 1980; Geider and Platt, 1986; Cullen and Lewis, 1988), xanthophyll cycling (Welschmeyer, personal communication), photosynthetic unit size (Falkowski, 1983), enzyme activity (Rivkin, 1990) and in vivo fluorescence (Therriault et al., 1990). Observations in the Arabian Sea (Sathyendranath et al., 1991) and modelling efforts (Simonot et al., 1988) also suggest that there may be feedback mechanisms operating so that the phytoplankton influence the mixing processes by causing increased absorption of light (heat) in the surface layer.

Theoretical single-cell models suggest a relationship between the variance of photoacclimative properties and the mixing rates (Lande and Lewis, 1989; Falkowski 
and Wirick, 1981; Yamazaki and Kamykowski, 1991), with higher mixing rates generally resulting in higher variance in the property investigated. Boundary effects are expected to reverse this trend, so that variances decrease with increasing strength of boundary effects (Lande and Lewis, 1989), and in a situation with both an upper and lower boundary, the variance decreases with increasing diffusivity when boundary effects extend throughout the mixed layer (Chapter IV, Fig. 3). One can thus ponder the possibility of going beyond the bulk properties and trying to extract information about mixing processes from the physiological properties of the individual cells themselves. As I show later in Chapter IV, the use of the higher moments of the distribution of photoacclimative properties should extend the dynamic range of the sensitivity of this method beyond that possible with bulk properties with similar timescales of photoacclimation.

Flow cytometry, a technique imported into oceanography from the biomedical arena, allows the rapid characterization of the optical properties such as light scatter and fluorescence of individual cells. With this information, specific populations can be identified and the mean and distribution of optical properties within these populations can be quantified. A thorough overview of this technique can be found in (Melamed et al., 1990; Olson et al., 1993; Shapiro, 1994). Early observations of field samples revealed a strong difference in the signatures of populations of Prochlorococcus spp. and Synechococcus spp. taken from within the surface mixed layer compared to those taken from below (Fig. 1). The mean fluorescence and light scatter are larger in the deeper sample, presumably due to photoacclimation to lower 
Figure 1 - "Typical" flow cytometric scattergram of a surface sample from the Sargasso Sea. These samples are from $50 \mathrm{~m}$ (within the seasonal mixed layer) (left panel) and $120 \mathrm{~m}$ (within the seasonal thermocline) (right panel) during the first cast of the October 1989 Sargasso Sea time-series $\left(35^{\circ} 25^{\prime} \mathrm{N}, 66^{\circ} 30^{\prime} \mathrm{W}\right)$. Each dot represents a single cell, with populations of Synechococcus spp. and Prochlorococcus spp. identified by their relative scatter and red fluorescence signals and the presence (Synechococcus spp.) or absence (Prochlorococcus spp.) of orange fluorescence. The "beads" are 0.57- $\mu \mathrm{m}$ microspheres used as an internal calibration. Using multiparameter data analysis, the mean and higher moments of optical properties (scatter, fluorescence, or some combination thereof) can be determined. The $18^{\circ}$ rotation of the axes shows the translation used to normalize the red fluorescence (see text, Fig. 2) 


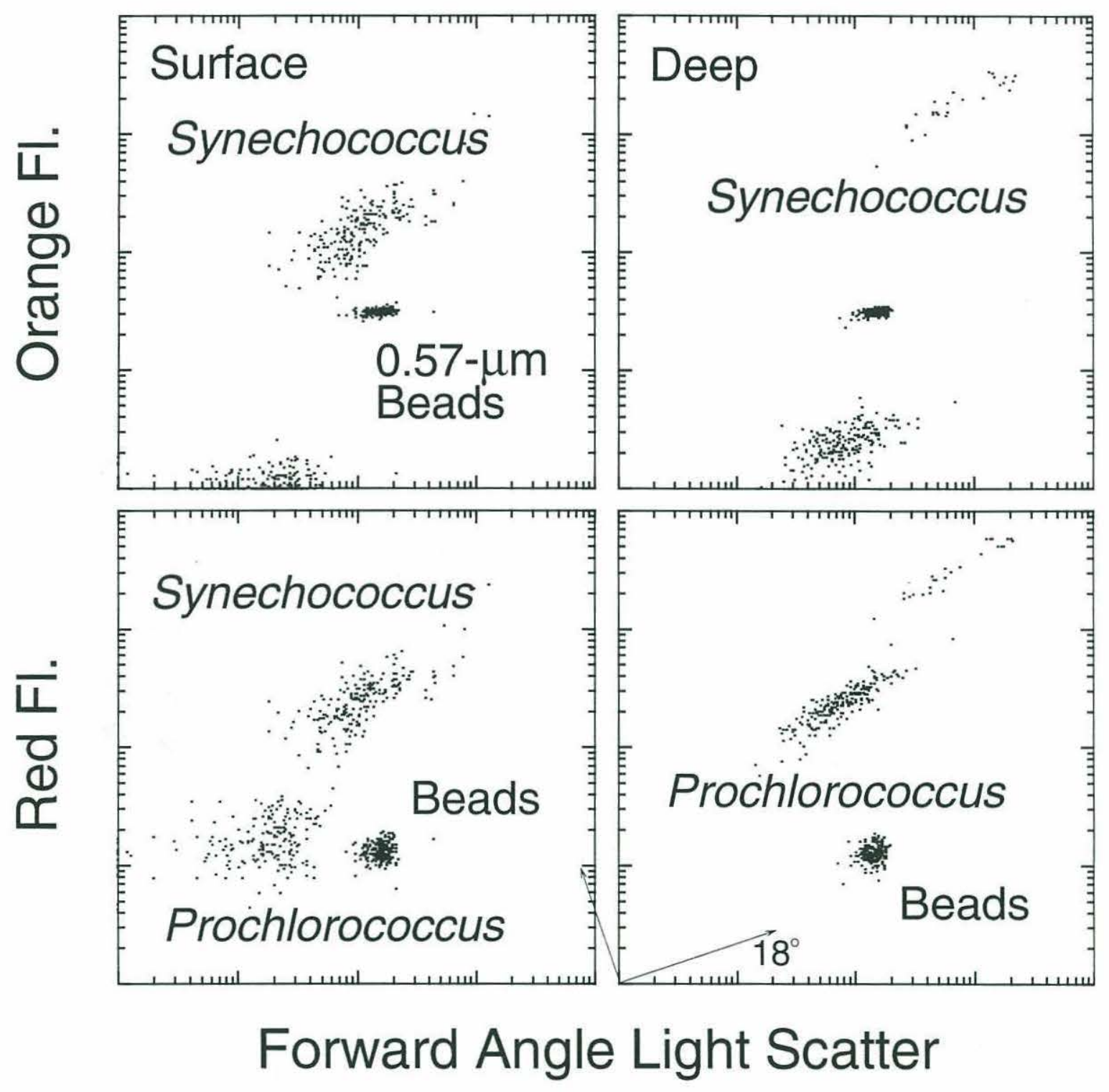


light levels. ${ }^{1}$ Furthermore, the relatively isolated deeper sample shows a reasonably strong correlation between red autofluorescence and forward angle light scatter.

Surface populations show a much weaker correlation. This was hypothesized to be the result of the increased variation in light histories among the cells in the surface layer relative to their deep counterparts, and, coupled with the change in mean values, provided the motivation for pursuing this research.

To explore the relationship between mixing dynamics in the open ocean surface layer and picophytoplankton optical properties, time-series observations were made during two cruises to the Sargasso Sea. The surface mixed layer can exhibit a diurnal shoaling of the thermocline due to the solar warming of the uppermost part of the water column (Price et al., 1986; Woods and Barkmann, 1986; Brainerd and Gregg, 1993). This surface warming can restrict wind-driven mixing to the newly shoaled mixed layer and reduce mixing below this layer (Price et al., 1986; Woods and Barkmann, 1986; Brainerd and Gregg, 1993). By sampling this changing water column over the course of a 24-hour or longer period, the effect of changes in the mixing dynamics on the distributions of phytoplankton single-cell optical properties can be explored.

\footnotetext{
${ }^{1}$ Because of the isolation of this population, this size difference may also be the result of different population structure, with the brighter cells being genetically distinct from their dim counterparts (Moore, personal communication). However, such changes in population structure are not expected to occur on the time-scales investigated here $(<1 \mathrm{~d})$, and thus the population dynamics were assumed stable.
} 
Table 1 - Location and date of diel time-series observations carried out in the Sargasso Sea.

\begin{tabular}{clcl}
\hline \hline \multicolumn{1}{c}{ Cruise } & \multicolumn{1}{c}{ Location } & Date & Conditions \\
\hline RV Oceanus 214 & $\begin{array}{l}\text { Sargasso Sea } \\
\left(35^{\circ} \mathrm{N}, 66^{\circ} \mathrm{W}\right)\end{array}$ & October 1989 & Oligotrophic \\
RV Endeavor 232 & $\begin{array}{l}\text { Sargasso Sea } \\
\left(34^{\circ} \mathrm{N}, 68^{\circ} \mathrm{W}\right)\end{array}$ & January 1992 & $\begin{array}{l}\text { Deep Winter } \\
\text { Mixing }\end{array}$ \\
\hline \hline
\end{tabular}

\section{Methods}

Time series measurements were made on two cruises to the Sargasso Sea (Table 1). During both of these cruises, CTD profiles and water samples were collected while following an 8-m holey-sock drogue set at $25 \mathrm{~m}$ to try to sample the same water mass. On average, samples were collected every two hours for a 24-hour period. Samples were collected via Niskin bottles mounted on a rosette fitted with a CTD; therefore, corresponding CTD measurements are available for each cast sampled.

On the October cruise, Niskin bottles were quickly subsampled after collection, taking care to minimize exposure to sunlight, and 2-ml samples from each depth were fixed with $0.1 \%$ glutaraldehyde for ten minutes and then stored in liquid nitrogen for later analysis in the lab (Vaulot et al., 1989; Olson et al., 1990). During the January cruise, the samples were run on board ship, within $2 \mathrm{~h}$ of collection. Again, the Niskin bottles were quickly subsampled after collection and samples were kept in the dark and cool until analysis. Twelve samples were collected per profile, and it was generally possible to run all of these before the next cast was ready.

All samples were analyzed using a FACScan flow cytometer (Becton- 
Dickinson). Scatter and fluorescence signals were collected and stored in a log-scaled list mode, with one data point for each cell measured. Standard $0.57-\mu \mathrm{m}$ microspheres (Polysciences) were used as an internal calibration, both to check instrument alignment and to calculate the concentration of cells. Mean scatter and fluorescence signals were normalized by dividing by the corresponding mean signal from the $0.57-\mu \mathrm{m}$ microspheres. Within each cruise, the mean scatter and fluorescence signals from the microspheres remained within $6 \%$ of each other, suggesting minimal instrument drift, if any.

After sample analysis and data collection, list mode data were further analyzed using CYTOPC flow cytometry data processing software (D. Vaulot). Populations of Prochlorococcus spp. and Synechococcus spp. as well as the $0.57-\mu \mathrm{m}$ microspheres were identified based on their relative red autofluorescence, orange autofluorescence (for Synechococcus spp.), right angle light scatter, and forward angle light scatter, and list modes corresponding to each population were created. Using the Prochlorococcus spp. data, the red fluorescence signal for each individual cell was normalized to the cube root of the forward angle light scatter (Chapter III) by rotating the two-parameter histogram of red fluorescence vs. forward angle light scatter (Fig. 1, 2). This normalized red fluorescence was the parameter used to characterize the photoacclimative state of the cells. Since this normalization was intended to remove diel patterns in red fluorescence resulting from cell growth and division (Chapter III), it does not necessarily correspond to the correlation between red fluorescence and forward angle light scatter seen within Prochlorococcus spp. populations (Fig. 1) A 
single parameter histogram of the normalized red fluorescence was created for each population sampled. From this histogram the mean and higher moments (see below) were calculated (Sokal and Rohlf, 1981).

All flow cytometric data has intrinsic variability, due to measurement error. In addition, the populations being measured contain "intrinsic" variation not directly associated with variation in light history resulting from vertical mixing processes. These include variations in cell size which are not accounted for in the normalization. The normalization used here only reflects diel variation arising from cell growth and division, and will not necessarily account for variation due to environmental factors (including factors other than light) or genetic variation between members of a population. To a first approximation, one can assume that this intrinsic variation is log-normally distributed. Clearly the variance is sensitive to all forms of variation, and the variance from different sources is simply additive to give the total variance. Both the skewness, $\mathrm{g}_{1}$, and kurtosis, $\mathrm{g}_{2}$, as defined in Sokal and Rohlf (1981):

$$
\begin{aligned}
& g_{1}=\frac{\sum(\Gamma-\bar{\Gamma})^{3}}{n s^{3}} \\
& g_{2}=\frac{\sum(\Gamma-\bar{\Gamma})^{4}}{n s^{4}}
\end{aligned}
$$

are sensitive to the magnitude of any superimposed intrinsic variation (which contributes to $\mathrm{s}^{2}$ ), in the sense that additional sources of variability that have no skewness or kurtosis associated with them will effectively "dilute" the skewness or 
Figure 2 - Same samples presented in figure 1, replotted to show the $18^{\circ}$ rotation used to remove diel patterns due to growth and division from red fluorescence signals. The $y$-axis represents the normalized red fluorescence and is equivalent to the red fluorescence signal divided by the cube root of the forward angle light scatter signal (since units are relative, translation was not considered). The $\mathrm{x}$-axis is the rotated forward angle scatter axis and is orthogonal to the normalized fluorescence. 

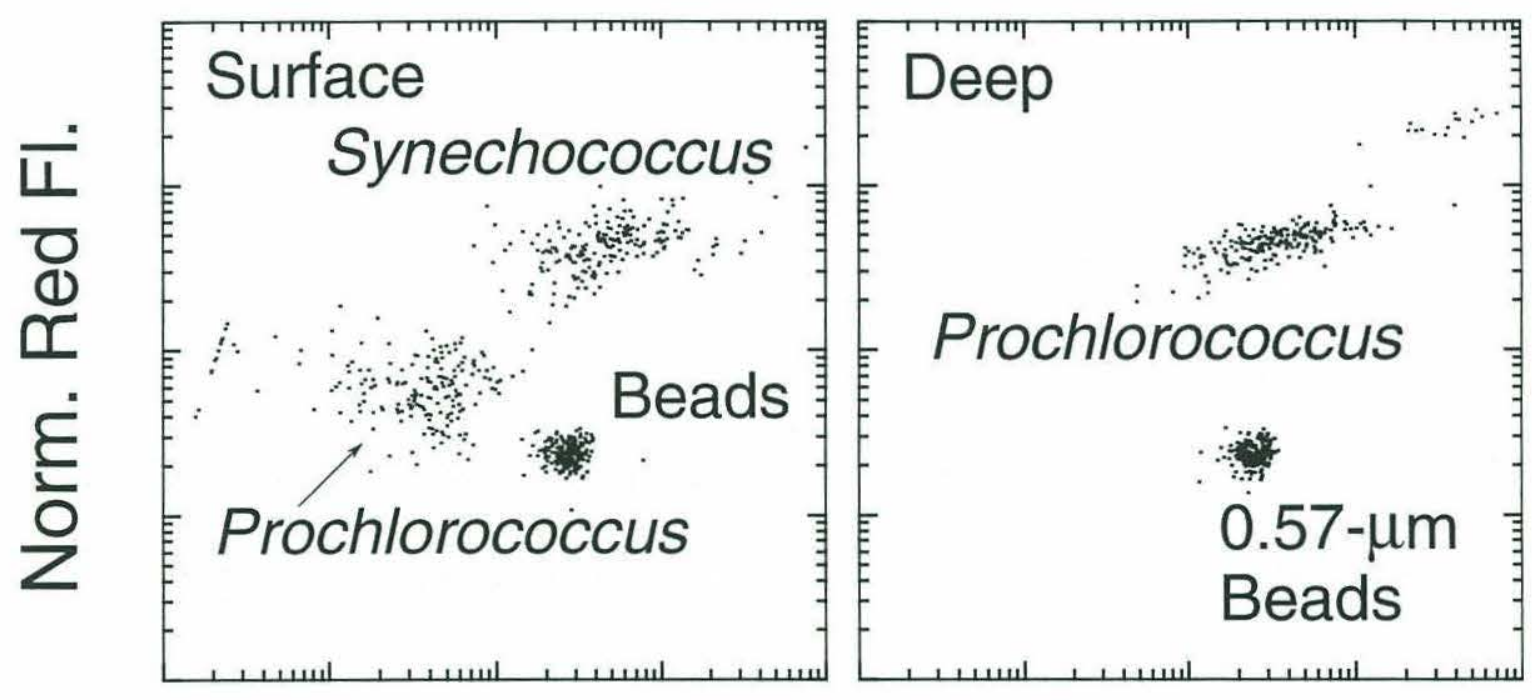
kurtosis attributable to mixing processes. This sensitivity can be removed in the case of the skewness by using the third moment, $(1 / n) \Sigma(\Gamma-\bar{\Gamma})^{3}$, as an indicator of the skewness in the population. Similarly, the sensitivity of the kurtosis to the intrinsic variation can be removed by multiplying the kurtosis by the standard deviation raised to the fourth power. This is equivalent to the fourth moment less three times the standard deviation to the fourth power, $(1 / n) \Sigma(\Gamma-\bar{\Gamma})^{4}-3 s^{4}$, identified here as the "corrected" fourth moment.

The third and corrected fourth moments provide an indication of departures from normality in the distribution (Fig. 3). While a zero third moment indicates a symmetric distribution (such as the normal distribution), a positive third moment indicates skewness to the right. A negative third moment indicates skewness to the left. The corrected fourth moment is an indicator of the kurtosis, or the "peakedness" of the curve. A negative corrected fourth moment indicates platykurtosis, or a flatter curve than the normal while a positive corrected fourth moment indicates leptokurtosis, or a more peaked curve than the normal, with data points concentrated near the mean and at the tails.

\section{Results}

\section{Oligotrophic, shoaling mixed layer:}

During the October, 1989, Sargasso Sea cruise, there was a definite shoaling of the mixed layer due to surface warming at midday (Fig. 4). During the afternoon, a density gradient was present in the upper $40 \mathrm{~m}$ that wasn't present during the morning 
hours.

Prochlorococcus spp. ${ }^{2}$ cell concentration, forward angle light scatter, red fluorescence and red fluorescence normalized to the cube root of forward angle light scatter were determined for this time series (Fig. 5). Forward angle light scatter shows a striking pattern of increase during the daytime, presumably due to cell growth, and decrease at night, presumably a function of cell division (Fig. 5b). Corresponding cell density measurements give some support for this, with a slight increase in cell numbers at the beginning of the experiment, when forward scatter is on the decline. Mean red autofluorescence shows a pattern of homogeneous upper $50 \mathrm{~m}$ during the early morning hours, followed by the development of a strong gradient of increasing mean red fluorescence with depth by late afternoon. The development of this gradient corresponds to the shoaling of the mixed layer in late morning and also the presence of photoacclimation to the light gradient. Photoacclimation during the nighttime, if present, will not lead to the development of a mean fluorescence gradient due to the absence of a light gradient. Normalized mean red fluorescence (Fig. 5d) shows a pattern very similar to that of the mean non-normalized red fluorescence, except that the homogeneous early morning value is more "centered" with respect to the gradient that develops later.

\footnotetext{
${ }^{2}$ Although Synechococcus spp. were also present in these samples, the analysis presented here is restricted to the more abundant Prochlorococcus spp., which generally outnumbered Synechococcus spp. by about 10:1. The rarer Synechococcus spp. were difficult to quantify because not enough cells per sample could be analyzed within a reasonable time (20 $\mathrm{min})$.
} 
Figure 3 - Examples of frequency distributions with non-zero third and corrected fourth moments. The normal distribution (zero third and fourth moments) is shown for reference. 

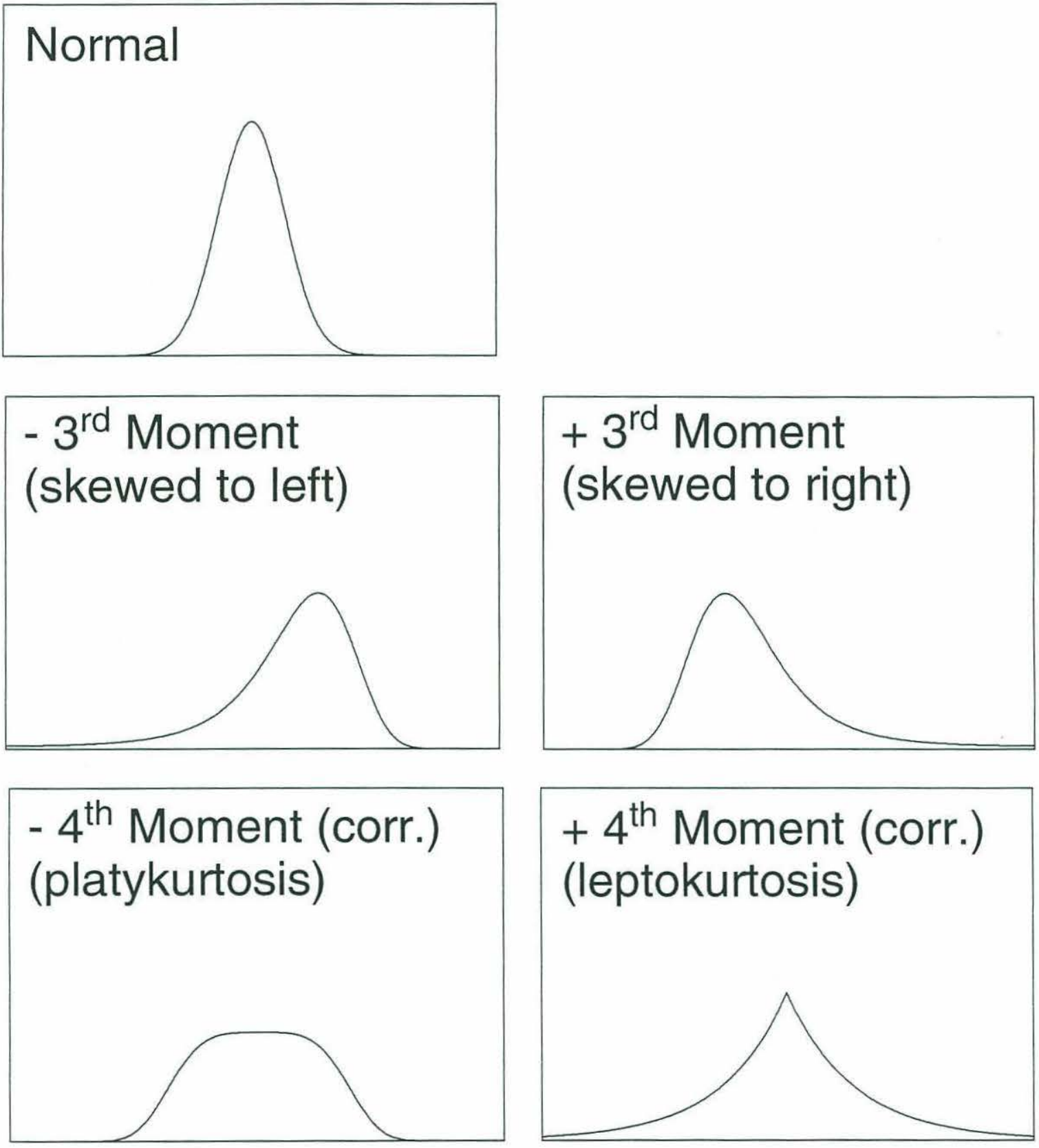
Figure 4 - Density (sigma-t) contours of October 1989 Sargasso Sea time-series.

These contours show a weakening of density stratification during the nighttime and the development of stratification by late morning. Daytime is from approximately 06:00 to $18: 00$. 


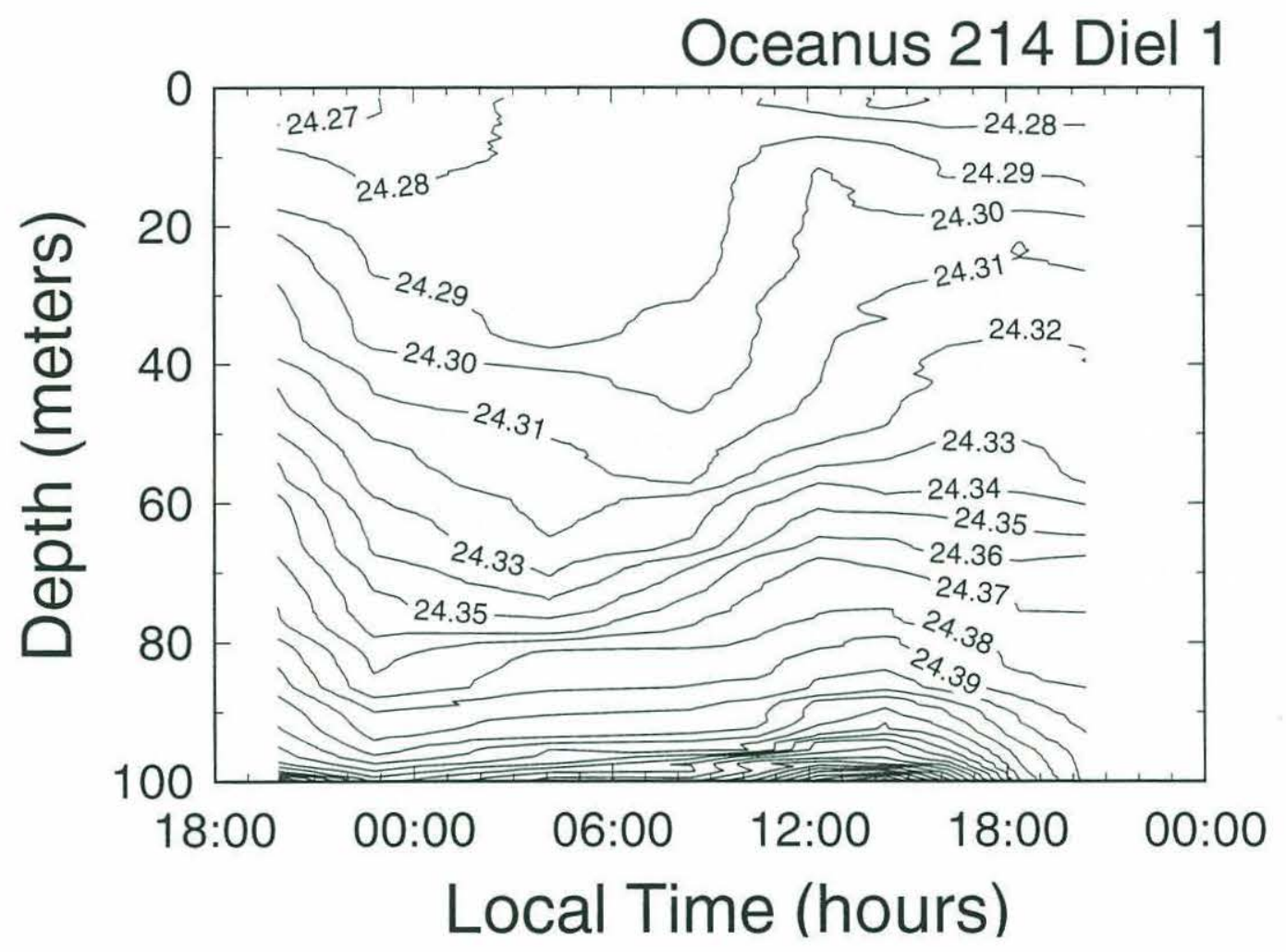


Figure 5 - Flow cytometric observations of Prochlorococcus spp. in the upper $50 \mathrm{~m}$ from the October 1989 Sargasso Sea time-series. Cell concentration (a), mean forward angle light scatter (b), mean red autofluorescence (c), and the mean red fluorescence normalized to the cube root of the mean forward angle light scatter (d) were determined using a FACScan flow cytometer. Fluorescence and scatter measurements are all relative to $0.57-\mu \mathrm{m}$ microspheres ("beads"). 
Oceanus 214 Diel 1
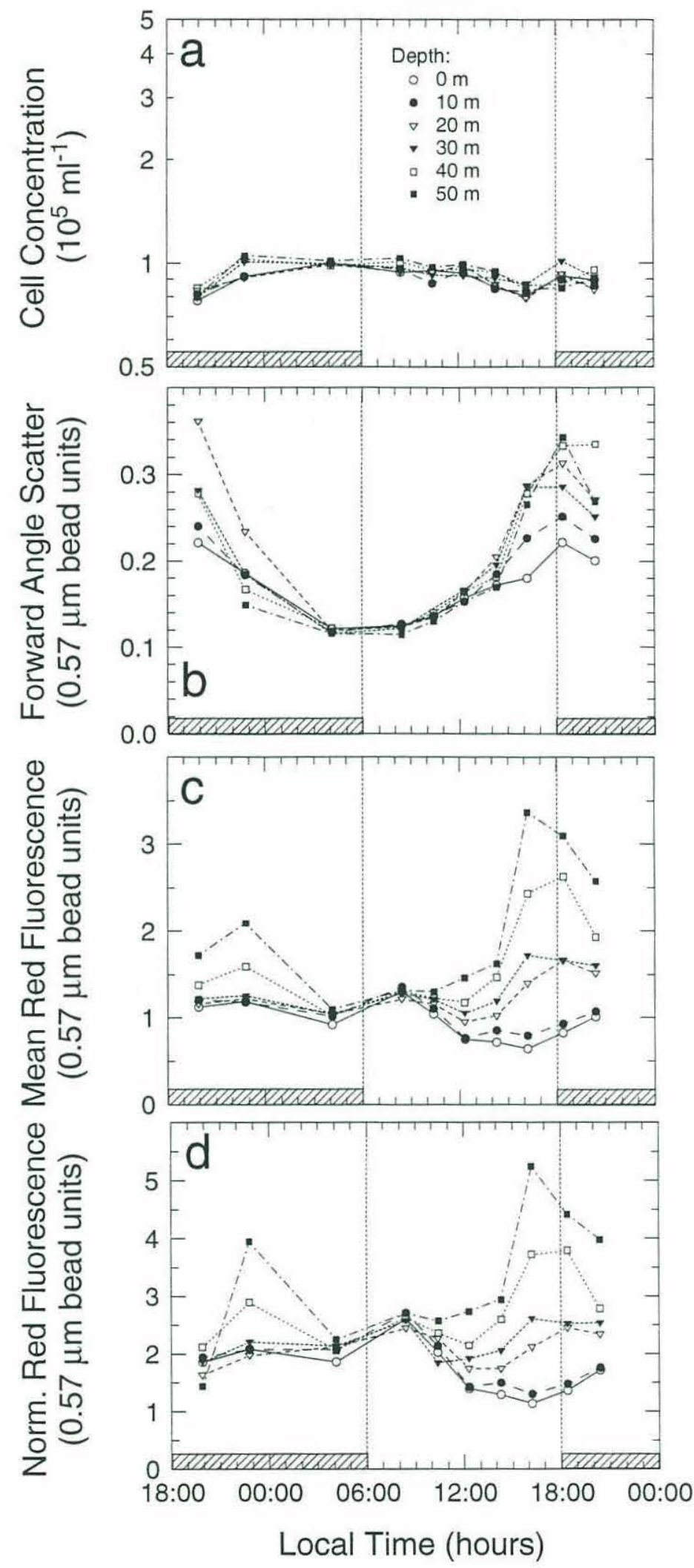


\section{Deep winter mixing, rain formed mixed layer:}

The January, 1992, Sargasso Sea time-series on the RV Endeavor cruise shows a near homogenous water column in the upper $200 \mathrm{~m}$ (Fig. 6). This is capped by a rain-formed stratified layer, as there was at least $1.8 \mathrm{~cm}$ of rain during the first few hours of the experiment.

The winter time-series shows a pattern somewhat similar to the oligotrophic time-series discussed above (Fig. 7). There is an increase in forward angle light scatter during the day, with a decrease after dusk. These forward scatter signals are also relatively large, suggesting a dampened pattern due to cell growth and division relative to that seen during the October time-series. Mean red fluorescence signals show the development of a gradient during the day presumably due to photoacclimation, and a rapid destruction of this gradient in the evening. Due to the reduced pattern in forward angle light scatter, the pattern in normalized red fluorescence is similar to that of mean red fluorescence. Both show a diel pattern superimposed on the gradient development/breakdown pattern.

\section{Higher moments:}

The higher moments, particularly the variance, show strong patterns during both time-series (Fig. 8-9). Both time-series show a tightening of the distributions (reduction of variance) during the daytime and an increase in the variance during the nighttime. The decrease in the variance is attributed to photoacclimation and reduced mixing during the daytime. The nighttime increase reflects the homogenization of the 
water column in the absence of photoacclimation.

One exception to this trend is the increase in variance observed in late afternoon during the October time-series near $20 \mathrm{~m}$ (Fig. 8b). This appears to be a result of not (necessarily) increased mixing, but rather the increase in the gradient in the mean seen at this time (Fig. 8a), as the variance is roughly proportional to not only the mixing rates relative to photoacclimation but also to the square of the gradient in the mean (Lande and Lewis, 1989). However, some mixing must be present in order for the variance to increase. Complete cessation of mixing below the diurnal thermocline would result in decreased variance throughout the water column.

The third and corrected fourth moments are more difficult to interpret. During the October time-series (Fig. 8c,d), the third moment was predominately to the negative (indicating skewness to the left). This may suggest that there is a non-linear photoacclimative process that is contributing to this skewing, or that there is source of intrinsic skew in these populations or in the measurement of their optical properties. However, the January deep-mixing time-series does not show this same predominance towards negative skewing. This time-series shows no overall pattern, however, there is a region of negative skewness corresponding to the region just after the gradient in the mean is established and it begins to break down.

The fourth moment shows strictly positive values during the October timeseries. These positive values indicate peaked distributions, which in this case are the result of long tails on the distributions. This seems to be the dominant effect operating during these observations, and its source is unclear. The lower values 
Figure 6 - Density (sigma-theta) contours during the January 1992 Sargasso Sea timeseries. The seasonal mixed layer extended to about $200 \mathrm{~m}$ during the entire experiment, with a rain-formed mixed layer near the surface. At least of $1.8 \mathrm{~cm}$ of rain fell during between 05:00 and 12:00 the first day. 


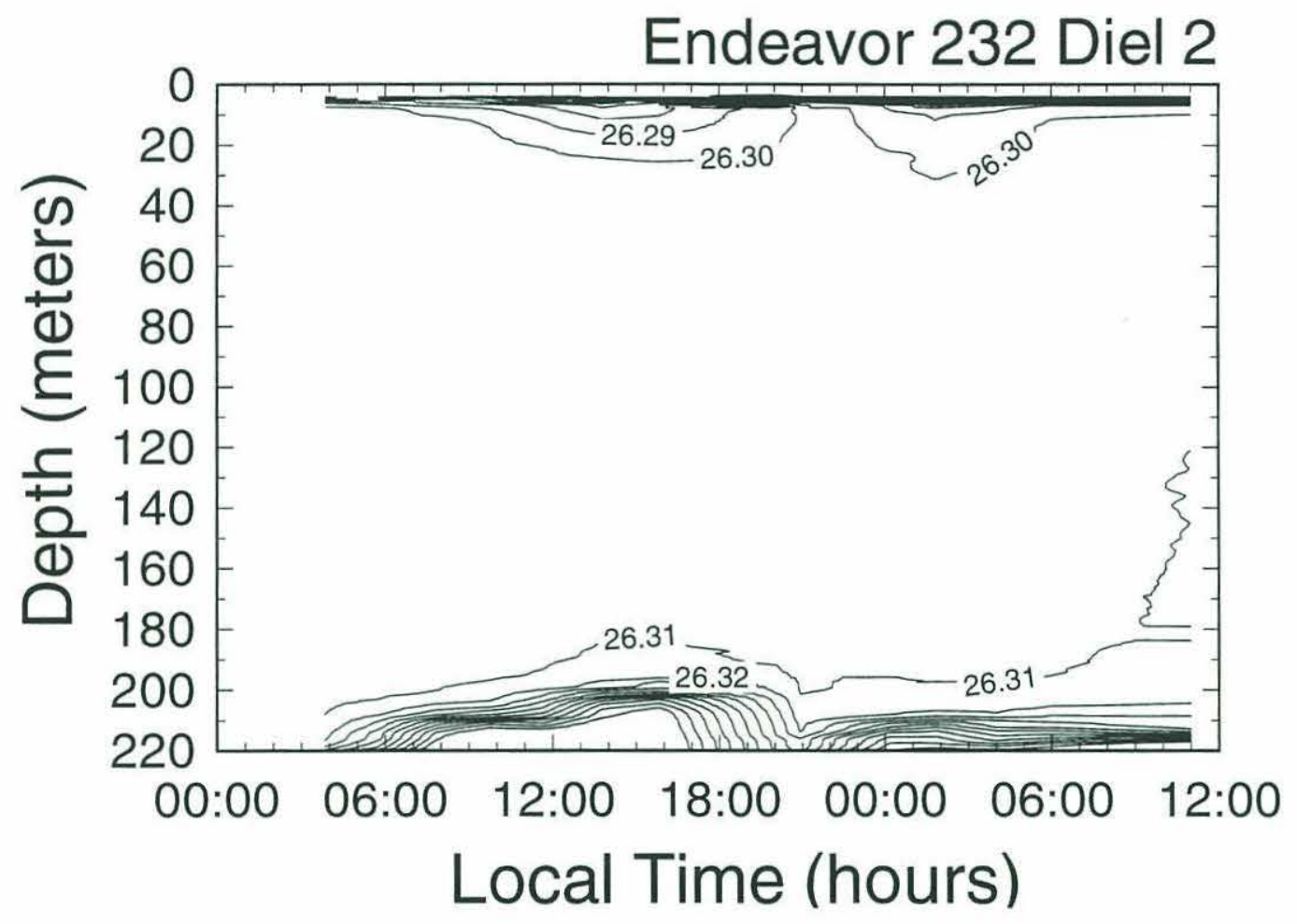


Figure 7 - Flow cytometric observations of Prochlorococcus spp. in the upper $75 \mathrm{~m}$ from the January 1992 Sargasso Sea time-series. Cell concentration (a), mean forward angle light scatter (b), mean red autofluorescence (c), and the mean red fluorescence normalized to the cube root of the mean forward angle light scatter (d) were determined using a FACScan flow cytometer. Fluorescence and scatter measurements are all relative to $0.57-\mu \mathrm{m}$ microspheres ("beads"). 
Endeavor 232 Diel 2
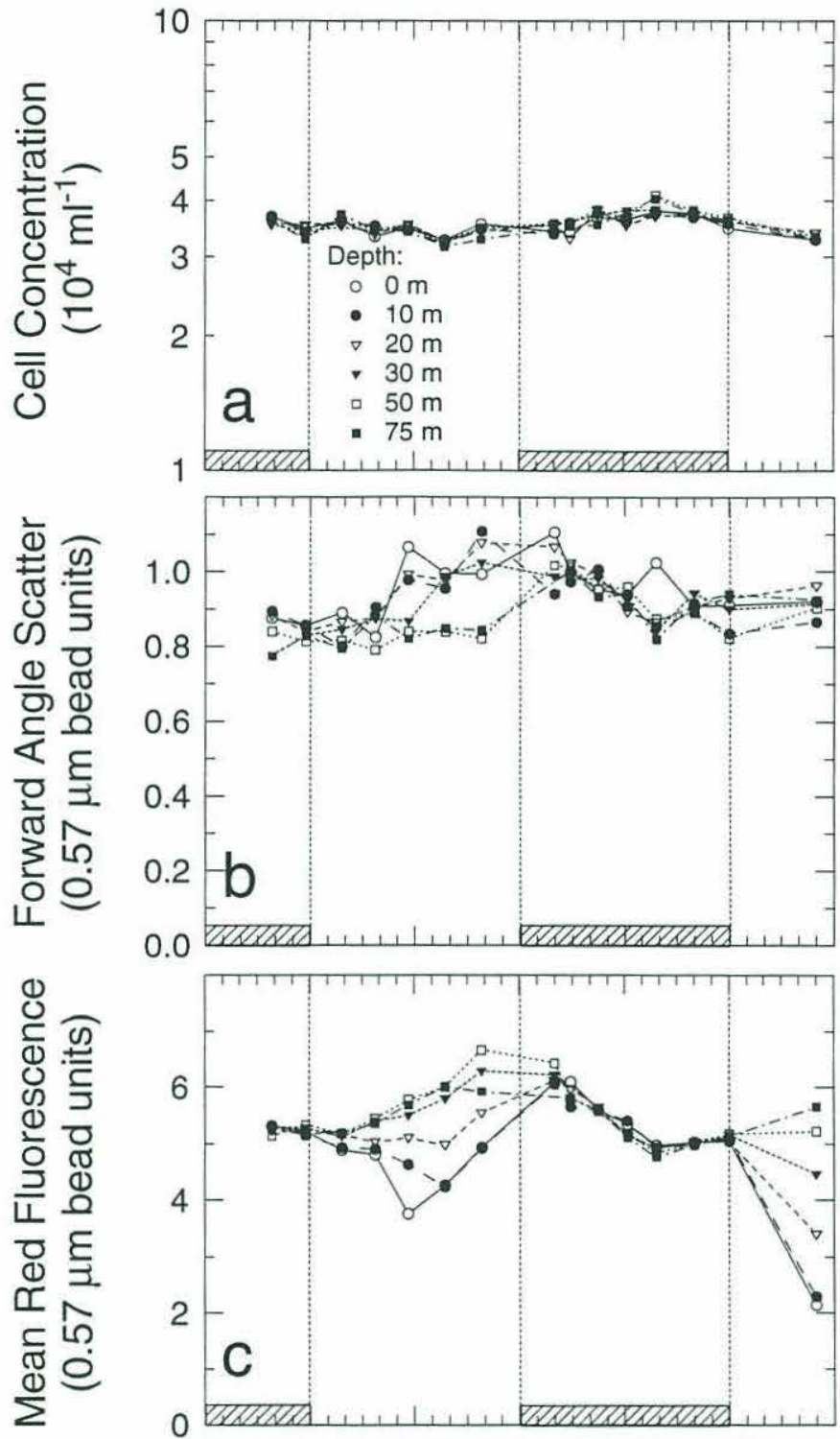

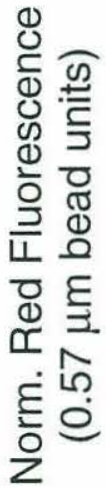

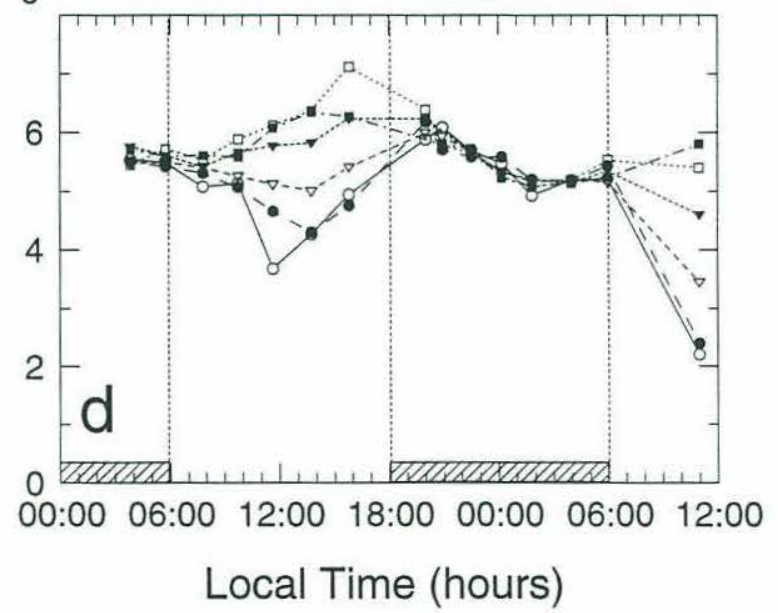


Figure 8 - Prochlorococcus spp. normalized red fluorescence mean (a), variance (b), third moment (c), and corrected fourth moment (fourth moment less three times the standard deviation, s, to the fourth power) (d) for the October time-series. All units are in log-scaled channels (raised to the appropriate power) as collected and binned by the data acquisition system. One decade corresponds to 64 channels. Normalization was done by dividing each cell's red fluorescence signal by the forward angle light scatter raised to the third power, and then the mean and higher moments were determined from the resulting normalized fluorescence histogram. 


\section{OC214 Diel 1}
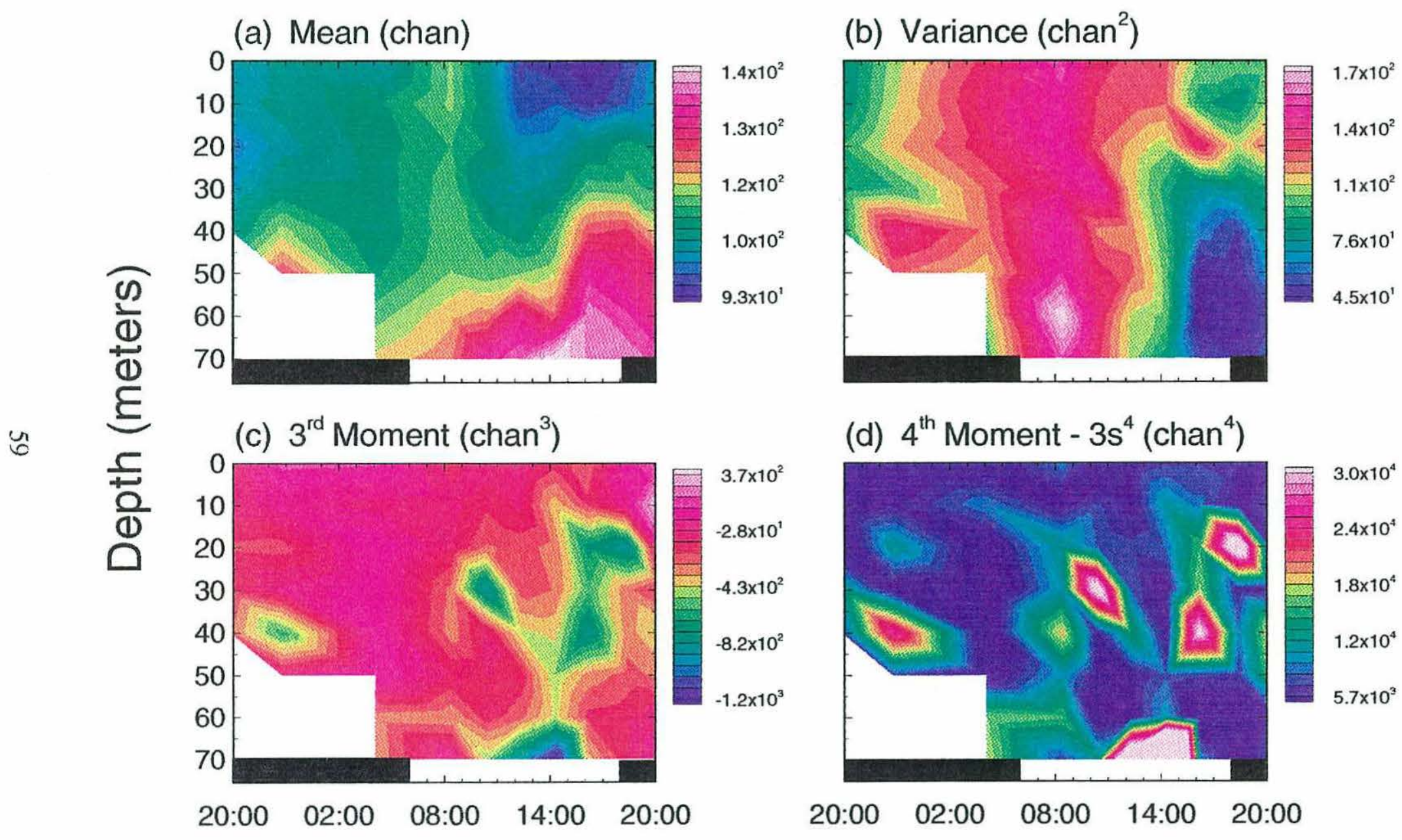

\section{Local Time (hours)}


Figure 9 - Prochlorococcus spp. normalized red fluorescence mean (a), variance (b), third moment (c), and corrected fourth moment (fourth moment less three times the standard deviation, s, to the fourth power) (d) for the January time-series. All units are in log-scaled channels (raised to the appropriate power) as collected and binned by the data acquisition system. One decade corresponds to 64 channels. Normalization was done by dividing each cell's red fluorescence signal by the forward angle light scatter raised to the third power, and then the mean and higher moments were determined from the resulting normalized fluorescence histogram. 


\section{Endeavor 232 Diel 2}

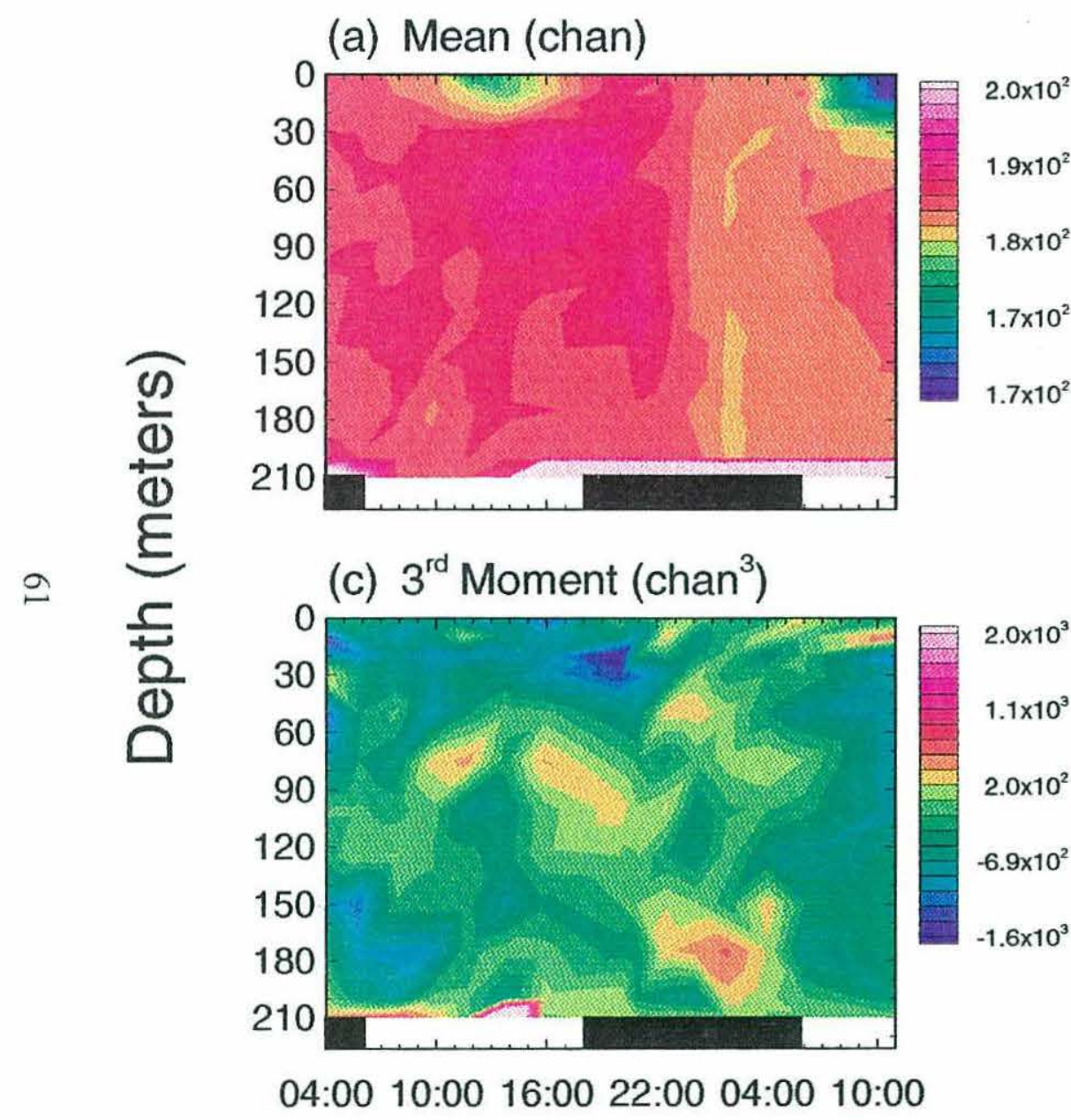

(b) Variance $\left(\right.$ chan $\left.^{2}\right)$

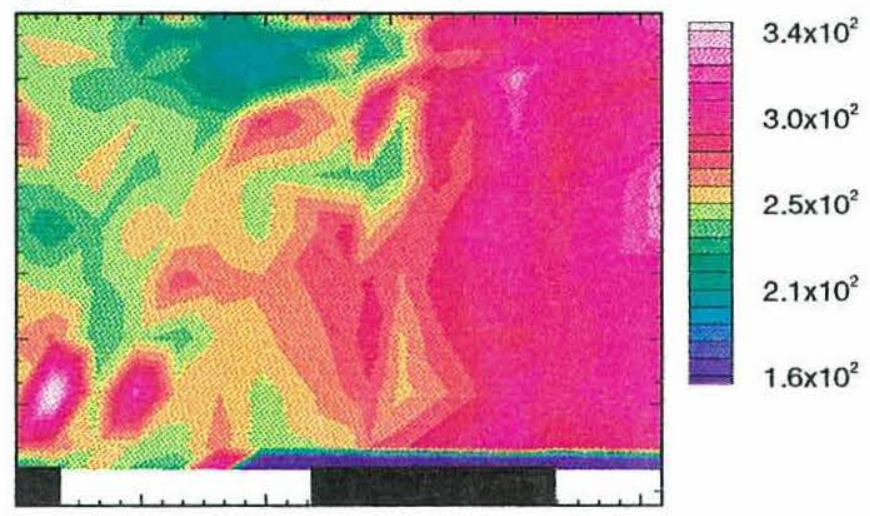

(d) $4^{\text {th }}$ Moment $-3 s^{4}\left(\operatorname{chan}^{4}\right)$

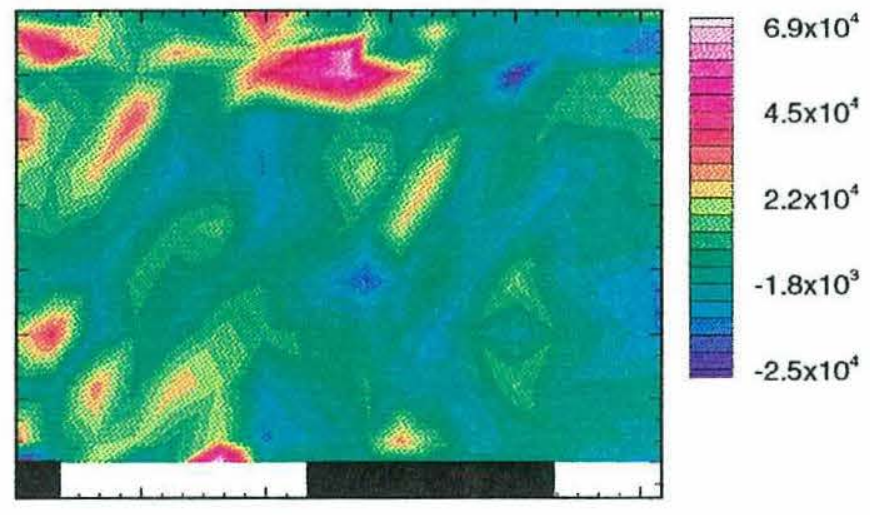

04:00 10:00 16:00 22:00 04:00 10:00

Local Time (hours) 
approach normality, with the kurtosis (corrected fourth moment divided by the variance squared) about 0.3 . The January time-series also shows no strong pattern in the fourth moment, however, values are both positive and negative, indicating both flattened and peaked curves. Most of the samples exhibit a kurtosis (not shown) in the range from -0.1 to +0.1 , which are not significantly different from zero based on an error of $\sim 0.1$ as calculated using the method of Sokal and Rohlf (1981). The fourth moment thus does not respond significantly to the changes in water column structure seen here.

\section{Discussion}

These diel time-series observations suggest a strong effect of mixing and resultant photoacclimation dynamics on the mean and variance of red autofluorescence. The diel signal seen in red fluorescence, resulting from phased cell growth and division, can be removed or reduced by using an appropriate normalization to forward scatter (Chapter III). The dominant patterns in both the mean and variance seem to be the result of photoacclimation during the day, which sets up a gradient in normalized fluorescence and mixing at night which breaks down this gradient. Because photoacclimation drives the normalized fluorescence towards a similar value at a given depth, the distributions tend to tighten during the day. At night, the variance of the distributions increases in both time-series, owing to mixing of the established gradient.

These results suggest limited utility for the third and fourth moments as diagnostic tools of mixing processes. However, they may prove useful for detecting 
special features, such as the boundary effects, which can be seen in the third moment. In addition, the overall negative third moment seen in the October time-series agrees qualitatively with stationary model simulations which predict stronger overall negative skewness in the presence of hysteresis (as represented with the logistic model, Chapter IV, Fig. 4b). The fourth moment deviated significantly from zero only when skewing was strong, and thus provided no information beyond that seen in the third moment.

\section{Acknowledgments}

I thank Brian Binder, Penny Chisholm, Mark Cochrane, Michele DuRand, Sheila Frankel, Zackary Johnson, Rob Olson, Amy Rovelstad and Erik Zettler for logistic and technical support at sea; the captain and crews of the RV Oceanus and the RV Endeavor; and chief scientists Rob Olson and John Waterbury. 


\section{References}

Brainerd, K. E. and M. C. Gregg. 1993. Diurnal restratification and turbulence in the oceanic surface mixed layer 1. Observations. J. Geophys. Res. 98:22,645-22,656.

Cullen, J. J. and M. R. Lewis. 1988. The kinetics of algal photoadaptation in the context of vertical mixing. J. Plankton Res. 10:1039-1063.

Denman, K. L. and A. E. Gargett. 1983. Time and space scales of vertical mixing and advection of phytoplankton in the upper ocean. Limnol. Oceanogr. 28:801-815.

Falkowski, P. G. 1983. Light-shade adaptation and vertical mixing of marine phytoplankton: A comparative field study. J. Mar. Res. 41:215-237.

Falkowski, P. G. and C. D. Wirick. 1981. A simulation model of the effects of vertical mixing on primary productivity. Mar. Biol. 65:69-75.

Gallegos, C. L. and T. Platt. 1982. Phytoplankton production and water motion in surface mixed layers. Deep-Sea Res. 29:65-76.

Geider, R. J. and T. Platt. 1986. A mechanistic model of photoadaptation in microalgae. Mar. Ecol. Prog. Ser. 30:85-92.

Kamykowski, D., S. A. McCollum and G. J. Kirkpatrick. 1988. Observations and a model concerning the translational velocity of a photosynthetic marine dinoflagellate under variable environmental conditions. Limnol. Oceanogr. 33:66-78.

Lande, R. and M. R. Lewis. 1989. Models of photoadaptation and photosynthesis by algal cells in a turbulent mixed layer. Deep-Sea Res. 36:1161-1175.

Laws, E. A. and T. T. Bannister. 1980. Nutrient- and light-limited growth of Thalassiosira fluviatilis in continuous culture, with implications for phytoplankton growth in the ocean. Limnol. Oceanogr. 25:457-473.

Lewis, M. R., E. P. W. Horne, J. J. Cullen, N. S. Oakey and T. Platt. 1984. Turbulent motions may control phytoplankton photosynthesis in the upper ocean. Nature. 311:49-50.

Lewis, M. R. and J. C. Smith. 1983. A small volume, short-incubation-time method for measurement of photosynthesis as a function of incident irradiance. Mar. Ecol. Prog. Ser. 13:99-102.

Marra, J. 1978a. Effect of short-term variations in light intensity on photosynthesis of a marine phytoplankter: A laboratory simulation study. Mar. Biol. 46:191-202. 
Marra, J. 1978b. Phytoplankton photosynthetic response to vertical movement in a mixed layer. Mar. Biol. 46:203-208.

Marra, J. 1980. Vertical mixing and primary productivity. in: Primary Productivity in the Sea. P. G. Falkowski (ed.). Plenum Press. New York.

Marra, J. and K. Heinemann. 1982. Photosynthesis response by phytoplankton to sunlight variability. Limnol. Oceanogr. 27:1141-1153.

Melamed, M. R., T. Lindmo and M. L. Mendelsohn. 1990. Flow Cytometry and Sorting, $2^{\text {nd }}$ Edition. Wiley-Liss, New York.

Olson, R. J., S. W. Chisholm, M. Altabet, E. R. Zettler and J. A. Dusenberry. 1990. Spatial and temporal distributions of prochlorophyte picoplankton in the North Atlantic Ocean. Deep-Sea Res. 37:1033-1051.

Olson, R. J., E. R. Zettler and M. D. DuRand. 1993. Phytoplankton analysis using flow cytometry. in: Handbook of Methods in Aquatic Microbial Ecology. P. F. Kemp (ed.). Lewis Publishers. Boca Raton.

Price, J. F., R. A. Weller and R. Pinkel. 1986. Diurnal cycling: Observations and models of the upper ocean response to diurnal heating, cooling, and wind mixing. $J$. Geophys. Res. 91:8411-8427.

Rivkin, R. B. 1990. Photoadaptation in marine phytoplankton: Variations in ribulose 1,5-bisphosphate activity. Mar. Ecol. Prog. Ser. 62:61-72.

Sathyendranath, S., A. D. Gouveia, S. R. Shetye, P. Ravindran and T. Platt. 1991. Biological control of surface temperature in the Arabian Sea. Nature. 349:54-56.

Savidge, G. 1988. Influence of inter- and intra-daily light-field variability on photosynthesis of coastal phytoplankton. Mar. Biol. 100:127-133.

Shapiro, H. M. 1995. Practical Flow Cytometry, Third Edition. Wiley-Liss, Inc. New York.

Simonot, J., Dollinger, E. and Le Treut, H. 1988. Thermodynamic-biological-optical coupling in the oceanic mixed layer. J. Geophys. Res. 93(C7):8193-8202.

Sokal, R. R. and F. J. Rohlf. 1981. Biometry, Second Edition. W. H. Freeman and Company. New York.

Therriault, J.-C., D. Booth, L. Legendre and S. Demers. 1990. Phytoplankton photoadaptation to vertical excursion as estimated by an in vivo fluorescence ratio. 
Mar. Ecol. Prog. Ser. 60:97-111.

Vaulot, D., C. Courties and F. Partensky. 1989. A simple method to preserve oceanic phytoplankton for flow cytometric analyses. Cytometry. 10:629-635.

Walsh, P. and L. Legendre. 1983. Photosynthesis of natural phytoplankton under high frequency light fluctuations simulating those induced by sea surface waves. Limnol. Oceanogr. 28:688-697.

Woods, J. D. and W. Barkmann. 1986. The response of the upper ocean to solar heating. I: The mixed layer. Quart. J. R. Met. Soc. 112:1-27.

Yamazaki, H. and D. Kamykowski. 1991. The vertical trajectories of motile phytoplankton in a wind-mixed water column. Deep-Sea Res. 38:219-241.

Yoder, J. A. and S. S. Bishop. 1985. Effects of mixing-induced irradiance fluctuations on photosynthesis of natural assemblages of coastal phytoplankton. Mar. Biol. 90:87-93. 


\section{Chapter III}

Photoacclimation in Photosynthetic Picoplankton and an Analysis of Their Potential Use as Tracers for Vertical Mixing 


\title{
Photoacclimation in Photosynthetic Picoplankton and an Analysis of Their Potential Use as Tracers for Vertical Mixing
}

\begin{abstract}
In order to use picophytoplankton as tracers for vertical mixing, an appropriate index of photoacclimative state and the kinetics of that parameter must be defined. Several time-series of reciprocal light shifts to Prochlorococcus marinus strain Med4 or natural populations of Prochlorococcus spp. were undertaken to determine the relevant kinetics. Laboratory experiments suggest that red fluorescence normalized to the cube root of forward angle light scatter may be an appropriate indicator of photoacclimation in Prochlorococcus spp. A logistic model for photoacclimation (Cullen and Lewis, 1988) was found to fit the resulting time-series reasonably well, with the most pronounced deviation from this model in the populations shifted to high irradiances. Photoacclimative rates ranged from 0.9 to $3 \mathrm{~d}^{-1}$, with the highest rate observed in larger Prochlorococcus spp. The smaller Prochlorococcus type yield rates that decrease with increasing temperature within the range studied $\left(24-26^{\circ} \mathrm{C}\right)$.
\end{abstract}




\section{Introduction}

There have been several approaches in the past to quantifying mixing rates in the ocean surface layer, including microstructure determinations of kinetic energy dissipation (Osborn, 1978; Oakey and Elliot, 1982; Shay and Gregg, 1986; Lombardo and Gregg, 1989; Moum et al., 1989) and measurements using tracers. Properties which have been proposed or used as tracers include nutrient concentrations (Garside, 1985), added chemical tracers such as dyes (Okubo, 1971) or radioisotopes (Quay et al., 1980), and phytoplankton cells (Lewis et al., 1984). Phytoplankton cells can be used as tracers if their physiological condition reflects their light (depth) history. By quantifying the physiological response to changes in light intensity it is theoretically possible to use field observations of physiological states to then infer mixing dynamics.

Picoplankton, in particular Prochlorococcus spp., should make excellent tracers for mixing processes because their small size ( 0.6 to $0.8 \mu \mathrm{m}$ diameter) makes them essentially neutrally buoyant and they are abundant and ubiquitous throughout much of the world oceans (Chisholm et al., 1988; Olson et al., 1990). These organisms can be studied with flow cytometry (see Chapter II) and their scatter and fluorescence properties measured. Because fluorescence is a function of pigment content, it should be indicative of the cell's light history, and should thus be useful in studying vertical mixing.

The model commonly used to represent the effects of vertical mixing on the vertical distribution of a photoacclimative parameter, $\Gamma$, is the reaction-diffusion 
equation (Lewis et al., 1984; Cullen and Lewis, 1988):

$$
\frac{\partial \bar{\Gamma}}{\partial t}=\frac{\partial}{\partial z} K_{v} \frac{\partial \bar{\Gamma}}{\partial z}+\gamma \Gamma\left(\frac{\Gamma_{\infty}-\bar{\Gamma}}{\Gamma_{\infty}}\right)
$$

where $\mathrm{t}$ is time and $\mathrm{z}$ is depth. Mixing of cells is parameterized by a vertical diffusivity, $\mathrm{K}_{\mathrm{v}}$, and photoacclimation is usually specified as a first-order process, with rate constant $\gamma . \Gamma_{\infty}$ is the fully acclimated value of the photoacclimative parameter. A logistic formulation for the photoacclimative term (Cullen and Lewis, 1988) was used here instead of a first-order formulation as it has the potential to account for hysteresis seen in photoacclimation rates (Prézelin and Matlick, 1980; Geider and Platt, 1986).

It is necessary to quantify the kinetics of photoacclimation, both in terms of the appropriate formulation and in the rate constant if one wishes to use phytoplankton cells as tracers. In the absence of mixing, equation (1) becomes:

$$
\frac{\partial \Gamma}{\partial t}=\gamma \Gamma\left(\frac{\Gamma_{\infty}-\Gamma}{\Gamma_{\infty}}\right) .
$$

The kinetics of photoacclimation can be quantified by subjecting cultures or field samples to shifts in light intensity and following the time course of change in the relevant photoacclimative parameter. I attempt here to define the kinetics of photoacclimation for the optical properties of the photosynthetic picoplankter 
Prochlorococcus marinus using laboratory based light shifts, and of natural populations of Prochlorococcus spp. in the field by subjecting them to light shifts under simulated in-situ conditions. Time course observations can then be fit to the above model (Eq. 2) to estimate both the rate constant, $\gamma$, and the fully acclimated value for the photoacclimative parameter, $\Gamma_{\infty}$.

\section{Methods}

\section{Laboratory}

Laboratory cultures of P. marinus, strain Med4 (Moore et al., 1995), were acclimated to a range of light intensities and subjected to reciprocal light shifts to quantify the kinetics of photoacclimation.

The experimental apparatus consisted of two water cooled Lexan ${ }^{\circledR}$ incubators, and two banks of three "Very High Output" (VHO) Daylight fluorescent bulbs. One incubator was located between the two light banks, and the second was situated on the opposite side of one bank of bulbs, so that it received light from only one bank instead of two. Blue screening (Roscolux blue \#62 and \#69) was used to control light levels in different regions of the incubators. Four light levels were used: 620,320, 110, and $54 \mu \mathrm{E} \mathrm{m}^{-2} \mathrm{~s}^{-1}$, as measured using a Biospherical Instruments $4 \pi$ sensor. The lights were timed such that they came on two at a time. The uppermost bulbs were on from 08:30 to $19: 30$, the middle bulbs from $09: 30$ to $18: 30$ and the lower bulbs from 10:30 to 17:30. This is a discrete approximation to patterns in photosynthetically active radiation (PAR) seen in the Sargasso Sea during a cruise there in October 1989 (data 
not shown). Temperature was maintained at $24{ }^{\circ} \mathrm{C}$ using a constant temperature circulating water bath.

Cells were grown in modified $\mathrm{K} / 10$ media as specified in Chisholm et al. (1992), except that the EDTA concentration was 10-fold more dilute $(1.2 \mu \mathrm{M})$.

Seawater for the media was collected from Vineyard Sound off Cape Cod (MA).

Cells were grown in $25 \mathrm{ml}$ of media in $25 \times 150 \mathrm{~mm}$ borosilicate tubes, with $1 \mathrm{ml}$ of sample transferred to a new tube with fresh media when cell concentrations reached approximately $10^{6} \mathrm{ml}^{-1}$.

Eight cultures were grown at each light level and their concentration, light scatter and fluorescence were monitored using a modified FACScan flow cytometer (Dusenberry and Frankel, 1994) until they reached steady exponential growth for at least three transfers (approximately 15 generations or three weeks). Once the cultures were stabilized and therefore acclimated to their respective light levels, two cultures from each light level were shifted to each of the three other light levels. This shift was done during the dark phase of the light:dark cycle. In addition, two cultures were kept at each light level to serve as controls. The cultures were then monitored using the FACScan every 2 hours for a period of 2 days. At each sampling time point, flow cytometric measurements of cell concentration, forward angle light scatter, right angle light scatter and red autofluorescence (from chlorophyll) were made. Data was collected in list mode, so that the signal for each parameter was recorded for every cell. Subsequent analysis was done with CYTOPC flow cytometry analysis software (D. Vaulot). All optical measurements were normalized to $0.57-\mu \mathrm{m}$ microspheres 
Table 1 - Cruises on which natural samples were incubated on deck under simulated in-situ conditions. The depths given are the depths from which samples were collected and the temperature is an average temperature in the incubators.

\begin{tabular}{|c|c|c|c|c|c|}
\hline Cruise & Date & Location & $\begin{array}{l}\text { Depths } \\
\text { (m) }\end{array}$ & $\begin{array}{c}\text { Surface } \\
\text { Irradiance } \\
\left(\mu \mathrm{E} \mathrm{m}^{-2} \mathrm{~s}^{-1}\right)\end{array}$ & $\begin{array}{c}\text { Temperature } \\
\left({ }^{\circ} \mathrm{C}\right)\end{array}$ \\
\hline $\begin{array}{l}\text { RV Oceanus } \\
214\end{array}$ & October 1989 & $\begin{array}{l}\text { Sargasso Sea } \\
\left(33^{\circ} \mathrm{N}, 66^{\circ} \mathrm{W}\right)\end{array}$ & $\begin{array}{l}15,48, \\
77\end{array}$ & $\begin{array}{c}1700 \\
\text { (Day 1) }\end{array}$ & 25 \\
\hline $\begin{array}{l}\text { RV Oceanus } \\
221\end{array}$ & July 1990 & $\begin{array}{l}\text { Sargasso Sea } \\
\left(34^{\circ} \mathrm{N}, 61^{\circ} \mathrm{W}\right)\end{array}$ & $\begin{array}{l}25,55 \\
70\end{array}$ & 2200 & 26 \\
\hline $\begin{array}{l}\text { RV Moana } \\
\text { Wave } \\
\text { 091-010 }\end{array}$ & August 1991 & $\begin{array}{l}\text { Equatorial } \\
\text { Pacific } \\
\left(0^{\circ}, 140^{\circ} \mathrm{W}\right)\end{array}$ & $\begin{array}{l}10,40, \\
60\end{array}$ & $2000^{a}$ & 27 \\
\hline
\end{tabular}

"Courtesy M. Fienholz

(Polysciences, Inc.), which were added to each sample as an internal standard.

\section{Field}

Field experiments were conceptually similar to the laboratory experiments. Natural samples were collected from three different depths in the water column and incubated on deck under simulated in-situ conditions in order to determine the time course of photoacclimation in natural populations.

Experiments were done on several different cruises in the Sargasso Sea and in the equatorial Pacific (Table 1). While the exact protocol differed slightly from cruise to cruise, the experiments were essentially the same. Samples were taken from three different depths corresponding to the estimated depths of the 50\%, 10\% and 3\% surface irradiance (Table 1). Acid cleaned GoFlos were used for sample collection to minimize contamination. Samples were collected at approximately 03:00 local time, 
with the experiment beginning before dawn. After collection, samples were transferred to acid cleaned $250-\mathrm{ml}$ polycarbonate bottles and two bottles from each depth sampled were placed into each of three water cooled screened on-deck incubators corresponding to the light levels sampled. The incubators were screened with neutral density screening on the Sargasso Sea cruises, and blue screening (Roscolux \#62 and \#69) on the equatorial Pacific cruise. During each experiment, 2-ml samples were taken periodically (every $2-4$ hours) from each bottle, fixed with 0.1\% glutaraldehyde (Vaulot et al., 1989; Olson et al., 1990) and stored in liquid nitrogen for later analysis in the lab. The experiments from the October Sargasso Sea cruise and the equatorial Pacific cruise were then analyzed using a standard FACScan flow cytometer. The July Sargasso Sea cruise was run on the modified FACScan (Dusenberry and Frankel, 1994) similar to the lab samples above. In all experiments, each sample was thawed individually and run immediately after thawing. Subsequent data analysis was the same as in the laboratory samples.

\section{Results}

\section{Laboratory}

In the laboratory, one would expect to see a gradient in optical properties, such as red fluorescence, across the light gradient the cells are acclimated to. After being subjected to a change in light intensity, the cells are expected to show a course of change towards the fully acclimated state corresponding to the new light level.

One of the dominant patterns seen the laboratory P. marinus, however, is a 
strong diel pattern in both forward angle scatter and red autofluorescence (Fig. 1-2). This pattern is attributed to changes in scatter and fluorescence arising from cell growth/cell cycle effects. Cell concentration measurements show a phasing of cell division (Fig. 3) with cell division (which occurs at night) corresponding to periods of decreasing mean scatter and fluorescence (Fig. 1-2).

While there is a noticeable pattern with the cultures at each light level showing a convergence towards a common value, this rate of convergence is difficult to estimate due to the strong diel signal present. Red fluorescence signals in the two highest light levels (620 and $320 \mu \mathrm{E} \mathrm{m} \mathrm{m}^{-2}$ ) show a twice-daily periodicity, with maxima in fluorescence at both "dawn" and "dusk." The low light incubators (110 and $54 \mu \mathrm{E} \mathrm{m}^{-2} \mathrm{~s}^{-1}$ ) show diel periodicity with maxima at the end of the light period. In an attempt to factor out this diel periodicity (due to growth), I sought to determine if fluorescence could be normalized to forward angle light scatter. A plot of the mean red fluorescence signal against the mean forward scatter signal for the control cultures shows a strong relationship for the lower light controls with mean red fluorescence $\propto$ (mean forward scatter) $^{1 / 3}$ (Fig. 4). This relationship reflects only the diel pattern of daytime increase and nighttime decrease in red fluorescence and scatter seen and does not reflect the correlation seen between red fluorescence and forward angle light scatter within Prochlorococcus spp. populations (Chapter II, Fig. 1). Since this diel pattern in fluorescence and scatter in the low light controls (and in the high light controls when only afternoon and early evening points are considered, Fig. 4) is consistent with patterns in cell concentration (fluorescence and scatter decreasing when 
numbers increase, all due to cell division) one can assume that this particular pattern is the result of cell growth and not photoacclimation. Red fluorescence can thus be normalized to the cube root of forward angle light scatter to remove or reduce the diel pattern attributed to cell growth. It is this normalized red fluorescence that was used as the photoacclimative parameter, $\Gamma$.

Normalized red fluorescence signals (Fig. 5) show a strong reduction in the periodicity of the signal, particularly in the low light bottles; this is expected as the normalization was based on the behavior of the low light controls. The twice-daily periodicity in the high light bottles was reduced to simple diel periodicity, with the maxima at dusk removed. This is the part of the twice-daily periodicity in these bottles that appears to be attributed to cell growth and division, based on cell concentration (Fig. 3a, b). These two high light controls (Fig. 5a, b) show a marked reduction in normalized fluorescence at the beginning of the photoperiod. This is primarily due to a reduction of the red fluorescence signal (Fig. 2). This decrease in fluorescence does not correspond to an increase in cell concentration (and thus does not seem attributable to cell division), and mirrors an increase that occurs during the dark period. This suggests that the photoacclimative process or processes acting at high light are different than those at low light in the sense that the high light controls show a depression in fluorescence during the light period and an increase at night which is not observed in low light controls. It is not clear what this process is, be it chlorophyll degradation and synthesis or a change in fluorescence yield due to some photoprotective mechanism; however, similar results have been seen in the field 
Figure 1 - Time-series measurements of mean forward angle light scatter for $P$. marinus strain Med4 during a laboratory reciprocal light shift experiment. Cells acclimated to light intensities of $620 \mu \mathrm{E} \mathrm{m}^{-2} \mathrm{~s}^{-1}$ (open circles), $320 \mu \mathrm{E} \mathrm{m}^{-2} \mathrm{~s}^{-1}$ (closed circles), $110 \mu \mathrm{E} \mathrm{m}^{-2} \mathrm{~s}^{-1}$ (open triangles) and $54 \mu \mathrm{E} \mathrm{m}^{-2} \mathrm{~s}^{-1}$ (closed triangles) were shifted to (a) $620 \mu \mathrm{E} \mathrm{m}^{-2} \mathrm{~s}^{-1}$, (b) $320 \mu \mathrm{E} \mathrm{m}^{-2} \mathrm{~s}^{-1}$, (c) $110 \mu \mathrm{E} \mathrm{m}^{-2} \mathrm{~s}^{-1}$ and (d) $54 \mu \mathrm{E} \mathrm{m}^{-2} \mathrm{~s}^{-1}$ prior to the first sampling point. All values are relative to $0.57-\mu \mathrm{m}$ microspheres (beads) which were used as an internal standard. Error bars represent one standard deviation, and are not shown when smaller than the symbol size. 


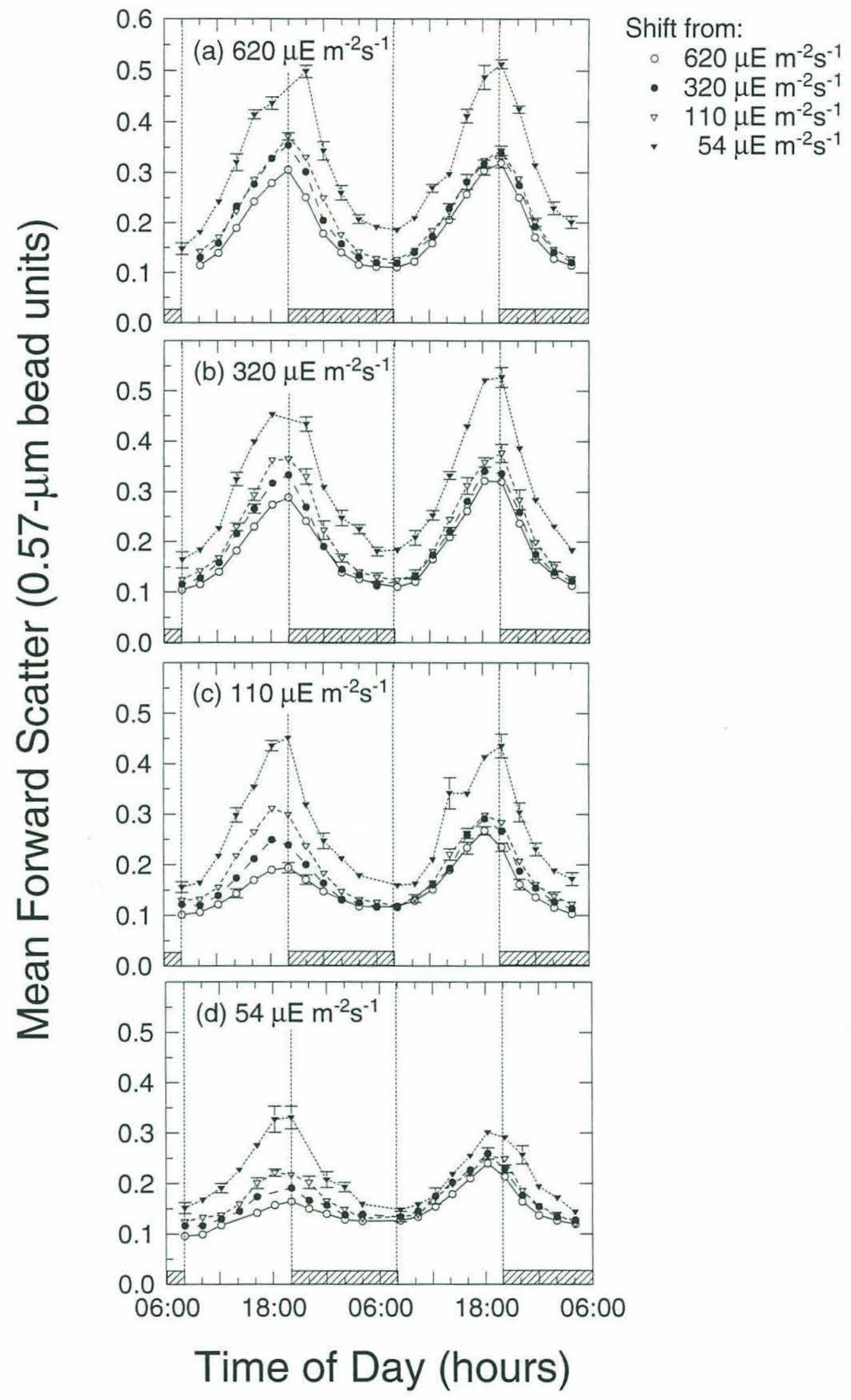


Figure 2 - Time-series measurements of mean red fluorescence for $P$. marinus strain Med4 during the reciprocal light shift experiment presented in figure 1. Cells acclimated to light intensities of $620 \mu \mathrm{E} \mathrm{m}^{-2} \mathrm{~s}^{-1}$ (open circles), $320 \mu \mathrm{E} \mathrm{m} \mathrm{m}^{-2} \mathrm{~s}^{-1}$ (closed circles), $110 \mu \mathrm{E} \mathrm{m}^{-2} \mathrm{~s}^{-1}$ (open triangles) and $54 \mu \mathrm{E} \mathrm{m}^{-2} \mathrm{~s}^{-1}$ (closed triangles) were shifted to (a) $620 \mu \mathrm{E} \mathrm{m}^{-2} \mathrm{~s}^{-1}$, (b) $320 \mu \mathrm{E} \mathrm{m}^{-2} \mathrm{~s}^{-1}$, (c) $110 \mu \mathrm{E} \mathrm{m}^{-2} \mathrm{~s}^{-1}$ and (d) $54 \mu \mathrm{E} \mathrm{m}^{-2} \mathrm{~s}^{-1}$. All values are relative to $0.57-\mu \mathrm{m}$ microspheres (beads) which were used as an internal standard. Error bars represent one standard deviation, and are not shown when smaller than the symbol size. 


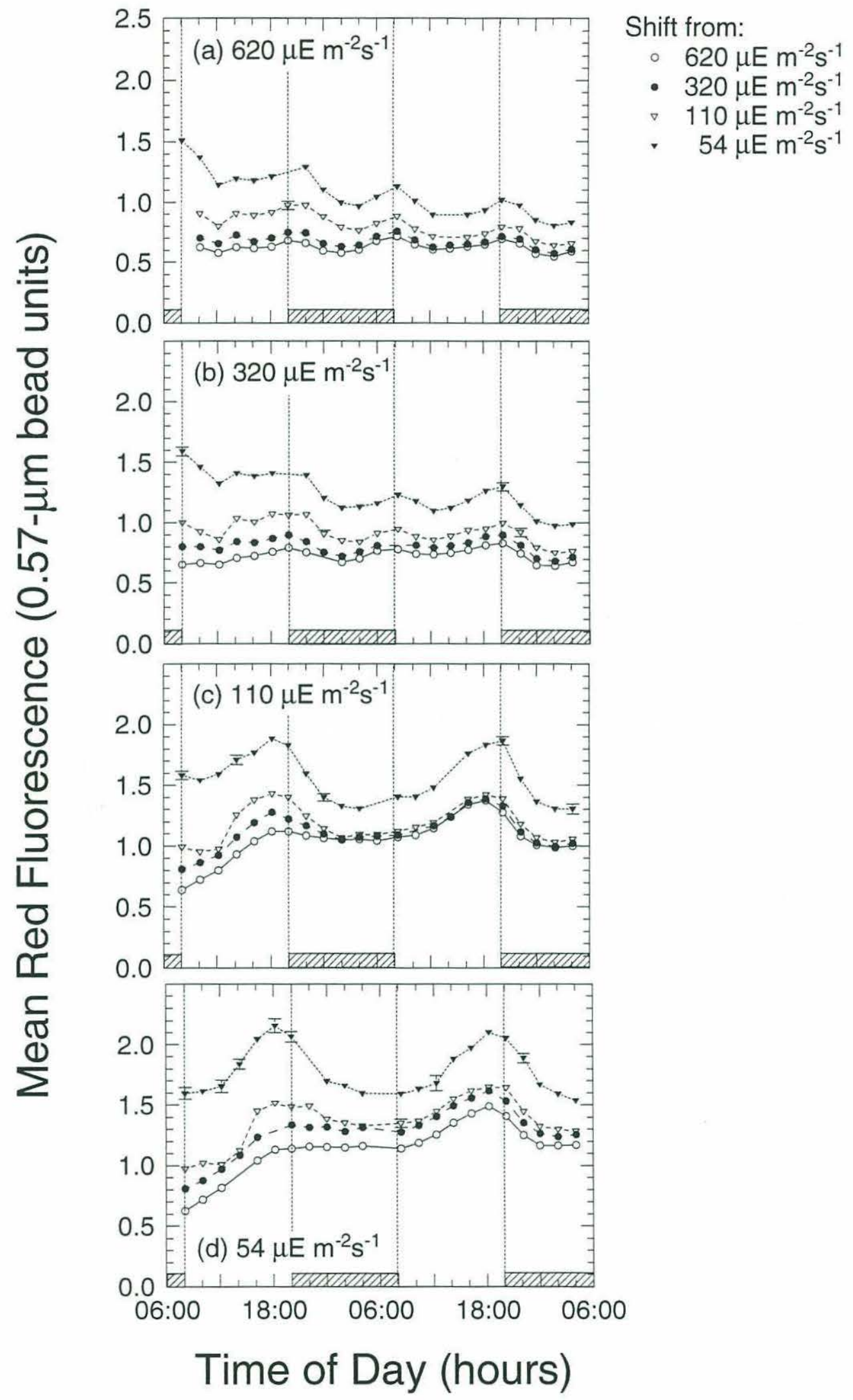


Figure 3 - Time-series measurements of cell concentration for P. marinus strain Med4 during the reciprocal light shift experiment presented in figure 1. Cells acclimated to light intensities of $620 \mu \mathrm{E} \mathrm{m}^{-2} \mathrm{~s}^{-1}$ (open circles), $320 \mu \mathrm{E} \mathrm{m}^{-2} \mathrm{~s}^{-1}$ (closed circles), $110 \mu \mathrm{E} \mathrm{m}^{-2} \mathrm{~s}^{-1}$ (open triangles) and $54 \mu \mathrm{E} \mathrm{m}^{-2} \mathrm{~s}^{-1}$ (closed triangles) were shifted to (a) $620 \mu \mathrm{E} \mathrm{m}^{-2} \mathrm{~s}^{-1}$, (b) $320 \mu \mathrm{E} \mathrm{m}^{-2} \mathrm{~s}^{-1}$, (c) $110 \mu \mathrm{E} \mathrm{m}^{-2} \mathrm{~s}^{-1}$ and (d) $54 \mu \mathrm{E} \mathrm{m}^{-2} \mathrm{~s}^{-1}$. Error bars not shown. 


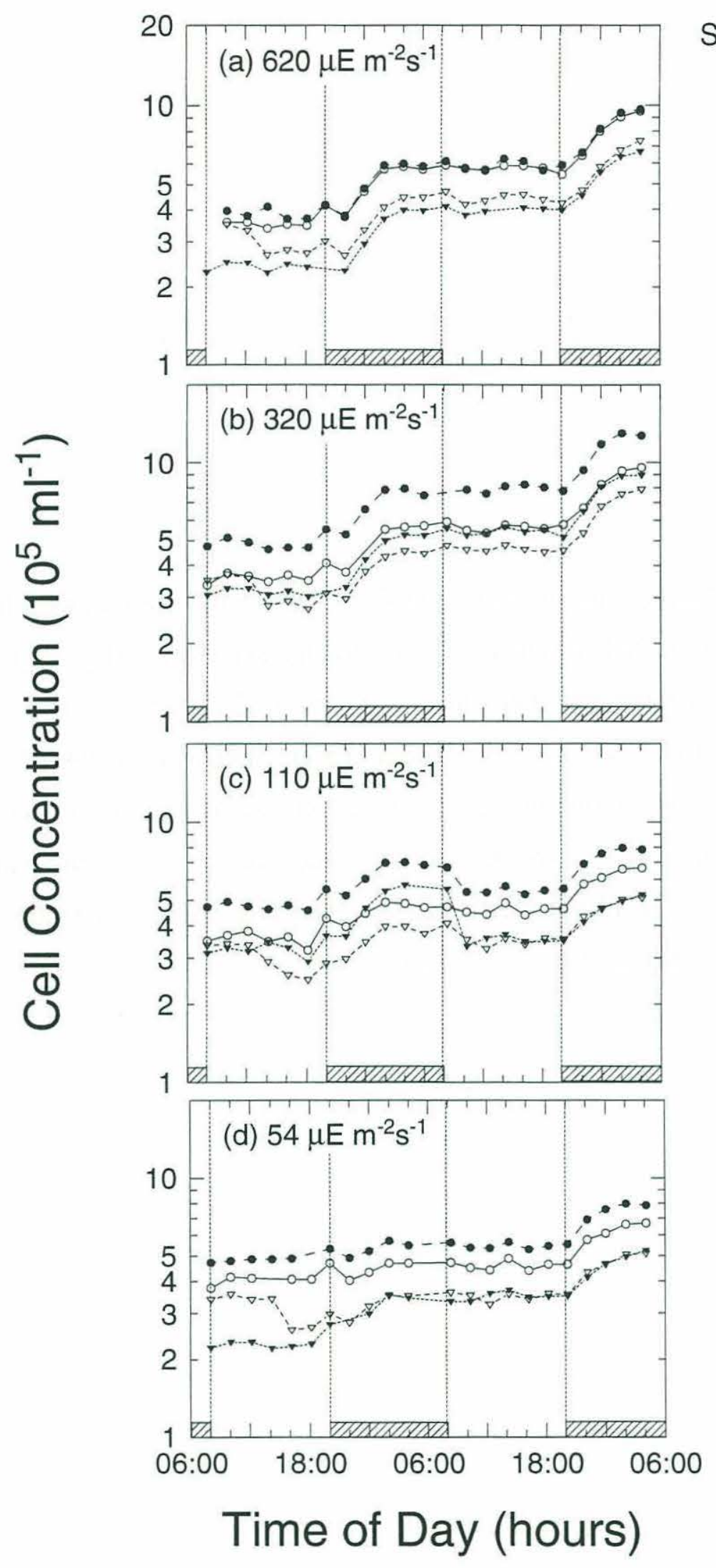

Shift from:

- $620 \mu \mathrm{E} \mathrm{m} \mathrm{m}^{-2} \mathrm{~s}^{-1}$

- $320 \mu \mathrm{E} \mathrm{m} \mathrm{m}^{-2} \mathrm{~s}^{-1}$

- $110 \mu \mathrm{E} \mathrm{m} \mathrm{m}^{-2} \mathrm{~s}^{-1}$

- $\quad 54 \mu \mathrm{E} \mathrm{m} \mathrm{m}^{-2} \mathrm{~s}^{-1}$ 
Figure 4 - Correlation between mean red fluorescence and mean forward angle light scatter for the control (unshifted) cultures in the laboratory experiment shown in figures 1 and 2. Cultures were acclimated to irradiances of $620 \mu \mathrm{E} \mathrm{m}^{-2} \mathrm{~s}^{-1}$ (open circles), $320 \mu \mathrm{E} \mathrm{m}^{-2} \mathrm{~s}^{-1}$ (closed circles), $110 \mu \mathrm{E} \mathrm{m}^{-2} \mathrm{~s}^{-1}$ (open triangles) and $54 \mu \mathrm{E} \mathrm{m} \mathrm{m}^{-2} \mathrm{~s}^{-1}$ (closed triangles). Solid lines show regression results; dotted lines connect data points sequentially. Regressions on the $620 \mu \mathrm{E} \mathrm{m}^{-2} \mathrm{~s}^{-1}$ and $110 \mu \mathrm{E} \mathrm{m}^{-2} \mathrm{~s}^{-1}$ treatments excluded points from 03:00 to 11:00. Error bars represent one standard deviation, and are not shown when smaller than the symbol size. 


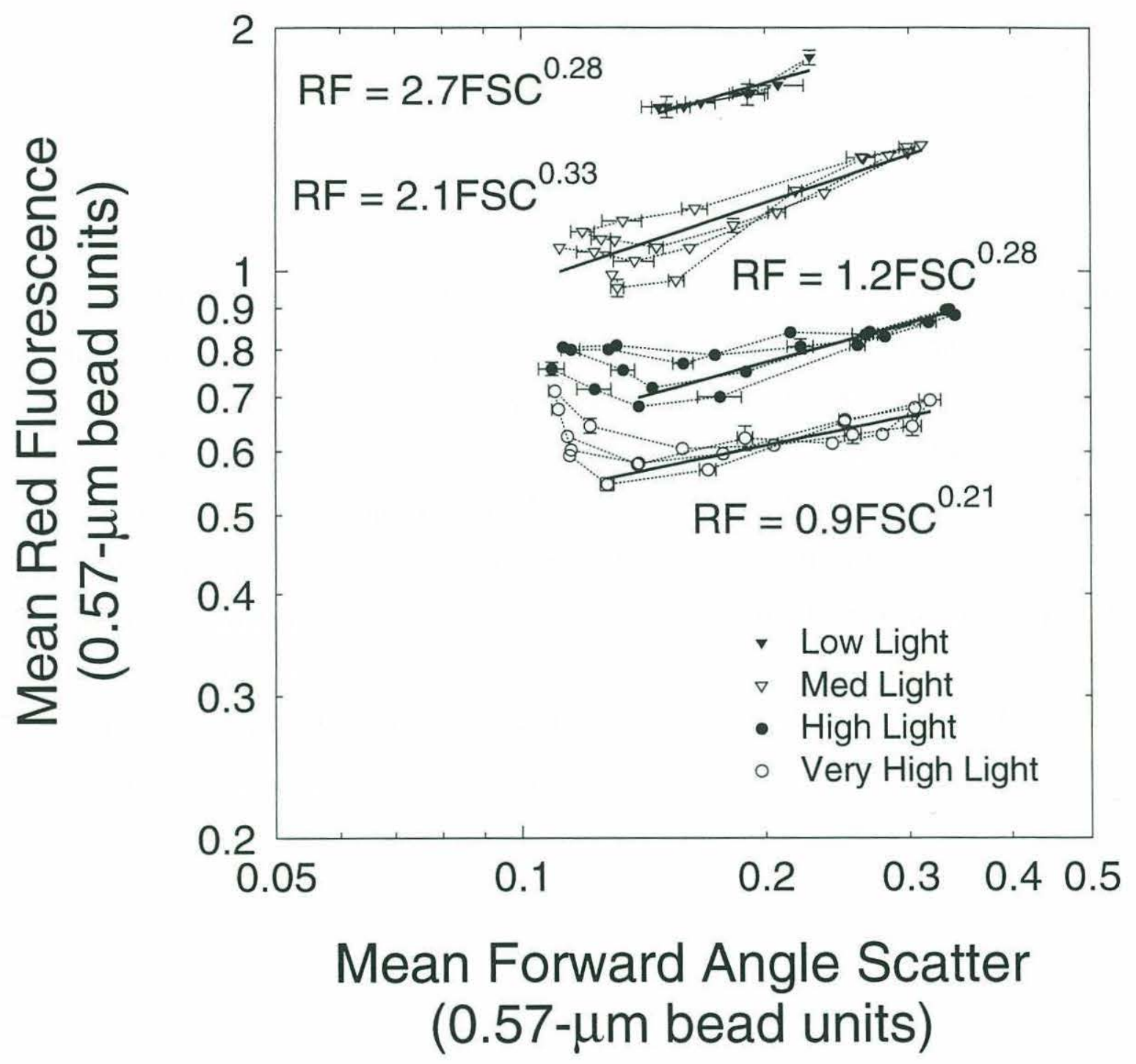


Figure 5 - Time-series measurements of mean red fluorescence normalized to the cube root of the mean forward angle light scatter signal for P. marinus strain Med4 during the reciprocal light shift experiment presented in figure 1. Cells acclimated to light intensities of $620 \mu \mathrm{E} \mathrm{m}^{-2} \mathrm{~s}^{-1}$ (open circles), $320 \mu \mathrm{E} \mathrm{m}^{-2} \mathrm{~s}^{-1}$ (closed circles), $110 \mu \mathrm{E} \mathrm{m}^{-2} \mathrm{~s}^{-1}$ (open triangles) and $54 \mu \mathrm{E} \mathrm{m}^{-2} \mathrm{~s}^{-1}$ (closed triangles) were shifted to (a) $620 \mu \mathrm{E} \mathrm{m}^{-2} \mathrm{~s}^{-1}$, (b) $320 \mu \mathrm{E} \mathrm{m}^{-2} \mathrm{~s}^{-1}$, (c) $110 \mu \mathrm{E} \mathrm{m}^{-2} \mathrm{~s}^{-1}$ and (d) $54 \mu \mathrm{E} \mathrm{m}^{-2} \mathrm{~s}^{-1}$. All values are relative to $0.57-\mu \mathrm{m}$ microspheres (beads) which were used as an internal standard. Error bars represent one standard deviation, and are not shown when smaller than the symbol size. Solid lines are a least squares fit to the logistic formula for photoacclimation (Eq. 2), which yields a rate, $\gamma$, of $2 \mathrm{~d}^{-1}$, and fully acclimated values, $\Gamma_{\infty}$, as shown. 


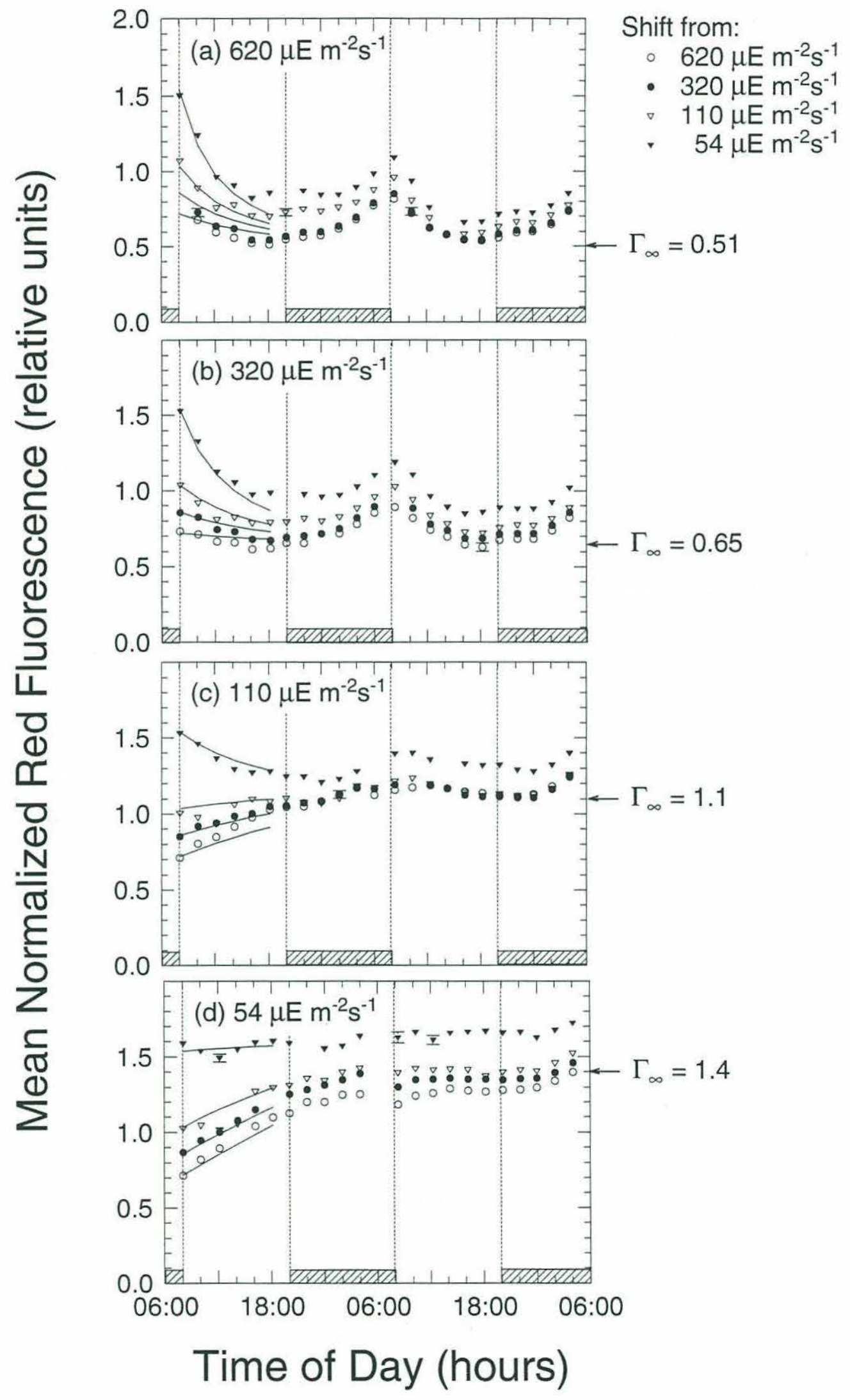


during on-deck bottle incubations (see below) and in in-situ observations from a strongly stratified surface layer (Appendix A). Greene et al. (1994) show similar patterns in their "maximum change in the quantum yield of fluorescence" as measured using fast repetition rate fluorometry during a time-series in the equatorial Pacific.

Mean normalized red fluorescence during the first day was fit to the logistic model of photoacclimation (Eq. 2) using a commercially available least squares algorithm (Jandel Scientific, 1992) (Fig. 5). The rate constant was assumed to be the same for all treatments, and the fully acclimated normalized fluorescence, $\Gamma_{\infty}$, was allowed to vary between light levels but assumed to be the same for all shifts to the same light intensity. This fit yields a rate, $\gamma$, of $2 \mathrm{~d}^{-1}$, and fully acclimated values of normalized fluorescence as shown in figure 5. Overall, the fit is reasonably good, with the exception of the high light controls. The convergence in the high light incubator is less than that predicted. Limiting the fit to just the $620 \mu \mathrm{E} \mathrm{m} \mathrm{m}^{-2} \mathrm{~s}^{-1}$ treatment or using a simple first-order model yields no improvement if the assumption of convergence to a common value is maintained (results not shown). This indicates that more than one mechanism is operating at different intensities and thus a single relatively simple first-order or logistic model is inadequate.

\section{Field:}

\section{Sargasso Sea, Oligotrophic, October 1989}

Prochlorococcus spp. in the surface waters of the Sargasso Sea during the October 1989 cruise shows a strong pattern/diel signal during the first 24 hours of the 
experiments which is similar to that seen in the laboratory (Fig. 6-8). Again, light scatter patterns correspond to changes in cell number, with increasing scatter during the day, and decreasing at night when the cells divided. Unfortunately, stormy weather (noontime $\mathrm{I}_{0}=200 \mu \mathrm{E} \mathrm{m} \mathrm{s}^{-1}$ ) arrived the second day and the cells show only a slight response at the highest light level with very little change in the 10\% and 3\% incubators. By the third day, the storm had started to clear up and the pattern in scatter, fluorescence, and cell division was again evident.

Red fluorescence was normalized to the cube root of the forward angle light scatter, and the values show a marked reduction in the diel pattern associated with cell growth and division (Fig. 9). Consistent with the weather patterns discussed above, we see the strongest photoacclimative effect during the first day, with very little photoacclimation during the second day. The limited acclimation seen during the second day shows the 50\% light level acclimating to a lower light intensity than they were acclimated to the previous day. Photoacclimation is again evident on the third day.

Mean normalized red fluorescence during the first day was fit to the logistic model (Eq. 2) as was the laboratory data (see above). This fit is problematic due to the limited sampling resolution; however, resolution is sufficient to estimate a rate of $1.4 \mathrm{~d}^{-1}$ and fully acclimated values for normalized fluorescence as shown in figure 9 . Within the limits of the resolution, the fits appear quite reasonable. There is a suggestion of lack of convergence in the $50 \%$ incubator, similar to that seen at high light levels in the laboratory (Fig. 5a). 
Figure 6 - Time-series measurements of mean forward angle light scatter for Prochlorococcus spp. during a simulated in-situ reciprocal light shift experiment carried out during the October 1989 cruise to the Sargasso Sea. Populations collected from $15 \mathrm{~m}$ (open circles), $48 \mathrm{~m}$ (closed circles) and $77 \mathrm{~m}$ (open triangles) were incubated on-deck in neutral density screened incubators yielding (a) $50 \%$, (b) $10 \%$ and (c) $3 \%$ of the incident irradiance $\left(\mathrm{I}_{0}\right)$. All values are relative to $0.57-\mu \mathrm{m}$ microspheres (beads) which were used as an internal standard. Error bars represent one standard deviation, and are not shown when smaller than the symbol size. 


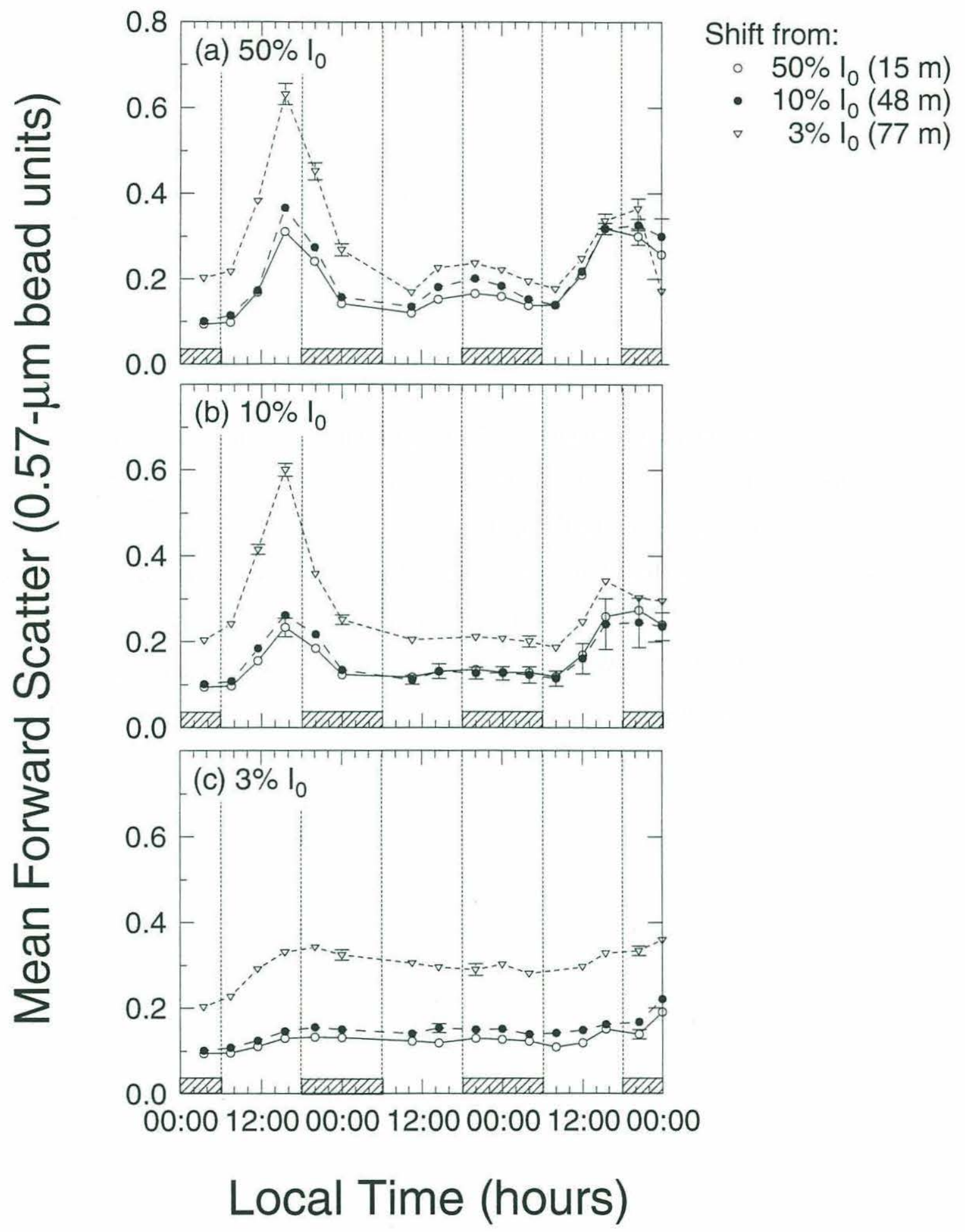


Figure 7 - Time-series measurements of mean red fluorescence for Prochlorococcus spp. during the simulated in-situ reciprocal light shift experiment represented in figure 6. Populations collected from $15 \mathrm{~m}$ (open circles), $48 \mathrm{~m}$ (closed circles) and $77 \mathrm{~m}$ (open triangles) were incubated on-deck in neutral density screened incubators yielding (a) $50 \%$, (b) $10 \%$ and (c) $3 \%$ of the incident irradiance $\left(\mathrm{I}_{0}\right)$. All values are relative to $0.57-\mu \mathrm{m}$ microspheres (beads) which were used as an internal standard. Error bars represent one standard deviation, and are not shown when smaller than the symbol size. 


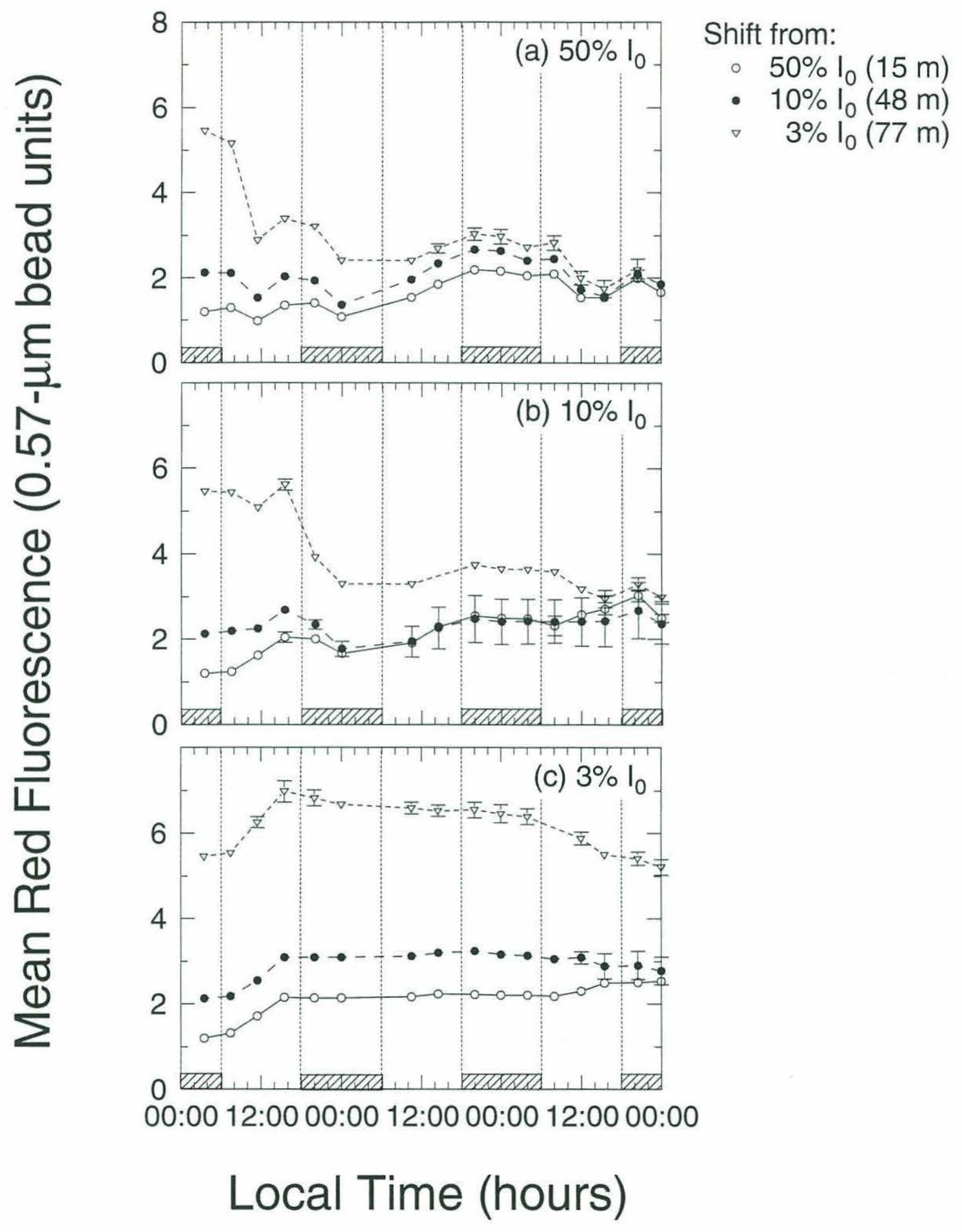


Figure 8 - Time-series measurements of cell concentration for Prochlorococcus spp. during the simulated in-situ reciprocal light shift experiment presented in figure 6. Populations collected from $15 \mathrm{~m}$ (open circles), $48 \mathrm{~m}$ (closed circles) and $77 \mathrm{~m}$ (open triangles) were incubated on-deck in neutral density screened incubators yielding (a) $50 \%$, (b) $10 \%$ and (c) $3 \%$ of the incident irradiance $\left(\mathrm{I}_{0}\right)$. Error bars represent one standard deviation, and are not shown when smaller than the symbol size. 


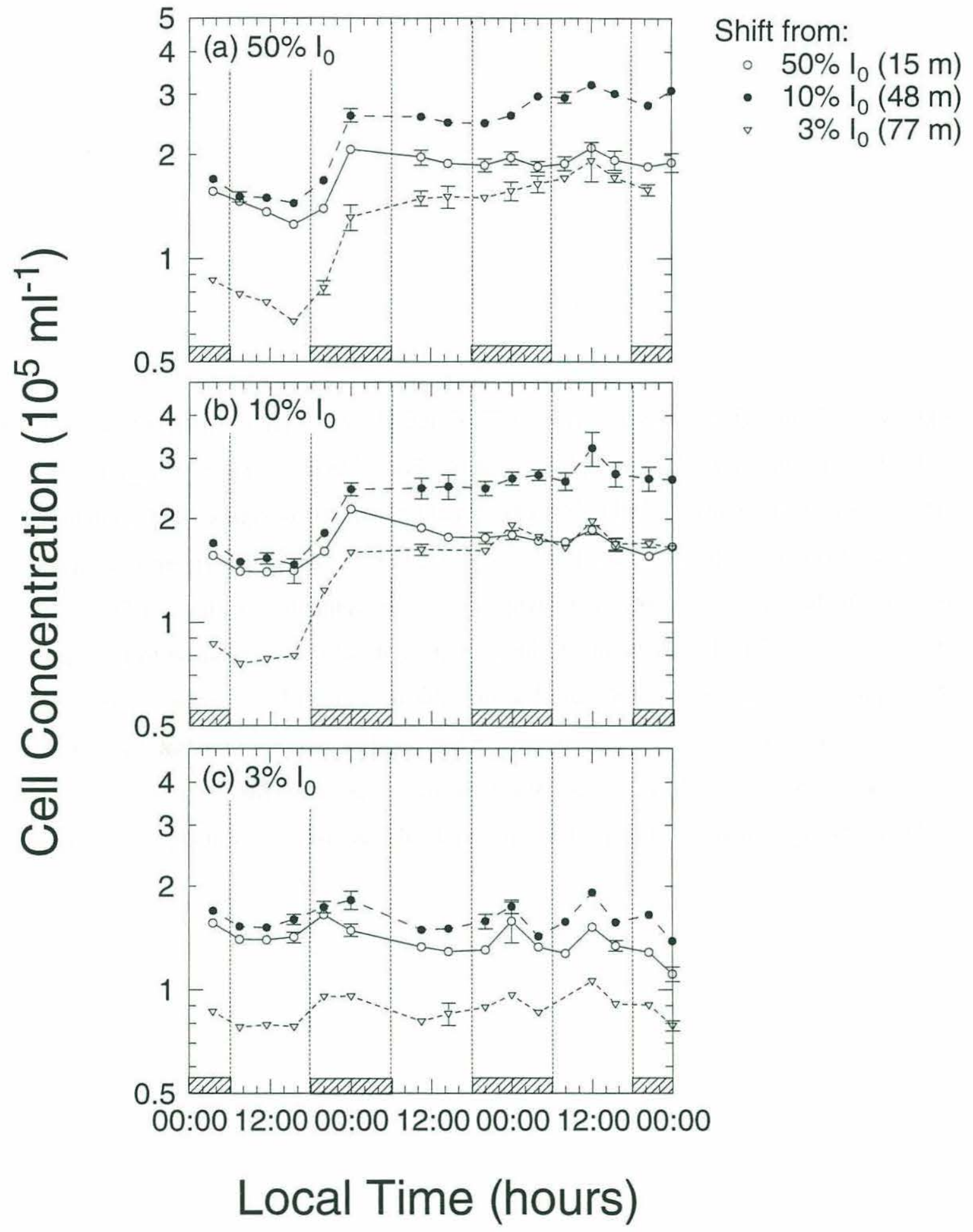


Figure 9 - Time-series measurements of mean red fluorescence normalized to the cube root of the mean forward angle light scatter for Prochlorococcus spp. during the simulated in-situ reciprocal light shift experiment presented in figure 6. Populations collected from $15 \mathrm{~m}$ (open circles), $48 \mathrm{~m}$ (closed circles) and $77 \mathrm{~m}$ (open triangles) were incubated on-deck in neutral density screened incubators yielding (a) $50 \%$, (b) $10 \%$ and (c) $3 \%$ of the incident irradiance $\left(\mathrm{I}_{0}\right)$. All values are relative to $0.57-\mu \mathrm{m}$ microspheres (beads) which were used as an internal standard. Error bars represent one standard deviation, and are not shown when smaller than the symbol size. Solid lines are a least squares fit to the logistic formula for photoacclimation (Eq. 2), which yields a photoacclimation rate, $\gamma$, of $1.4 \mathrm{~d}^{-1}$, and fully acclimated values, $\Gamma_{\infty}$, as shown. 


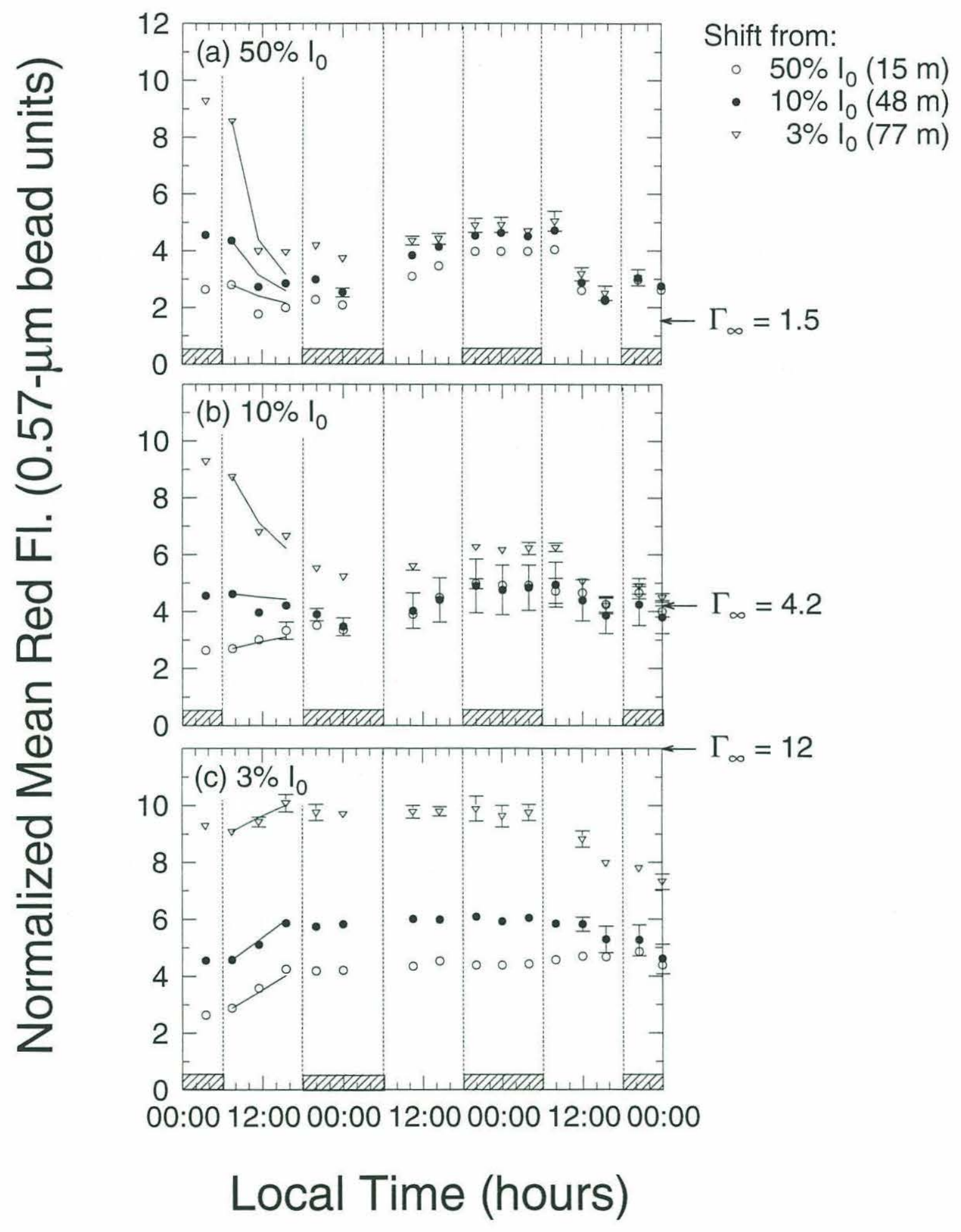




\section{Sargasso Sea, Oligotrophic, July 1990}

A mid summer cruise to the Sargasso Sea (RV Oceanus 221, Table 1) yielded Prochlorococcus spp. with patterns in forward angle light scatter measurements (Fig. 10) similar to that seen on the October cruise. However, the corresponding red fluorescence measurements (Fig. 11) do not show a drop when the mean value of the forward angle light scatter drops, suggesting a lack of cell division, and that the change in forward angle light scatter reflects a shrinking of cells during the nighttime. This observation is consistent with patterns of cell density (Fig. 12) which show an overall decrease in cell numbers throughout the experiment. However, the density measurements at the 50\% $\mathrm{I}_{0}$ light level (Fig. 12a) show a either a faster decrease in cell numbers during the daytime than at night or a slight increase at night (shift from $50 \% \mathrm{I}_{0}$, Fig. 12a). This pattern could be attributed conditions where cell division at night compensates for grazing at that time. One should expect mean fluorescence to decrease during cell division, and this does not appear to occur (Fig. 11a). This may indicate that same process that caused the increase in fluorescence seen in the laboratory $P$. marinus during the night is also operating here, but that its effects are masked by cell division. Alternatively, the lack of a decrease in fluorescence may suggest that loss rates are higher during the light period than during the dark, either due to higher grazing during the day or light-induced cell loss. While this is further supported by the faster rates of loss (particularly during the second day, Fig. 12) at higher light levels, the nighttime increase in cell concentration in the $50 \%$ to $50 \% \mathrm{I}_{0}$ shift (Fig. 12a) supports the first alternative. 
Weather patterns were very consistent, with clear days throughout the experiment (noontime $\mathrm{I}_{0}=2200 \mu \mathrm{E} \mathrm{m}^{-2} \mathrm{~s}^{-1}$ ). Normalized fluorescence (Fig. 13) shows strong acclimation during the first day, as seen on the October Sargasso Sea cruise (Fig. 9), with apparent convergence in the $50 \%$ and $10 \%$ incubators by the second day. On the second and third day, the high light incubator show patterns similar to the high light laboratory incubator, with a sharp decrease in normalized red fluorescence in the early morning, with subsequent increases in normalized fluorescence during the evening and nighttime. The raw mean red fluorescence shows an increase during the daytime (after the initial drop) (Fig. 11) which ceases during the evening. This increase can thus be attributed to growth, and the flat normalized fluorescence curve supports this. The nighttime increase in normalized fluorescence appears to be the result of a near constant pigment concentration within a shrinking cell.

Fits of the time course of mean normalized fluorescence to the logistic model (Eq. 2) yield a rate of $0.9 \mathrm{~d}^{-1}$, the slowest rate estimated here, with fully acclimated values as shown in figure 13. Fits are again reasonable, with no consistent deviation. However, the slow rate constant underestimates the increase observed in the $25 \mathrm{~m}$ sample $\left(50 \% \mathrm{I}_{0}\right)$ shifted to lower light intensities.

\section{Equatorial Pacific, High Nutrient Low Chlorophyll Region, August 1991}

The third field experiment was carried out using samples from the equatorial Pacific (Table 1). This region is characterized as a "high nutrient, low chlorophyll" 
Figure 10 - Time-series measurements of mean forward angle light scatter for Prochlorococcus spp. during a simulated in-situ reciprocal light shift experiment carried out during the July 1990 cruise to the Sargasso Sea. Populations collected from $25 \mathrm{~m}$ (open circles), $55 \mathrm{~m}$ (closed circles) and $70 \mathrm{~m}$ (open triangles) were incubated on-deck in neutral density screened incubators yielding (a) $50 \%$, (b) $10 \%$ and (c) $3 \%$ of the incident irradiance $\left(\mathrm{I}_{0}\right)$. All values are relative to $0.57-\mu \mathrm{m}$ microspheres (beads) which were used as an internal standard. Error bars represent one standard deviation, and are not shown when smaller than the symbol size. 


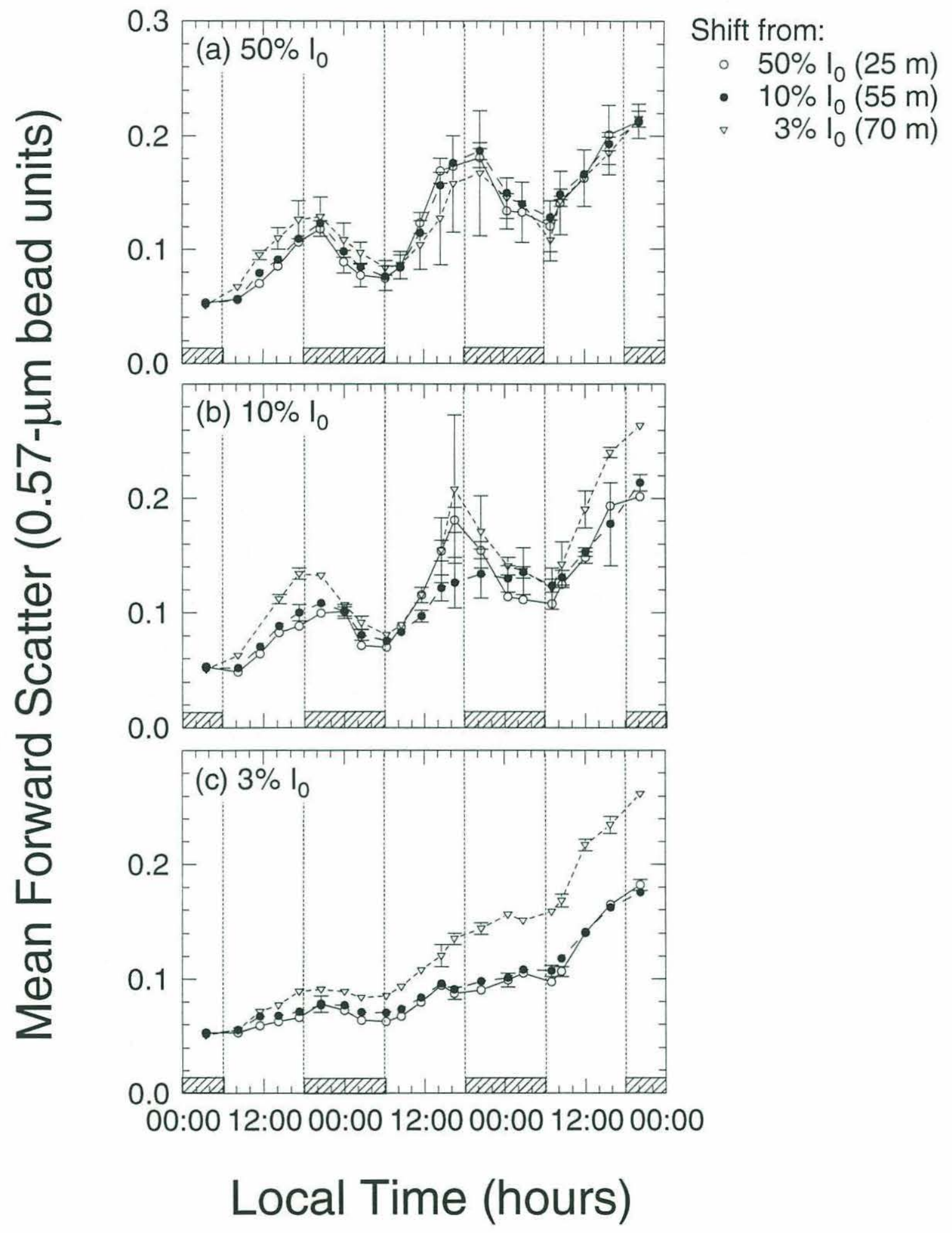


Figure 11 - Time-series measurements of mean red fluorescence for Prochlorococcus spp. during the simulated in-situ reciprocal light shift experiment represented in figure 10. Populations collected from $25 \mathrm{~m}$ (open circles), $55 \mathrm{~m}$ (closed circles) and $70 \mathrm{~m}$ (open triangles) were incubated on-deck in neutral density screened incubators yielding (a) $50 \%$, (b) $10 \%$ and (c) $3 \%$ of the incident irradiance $\left(\mathrm{I}_{0}\right)$. All values are relative to $0.57-\mu \mathrm{m}$ microspheres (beads) which were used as an internal standard. Error bars represent one standard deviation, and are not shown when smaller than the symbol size. 


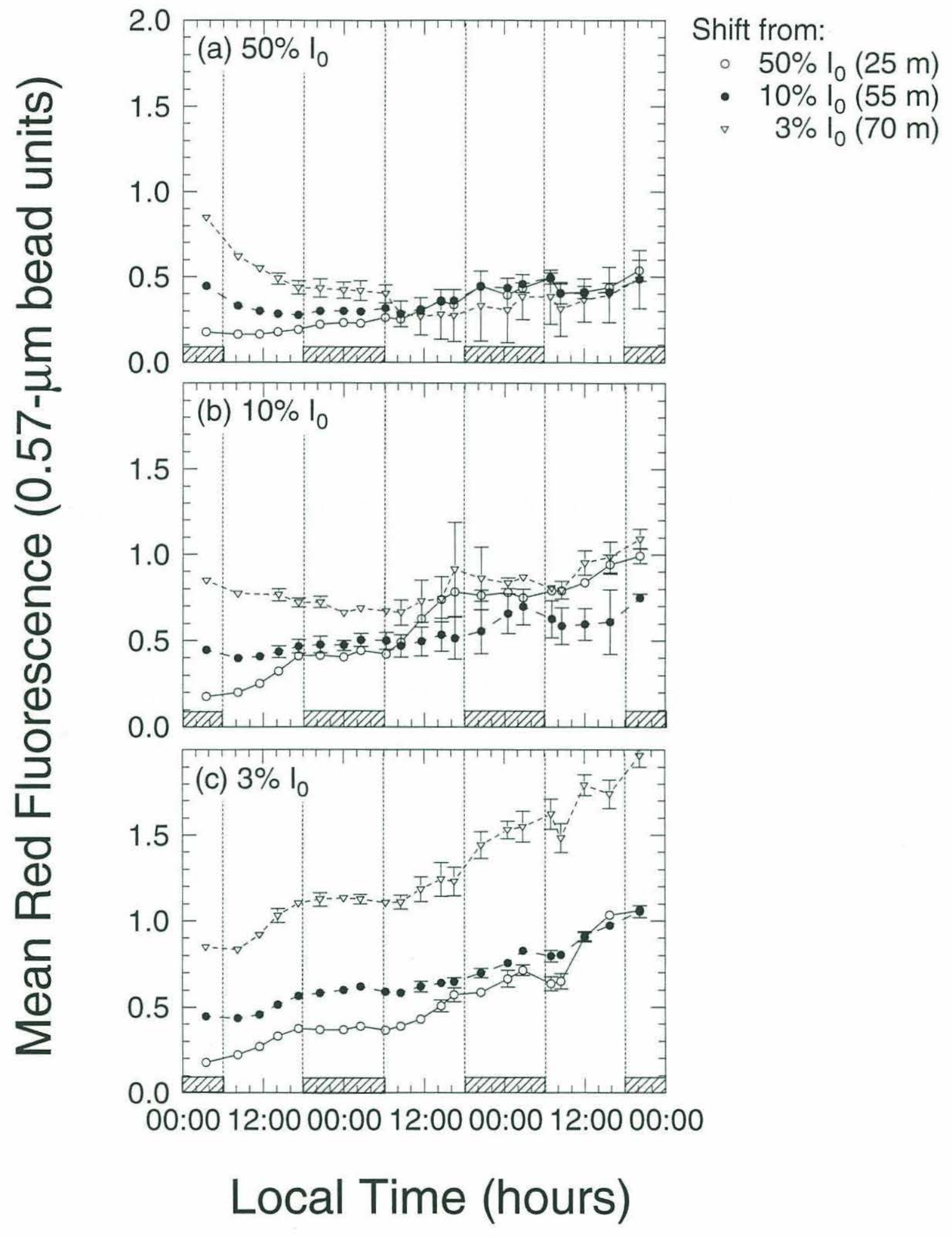


Figure 12 - Time-series measurements of cell concentration for Prochlorococcus spp. during the simulated in-situ reciprocal light shift experiment represented in figure 10 . Populations collected from $25 \mathrm{~m}$ (open circles), $55 \mathrm{~m}$ (closed circles) and $70 \mathrm{~m}$ (open triangles) were incubated on-deck in neutral density screened incubators yielding (a) $50 \%$, (b) $10 \%$ and (c) $3 \%$ of the incident irradiance $\left(\mathrm{I}_{0}\right)$. Error bars represent one standard deviation, and are not shown when smaller than the symbol size. 


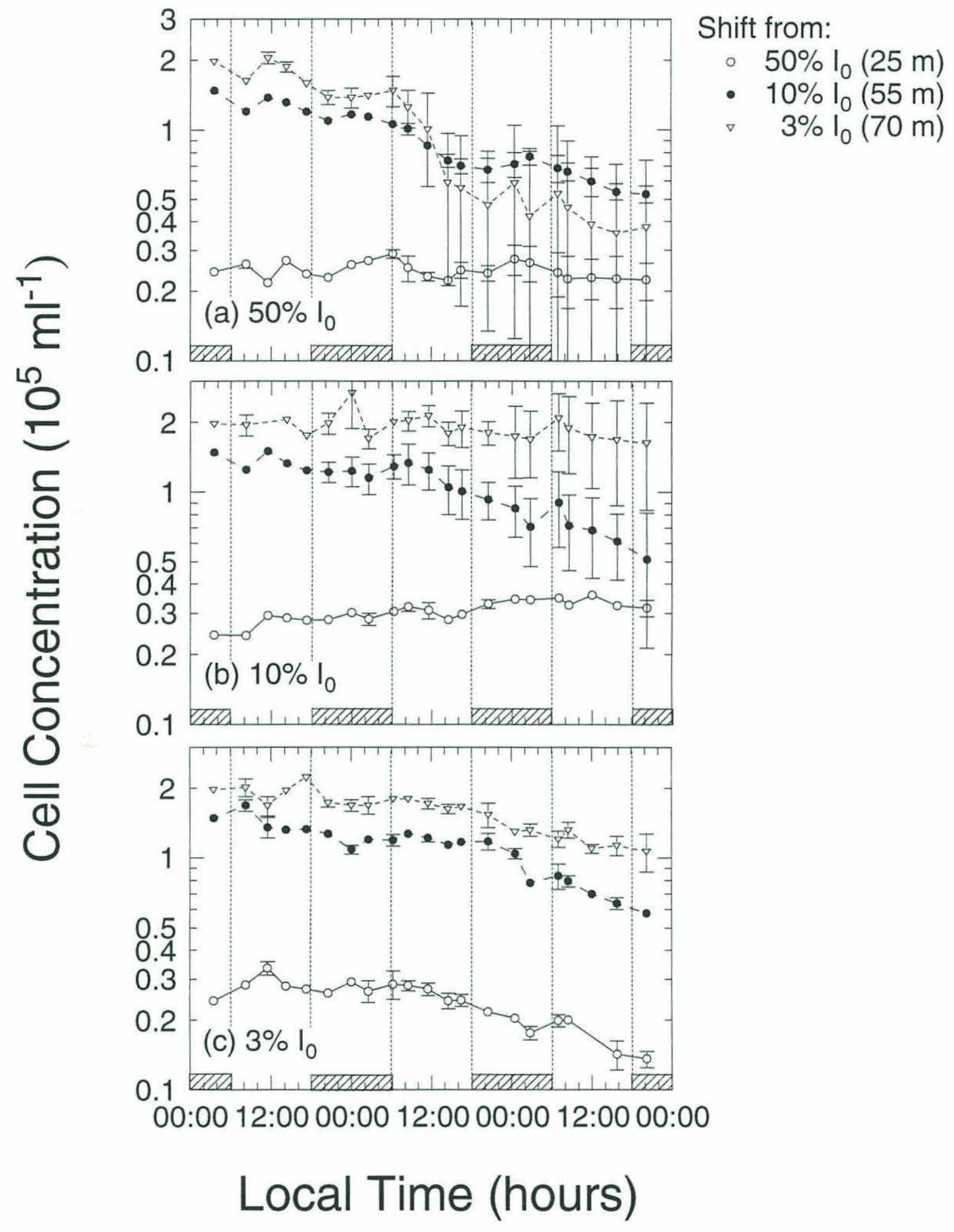


Figure 13 - Time-series measurements of mean red fluorescence normalized to the cube root of the mean forward angle light scatter for Prochlorococcus spp. during the simulated in-situ reciprocal light shift experiment represented in figure 10.

Populations collected from $25 \mathrm{~m}$ (open circles), $55 \mathrm{~m}$ (closed circles) and $70 \mathrm{~m}$ (open triangles) were incubated on-deck in neutral density screened incubators yielding (a) $50 \%$, (b) $10 \%$ and (c) $3 \%$ of the incident irradiance $\left(\mathrm{I}_{0}\right)$. All values are relative to $0.57-\mu \mathrm{m}$ microspheres (beads) which were used as an internal standard. Error bars represent one standard deviation, and are not shown when smaller than the symbol size. Solid lines are a least squares fit to the logistic model for photoacclimation (Eq. 2 ), which yields a photoacclimation rate, $\gamma$, of $0.9 \mathrm{~d}^{-1}$, and fully acclimated values, $\Gamma_{\infty}$, as shown. 


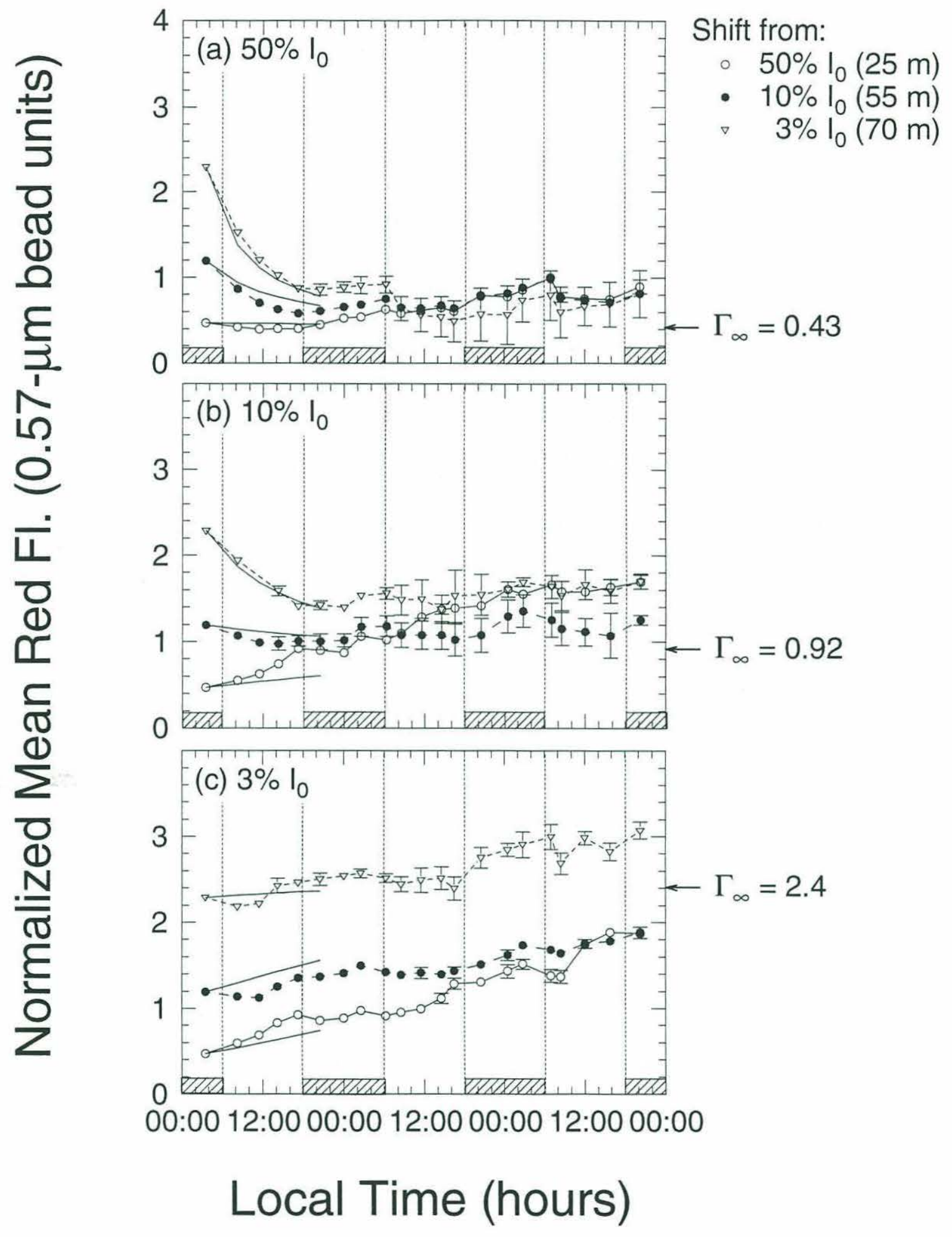


region, and also has surface temperatures greater than the previous two experiments. Forward angle light scatter (Fig. 14) shows increasing forward scatter during the daytime, with a decrease at night. As in the lab, the decrease in forward angle light scatter corresponds to an increase in cell number (Fig. 15).

Red fluorescence seems to show a combination of the processes seen earlier. All three light levels show a decrease in red fluorescence during the early morning hours of the experiment (Fig. 16). The $10 \%$ and $3 \% \mathrm{I}_{0}$ incubations also have a decrease in red fluorescence at the beginning of the dark period (Fig. 16b,c), which corresponds to cell division (Fig. 15b,c). However, the $50 \% \mathrm{I}_{0}$ incubations do not show this trend (Fig. 16a). Instead, red fluorescence appears to be relatively flat during the nighttime, following a slight increase in the evening. While this would seem to suggest that there is no cell division, this could be a combination of cell division which results in a decrease in mean red fluorescence and the process resulting in the nighttime red fluorescence increase seen in the laboratory. These two process effectively cancel each other out, and there is a suggestion of an increase in red fluorescence which precedes the increase in cell number (Fig. 15a, 16a).

Red fluorescence was normalized to the square root of forward angle light scatter. The square root was chosen because these cells are larger (as indicated by their forward angle light scatter) than those in the experiments discussed above, and the larger cell suggests a less steep relationship between forward angle light scatter and volume (Appendix B). The cube root normalization represents a normalization of the red fluorescence to approximately the cross-sectional area of the cell for the 
smaller cells (Appendix B). These cells are similar to Synechococcus spp. in forward scatter; so I assume that forward scatter is approximately proportional to the radius to the fourth power for these cells as I did for Synechococcus spp. (Appendix B). The appropriate normalization of red fluorescence to the cross-sectional area then becomes red fluorescence normalized to the square root of forward angle light scatter.

Mean normalized fluorescence fitted to the logistic model (Eq. 2) yields good fits (Fig. 17), with a rate, $\gamma$, of $3 \mathrm{~d}^{-1}$ and fully acclimated values of normalized fluorescence as shown in figure 17. This is the highest rate seen here, and it may reflect a difference in physiology between the large and small Prochlorococcus cell types. Alternatively, it may be an artifact resulting from apparent lack of photoacclimation which results in increased normalized fluorescence; each treatment in this experiment yielded a decrease in normalized fluorescence over time.

Estimates of the value of normalized fluorescence of fully acclimated cells is approximately linear with depth above $100 \mu \mathrm{E} \mathrm{m}^{-2} \mathrm{~s}^{-1}$ (Fig. 18). The two experiments which were done on the unmodified FACScan (Dusenberry and Frankel, 1994) show a much larger range in the fully acclimated normalized fluorescence (Fig. 18, upper axis). The scales chosen here suggest that the change in fluorescence yield between the two instrument configurations is approximately five-fold (relative to $0.57-\mu \mathrm{m}$ microspheres). ${ }^{1}$ The two Sargasso Sea experiments show relatively high values of the

\footnotetext{
${ }^{1}$ If true, this differs from the 2.5 -fold decrease in cell fluorescence relative to $0.57-\mu \mathrm{m}$ microspheres for the modified FACScan relative to the unmodified instrument reported by Dusenberry and Frankel (1994) for a relatively dim population of $P$. marinus. I believe this indicates that the decrease in fluorescence relative to $0.57-\mu \mathrm{m}$ microspheres can be greater for brighter cells.
} 
Figure 14 - Time-series measurements of mean forward angle light scatter for Prochlorococcus spp. during a simulated in-situ reciprocal light shift experiment carried out during the August 1991 cruise to the equatorial Pacific. Populations collected from $10 \mathrm{~m}$ (open circles), $40 \mathrm{~m}$ (closed circles) and $60 \mathrm{~m}$ (open triangles) were incubated on-deck in neutral density screened incubators yielding (a) $50 \%$, (b) $10 \%$ and (c) $3 \%$ of the incident irradiance $\left(\mathrm{I}_{0}\right)$. All values are relative to $0.57-\mu \mathrm{m}$ microspheres (beads) which were used as an internal standard. Error bars represent one standard deviation, and are not shown when smaller than the symbol size. 


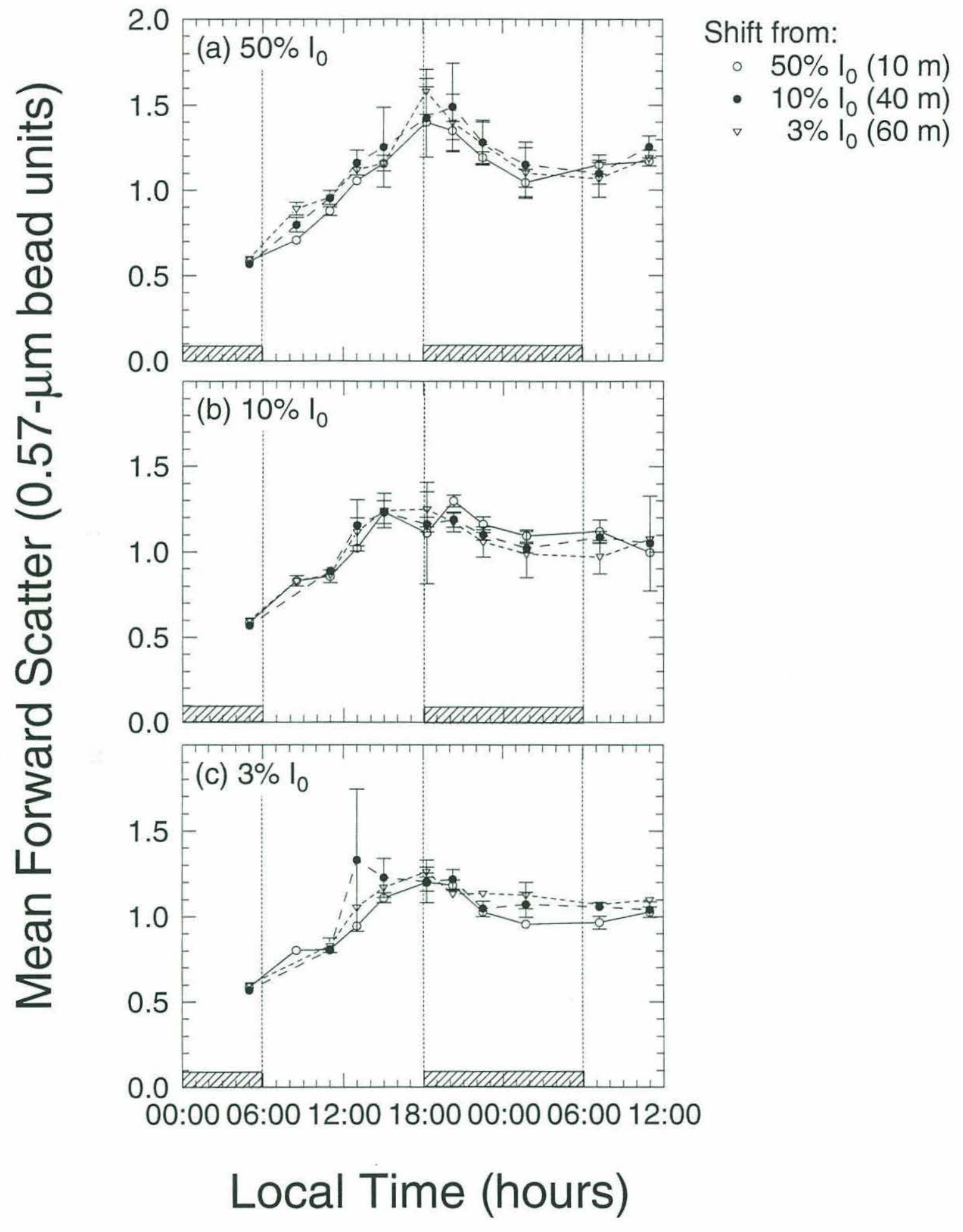


Figure 15 - Time-series measurements of cell concentration for Prochlorococcus spp. during the simulated in-situ reciprocal light shift experiment presented in figure 14. Populations collected from $10 \mathrm{~m}$ (open circles), $40 \mathrm{~m}$ (closed circles) and $60 \mathrm{~m}$ (open triangles) were incubated on-deck in neutral density screened incubators yielding (a) $50 \%$, (b) $10 \%$ and (c) $3 \%$ of the incident irradiance $\left(\mathrm{I}_{0}\right)$. Error bars represent one standard deviation, and are not shown when smaller than the symbol size. 


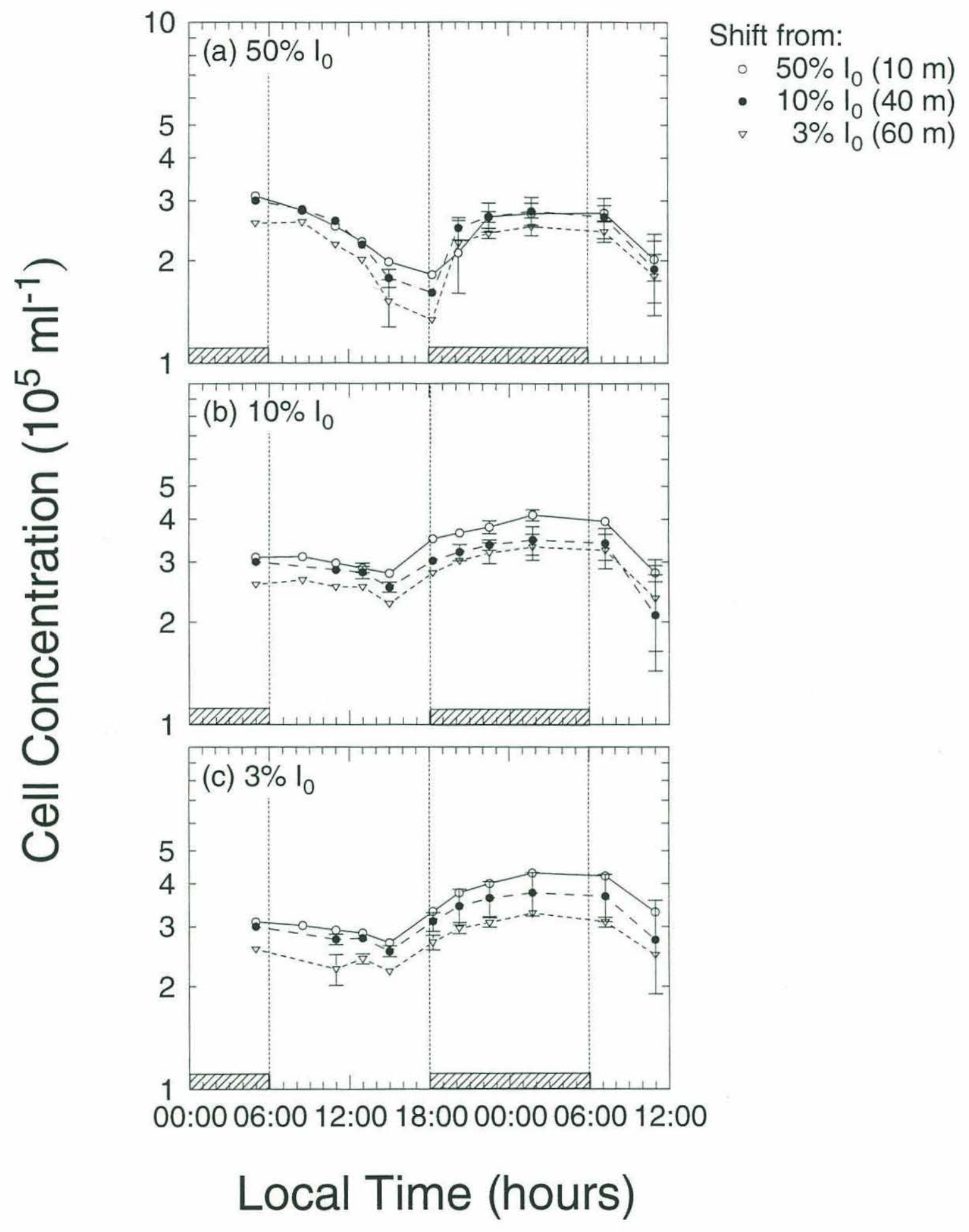


Figure 16 - Time-series measurements of mean red fluorescence for Prochlorococcus spp. during the simulated in-situ reciprocal light shift experiment presented in figure 14. Populations collected from $10 \mathrm{~m}$ (open circles), $40 \mathrm{~m}$ (closed circles) and $60 \mathrm{~m}$ (open triangles) were incubated on-deck in neutral density screened incubators yielding (a) $50 \%$, (b) $10 \%$ and (c) $3 \%$ of the incident irradiance $\left(\mathrm{I}_{0}\right)$. All values are relative to $0.57-\mu \mathrm{m}$ microspheres (beads) which were used as an internal standard. Error bars represent one standard deviation, and are not shown when smaller than the symbol size. 


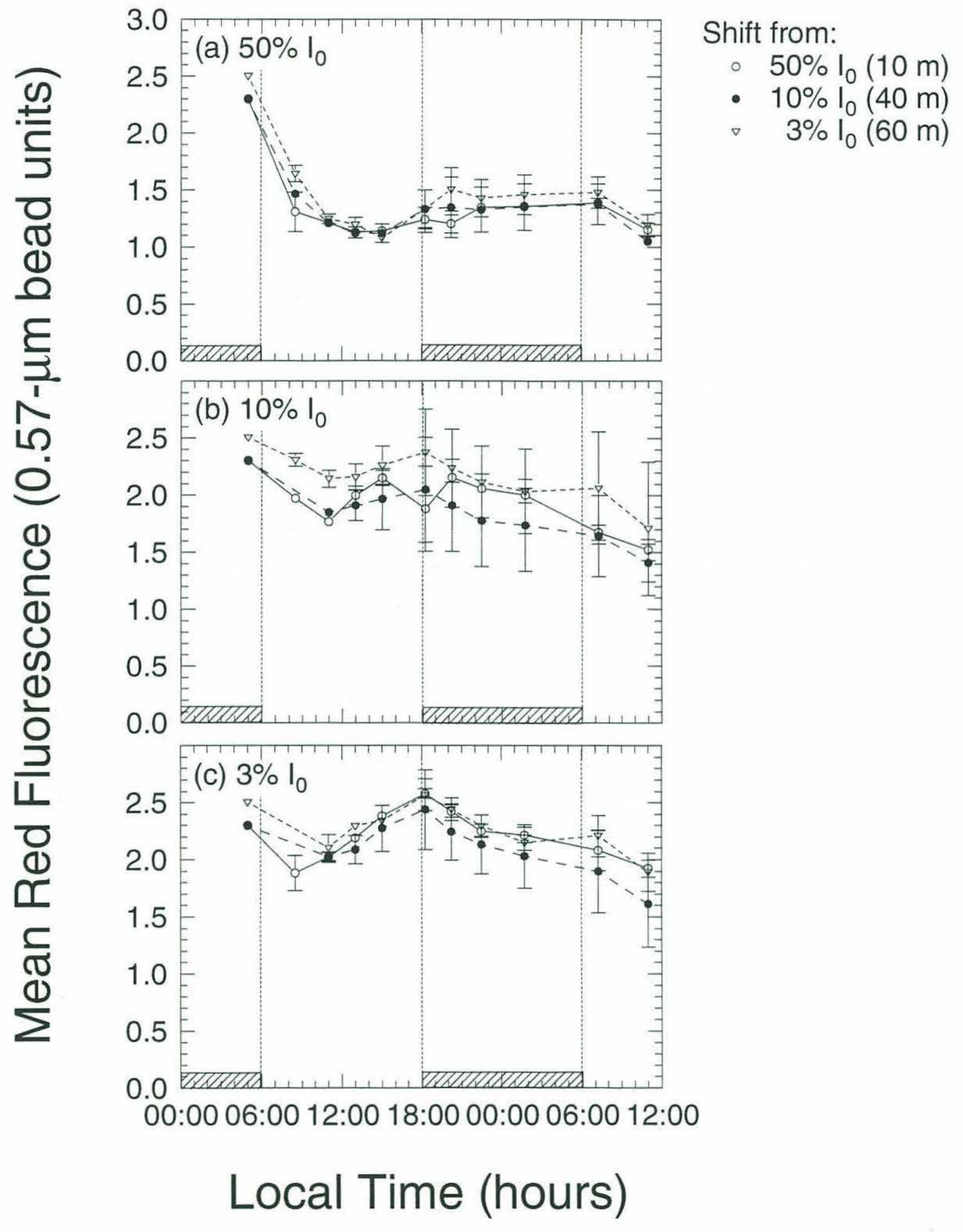


Figure 17 - Time-series measurements of mean red fluorescence normalized to the square root of mean forward angle light scatter for Prochlorococcus spp. during the simulated in-situ reciprocal light shift experiment presented in figure 14. Populations collected from $10 \mathrm{~m}$ (open circles), $40 \mathrm{~m}$ (closed circles) and $60 \mathrm{~m}$ (open triangles) were incubated on-deck in neutral density screened incubators yielding (a) $50 \%$, (b) $10 \%$ and (c) $3 \%$ of the incident irradiance $\left(\mathrm{I}_{0}\right)$. All values are relative to $0.57-\mu \mathrm{m}$ microspheres (beads) which were used as an internal standard. Error bars represent one standard deviation, and are not shown when smaller than the symbol size. Solid lines are a least squares fit to the logistic model for photoacclimation (Eq. 2), which yields a photoacclimation rate, $\gamma$, of $3 \mathrm{~d}^{-1}$, and fully acclimated values, $\Gamma_{\infty}$, as shown. 


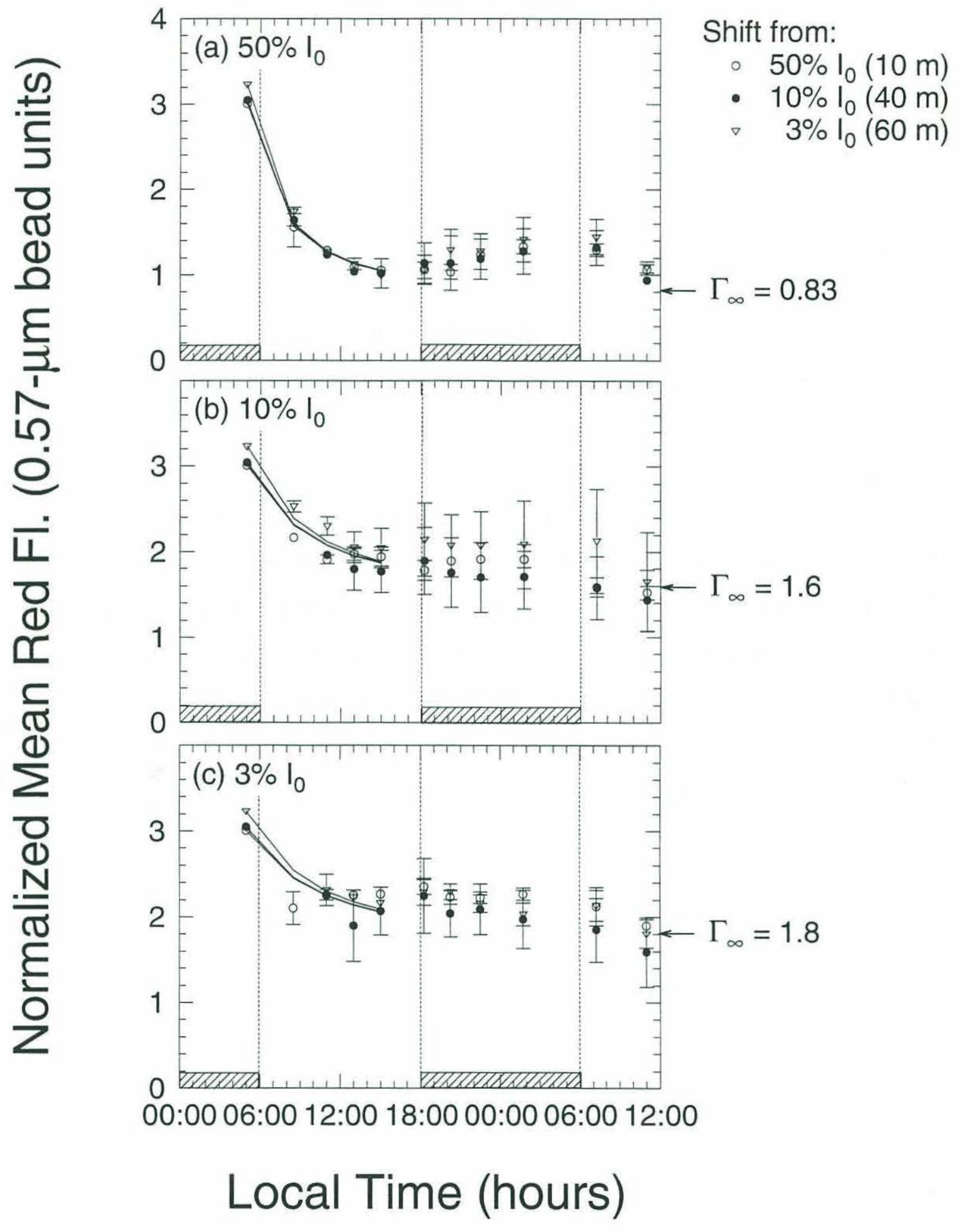


Figure 18 - Estimates of the fully acclimated values of normalized red fluorescence based on fits of the logistic model (Eq. 2) to the data presented in figures 5, 9, 13 and 17, plotted as a function of irradiance. The upper axis corresponds to the October 1989 Sargasso Sea cruise (closed triangles) and the August 1991 Equatorial Pacific cruise (closed circles); these experiments were run on the FACScan prior to modification. The lower axis corresponds to the July 1990 Sargasso Sea cruise (open triangles) and the laboratory experiment (open circles), which were run on the modified FACScan (Dusenberry and Frankel, 1994). Both Sargasso Sea experiments (triangles) were done using neutral density screened incubators, while the Equatorial Pacific experiment and the laboratory experiment (circles) were done using blue screening on the incubators. Light intensities for neutral density screened incubators (triangles) were corrected to the equivalent photon flux as in the blue screened incubators in the 420 to $500 \mathrm{~nm}$ range. The solid line represents a regression for the laboratory experiment: $\Gamma_{\infty}=0.40 \ln I+3.0\left(r^{2}=0.99\right)$. 


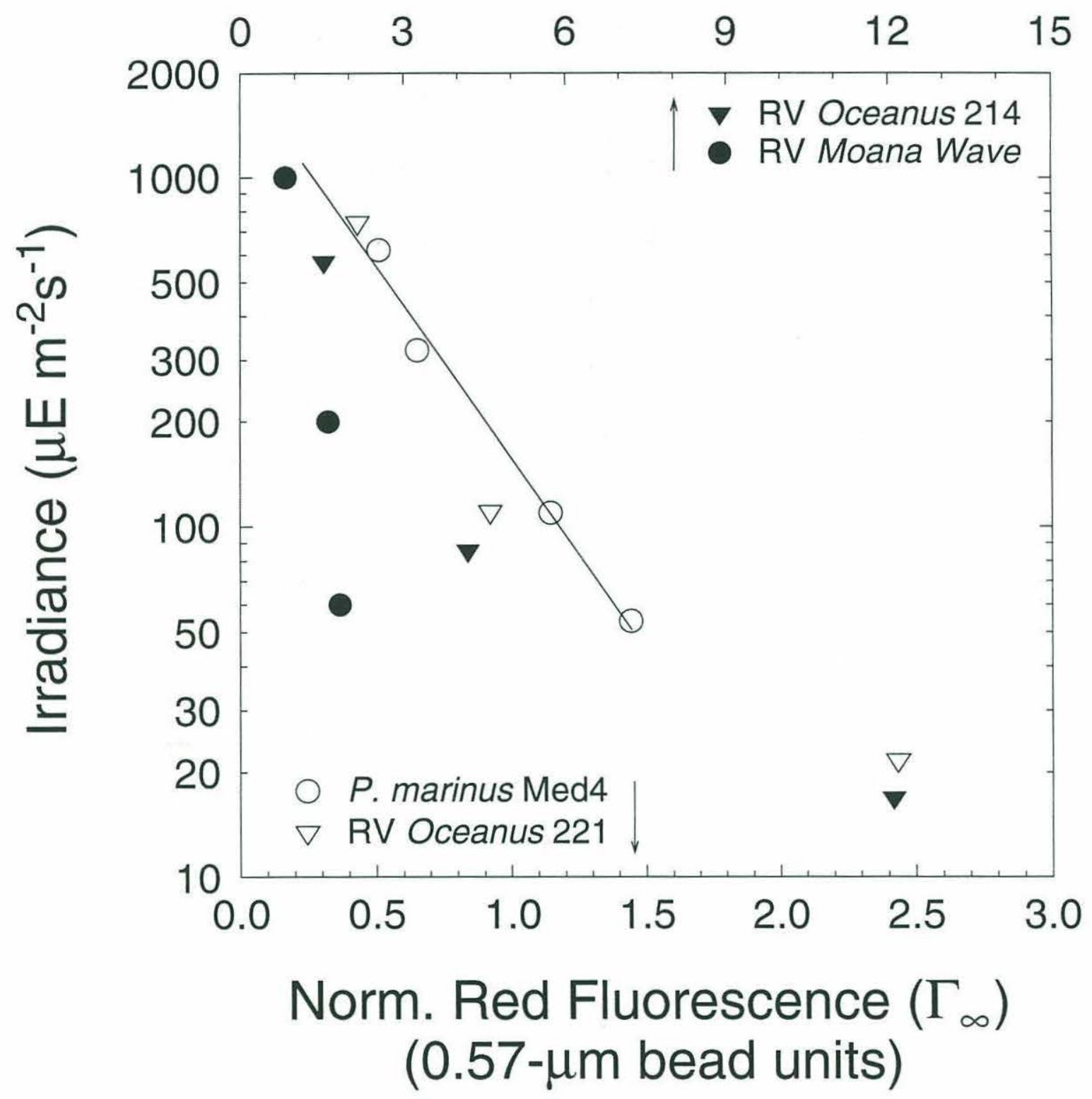


fully-acclimated normalized red fluorescence at the lowest light levels used in these experiments. These two experiments were done in neutral density (as opposed to blue) screened incubators. For the same overall light intensity $\left(3 \% \mathrm{I}_{0}\right)$ neutral density screening absorbs much more in the blue region than the blue screening. Since blue light is absorbed more efficiently, the neutral density screened incubators are effectively much lower intensity than the blue screened incubators. This is the most probable explanation for the sharp increase seen in the fully acclimated normalized fluorescence at low light levels in neutral density screened incubators.

The fitted photoacclimative rate varies from $0.8 \mathrm{~d}^{-1}$ to $3 \mathrm{~d}^{-1}$ (Fig. 19), with a decrease in the rate with increasing temperature among the small Prochlorococcus cell type (all experiments except the equatorial Pacific). The largest value for these cells corresponds to the laboratory culture of $P$. marinus strain Med4, and the $24{ }^{\circ} \mathrm{C}$ temperature corresponds to the maximal growth temperature reported for this strain (Moore et al., 1995). The lower values seen in the field experiments may indicate that these populations are also growing at a supra-optimal growth temperature.

\section{Discussion}

All of these experiments combine to suggest that the photoacclimation kinetics for $P$. marinus normalized fluorescence can be approximated using a logistic kinetic formulation (Cullen and Lewis, 1988). The rate constants estimated vary by more than a factor of three, but these results (for the small Prochlorococcus cell type) suggest that the rate is a decreasing function of temperature within the range of 
temperature observed $\left(24^{\circ} \mathrm{C}\right.$ to $\left.26^{\circ} \mathrm{C}\right)$. Further experiments are necessary at lower temperatures $\left(<24{ }^{\circ} \mathrm{C}\right)$ to more completely characterize the photoacclimation kinetics, and to determine where the maximum in photoacclimation rate lies.

Strains of the larger Prochlorococcus spp. have now been isolated (Moore, personal communication), so further laboratory experiments using these cells should clarify the relatively high rate of change in normalized fluorescence observed in the equatorial Pacific experiment. In addition, an appropriate normalization for these cells must be determined experimentally.

The fully acclimated normalized fluorescence values, however, appear linear with the logarithm of light intensity from irradiances of $1200 \mu \mathrm{E} \mathrm{m}^{-2} \mathrm{~s}^{-1}$ down to approximately $50 \mu \mathrm{E} \mathrm{m}^{-2} \mathrm{~s}^{-1}$ for blue light $\left(100 \mu \mathrm{E} \mathrm{m}^{-2} \mathrm{~s}^{-1}\right.$ for white light); however, differences in machine configuration and cell size need to be considered. The actual slope of this relationship is a function of the machine configuration and cell size, with the modified FACScan yielding a relationship (for the laboratory experiment) of $\Gamma_{\infty}=$ $0.40 \operatorname{lnI}+3.0\left(r^{2}=0.99\right)$, where I is the irradiance (Fig. 18). If the attenuation coefficient of light, $\mathrm{k}$, is known, this relationship can be represented as a function of depth, and will produce a linear relationship between $\Gamma_{\infty}$ and depth if $\mathrm{k}$ is constant. However, there is a suggestion that the slope of the $\Gamma_{\infty}$-irradiance curve is steeper at high light levels, so this curve should not be extrapolated to irradiances above $1000 \mu \mathrm{E} \mathrm{m} \mathrm{m}^{-2} \mathrm{~s}^{-1}$.

High light levels show the most consistent deviation from the logistic model, and nighttime increases in both red fluorescence and normalized red fluorescence 
Figure 19 - Estimates of the photoacclimation rate for normalized red fluorescence based on fits of the logistic model (Eq. 2) to the data presented in figures 5, 9, 13 and 17, plotted as a function of temperature. Symbols correspond to those used in figure 18. 


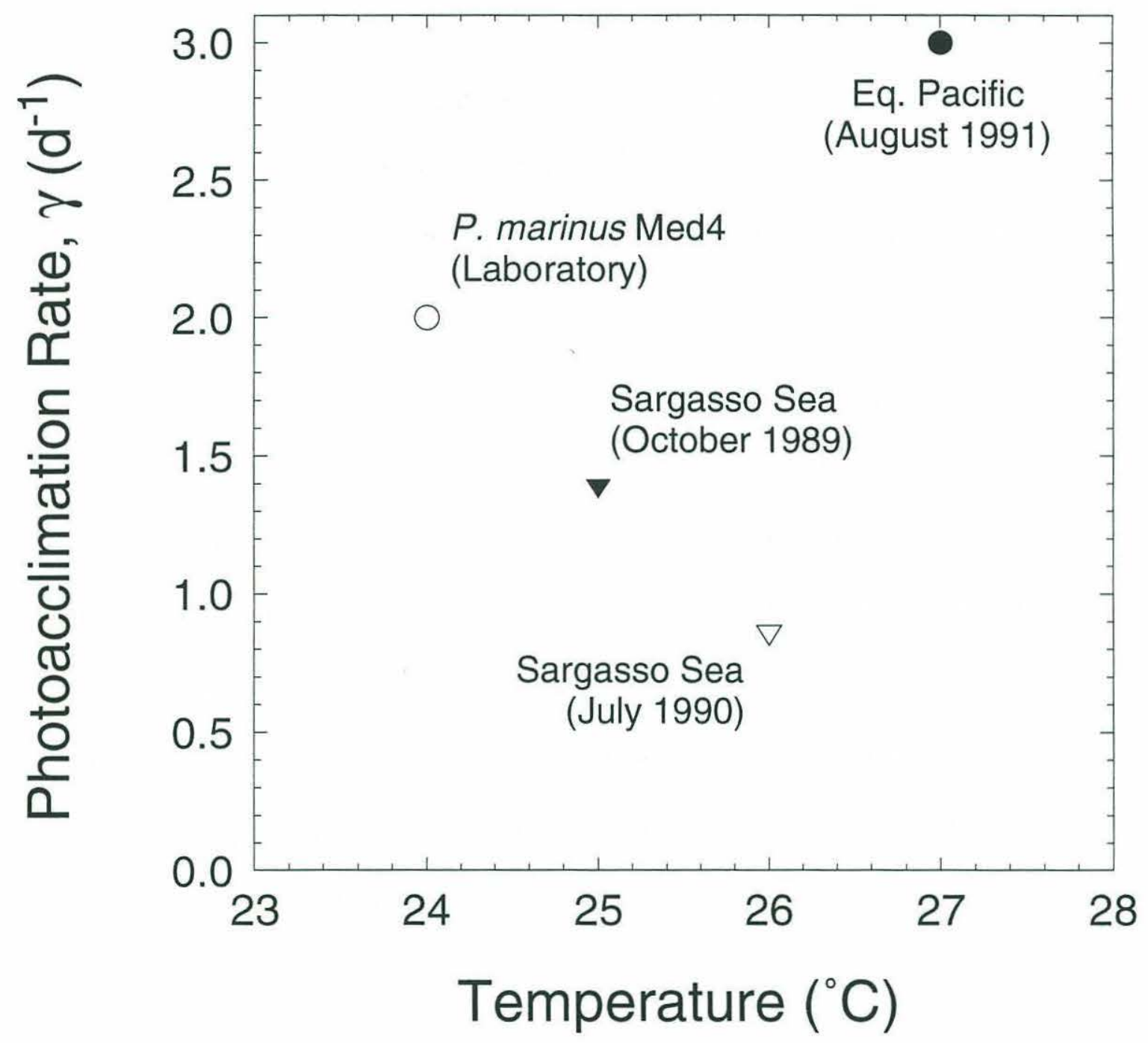


occur at these high light levels (Fig. 2, 4). The mechanism for this is unclear; however, two possibilities present themselves. Pigment concentrations may account for the change, suggesting that there is destruction of pigment during the daytime and synthesis during the afternoon and nighttime. Alternatively, the fluorescence yield may be decreasing due to a photoprotective mechanism, possibly similar to xanthophyll cycling seen in some eukaryotic phytoplankton (Demers et al., 1991). An understanding of the processes acting here would be facilitated by further diel studies of pigment concentrations and fluorescence at high light intensities.

\section{Acknowledgments}

I thank Brian Binder, Raffaella Casotti, Penny Chisholm, Michele DuRand, Alnoor Ebrahim, Sheila Frankel, Rob Olson, Lynn Reid and Erik Zettler for logistic and technical support at sea; Jim Falter, Erin Graham, Paul Moody, Nicole Poulton and Alex Worden for technical support in the lab; the captain and crews of the RV Oceanus and the RV Moana Wave; and chief scientists Ken Bruland, Rob Olson, John Waterbury and Ollie Zafiriou. I thank Lisa Moore for providing the starting culture of P. marinus strain Med4 and Daniel Vaulot for allowing the use of CYTOPC. 


\section{References}

Chisholm, S. W. and others. 1992. Prochlorococcus marinus nov. gen. nov. sp.: An oxyphototrophic marine prokaryote containing divinyl chlorophyll $a$ and $b$. Arch. Microbiol. 157:297-300.

Chisholm, S. W., R. J. Olson, E. R. Zettler, R. Goericke, J. B. Waterbury and N. A. Welschmeyer. 1988. A novel free-living prochlorophyte abundant in the oceanic euphotic zone. Nature. 334:340-343.

Cullen, J. J. and M. R. Lewis. 1988. The kinetics of algal photoadaptation in the context of vertical mixing. J. Plankton Res. 10:1039-1063.

Demers, S., S. Roy, R. Gagnon and C. Vignault. 1991. Rapid light-induced changes in cell fluorescence and in xanthophyll-cycle pigments of Alexandrium excavatum (Dinophyceae) and Thalassiosira pseudonana (Bacillariophyceae): A photoprotection mechanism. Mar. Ecol. Prog. Ser. 76:185-193.

Dusenberry, J. A. and S. L. Frankel. 1994. Increasing the sensitivity of a FACScan flow cytometer to study oceanic picoplankton. Limnol. Oceanogr. 39:206-209.

Garside, C. 1985. The vertical distribution of nitrate in open ocean surface water. Deep-Sea Res. 32:723-732.

Geider, R. J. and T. Platt. 1986. A mechanistic model of photoadaptation in microalgae. Mar. Ecol. Prog. Ser. 30:85-92.

Greene, R. M., Z. S. Kolber, D. G. Swift, N. W. Tindale and P. G. Falkowski. 1994. Physiological limitation of phytoplankton photosynthesis in the eastern equatorial Pacific determined from variability in the quantum yield of fluorescence. Limnol. Oceanogr. 39:1061-1074.

Jandel Scientific. 1992. Sigmaplot Scientific Graph System. Jandel Corporation. San Rafael, CA.

Lewis, M. R., J. J. Cullen and T. Platt. 1984. Relationships between vertical mixing and photoadaptation of phytoplankton: Similarity criteria. Mar. Ecol. Prog. Ser. 15:141-149.

Lombardo, C. P. and M. C. Gregg. 1989. Similarity scaling of viscous and thermal dissipation in a convecting surface boundary layer. J. Geophys. Res. 94:6273-6284.

Moore, L. R., R. Goericke and S. W. Chisholm. 1995. The comparative physiology of Synechococcus and Prochlorococcus: Influence of light and temperature on 
growth, pigments, fluorescence and absorptive properties. Mar. Ecol. Prog. Ser. (in press).

Moum, J. N., D. R. Caldwell and C. A. Paulson. 1989. Mixing in the equatorial surface layer and thermocline. J. Geophys. Res. 94:2005-2021.

Oakey, N. S. and J. A. Elliot. 1982. Dissipation within the surface mixed layer. $J$. Phys. Oceanogr. 12:171-185.

Okubo, A. 1971. Oceanic diffusion diagrams. Deep-Sea Res. 18:789-802.

Olson, R. J., S. W. Chisholm, E. R. Zettler, M. A. Altabet and J. A. Dusenberry. 1990. Spatial and temporal distributions of prochlorophyte picoplankton in the North Atlantic Ocean. Deep-Sea Res. 37:1033-1051.

Osborn, T. R. 1978. Measurements of energy dissipation adjacent to an island. J. Geophys. Res. 83:2939-2957.

Prézelin, B. B. and H. A. Matlick. 1980. Time-course of photoadaptation in the photosynthesis-irradiance relationship of a dinoflagellate exhibiting photosynthetic periodicity. Mar. Biol. 58:85-96.

Quay, P. D., W. S. Broecker, R. H. Hesslein and D. W. Schindler. 1980. Vertical diffusion rates determined by tritium tracer experiments in the thermocline and hypolimnion of two lakes. Limnol. Oceanogr. 25:201-218.

Shay, T. J. and M. C. Gregg. 1986. Convectively driven turbulent mixing in the upper ocean. J. Phys. Oceanogr. 16:1777-1798.

Vaulot, D., C. Courties and F. Partensky. 1989. A simple method to preserve oceanic phytoplankton for flow cytometric analyses. Cytometry. 10:629-635. 


\section{Chapter IV}

Steady State Single-Cell Model Simulations of Photoacclimation in a Vertically Mixed Layer 


\title{
Steady State Single-Cell Model Simulations of Photoacclimation in a Vertically Mixed Layer
}

\begin{abstract}
Model simulations of the effects of vertical mixing and photoacclimation were done for both first-order and logistic representations of photoacclimation kinetics, in order to quantify the effects of vertical mixing and/or hysteresis on the higher moments of a photoacclimative parameter. Steady state was assumed as to simplify the model and provide a starting point for further investigations. In the simple mixed layer modelled here, hysteresis (as represented by the logistic model of photoacclimation) yields populations which are more surface acclimated at high mixing rates than the simulation without hysteresis. In both models, patterns in the mean value of a photoacclimative parameter show a simple gradient at slow mixing relative to photoacclimation which breaks down with increasing mixing and as the mixed layer approaches homogeneity. Corresponding to this pattern, the variance and higher moments of the photoacclimative parameter all show trends which are diagnostic of mixing rates or boundary effects.
\end{abstract}




\section{Introduction}

Phytoplankton photoacclimation has been studied extensively in the context of vertical mixing, both experimentally (Marra, 1978a,b, 1980; Gallegos and Platt, 1982; Falkowski, 1983; Lewis et al., 1984b; Yoder and Bishop, 1985; Savidge, 1988) and theoretically (Platt and Gallegos, 1980; Falkowski and Wirick, 1981; Woods and Onken, 1982; Lewis et al., 1984a; Cullen and Lewis, 1988; Lande and Lewis, 1989). Both approaches have been aimed at quantifying the effects of vertical mixing on phytoplankton physiology and consequently productivity. In addition, there is a potential to use phytoplankton as tracers for vertical mixing processes via their lightsensitive physiological responses (Lewis et al., 1984a).

Traditionally, studies of using phytoplankton as tracers have focussed on bulk property approaches such as analysis of photosynthesis-irradiance relationships (Falkowski and Wirick, 1981; Lewis and Smith, 1983), carbon to chlorophyll ratios (Laws and Bannister, 1980; Geider and Platt, 1986; Cullen and Lewis, 1988), reaction center size (Falkowski, 1983), photosynthetic enzyme activity (Rivkin, 1990) or in vivo fluorescence (Therriault et al., 1990), with only a few authors presenting single-cell models (Falkowski and Wirick, 1981; Lande and Lewis, 1988; Yamazaki and Kamykowski, 1991). The latter, while computationally more difficult, have been argued to be more accurate when non-linear processes are involved (Woods and Onken, 1982; Lande and Lewis, 1988); conversely, differences between single cell models and bulk property models can be small when linear processes are studied (Lande and Lewis, 1988). 
Relatively new instrumentation, in particular flow cytometry (Yentsch et al., 1983; Olson et al., 1985; Li and Wood, 1988), allows the quantification of optical properties of individual cells, and therefore the quantification of the distribution of these properties among a population of cells. With an appropriate theoretical framework, the benefits of such observations are two-fold: one can use these measurements to better understand how phytoplankton are responding to changes in their physical environment, and conversely, one can use the physiological response as an indicator of changes in the physical environment.

I present here a comparison of two single-cell models of phytoplankton photoacclimation in the context of vertical mixing. The first model is a simple firstorder model which has commonly been used in studies of photoacclimation in a vertically mixed environment (Lewis et al., 1984a), but which has been found inadequate to express hysteresis sometimes seen in photoacclimation kinetics (Prézelin and Matlick, 1980; Geider and Platt, 1986; see also Chapter III). The second model is a logistic model which is an alternative to the first-order model which is one means of expressing hysteresis (Cullen and Lewis, 1988).

Both models presented here are oversimplifications, primarily due to assumptions of steady-state and constant diffusivity with depth (see Model Assumptions, below). The purpose here is to develop an understanding of how the higher moments of a photoacclimative parameter will respond to mixing rates and boundary conditions. Thus the work presented here is a "first cut" towards developing time-dependent (i.e. diffusivity, photoacclimation, or mixed layer changing with time) 
or depth-dependent (i.e. diffusivity changing with depth) models of photoacclimationdiffusion processes. This approach provides a framework, albeit limited due to the assumption of steady state, for interpreting results presented elsewhere, particularly field in-situ observations (Chapter II). It also shows the diagnostic potential for using higher moments of some photoacclimative property as indicators of mixing processes.

\section{Model Assumptions}

\section{Photoacclimation:}

Photoacclimation was assumed to follow one of two kinetic processes: first order (Falkowski, 1980, 1983, 1984; Rivkin et al., 1982; Post et al., 1984; Lewis et al., 1984a) or logistic (Cullen and Lewis, 1988) with a rate constant, $\gamma$. With first order kinetics, the time dependence, t, of a bulk or mean photoacclimative parameter, $\bar{\Gamma}$, is given by:

$$
\frac{\partial \bar{\Gamma}}{\partial t}=\gamma\left(\Gamma_{\infty}-\bar{\Gamma}\right)
$$

where $\Gamma_{\infty}$ is the fully acclimated value of the parameter under consideration. The logistic formulation, introduced by Cullen and Lewis (1988) to parameterize hysteresis seen in photoacclimation rates (Prézelin and Matlick, 1980; Geider and Platt, 1986; see also Chapter III), is represented as:

$$
\frac{\partial \bar{\Gamma}}{\partial t}=\gamma \bar{\Gamma}\left(\frac{\Gamma_{\infty}-\bar{\Gamma}}{\Gamma_{\infty}}\right)
$$


The fully acclimated value of the photoacclimative parameter, $\Gamma_{\infty}$, is assumed in both models to be linearly related to the logarithm of light intensity. For simplicity, I further assume a constant attenuation coefficient for light (ignoring color dependence (Jerlov, 1976)) and a constant surface irradiance, so that $\Gamma_{\infty}$ becomes a linear function of depth, z:

$$
\Gamma_{\infty}=b z+a
$$

where $\mathrm{a}$ and $\mathrm{b}$ are constants.

\section{Mixed Layer:}

I assume a simple box model of the surface mixed layer with depth, h, and with mixing parameterized by a vertical diffusivity, $\mathrm{K}_{\mathrm{v}}$, which is constant throughout. Both upper and lower boundaries are considered reflecting, with no flux conditions imposed at both. The depth of the mixed layer is further assumed to be less than the depth of the euphotic zone, such that cells at all depths experience sufficient light to drive photoacclimation.

\section{Model Design:}

Traditionally, these two processes, mixing and photoacclimation, have been represented by a one-dimensional reaction diffusion equation of the form:

$$
\frac{\partial \bar{\Gamma}}{\partial t}=K_{v} \frac{\partial^{2} \bar{\Gamma}}{\partial z^{2}}+\gamma\left(\Gamma_{\infty}-\bar{\Gamma}\right)
$$


where the second term on the right side represents the first-order form of photoacclimation and can be replaced with the logistic formulation (Eq. 2).

From the individual cell's point of view, Eq. 4 can be rewritten in terms of the variables $\Gamma$ and $\mathrm{z}$ :

$$
\begin{gathered}
\frac{d \Gamma}{d t}=\gamma\left(\Gamma_{\infty}-\Gamma\right), \text { and } \\
\frac{d z}{d t}=\sqrt{2 K_{v}} \xi_{t}
\end{gathered}
$$

where $\xi_{\mathrm{t}}$ is a "white noise" term used to represent the turbulent vertical movement. These equations can be combined into a two-dimensional Fokker-Planck equation (see Gardiner, 1985) for the probability density function of cells in $\Gamma$ - and z- space:

$$
\frac{\partial N}{\partial t}=-\frac{\partial}{\partial \Gamma}\left(N \gamma\left[\Gamma_{\infty}-\Gamma\right]\right)+K_{v} \frac{\partial^{2} N}{\partial z^{2}} .
$$

A similar approach with the logistic formulation for the photoacclimative kinetics yields:

$$
\frac{\partial N}{\partial t}=-\frac{\partial}{\partial \Gamma}\left(N \gamma \Gamma\left[\frac{\Gamma_{\infty}-\Gamma}{\Gamma_{\infty}}\right]\right)+K_{v} \frac{\partial^{2} N}{\partial z^{2}} .
$$

For the purposes of this analysis, steady state was assumed. These systems approach steady state on time scales of $\gamma^{-1}$ (Lande and Lewis, 1988), thus the assumption of steady state is valid for those situations which have been under similar 
conditions for $\gamma^{-1}$ time. For faster modes of photoacclimation, such as for parameters of photosynthesis-irradiance relationships with time-scales as short as a few hours (Lewis et al., 1984a) the assumption of steady state may be quite reasonable. For parameters which change more slowly, such as chlorophyll to carbon ratios (Cullen and Lewis, 1988) or cellular chlorophyll content (Falkowski, 1984; Post et al., 1984), it will prove necessary to utilize a time-dependent model (such as in Chapter V), as the daily photoperiod alone is not sufficiently long to allow steady state to be attained. However, the steady state approximation provides a good first approach to the problem and facilitates comparisons between the two models and evaluation of the potential to use individual cells as living tracers for mixing. From this point, development of a time-dependent model is straightforward, albeit computationally intensive.

Field data contains variation due not to mixing processes, but to measurement error during analysis or variation due to other environmental or genetic factors. Assuming this variability to be log-normally distributed (as in Chapter II), discussion of the higher moments of the photoacclimative parameter, $\Gamma$, will be facilitated by the introduction of $\Gamma^{*}$ :

$$
\Gamma^{*}=\log _{10} \Gamma
$$

This also corresponds directly to flow cytometric data acquisition, where use of logarithmic scales is the norm.

Substituting eq. (9) into eqs. (7) and (8) and setting the time derivatives to zero (for steady state) yields: 


$$
\begin{aligned}
& -\frac{1}{\ln 10} \frac{\partial}{\partial \Gamma^{*}}\left(N \gamma\left[\frac{\Gamma_{\infty}}{10^{*}}-1\right]\right)+K_{v} \frac{\partial^{2} N}{\partial z^{2}}=0, \text { and } \\
& -\frac{1}{\ln 10} \frac{\partial}{\partial \Gamma^{*}}\left(N \gamma\left[\frac{\Gamma_{\infty}-10^{\Gamma^{*}}}{\Gamma_{\infty}}\right]\right)+K_{v} \frac{\partial^{2} N}{\partial z^{2}}=0 .
\end{aligned}
$$

Equations (10) and (11) can be used to derive the probability distributions of cells as a function of $\Gamma^{*}$ and $\mathrm{z}$ at steady state.

Reflecting boundary conditions

$$
\frac{\partial N}{\partial z}=0
$$

were imposed at both the upper and lower boundaries, corresponding to the ocean surface and the base of the mixed layer. This assumes no mixing across these boundaries. For $\Gamma>\Gamma_{\infty, \mathrm{h}}$ and $\Gamma<\Gamma_{\infty, 0}, \mathrm{~N}$ was set to zero, and the integral over $\Gamma$ at each depth was constrained to 1 .

Deviations from normality in the above probability distributions can be quantified by determining the skewness and kurtosis in the distributions (see Chapter II, Fig. 3). The skewness gives an indication of the asymmetry of the distribution, with negative skewness (skewed to the left) indicates a drawn out left tail on the distribution with positive skewness (skewed to the right) suggesting a relatively drawn out right tail. The kurtosis is an indicator of the flatness or peakedness of the curve. Negative kurtosis (platykurtosis) indicates a flat distribution, with positive kurtosis 
(leptokurtosis) suggesting a peaked distribution.

The sensitivity of the skewness and the kurtosis (as defined in Sokal and Rohlf, 1981) to intrinsic (non-mixing) variation was removed by using the third moment as an indicator of skewness and the fourth moment less three times the standard deviation to the fourth power as an indicator of kurtosis (Chapter II). The model presented here does not incorporate this intrinsic variation directly, thus it is necessary to use indicators which are insensitive to the presence of such variation. The removal of this sensitivity necessitates the assumption that the intrinsic variation be normally distributed on the same scale that the higher moments are measured on, hence the use of the log scale.

The error in the higher moments from flow cytometric analyses, however, increases with increasing intrinsic variation. Significance of the model results was determined using the methods presented in Sokal and Rohlf (1981), assuming a sample size of 5000 events and intrinsic variation of $19 \%$ of the mean, which represents the least variation for normalized fluorescence seen in isolated field samples (data not shown). The gradient with depth in the fully acclimated value of the photoacclimative parameter, $\Gamma_{\infty}$, will also affect significance, with the results increasingly significant for stronger gradients. A ten-fold increase in $\Gamma$ over the depth of the mixed layer was used in estimating significance.

\section{Results}

Equations (10) and (11) were solved numerically using a finite difference 
approximation (Appendix D) for a series of values of $K_{V} \gamma^{-1} h^{-2}$, the ratio of the photoacclimative time-scale, $\gamma^{-1}$, to the mixing time-scale $\mathrm{K}_{\mathrm{v}} \gamma^{-1} \mathrm{~h}^{2}$ (Fig. 1).

With the probability density functions derived from eqs. (10) and (11), it is straightforward to derive the mean and higher moments (Fig. 2-5). The mean values (Fig. 2) show a simple pattern of a strong gradient for low values of $K_{v} \gamma^{-1} h^{-2}$ which breaks down with increasing $\mathrm{K}_{\mathrm{v}} \gamma^{-1} \mathrm{~h}^{-2}$. This breakdown of the gradient occurs first at the boundaries and then propagates inward as the extent of the boundary effect increases. The major difference between the mean values predicted by the two models is the value of $\bar{\Gamma}^{*}$ for the homogeneous mixed layer, with the logistic model producing mean values which are more nearly surface acclimated than those in the first-order model. This is due to hysteresis, which as represented here, results in faster acclimation for a shift to high light levels than the reciprocal shifts to low light levels. The first-order model, lacking hysteresis, produces homogeneity at a mean value for $\bar{\Gamma}^{*}$ corresponding to the mean depth within the mixed layer.

Model results of the variance due to mixing only (Fig. 3) show similar patterns for both the first order (Fig. 3a) and logistic (Fig. 3b) formulations. Variance due to other sources is additive to this variance. Because of the curvature in $\Gamma_{\infty}$ (a linear relationship with depth on a log-scale) the variance begins to increase with increasing $\mathrm{K}_{\mathrm{v}} \gamma^{-1} h^{-2}$ at an intermediate depth near the surface. As increasing $\mathrm{K}_{\mathrm{V}} \gamma^{-1} h^{-2}$ yields higher variances overall, boundary effects serve to keep the variance near the boundaries to a minimum, with the maximum variance in the interior (see also Lande and Lewis, 1988). As the mixed layer becomes homogeneous at high $\mathrm{K}_{\mathrm{v}} \gamma^{-1} \mathrm{~h}^{-2}$, the variance begins 
to decrease with increasing $\mathrm{K}_{\mathrm{V}} \gamma^{-1} \mathrm{~h}^{-2}$. This is due to the inability of the cells to acclimate to rapidly changing light levels, thus they acclimate to some average intensity experienced. In addition, because of the hysteresis in the logistic model, the region of maximum variance is also closer to the surface than in the first-order model. Due to the additive effect of variance from non-mixing processes, this variance due to mixing becomes an insensitive indicator of $\mathrm{K}_{\mathrm{V}} \gamma^{-1} \mathrm{~h}^{-2}$ when the variance attributed to photoacclimation/mixing processes is much less than that due to other processes.

The third moment, an indicator of skewness, is independent of the superimposed variation (which in itself has a third moment equal to zero). Thus no adjustments need to be made to account for changes in the third moment resulting from non-mixing processes. The third moment (Fig. 4) shows the extent of boundary effects, as its effect is strongest at the transition range between the near homogeneous boundary region and the and the interior region with the strong gradient. As was the case with the variance, the use of the log scaling exaggerates this effect near the surface and minimizes it near the base of the mixed layer.

The corrected fourth moment (the fourth moment less three times the standard deviation to the fourth power) (Fig. 5) complements the third moment. The region of the most negative fourth moment (platykurtosis) corresponds to the area between the maxima and minima in the third moment. The distribution approaches bimodality in this region (Fig. 1, $\mathrm{K}_{\mathrm{V}} \gamma^{-1} \mathrm{~h}^{-2}=0.051$ ) due to a "meeting" of the boundary effects from the upper and lower boundaries. 
Figure 1a - Probability density of a photoacclimative parameter as a function of depth generated by the first-order photoacclimation-diffusion model (Eq. 10), for a range of values of $\mathrm{K}_{\mathrm{V}} \gamma^{-1} h^{-2}$. Both depth and the photoacclimative parameter were made nondimensional. Depth was expressed as a fraction of the mixed layer depth, h. The photoacclimative parameter was expressed as the range from the surface fully acclimated value of the parameter $\left(\Gamma_{0, \infty}^{*}\right)$ to the fully acclimated value at the base of the mixed layer $\left(\Gamma_{\mathrm{h}, \infty}^{*}\right)$. Contours are evenly spaced between zero and the maximum for each simulation. 


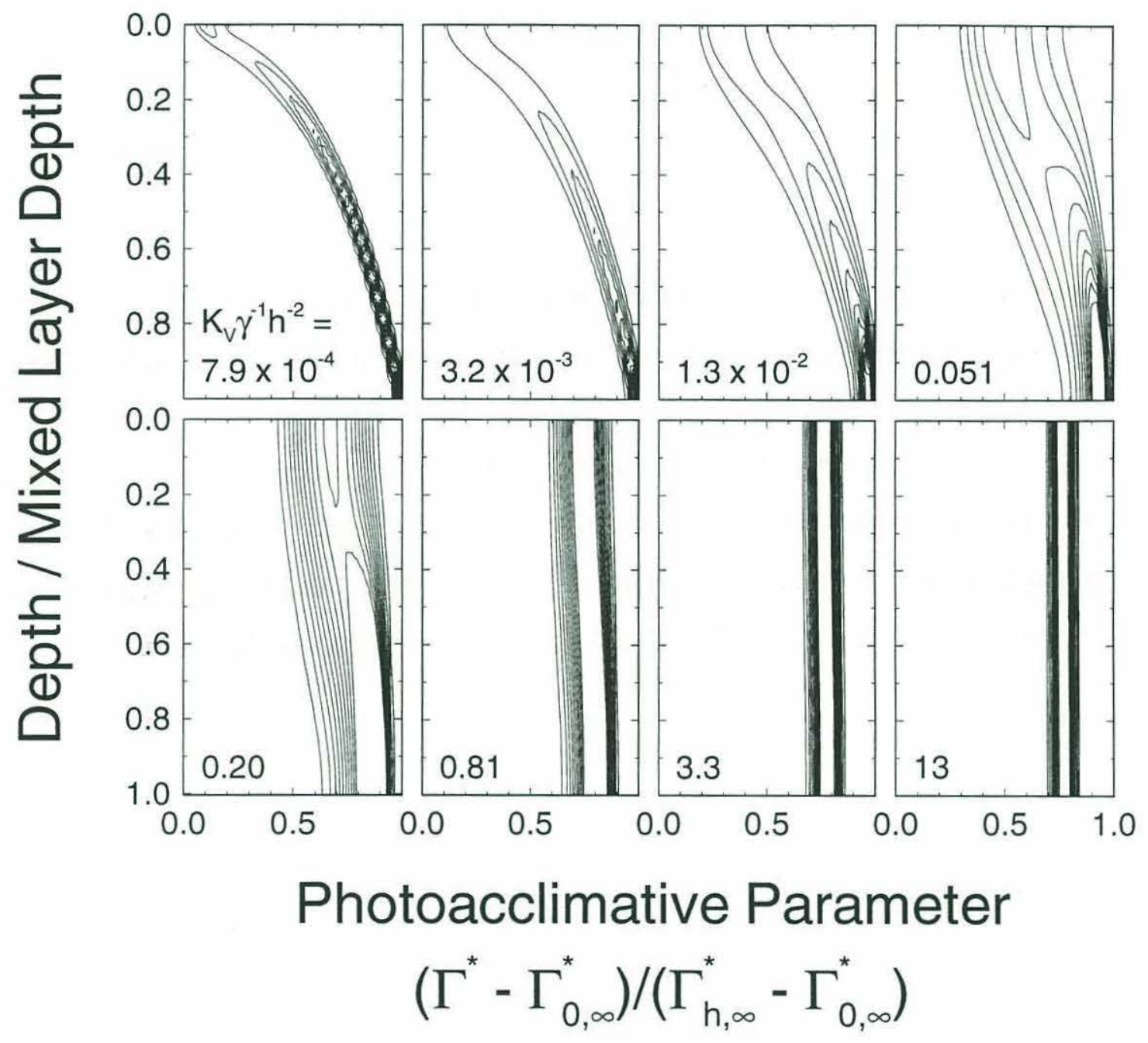


Figure 1b - Probability density functions as in figure 1a for the logistic photoacclimation-diffusion model (Eq. 11), for a range of values of $\mathrm{K}_{\mathrm{v}} \gamma^{-1} \mathrm{~h}^{-2}$. Both depth and the photoacclimative parameter were made non-dimensional. Depth was expressed as a fraction of the mixed layer depth, $h$. The photoacclimative parameter was expressed as the range from the surface fully acclimated value $\left(\Gamma_{0, \infty}^{*}\right)$ of the parameter to the fully acclimated value at the base of the mixed layer $\left(\Gamma_{\mathrm{h}, \infty}^{*}\right)$. Contours are evenly spaced between zero and the maximum for each simulation. 


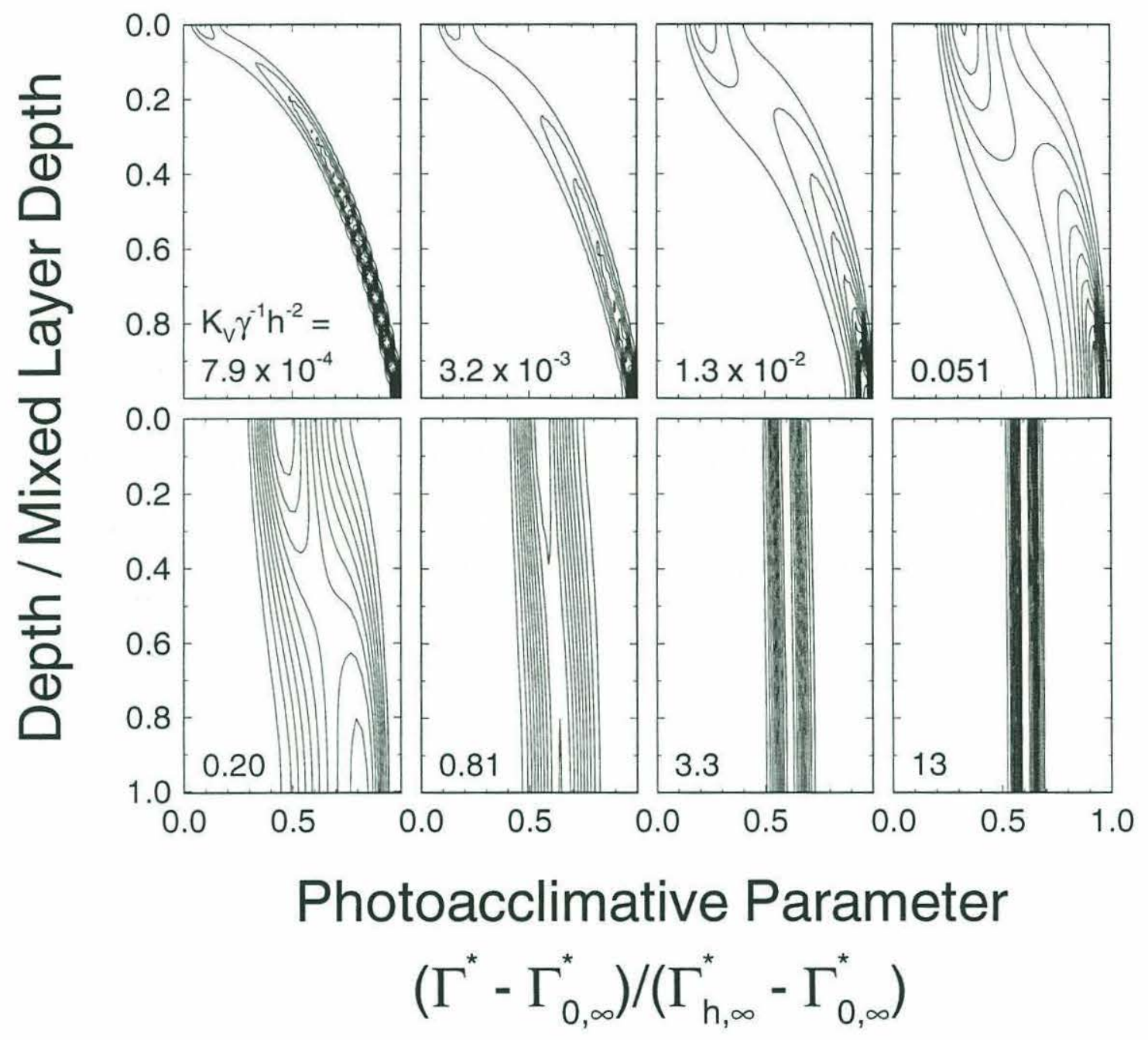


Figure 2 - Contours of mean photoacclimative parameter, $\Gamma$, as a function of depth (relative to the mixed layer depth) and $\mathrm{K}_{\mathrm{v}} \gamma^{-1} h^{-2}$ for the first-order (a) and logistic (b) photoacclimation models. The photoacclimative parameter was made non-dimensional as in figure 1 , and the contours are expressed in units of $\Gamma_{\mathrm{h}, \infty}^{*}-\Gamma_{0, \infty}^{*}$. 


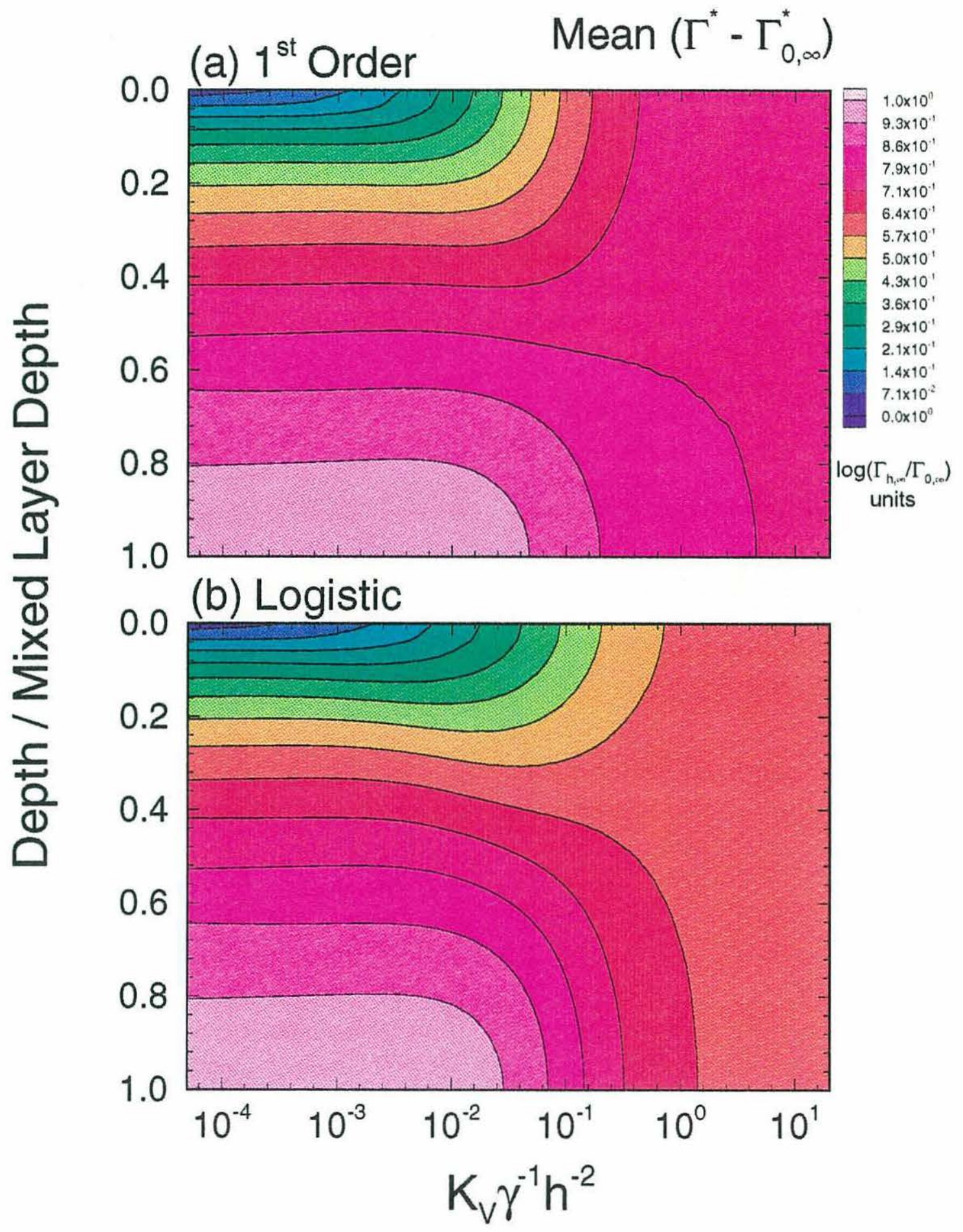


Figure 3 - Contours of the variance in the photoacclimative parameter, $\Gamma$, as a function of depth (relative to the mixed layer depth) and $\mathrm{K}_{\mathrm{V}} \gamma^{-1} \mathrm{~h}^{-2}$ for the first-order (a) and logistic (b) photoacclimation models. The photoacclimative parameter was made non-dimensional as in figure 1 , and the contours are expressed in units of $\left(\Gamma_{\mathrm{h}, \infty}^{*}-\Gamma_{0, \infty}^{*}\right)^{2}$. Values greater than $2.4 \times 10^{-4}$ are significant (see Methods). 


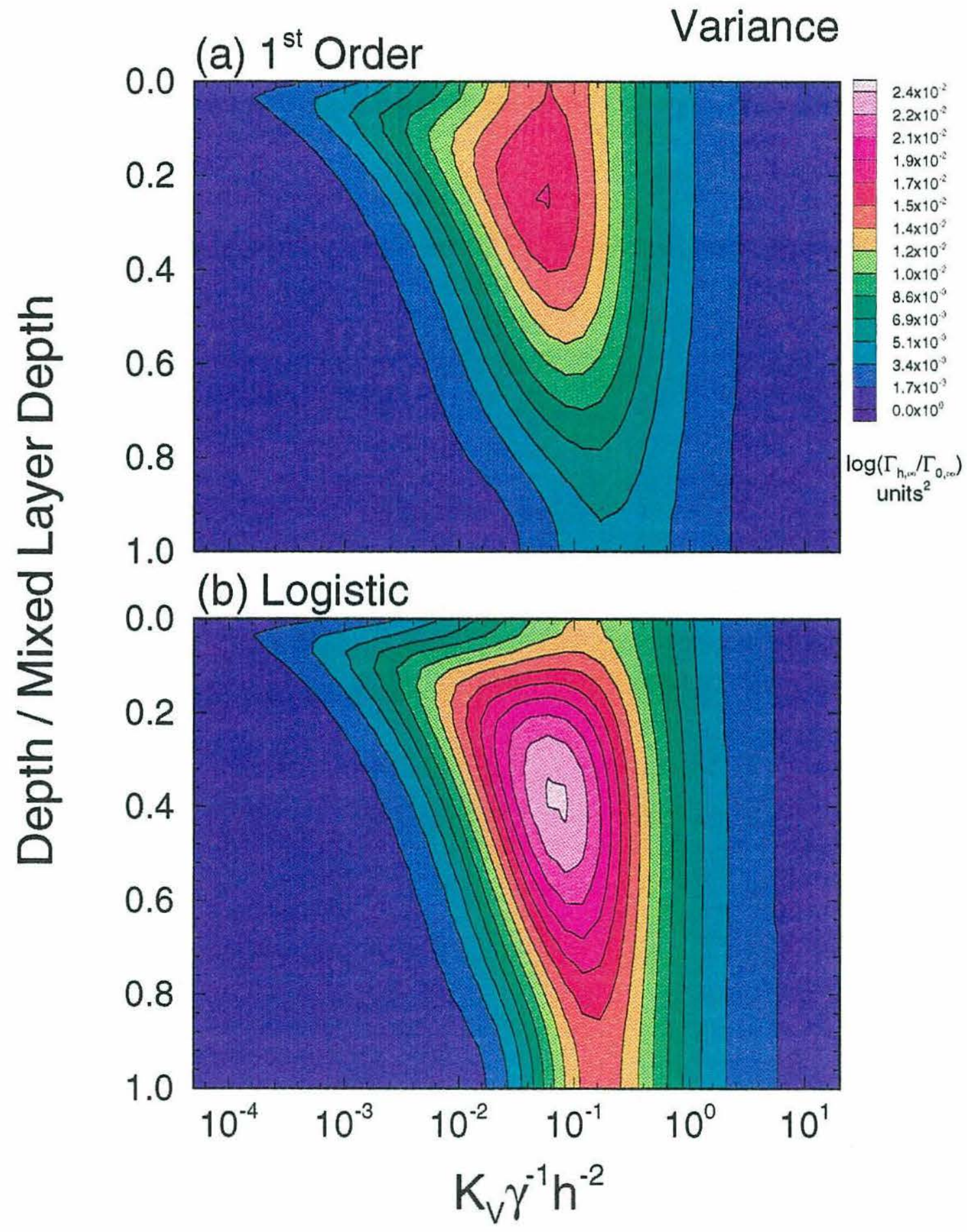


Figure 4 - Contours of the third moment of the photoacclimative parameter, $\Gamma$, as a function of depth (relative to the mixed layer depth) and $\mathrm{K}_{\mathrm{V}} \gamma^{-1} \mathrm{~h}^{-2}$ for the first-order (a) and logistic (b) photoacclimation models. The photoacclimative parameter was made non-dimensional as in figure 1 , and the contours are expressed in units of $\left(\Gamma_{\mathrm{h}, \infty}^{*}-\Gamma_{0, \infty}^{*}\right)^{3}$. Values greater than $2.0 \times 10^{-5}$ or less than $-2.0 \times 10^{-5}$ are significant (see Methods). 


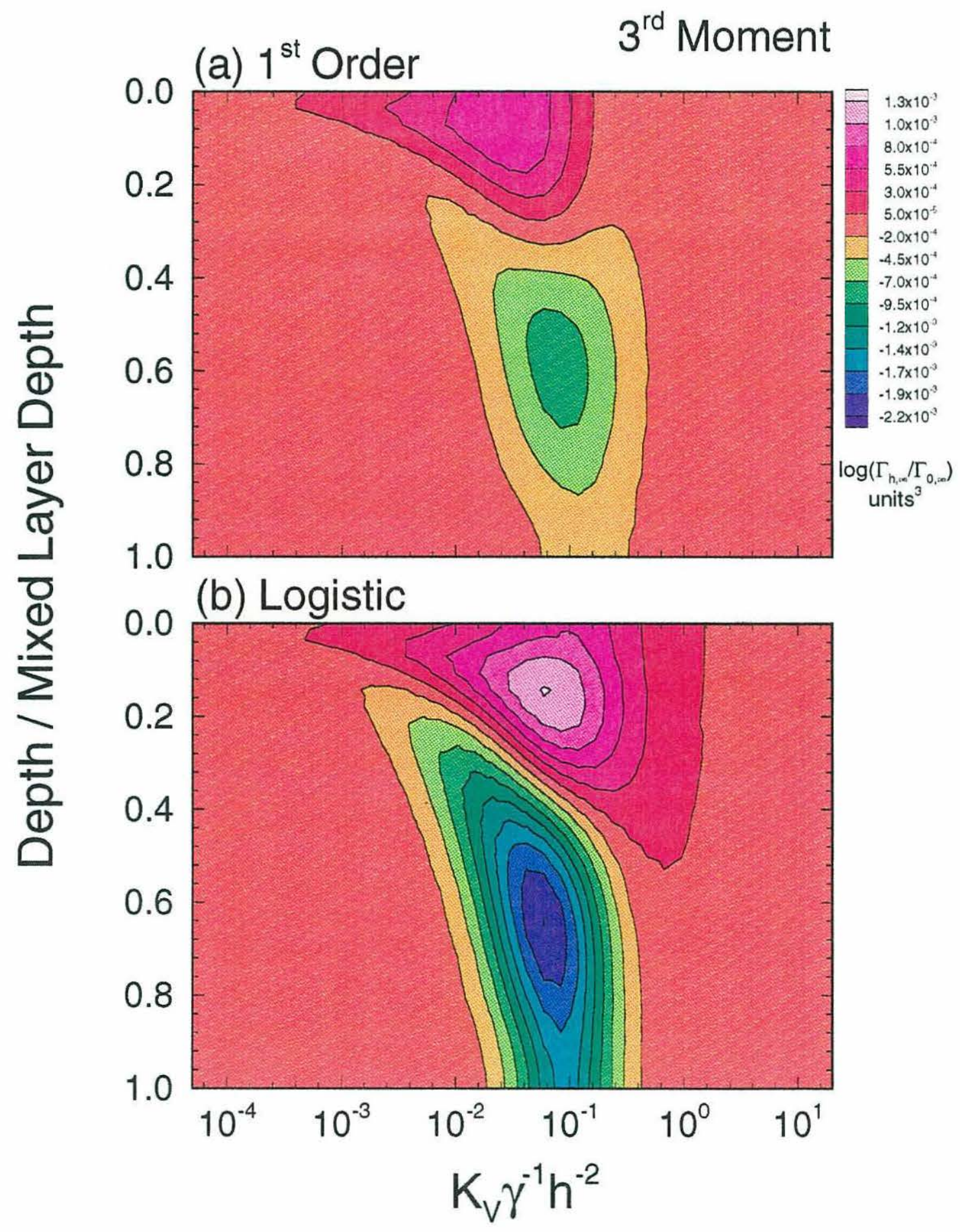


Figure 5 - Contours of the fourth moment, less three times the standard deviation to the fourth power, of the photoacclimative parameter, $\Gamma$, as a function of depth (relative to the mixed layer depth) and $\mathrm{K}_{\mathrm{V}} \gamma^{-1} h^{-2}$ for the first-order (a) and logistic (b) photoacclimation models. The photoacclimative parameter was made non-dimensional as in figure 1 , and the contours are expressed in units of $\left(\Gamma_{\mathrm{h}, \infty}^{*}-\Gamma_{0, \infty}^{*}\right)^{4}$. Values greater than $4.0 \times 10^{-5}$ or less than $-4.0 \times 10^{-5}$ are significant (see Methods). 


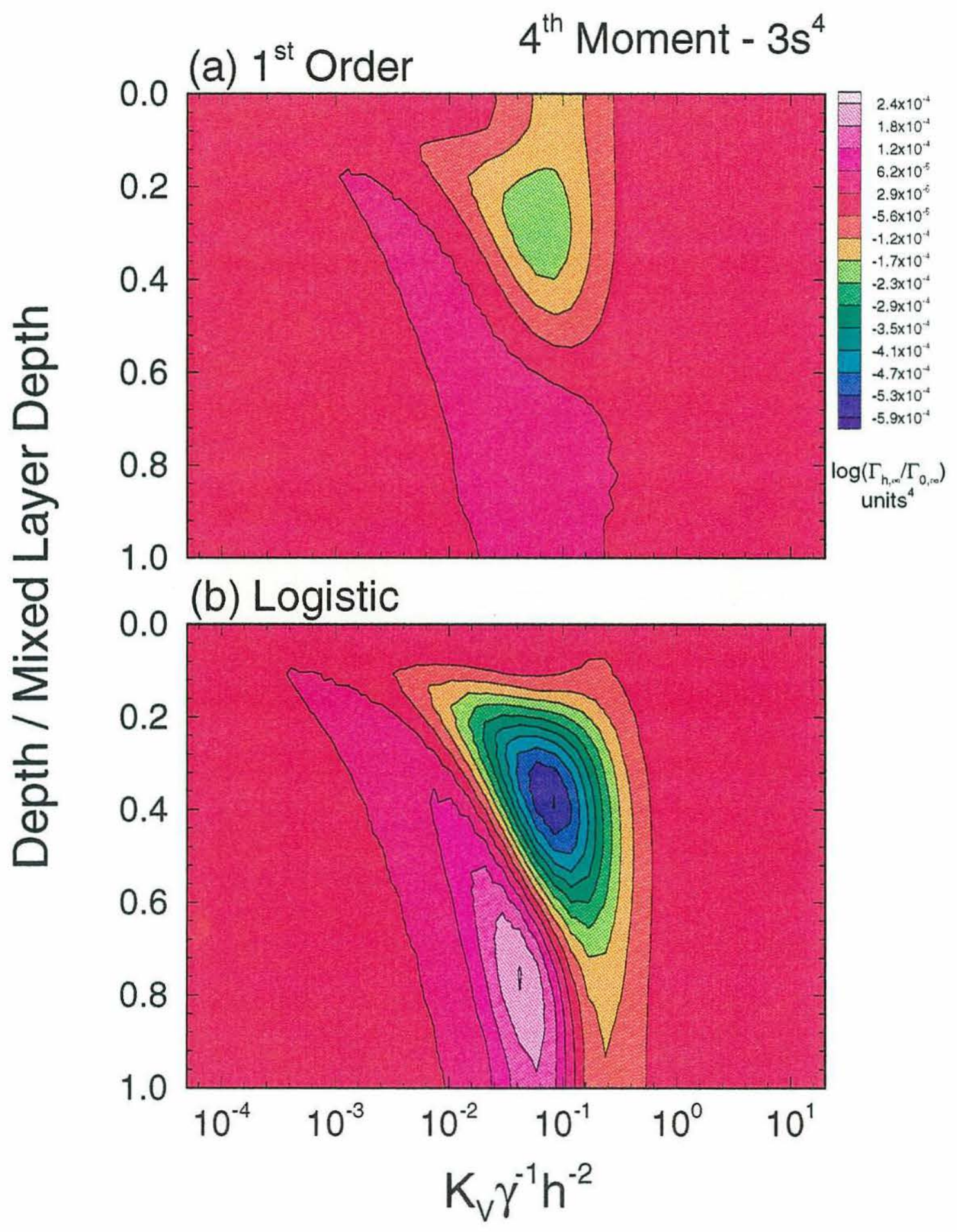




\section{Discussion}

The variance and higher moments of a photoacclimative parameter show distinct patterns that vary as a function of relative photoacclimation and mixing timescales $\left(\mathrm{K}_{\mathrm{v}} \gamma^{-1} \mathrm{~h}^{-2}\right)$, and should thus be useful as indicators of vertical mixing processes. While the mean value is fairly sensitive near the boundaries (Fig. 2), it is a relatively insensitive indicator of mixing in the interior, sensitive only in the range of $\mathrm{K}_{\mathrm{v}} \gamma^{-1} \mathrm{~h}^{-2}$ values near 0.1 . While it is still necessary to choose photoacclimative parameters that change on time-scales commensurate with the mixing time-scale (Lewis et al., 1984a), the variance and higher moments show increased sensitivity at a wider range of $\mathrm{K}_{\mathrm{v}} \gamma^{-1} h^{-2}$ values (Fig. 3-5), and thus add dynamic range to the potential use of physiological properties as indicators of mixing processes. As is the case in bulk property models (Lewis et al., 1984a) the use of additional parameters with different photoacclimation rates, $\gamma$, will serve to further increase the dynamic range of the method by effectively shifting the patterns seen in figures 2 through 5 along the $\mathrm{K}_{\mathrm{V}} \gamma^{-1} h^{-2}$ axis.

The sensitivity of using single-cell photoacclimative properties for quantifying mixing rates is limited by the presence of other sources of variation in $\Gamma^{*}$. Field measurements of variance in $\Gamma^{*}$ among a population of phytoplankton cells will be dominated by the largest source of variability. It is therefore necessary to choose a photoacclimative parameter with the largest depth gradient (i.e. $\Gamma_{\infty, \mathrm{h}} / \Gamma_{\infty, 0}$ ) relative to the variance which can be attributed to sources other that photoacclimation/mixing 
processes.

Boundary effects also play an important role in determining the distributions of a photoacclimative parameter. Similar to the Lande and Lewis (1988) model, these results show increasing variance with increasing mixing in the absence of boundary effects, and decreasing variance as one gets closer to the boundary. In the presence of two boundaries, however, the variance in a photoacclimative parameter as predicted by either model will eventually begin to decrease with increasing mixing rates (Fig. 3) as boundary effects extend throughout the mixed layer. Boundary effects are also visible in the third moment of the photoacclimative parameter, with the transition region between the boundary region and the interior showing maxima or minima in the third moment.

The model presented here is an overly simplistic one; however, it provides an insightful starting point for understanding the possible effects of mixing processes on single-cell photoacclimative properties, and the interpretation of observed distributions of a photoacclimative property in the context of vertical mixing. Future enhancements to this model include time-dependent photoacclimation kinetics (to reflect the daily photoperiod) and time- and space-dependent variation in mixing rates (to reflect diel variations in mixed layer dynamics). A quasi-steady random walk model (steady mixing on a light:dark cycle) is presented in Chapter $\mathrm{V}$ and gives an indication of the time evolution of the mean and higher moments of a photoacclimative parameter that might be expected under the daily photoperiod. 


\section{Acknowledgments}

I thank Kaye Brubaker and Jim Price for helpful discussions and insights. 


\section{References}

Cullen, J. J. and M. R. Lewis. 1988. The kinetics of algal photoadaptation in the context of vertical mixing. J. Plankton Res. 10:1039-1063.

Falkowski, P. G. 1980. Light-shade adaptation in marine phytoplankton. in: Primary Productivity in the Sea. P. G. Falkowski (ed.). Plenum Press. New York.

Falkowski, P. G. 1983. Light-shade adaptation and vertical mixing of marine phytoplankton: A comparative field study. J. Mar. Res. 41:215-237.

Falkowski, P. G. 1984. Kinetics of adaptation to irradiance in Dunaliella tertiolecta. Photosynthetica. 18:62-68.

Falkowski, P. G. and C. D. Wirick. 1981. A simulation model of the effects of vertical mixing on primary productivity. Mar. Biol. 65:69-75.

Gallegos, C. L. and T. Platt. 1982. Phytoplankton production and water motion in surface mixed layers. Deep-Sea Res. 29:65-76.

Gardiner, C. W. 1985. Handbook of Stochastic Methods for Physics, Chemistry, and the Natural Sciences, Second Edition. Springer-Verlag. New York.

Geider, R. J. and T. Platt. 1986. A mechanistic model of photoadaptation in microalgae. Mar. Ecol. Prog. Ser. 30:85-92.

Jerlov, N. G. 1976. Marine Optics. Elsevier. New York.

Lande, R. and M. R. Lewis. 1989. Models of photoadaptation and photosynthesis by algal cells in a turbulent mixed layer. Deep-Sea Res. 36:1161-1175.

Laws, E. A. and T. T. Bannister. 1980. Nutrient- and light-limited growth of Thalassiosira fluviatilis in continuous culture, with implications for phytoplankton growth in the ocean. Limnol. Oceanogr. 25:457-473.

Lewis, M. R., J. J. Cullen and T. Platt. 1984a. Relationships between vertical mixing and photoadaptation of phytoplankton: Similarity criteria. Mar. Ecol. Prog. Ser. 15:141-149.

Lewis, M. R., E. P. W. Horne, J. J. Cullen, N. S. Oakey and T. Platt. 1984b. Turbulent motions may control phytoplankton photosynthesis in the upper ocean. Nature. 311:49-50.

Lewis, M. R. and J. C. Smith. 1983. A small volume, short-incubation-time method 
for measurement of photosynthesis as a function of incident irradiance. Mar. Ecol. Prog. Ser. 13:99-102.

Marra, J. 1978a. Effect of short-term variations in light intensity on photosynthesis of a marine phytoplankter: A laboratory simulation study. Mar. Biol. 46:191-202.

Marra, J. 1978b. Phytoplankton photosynthetic response to vertical movement in a mixed layer. Mar. Biol. 46:203-208.

Marra, J. 1980. Vertical mixing and primary productivity. in: Primary Productivity in the Sea. P. G. Falkowski (ed.). Plenum Press. New York.

Olson, R. J., D. Vaulot and S. W. Chisholm. 1985. Marine phytoplankton distributions measured using shipboard flow cytometry. Deep-Sea Res. 32:12731280 .

Platt, T. and C. L. Gallegos. 1980. Modelling Primary Production. in: Primary Productivity in the Sea. P. G. Falkowski (ed.). Plenum Press. New York.

Post, A. F., Z. Dubinsky, K. Wyman and P. G. Falkowski. 1984. Kinetics of lightintensity adaptation in a marine planktonic diatom. Mar. Biol. 83:231-238.

Prézelin, B. B. and H. A. Matlick. 1980. Time-course of photoadaptation in the photosynthesis-irradiance relationship of a dinoflagellate exhibiting photosynthetic periodicity. Mar. Biol. 58:85-96.

Rivkin, R. B. 1990. Photoadaptation in marine phytoplankton: Variations in ribulose 1,5-bisphosphate activity. Mar. Ecol. Prog. Ser. 62:61-72.

Rivkin, R. B., H. H. Seliger, E. Swift and W. H. Biggley. 1982. Light-shade adaptation by the oceanic dinoflagellates Pyrocystis noctiluca and $P$. fusiformis. Mar. Biol. 68:181-191.

Savidge, G. 1988. Influence of inter- and intra-daily light-field variability on photosynthesis of coastal phytoplankton. Mar. Biol. 100:127-133.

Sokal, R. R. and F. J. Rohlf. 1981. Biometry, Second Edition. W. H. Freeman and Company. New York.

Therriault, J.-C., D. Booth, L. Legendre and S. Demers. 1990. Phytoplankton photoadaptation to vertical excursion as estimated by an in vivo fluorescence ratio. Mar. Ecol. Prog. Ser. 60:97-111.

Woods, J. D. and R. Onken. 1982. Diurnal variation and primary production in the 
ocean - preliminary results of a Lagrangian ensemble model. J. Plankton Res. 4:735-756.

Yamazaki, H. and D. Kamykowski. 1991. The vertical trajectories of motile phytoplankton in a wind-mixed water column. Deep-Sea Res. 38:219-241.

Yentsch, C. M. and others. 1983. Flow cytometry and sorting: A powerful technique with potential applications in aquatic sciences. Limnol. Oceanogr. 28:1275-1280.

Yoder, J. A. and S. S. Bishop. 1985. Effects of mixing-induced irradiance fluctuations on photosynthesis of natural assemblages of coastal phytoplankton.

Mar. Biol. 90:87-93. 


\section{Chapter V}

\section{Experimental Analysis of the Simulated Effects of Vertical Mixing on Picophytoplankton Fluorescence: A Calibration for Field Applications}




\title{
Experimental Analysis of the Simulated Effects of Vertical Mixing on Picophytoplankton Fluorescence: A Calibration for Field Applications
}

\begin{abstract}
In order to quantify the effects of mixing across a light gradient on the mean and higher moments of picophytoplankton single-cell photoacclimative properties , laboratory simulations were carried out using a mixostat apparatus. This apparatus, operating on principles often used in chemostats and cyclostats, is a continuous culture system which is capable of simulating a random walk across a light gradient. This random walk is simulated at the individual cell level, so that the effects of mixing should be evident in the distribution of photoacclimative properties within a population.

Laboratory simulations of four different mixing rates yield characteristic diel patterns (10:14 light:dark cycle) in the mean and variance of normalized red fluorescence of the picophytoplankter Prochlorococcus marinus strain Med4. All four simulations show increasing gradients in the mean normalized red fluorescence during the daytime due to photoacclimation, and a breakdown of this gradient during the dark due to mixing. The corresponding variance also decreases during the day as a result of photoacclimation, and increases at night at the system is homogenized.

The system was modelled using a simple time-dependent photoacclimation diffusion model. Model results for the mean and the variance were similar to those found in the mixostat. These results provide a qualitative basis for interpreting field observations of picophytoplankton optical properties with respect to the mixing environment.
\end{abstract}




\section{Introduction}

Because phytoplankton photoacclimate on a time scale relevant to vertical mixing, it is important to understand both these processes to interpret and model profiles of primary productivity, and to interpret ocean color measurements.

Moreover, an understanding of vertical mixing and surface photoinhibition is necessary for interpreting the effects of increased UV radiation on phytoplankton.

Light-sensitive biological properties have been recognized as potential indicators for mixing processes for some time. To date, most of the work in this area has focussed on the use of properties measured on a bulk water sample. These include photosynthesis-irradiance relationships (Falkowski and Wirick, 1981; Lewis and Smith, 1983), carbon/chlorophyll ratios (Laws and Bannister, 1980; Geider and Platt, 1986; Cullen and Lewis, 1988), xanthophyll cycling (Welschmeyer, personal communication), photosynthetic unit size (Falkowski, 1983), photosynthetic enzyme activity (Rivkin, 1990) and in vivo fluorescence (Therriault et al., 1990). Using bulk properties as indicators of mixing processes suffers from limitations that they depend on species composition of the sample and may be expected to vary spatially and temporally. In addition, the time scales of photoacclimation and vertical mixing must be similar, otherwise the parameter being measured will not be a sensitive indicator of mixing rates (Lewis et al., 1984). The use of flow cytometric measurements of picoplankton optical properties circumvents to some degree both of these limitations (Chapter IV).

The general model used here to represent the effects of vertical mixing on the 
vertical distribution of a photoacclimative parameter, $\Gamma$, is the reaction-diffusion equation (Lewis et al., 1984; Cullen and Lewis, 1988):

$$
\frac{\partial \bar{\Gamma}}{\partial t}=\frac{\partial}{\partial z} K_{v} \frac{\partial \bar{\Gamma}}{\partial z}+\gamma \Gamma\left(\frac{\Gamma_{\infty}-\bar{\Gamma}}{\Gamma_{\infty}}\right)
$$

where $\mathrm{t}$ is time and $\mathrm{z}$ is depth. Mixing is parameterized by a vertical diffusivity, $\mathrm{K}_{\mathrm{v}}$, with photoacclimation parameterized as a logistic process (Cullen and Lewis, 1988) (Chapter III). The purpose of this study was to use single cell optical properties from cells grown in a controlled mixing environment ( $\mathrm{K}_{\mathrm{V}}$ and boundary conditions known) to calibrate and verify a single-cell version of this model of the effects of vertical mixing on picoplankton optical properties.

In the past, most studies of phytoplankton physiological responses to fluctuating light levels have involved placing cultures under a fluctuating light source (Marra, 1978a) or with bottle incubations of field samples which were cycled up and down in the water column (Marra, 1978b). Kirkpatrick et al. (1990) have developed the SUPA ("Self-contained Underwater Photosynthesis Apparatus") which contains a culture vessel and can be moved in response to water motion (i.e. it can take a random walk in the water column). In each of these approaches, an entire population of cells was subjected to fluctuations in light intensity, and relevant physiological parameters, usually productivity, measured.

In order to investigate the effects of fluctuating light at the single cell level, it becomes necessary to simulate fluctuating light levels from the viewpoint of a single 
cell. Gallegos and Platt (1982) introduced the SEDA ("Simulated Eddy Diffusion Apparatus"), which uses a cyclic pumping mechanism to simulate a random walk across a light gradient. Individual cells in this system cycle independently, and not as the entire population. We have developed a continuous culture system based on similar principles as an experimental analog to the upper ocean surface layer.

\section{Mixostat Apparatus}

\section{Methods}

A set of linked chemostat-like apparati were used to simulate a random walk through a light gradient similar to that which would be experienced by cells under the influence of vertical mixing (Fig. 1). This is a closed system of six interconnected 250-ml polycarbonate bottles fitted with a neck fashioned from a Plastipak ${ }^{\circledR}$ syringe (Becton-Dickinson) (useable volume $=350 \mathrm{ml}$ ). The system was housed in an air cooled light box whose temperature varied with room temperature but was approximately $21-23^{\circ} \mathrm{C}$. Eight "High Output" cool white fluorescent bulbs were used as a light source. The second through the sixth bottles were screened with increasing layers of blue filters (Roscolux \#62 and \#69). Light levels, measured using a Biospherical Instruments Inc. QSL-100 4 $\pi$ sensor were 500, 260, 110, 50, 24, and $11 \mu$ Ein $\mathrm{m}^{-2} \mathrm{~s}^{-1}$ respectively. This represents equivalent depth intervals between bottles, h, of approximately $15 \mathrm{~m}$ for an attenuation coefficient measured in the Sargasso Sea $\left(35^{\circ} 25^{\prime} \mathrm{N}, 66^{\circ} 30^{\prime} \mathrm{W}\right.$, October 1989) of $0.05 \mathrm{~m}^{-1}$.

Mixing is simulated by using positive air pressure to force a known volume of 
fluid from each bottle to the next. Air pressure was regulated so that during each cycle $10 \mathrm{ml}$ of the culture from the darkest bottle was transferred to the next, where it mixed with the contents of that bottle. Then $10 \mathrm{ml}$ of culture from that bottle is transferred to the next and so on until it accumulates in the unscreened bottle. The air pressure is then reversed, and the same amount of fluid (but not same fluid) is transferred back. As a cell has a particular probability of being transferred to an adjacent bottle or remaining in its current bottle during each cycle, this sets up a random walk at the single cell level along the light gradient. A vertical diffusivity, $\mathrm{K}_{\mathrm{v}}$, can be calculated from (Gallegos and Platt, 1982):

$$
K_{v}=\frac{F(1-F) h^{2}}{\tau_{m}}
$$

where $\mathrm{F}$ equals the fraction of fluid transferred each cycle (volume fluid transferred/volume per bottle), $\mathrm{h}$ is the depth difference represented by the difference in screening between adjacent bottles, and $\tau_{\mathrm{m}}$ is the total cycle length. Four cycle lengths of 2, 4, 16, and $32 \mathrm{~min}$. were chosen, representing diffusivities of 600,300 , 80 , and $40 \mathrm{~cm}^{2} \mathrm{~s}^{-1}$ respectively.

The mixostat was also operated as a continuous culture system, similar to a chemostat or cyclostat. Fresh media was added at the darkest screened bottle, and overflow culture is removed at the same bottle (Fig. 1). In a conventional chemostat, the growth rate (at steady state) is equal to and controlled by the dilution rate, assuming the dilution rate is less than the maximum growth rate as determined by 
Figure 1 - Schematic of mixostat apparatus. This is a closed system of six interconnected bottles which are successively screened to represent the light gradient that occurs with depth in the water column. Continuous culture growth dynamics are maintained, similar to a chemostat or cyclostat, by a continuous inflow of fresh media at the darkest screened bottle and waste removal at the same bottle. Fresh media (nutrients) is transferred to the other bottles by the mixing dynamics of the system. Vertical mixing is simulated using a cyclic pumping mechanism. Air lines at both ends of the system are operated by solenoid valves which alternate the incoming air flow between the darkest and brightest bottles in the system. During each cycle positive pressure is applied to the darkest end bottle causing a small fraction of the culture in that bottle to be transferred to the next bottle up, where it mixes with the contents of that bottle. That same amount of fluid (but not the same fluid) is then transferred to the next bottle in the series and so on until the fluid accumulates in the brightest bottle. The air pressure is then reversed and the process repeats in the opposite direction. Because a cell in the system has a given probability of being transferred out of its current bottle into an adjacent bottle (or remaining in its current bottle) during each cycle, this sets up a random walk at the individual cell level across the light gradient. 


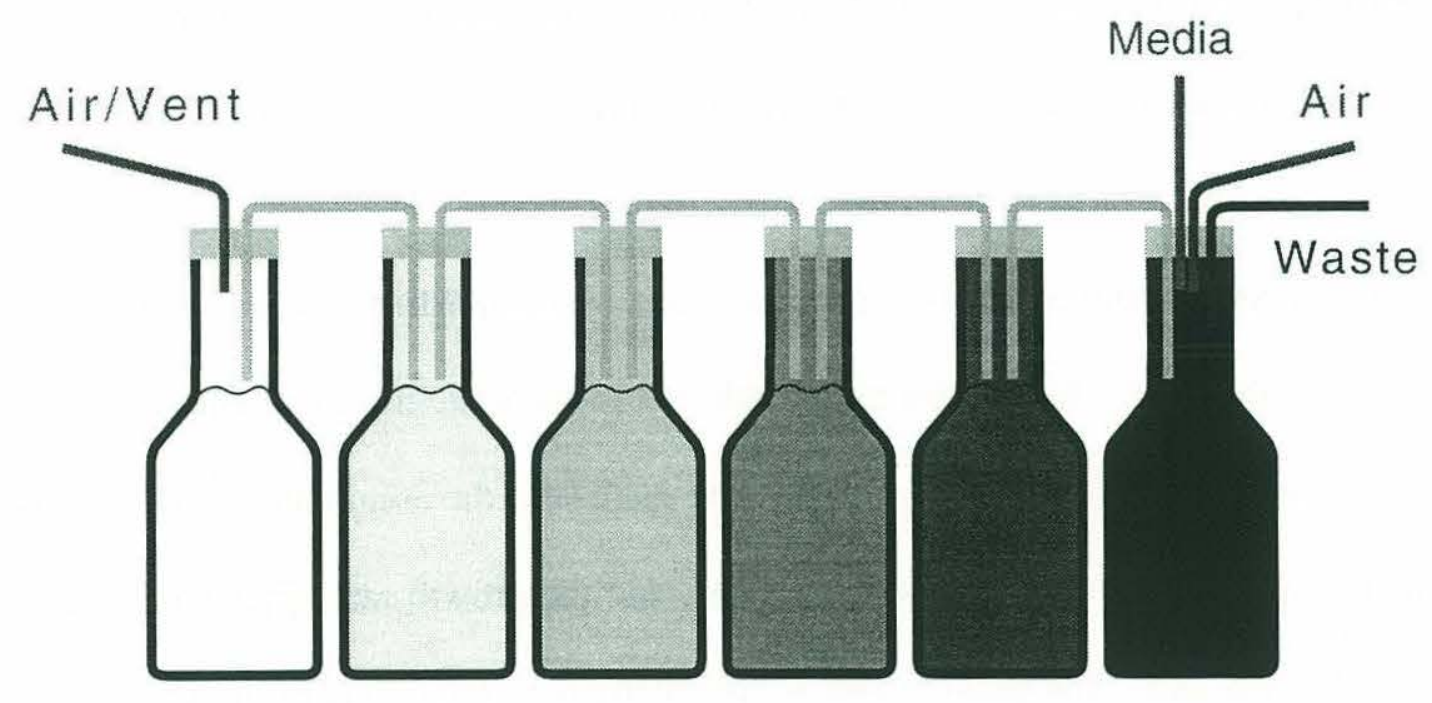


external variables such as light or temperature. The situation where the growth rate and the dilution rate are equivalent is based on the assumption of instantaneous mixing throughout the culture vessel, so that nutrients introduced and cells produced are evenly distributed throughout the vessel. By design, the mixostat violates this assumption. An overall dilution rate (flow rate/total system volume) for a mixostat system which is comparable to the maximum growth rate in the system will cause the darkest screened bottle to experience an effective dilution rate (flow rate/volume per bottle) which exceeds the maximum growth rate. The washout rate in the darkest bottle will thus exceed the growth rate, and the difference (at steady state) will be made up by cells coming in from the second darkest bottle. Thus a gradient in cell number across the bottles will be established (see Mixostat/Mixed Layer Model, below). Furthermore, the net overall growth rate in the system will be significantly less than the dilution rate. As the mixing rate increases, the assumption (for chemostat theory) of instantaneous mixing is approached, and the growth rate approaches the overall dilution rate. The dilution rate in the mixostat is analogous to the flux term, $\mathrm{D}$, in the model presented below. A media inflow rate of $1 \mathrm{ml} \mathrm{min}^{-1}$ was chosen as it gave an overall dilution rate of $0.69 \mathrm{~d}^{-1}$ (total system volume $=2100 \mathrm{ml}$ ). Thus at high mixing rates, cell growth approached 1 doubling per day.

Prochlorococcus marinus strain Med4, isolated from the surface waters in the Mediterranean Sea, was used because it is one of the hardier strains we have in culture and seems surface adapted (Moore et al., 1995) Cells were grown in modified K/10 (-Cu) media as in (Chisholm et al., 1992), except that the EDTA concentration was 10 
fold more dilute $(1.2 \mu \mathrm{M})$ and urea was added. In order to reduce cell densities to a manageable level for flow cytometric analysis, nitrogen concentrations were reduced approximately 16-fold to a combination of $3.1 \mu \mathrm{M} \mathrm{NH}_{4}$ and $0.6 \mu \mathrm{M}$ urea, yielding a $\mathrm{N}: \mathrm{P}$ ratio of 0.37 . As cell densities responded to changes in nitrogen loading, nitrogen appears to be the limiting nutrient in the system.

Cells were monitored using a modified FACScan flow cytometer (Dusenberry and Frankel, 1994) to determine cell concentration, light scatter and red autofluorescence (due to chlorophyll). Data were collected in list mode, allowing quantification and data manipulation at the single cell level. Subsequent analysis was done with CYTOPC flow cytometry analysis software (D. Vaulot). All optical measurements were normalized to $0.57-\mu \mathrm{m}$ microspheres (Polysciences, Inc.) which were added to each sample as an internal standard.

The system was operated on a 10:14 light:dark cycle. For each mixing rate, the system was operated until no changes in cell concentration or fluorescence were observed for at least 9 days, with samples taken at the same time (mid-afternoon) each day sampled. Upon reaching this "quasi-steady" state, a time-series of samples were collected over the 24-hour photoperiod and analyzed using the FACScan.

Red fluorescence signals were normalized to the cube root of the corresponding forward angle light scatter signal by rotating the two-parameter histogram $18^{\circ}$ (Chapter II, Fig. 1-2). A single parameter histogram of the normalized red fluorescence was then created, and the method of Sokal and Rohlf (1981) was used to calculate the higher moments. The third moment was used as an indicator of the skewness of the 
population and a corrected fourth moment (the fourth moment less 3 times the standard deviation to the fourth power) was used as an indicator of the kurtosis. This was done to remove sensitivity to intrinsic variation (assuming such intrinsic variation to be log-normally distributed) (Chapter II).

\section{Results}

Time-averaged cell concentration gradients across the bottles show a strong dependence on mixing rates (Fig. 2). As should be expected, high mixing rates yield more nearly homogeneous cell concentrations, while low mixing rates show a decrease in cell number with decreasing light level (bottle) due to the washout effect in the lowest light bottle. In addition, at the two higher mixing rates, nutrient supply to and washout from the brighter bottles are faster, thus yielding lower overall cell concentrations as would be expected from simple chemostat theory (Bazin, 1981).

Patterns of growth and fluorescence in the system also showed a strong dependence on mixing rates (Fig. 3-6). In all experiments, photoacclimation during the day drove the development of a gradient in normalized fluorescence across the bottles. During the dark period, mixing in the absence of photoacclimation reduced this gradient, and at higher mixing rates, was able to eliminate it.

The higher mixing rate experiments $\left(300\right.$ and $\left.600 \mathrm{~cm}^{2} \mathrm{~s}^{-1}\right)$ show an interesting phenomenon not seen elsewhere in my research. Cell numbers increase in early morning prior to the increase in forward angle light scatter during the day (Fig. 5 - 6). The reduction in forward angle light scatter that occurs during the dark phase occurs 
more slowly than the reduction seen in the lower mixing rates. In addition, while forward angle scatter increases throughout the day, the mean red fluorescence stabilizes, resulting in the normalized fluorescence showing a drop for all bottles about halfway through the light period. There is also an overall increase in normalized fluorescence during the nighttime which is also suggested by the low mixing rate experiments (Fig. 3-4). This increase appears to be the result of cell shrinkage as there is a slight decrease in red fluorescence during the night and a greater decrease in forward angle scatter.

These results suggest that cell growth patterns in the nutrient limited mixostat show either a lack of phasing of cell division (or non-detectable phasing) or that division does not occur at dusk. This differs fundamentally from growth patterns in light limited batch culture, which show division at dusk (Chapter III). Interestingly enough, this difference appears to be greatest at fast growth rates (i.e. fast mixing rates), where a division burst occurs early in the light period. This suggests that nutrient limitation results in cell cycle arrest later in the cycle than does light limitation (or that light limitation doesn't arrest until after division). Another possibility is that release from arrest may be faster in nutrient limited cells as opposed to light limited cells. Most likely, it seems that nutrient limitation prevents cells that have been light blocked early in their cycle (i.e. cells that divided at dusk) from dividing before the following dusk, and these cells are thus more nearly ready to divide at the beginning of the light phase, and do so at that time.

Because these samples were analyzed via flow cytometry, the variance and 
Figure 2 - Time averaged cell concentrations for laboratory mixostat experiment for diffusivities of $40 \mathrm{~cm}^{2} \mathrm{~s}^{-1}$ (open circles), $80 \mathrm{~cm}^{2} \mathrm{~s}^{-1}$ (closed circles), $300 \mathrm{~cm}^{2} \mathrm{~s}^{-1}$ (open triangles), and $600 \mathrm{~cm}^{2} \mathrm{~s}^{-1}$ (closed triangles). "Error" bars represent the variation seen in cell concentrations during the 24-hour experiment. The vertical axis shows the approximate gradient seen in light intensity across the bottles. 


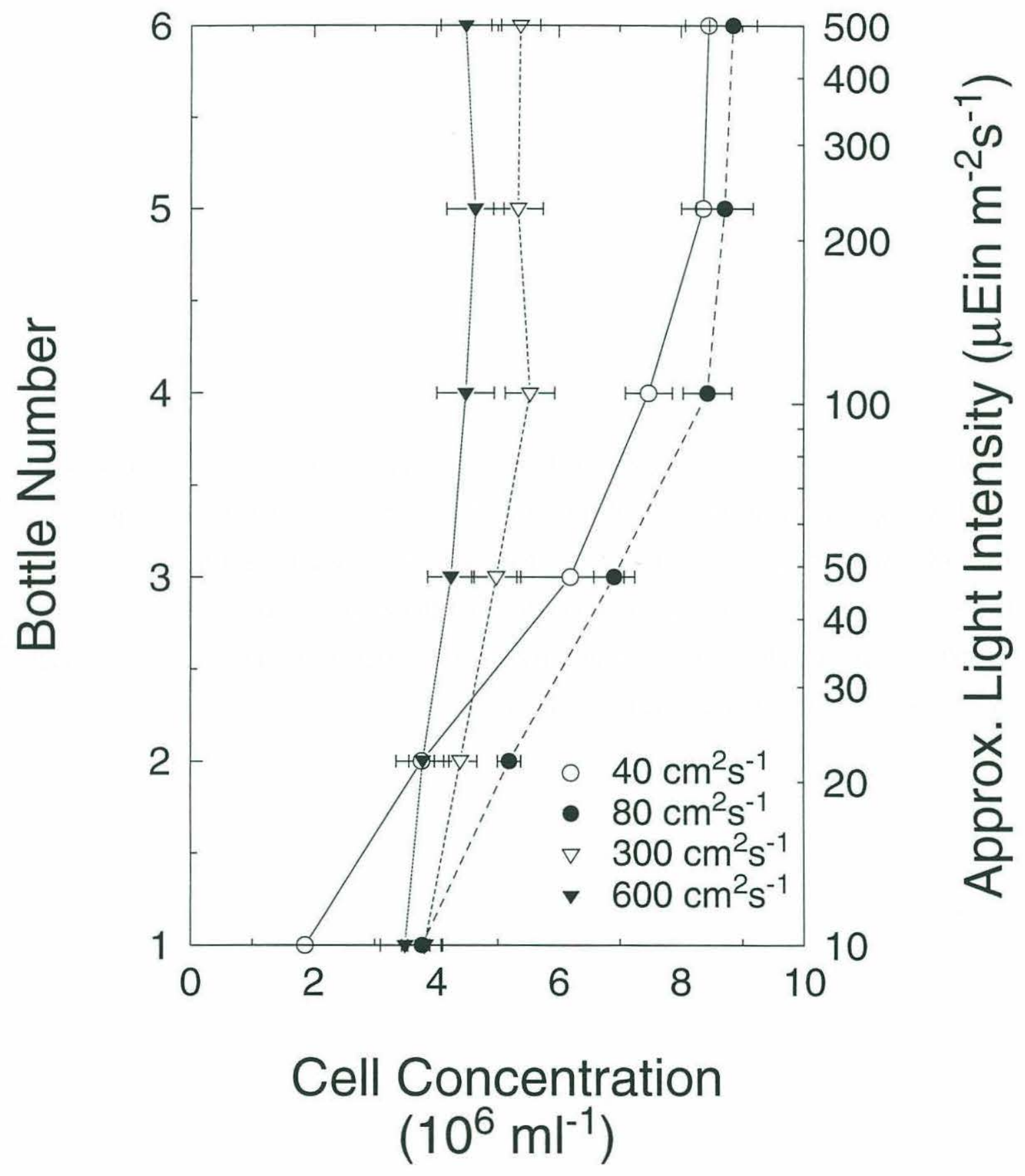


Figure 3 - Time series observations of $P$. marinus optical properties in the mixostat apparatus operated at a simulated diffusivity of $40 \mathrm{~cm}^{2} \mathrm{~s}^{-1}$. Aliquots were analyzed via flow cytometry to determine (a) cell concentration, (b) forward angle light scatter, and (c) red autofluorescence due to chlorophyll. Red fluorescence values were also normalized to the cube root of forward angle light scatter (d) to remove potential cell cycle patterns in red fluorescence (Chapter II). 

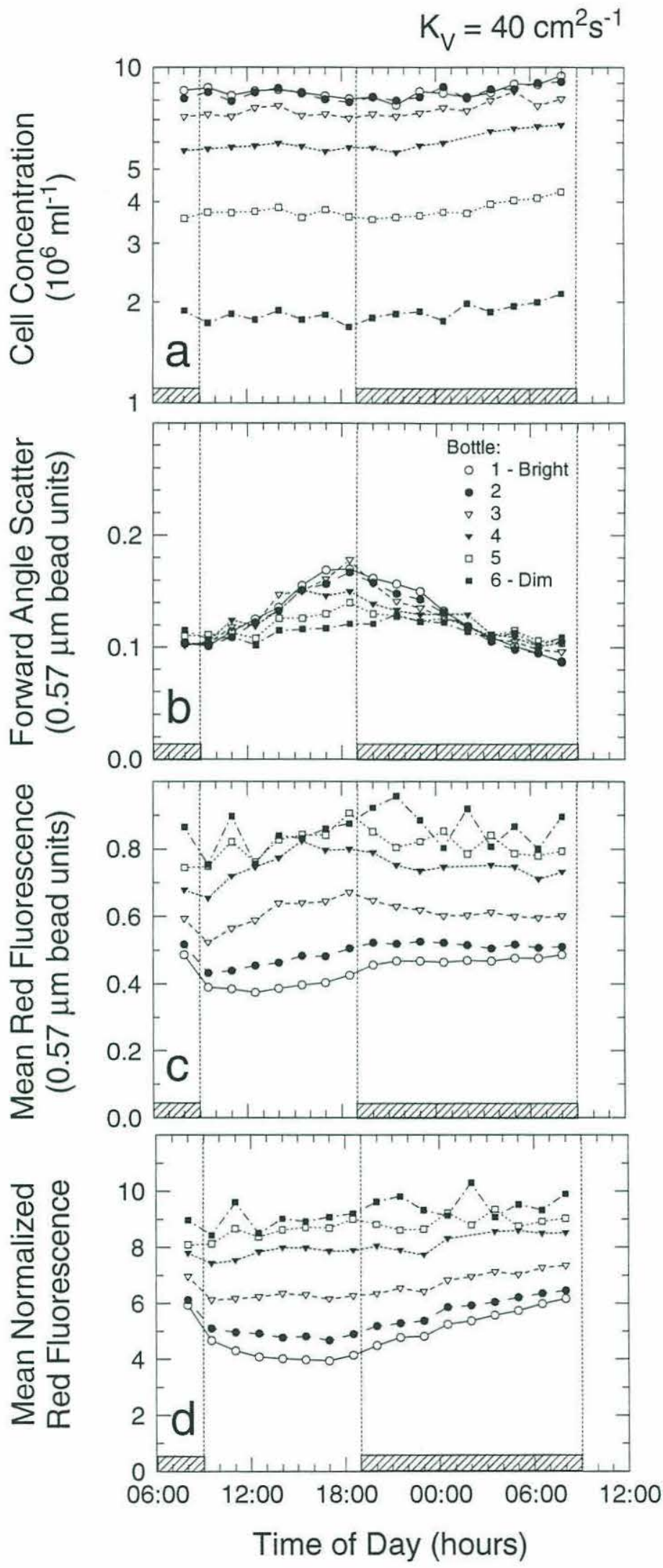
Figure 4 - Time series observations of $P$. marinus optical properties in the mixostat apparatus operated at a simulated diffusivity of $80 \mathrm{~cm}^{2} \mathrm{~s}^{-1}$. Aliquots were analyzed via flow cytometry to determine (a) cell concentration, (b) forward angle light scatter, and (c) red autofluorescence due to chlorophyll. Red fluorescence values were also normalized to the cube root of forward angle light scatter (d) to remove potential cell cycle patterns in red fluorescence (Chapter II). 

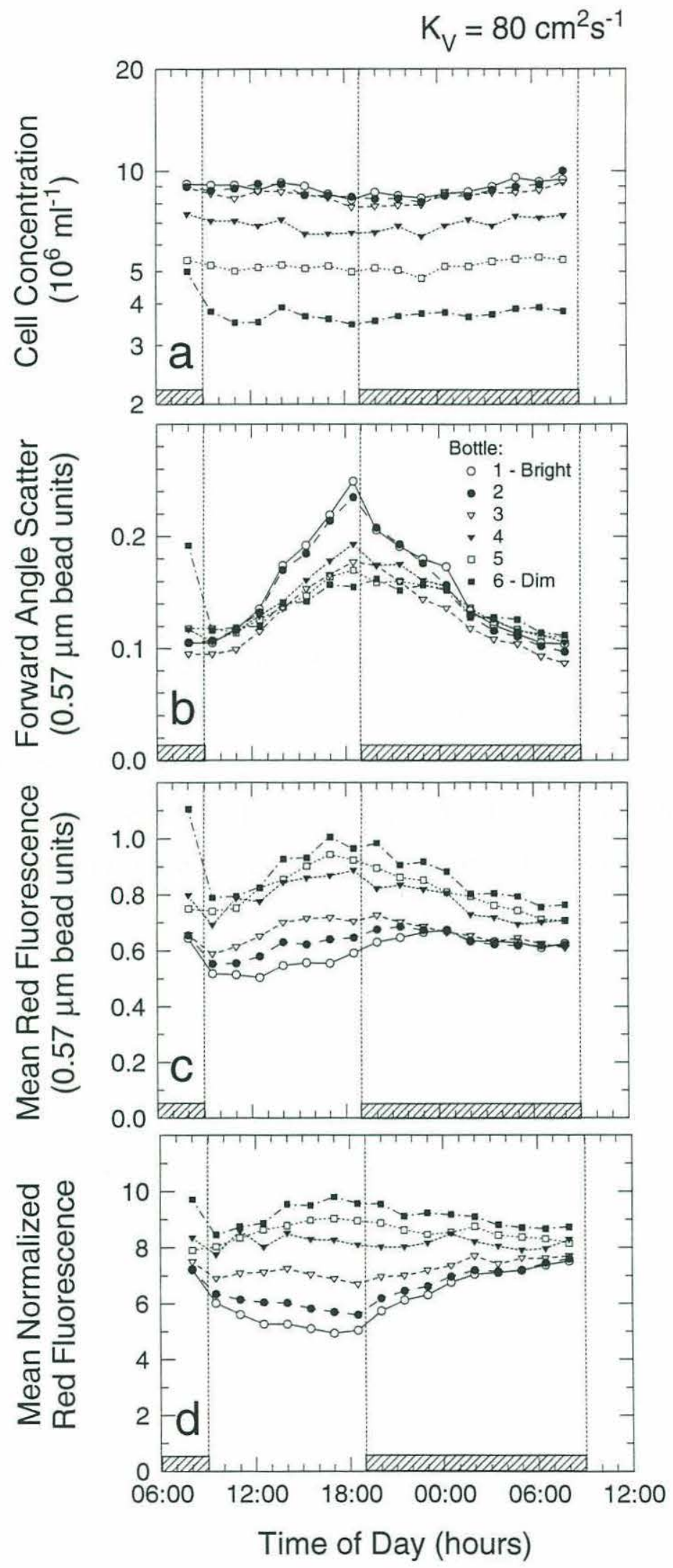
Figure 5 - Time series observations of $P$. marinus optical properties in the mixostat apparatus operated at a simulated diffusivity of $300 \mathrm{~cm}^{2} \mathrm{~s}^{-1}$. Aliquots were analyzed via flow cytometry to determine (a) cell concentration, (b) forward angle light scatter, and (c) red autofluorescence due to chlorophyll. Red fluorescence values were also normalized to the cube root of forward angle light scatter (d) to remove potential cell cycle patterns in red fluorescence (Chapter II). 

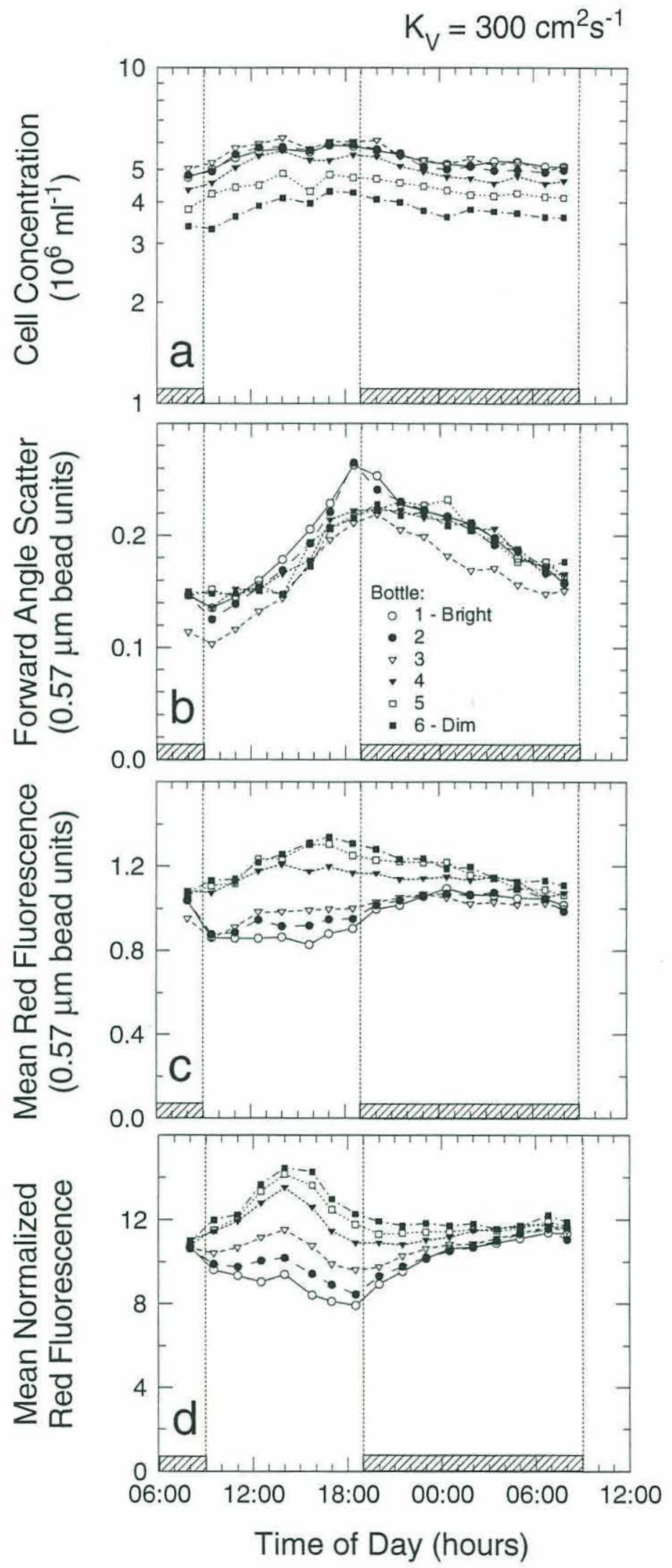
Figure 6 - Time series observations of $P$. marinus optical properties in the mixostat apparatus operated at a simulated diffusivity of $600 \mathrm{~cm}^{2} \mathrm{~s}^{-1}$. Aliquots were analyzed via flow cytometry to determine (a) cell concentration, (b) forward angle light scatter, and (c) red autofluorescence due to chlorophyll. Red fluorescence values were also normalized to the cube root of forward angle light scatter (d) to remove potential cell cycle patterns in red fluorescence (Chapter II). 

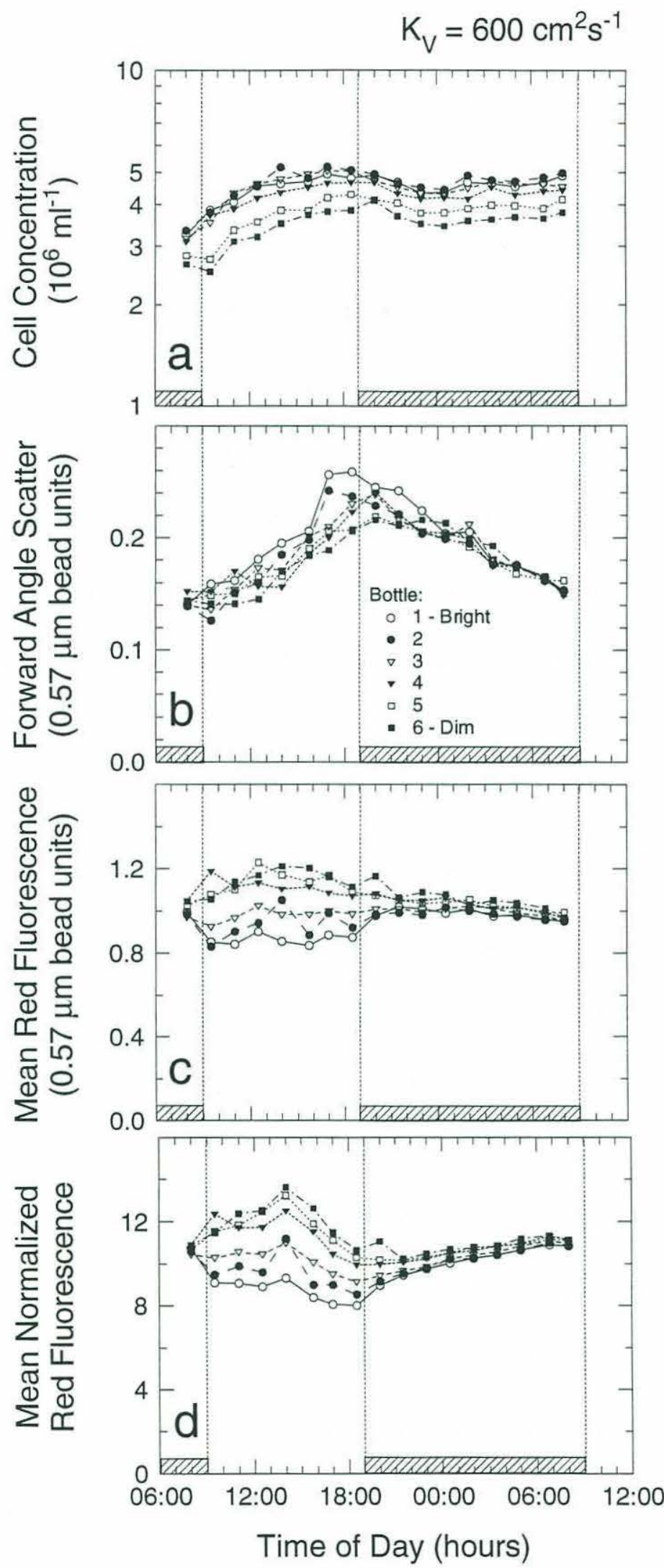
higher moments of normalized fluorescence for the populations in each bottle can be determined (Fig. 7-10). As discussed earlier, the mean values of normalized fluorescence (and raw red fluorescence) show a development of a gradient during the light period due to photoacclimation. The distributions in the high light bottles also tighten during the day and widen at night as seen by the variance of these distributions (Fig. 7-10b). This daytime tightening is an indicator of both photoacclimation and boundary effects, both of which result in tightening of distributions. The apparent lack of such tightening in the low light bottles (bottles 1 and 2) suggests that there may be a cutoff light intensity, below which photoacclimation will not occur. It may also be partly due to the washing out of cells from bottle 1 (darkest bottle) resulting in a greater influence of cells higher light bottles in the population found in bottle 1.

If the upper and lower boundaries in the system were reflective, we would expect to see a skewing of the distributions away from the boundaries (Chapter IV). Thus we would expect to see a positive third moment in the higher light bottles and a negative third moment in the low light bottles. However, what we see is a general pattern of negative third moment throughout, with only the slowest mixing rates showing near zero or slightly positive values of the third moment in the high light bottles. The third moment does, however, become increasingly negative as one moves to lower light levels, as expected.

The third moment also shows a diel pattern at all mixing rates. During the "daytime," the gradient in the third moment is the strongest, and this gradient breaks down after the lights go off. This complements the pattern seen in the mean, and is 
expected if the gradient in the third moment is driven by photoacclimation. In the absence of photoacclimation (when the lights are off) mixing destroys the gradient.

The corrected fourth moment (the fourth moment less three times the standard deviation to the fourth power) also shows a diel response in the mixostat (Fig. 7-10d), which is most pronounced at the higher mixing rates. The slowest mixing rate, $40 \mathrm{~cm}^{2} \mathrm{~s}^{-1}$ (Fig. 7) shows negative corrected fourth moment in the interior bottles, suggesting that the distribution is a flattened one. This is expected in a mixing environment when upper and lower boundaries exist and mixing is sufficient to just allow boundary effects to extend into the interior region. In effect, the boundaries are cutting off the tails of the interior distributions. This variable show minimal change in the $80 \mathrm{~cm}^{2} \mathrm{~s}^{-1}$ experiment, suggesting a lack of sensitivity to mixing and photoacclimation induced changes. However, at the high mixing rates, the corrected fourth moment is reduced during the nighttime, as is intuitively expected from the homogenization of the cells throughout the bottles. Again, this appears to be the result of boundary effects, which prevent photoacclimation to light levels above or below those present within the range in the bottles, thus effectively removing the contribution of the tails of these distributions.

\section{Mixostat / Mixed Layer Model}

The modelling approach here is two-fold. I seek to represent the growth dynamics of the system as this will determine the distribution of cell number among the bottles. Then we apply this analysis to develop a quasi-steady photoacclimation 
Figure 7 - Time-series contours of the mean and higher moments of normalized red fluorescence from the mixostat simulation operated at $40 \mathrm{~cm}^{2} \mathrm{~s}^{-1}$. Shown here are the (a) mean, (b) variance, (c) third moment, and indicator of skewness, and (d) the fourth moment less three times the standard deviation raised to the fourth power, an indicator of kurtosis. Units are in the log scale channel size of data collection, based on 64 channels per decade. 
Mixostat: $\mathrm{K}_{\mathrm{v}}=40 \mathrm{~cm}^{2} \mathrm{~s}^{-1}$

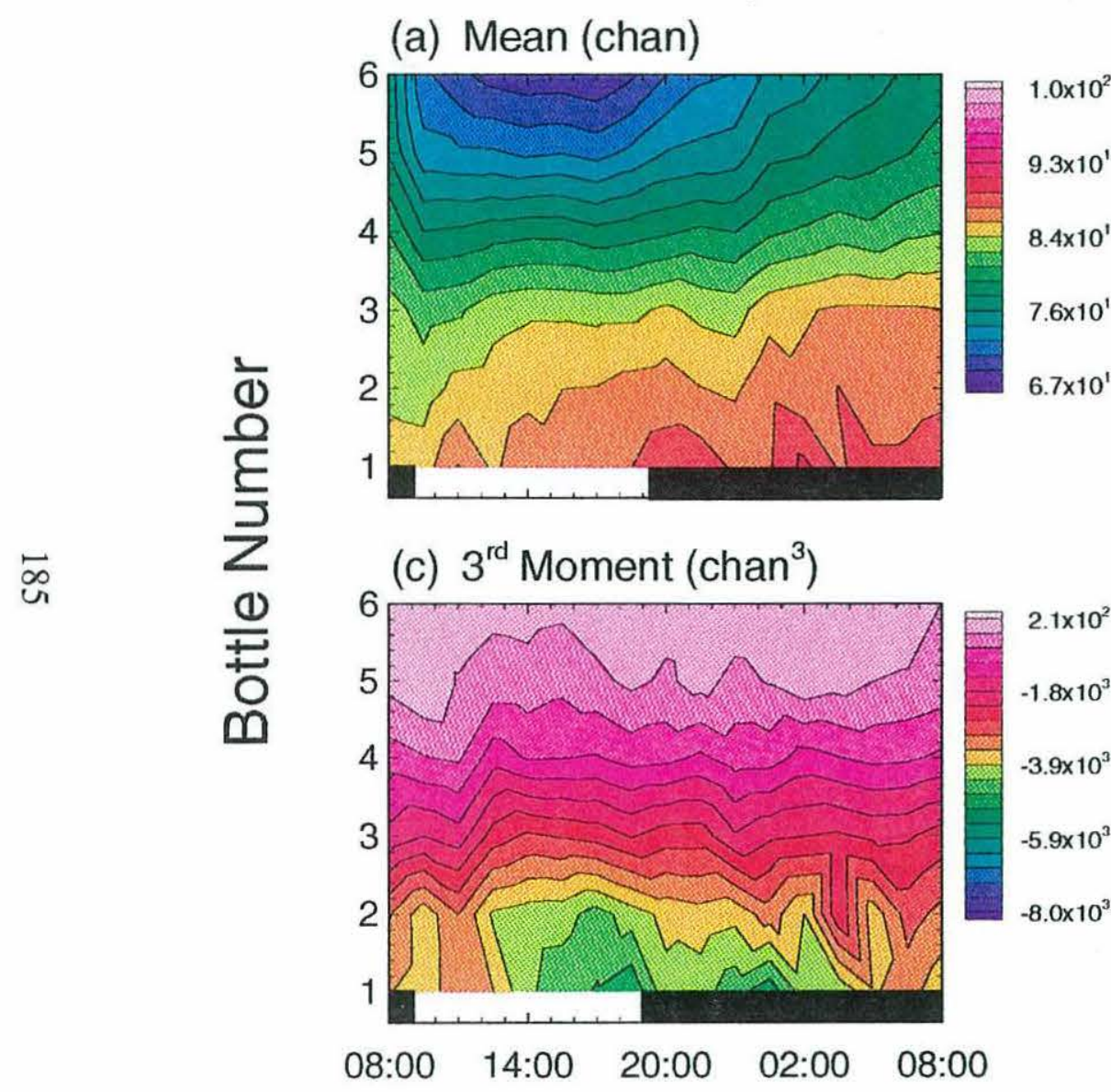

(b) Variance $\left(\mathrm{chan}^{2}\right)$

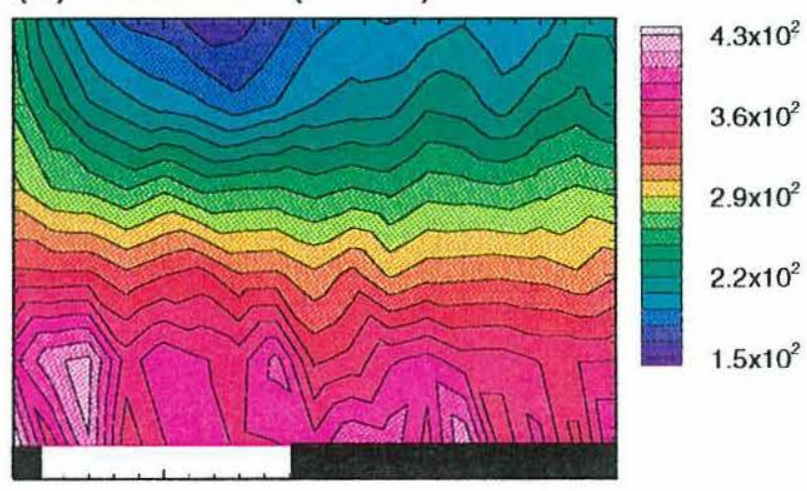

(d) $4^{\text {th }}$ Moment $-3 s^{4}\left(\operatorname{chan}^{4}\right)$

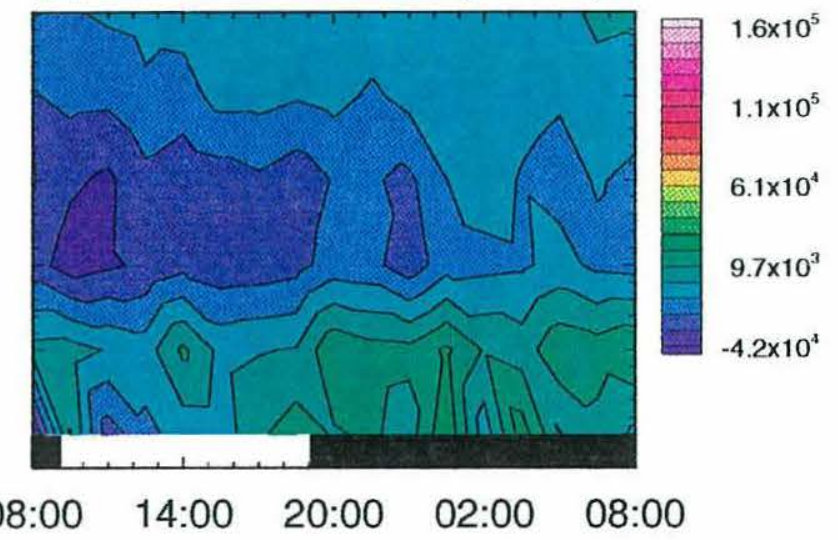

Time of Day (hours) 
Figure 8 - Time-series contours of the mean and higher moments of normalized red fluorescence from the mixostat simulation operated at $80 \mathrm{~cm}^{2} \mathrm{~s}^{-1}$. Shown here are the (a) mean, (b) variance, (c) third moment, and indicator of skewness, and (d) the fourth moment less three times the standard deviation raised to the fourth power, an indicator of kurtosis. Units are in the log scale channel size of data collection, based on 64 channels per decade. 
Mixostat: $\mathrm{K}_{\mathrm{v}}=80 \mathrm{~cm}^{2} \mathrm{~s}^{-1}$

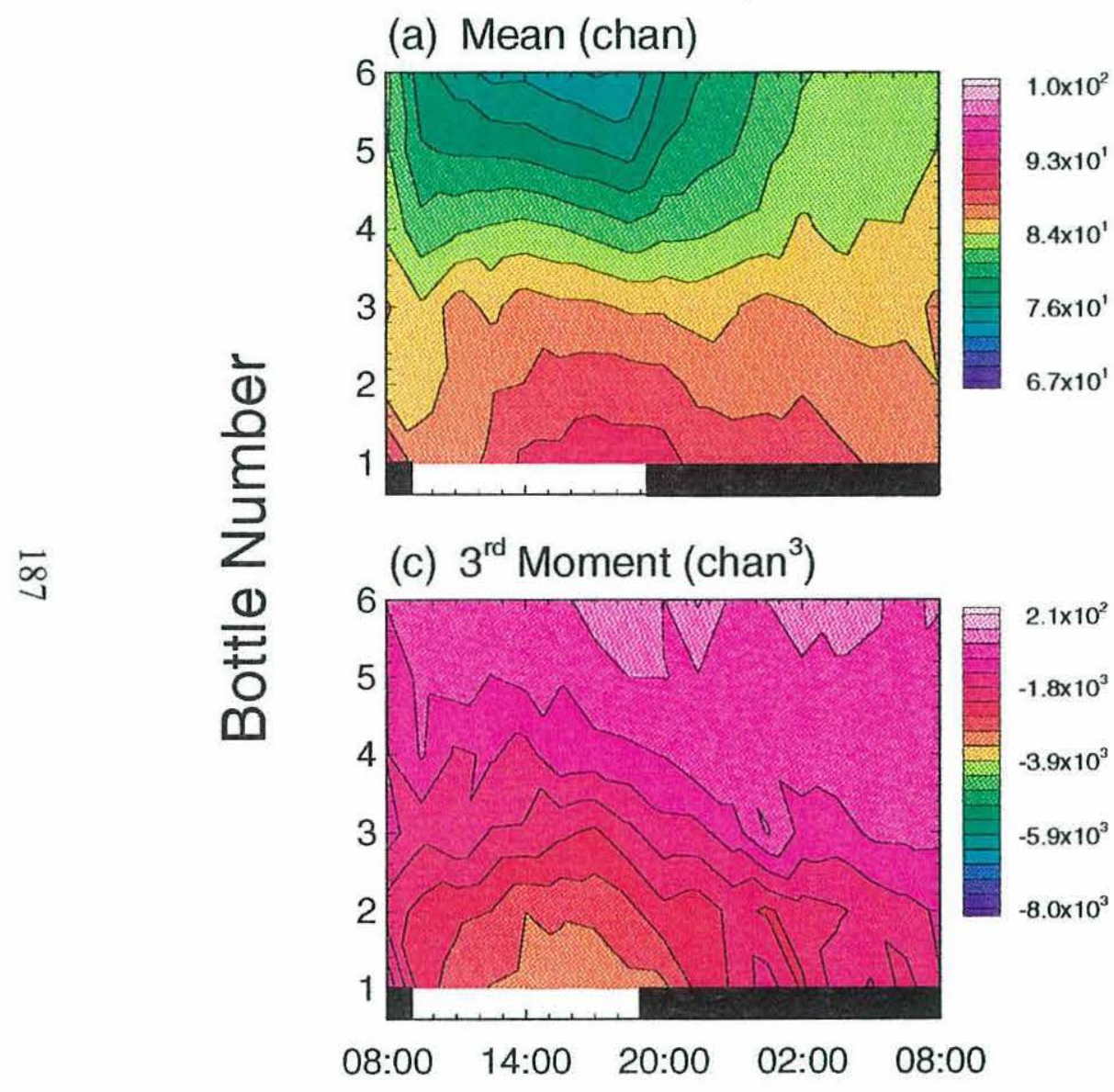

(b) Variance $\left(\mathrm{chan}^{2}\right)$

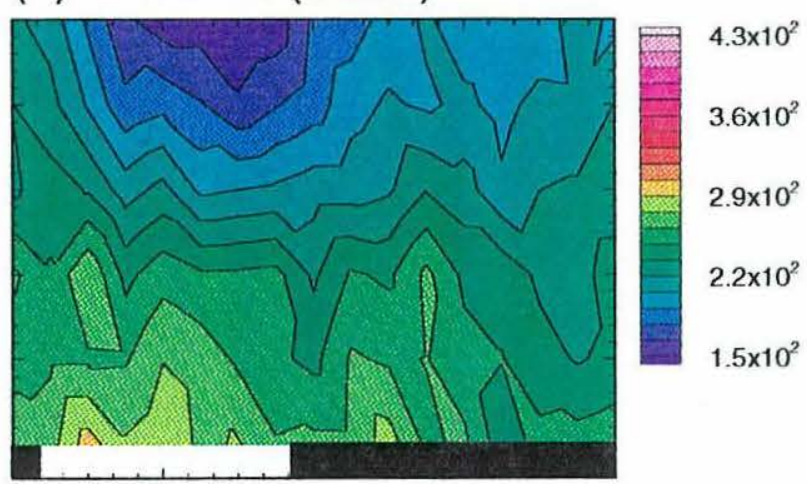

(d) $4^{\text {th }}$ Moment $-3 s^{4}\left(\operatorname{chan}^{4}\right)$

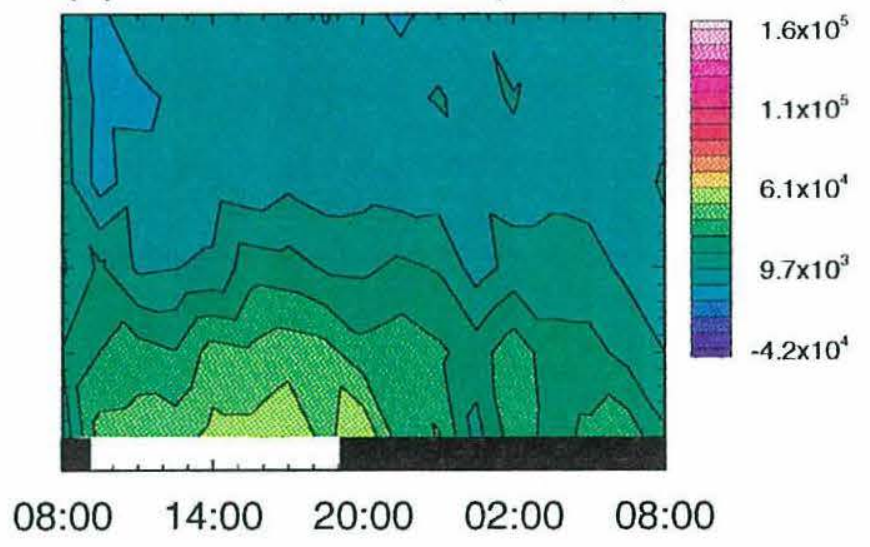

Time of Day (hours) 
Figure 9 - Time-series contours of the mean and higher moments of normalized red fluorescence from the mixostat simulation operated at $300 \mathrm{~cm}^{2} \mathrm{~s}^{-1}$. Shown here are the (a) mean, (b) variance, (c) third moment, and indicator of skewness, and (d) the fourth moment less three times the standard deviation raised to the fourth power, an indicator of kurtosis. Units are in the log scale channel size of data collection, based on 64 channels per decade. 
Mixostat: $\mathrm{K}_{\mathrm{v}}=300 \mathrm{~cm}^{2} \mathrm{~s}^{-1}$

(a) Mean (chan)

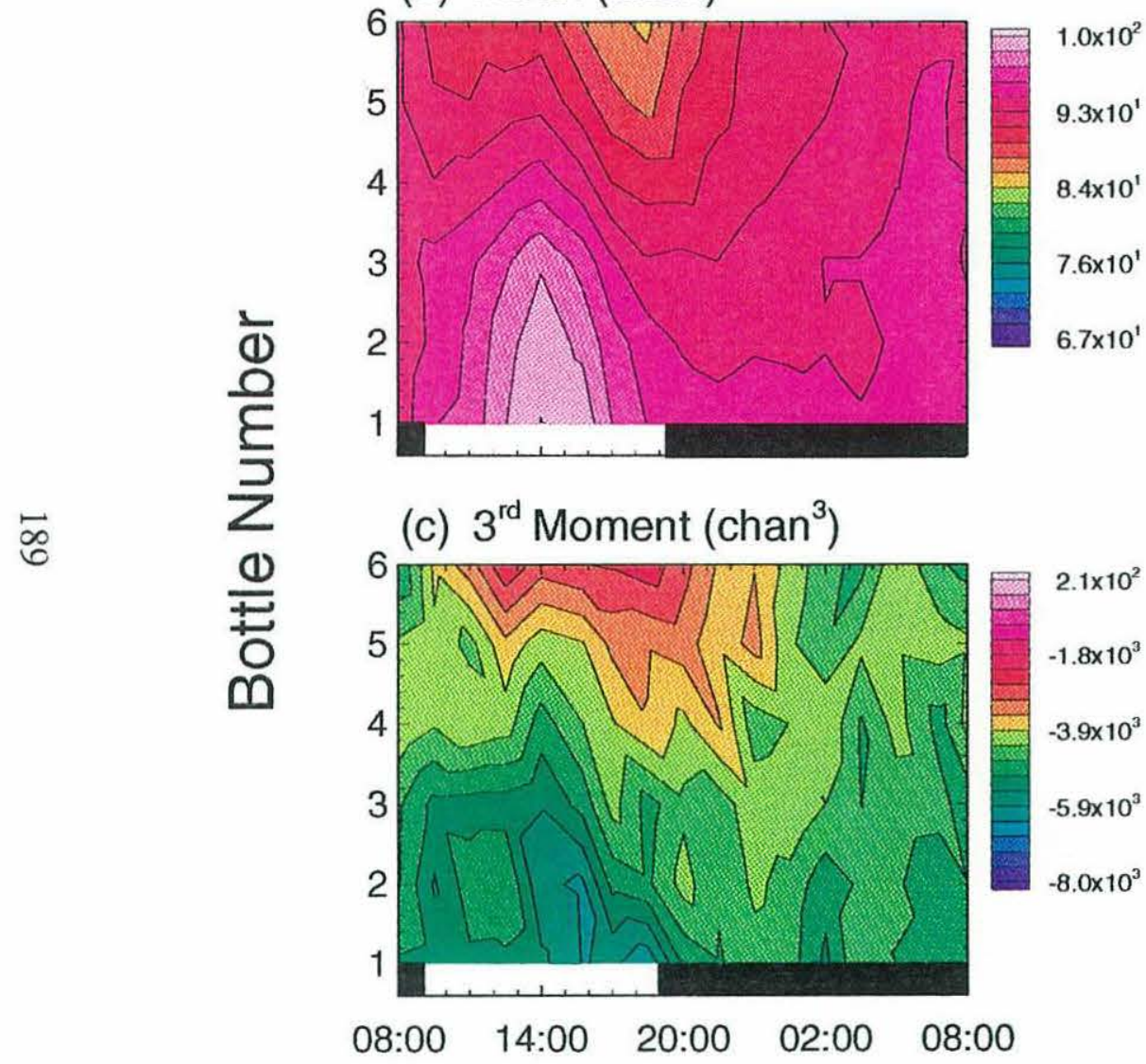

(b) Variance $\left(\mathrm{chan}^{2}\right)$

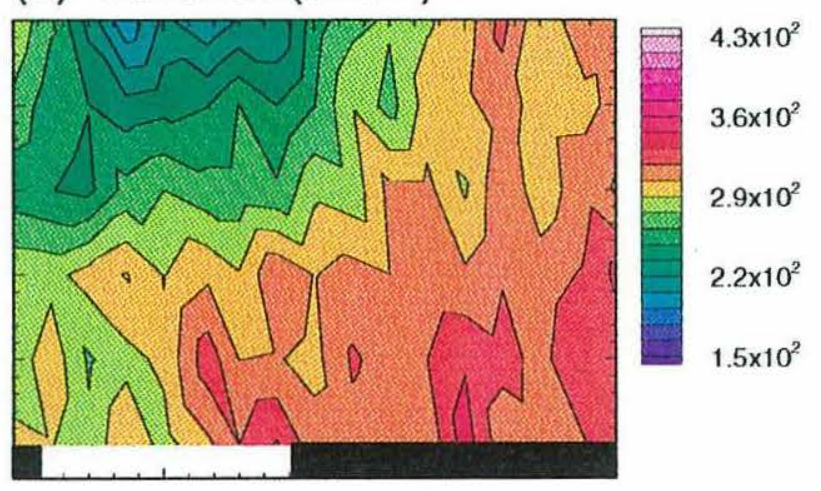

(d) $4^{\text {th }}$ Moment $-3 s^{4}\left(\operatorname{chan}^{4}\right)$

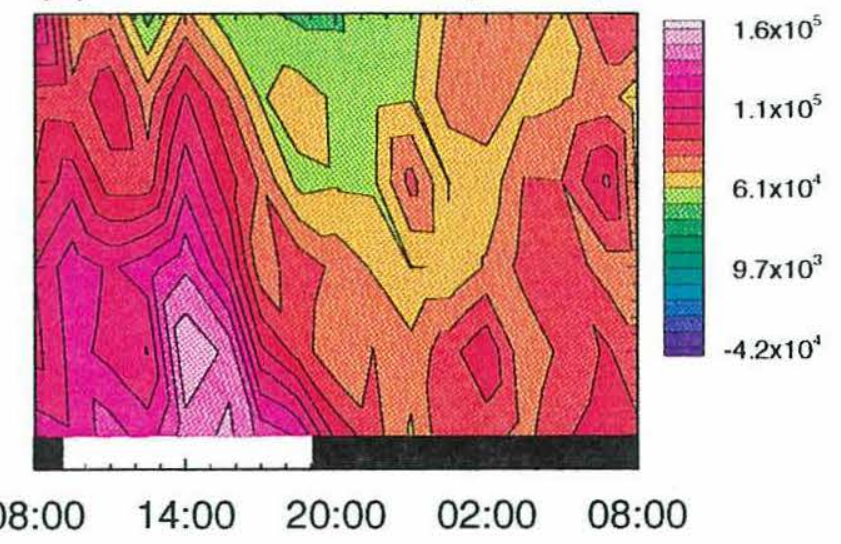

Time of Day (hours) 
Figure 10 - Time-series contours of the mean and higher moments of normalized red fluorescence from the mixostat simulation operated at $600 \mathrm{~cm}^{2} \mathrm{~s}^{-1}$. Shown here are the (a) mean, (b) variance, (c) third moment, and indicator of skewness, and (d) the fourth moment less three times the standard deviation raised to the fourth power, an indicator of kurtosis. Units are in the log scale channel size of data collection, based on 64 channels per decade. 


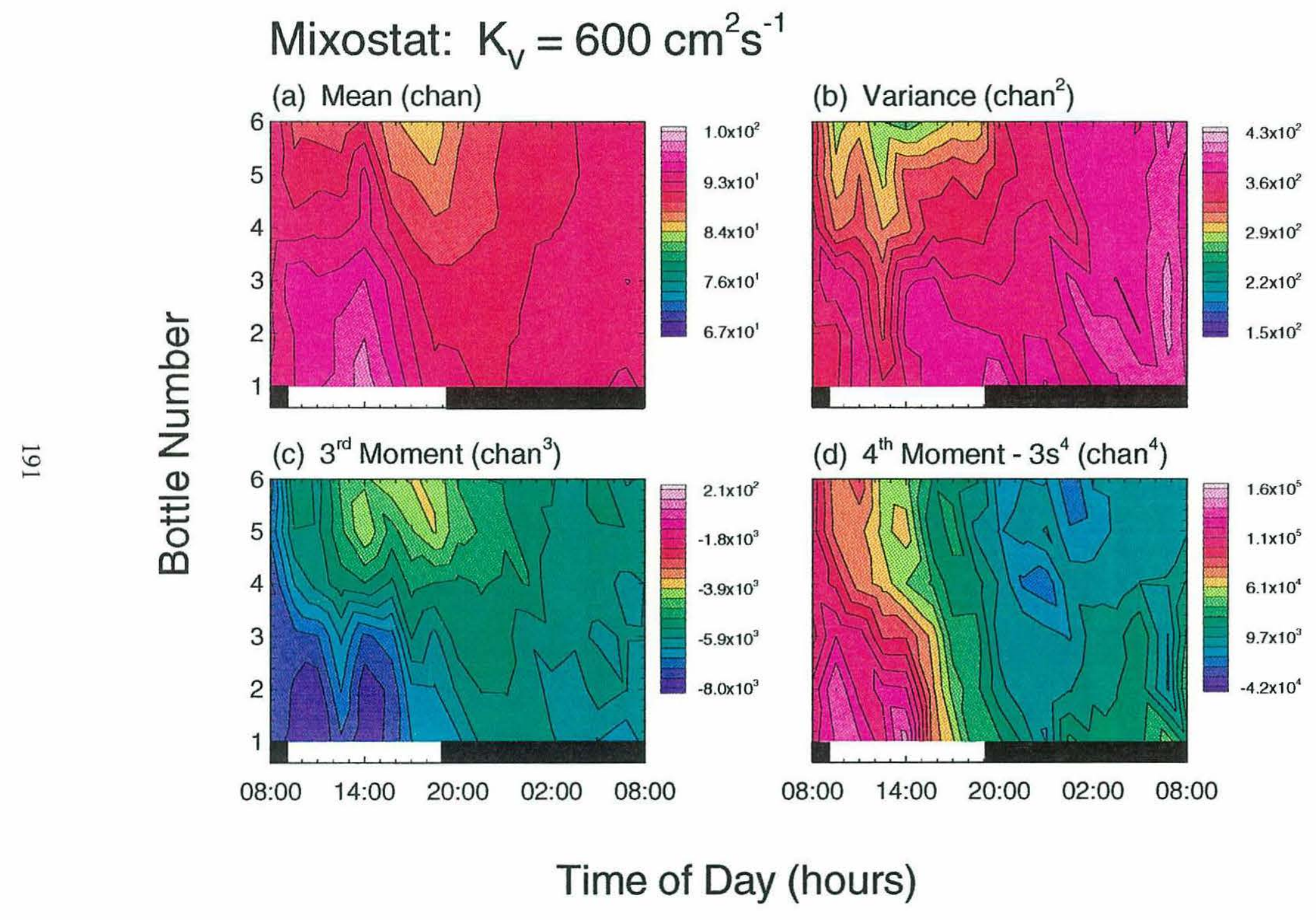


diffusion model of the mean and higher moments of $P$. marinus light scatter and fluorescence.

\section{Model Assumptions: Growth Model}

The growth model was developed as the continuous analog to the mixostat continuous culture system discussed above. This was modeled as a continuous system instead of a discrete system representing the six actual bottles in the mixostat system so that the equations presented here can be readily incorporated into a photoacclimation-diffusion model for a continuous mixed layer.

The model assumes a surface layer of depth, h, with constant mixing throughout parameterized by a constant diffusivity, $\mathrm{K}_{\mathrm{V}}$. Fresh nutrients are supplied across the boundary, but it was necessary to assume that cell densities below this layer are zero. Thus the flux of cells is strictly out of the mixed layer. In a continuous system subject to these assumptions, cell concentration, n, and substrate (nutrient) concentration, $\mathrm{S}$, can be modelled with one-dimensional diffusion equations:

$$
\begin{gathered}
\frac{\partial n}{\partial t}=K_{v} \frac{\partial^{2} n}{\partial z^{2}}+\mu n-D n \delta(z-h) \\
\frac{\partial S}{\partial t}=K_{v} \frac{\partial^{2} S}{\partial z^{2}}-\frac{\mu n}{Q}+D\left(S_{0}-S\right) \delta(z-h)
\end{gathered}
$$

where $\mathrm{n}$ and $\mathrm{S}$ are cell and substrate concentrations, respectively, $\mathrm{t}$ is time, $\mathrm{z}$ is depth, $\mathrm{K}_{\mathrm{v}}$ is the vertical diffusivity, $\mu$ is the growth rate of cells, $\mathrm{Q}$ is the cell quota for $\mathrm{S}$ and 
$\mathrm{D}$ is the effective dilution rate. The dirac delta terms represent flux out of the system across the lower boundary, and the flux of fresh substrate into the system at the same boundary. Growth is assumed a function of substrate concentration according to Monod kinetics:

$$
\mu=\frac{\mu_{m} S}{k_{m}+S}
$$

where $\mu_{\mathrm{m}}$ is the maximum growth rate (at a given light intensity) and $\mathrm{k}_{\mathrm{m}}$ is the halfsaturation constant. It was assumed that $\mathrm{k}_{\mathrm{m}}$ and $\mathrm{Q}$ were independent of depth and constant, ignoring growth dependence of Q (see Model Results: Growth Model below). Data from Moore et al. (1995) and growth rates from the laboratory experiment in Chapter III were fitted to an empirical relationship for $\mu_{\mathrm{m}}$ similar to that used by Platt et al. (1980) for photosynthesis:

$$
\mu_{m}=\mu_{m}^{s}\left(1-e^{-\alpha I / \mu_{m}^{s}}\right) e^{-\beta I / \mu_{m}^{s}}
$$

where I is the light intensity, $\alpha$ and $\beta$ are empirical constants, and $\mu_{\mathrm{m}}^{\mathrm{s}}$ is the maximum growth rate at saturating light intensities. Values of $\alpha=3.8 \times 10^{-2}, \beta=2.8 \times 10^{-4}$ and $\mu_{\mathrm{m}}^{\mathrm{s}}=0.62 \mathrm{~d}^{-1}$ were obtained by non-linear curve fitting software (Jandel Scientific, 1992).

Reflective boundary conditions were imposed at both the upper and lower boundaries:

$$
\frac{\partial n}{\partial z}=0 \quad \text { at } z=0, h
$$




$$
\frac{\partial S}{\partial z}=0 \quad \text { at } z=0, h
$$

Equations (3) through (8) define the growth dynamics for the continuous box model approximation to the mixostat system.

The growth model was solved for various substrate quotas ranging from $1.7 \mathrm{x}$ $10^{-16}$ to $6.7 \times 10^{-16}$ moles $\mathrm{N}$ per cell, representing C:N ratios in the range of 6 to 11 (R. Olson, personal communication) and cell diameters of 0.6 to $0.8 \mu \mathrm{m}$ (Chisholm et

al., 1988). Carbon content of P. marinus was assumed similar to Synechococcus spp.

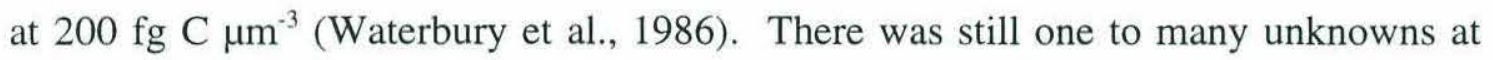
this point, so surface cell concentrations were taken as equal to the daily average in the unscreened bottle in the corresponding laboratory experiment.

Model simulations were done for diffusivities of $600,300,80$, and $40 \mathrm{~cm}^{2} \mathrm{~s}^{-1}$, corresponding to those diffusivities done experimentally in the lab.

\section{Model Assumptions: Photoacclimation - Diffusion Model}

Superimposed upon the dynamics of cell growth is the photoacclimation of individual cells in response to changes in light intensity induced by vertical mixing. Equation (1) was used to represent the time rate of change in a photoacclimative parameter, $\Gamma$. The fully acclimated value of the photoacclimative parameter, $\Gamma_{\infty}$, is represented as a linear function of depth (Appendix C, see also Chapter III). Reflective boundary conditions for $\Gamma$, similar to those for $\mathrm{n}$ and $\mathrm{S}$ in the growth model, are also imposed: 


$$
\frac{\partial \Gamma}{\partial z}=0 \quad \text { at } z=0, h
$$

Cell concentrations derived from the mixostat growth dynamics model were used to as an input to the photoacclimation diffusion model, which was solved using a finite difference numerical algorithm (Appendix E). The photoacclimation-diffusion model necessarily incorporates the 10:14 light:dark cycle, and a quasi-steady state solution was sought based on the 24-hour photoperiod such that each day is the same as the previous day. A photoacclimation rate, $\gamma$, of $3.5 \mathrm{~d}^{-1}$ was used for the light period (Appendix C). The photoacclimation rate was assumed to be zero during the dark phase. Model simulations were done for diffusivities of $600,300,80$, and 40 $\mathrm{cm}^{2} \mathrm{~s}^{-1}$, again corresponding to those diffusivities done experimentally in the lab.

\section{Model Results: Growth Model}

This model predicts a strong dependence of cell concentrations on $\mathrm{K}_{\mathrm{V}}$ (Fig. 11). Cell numbers show an increasing depth (bottle) gradient with decreasing mixing rates, as expected since mixing tends to homogenize the bottles. While both $\mathrm{S}$ and $\mu$ were found to be sensitive to Q (Fig. 12,13), cell concentration profiles depend primarily on the diffusivity, and were relatively insensitive to Q (Fig. 11). Time averaged cell concentrations from the mixostat show patterns very similar to that predicted by the model presented here (Fig. 2, 11).

The growth model predicts growth rates at the higher mixing rates (Fig. 13c, d) equivalent to light limited growth rates. Because the mixostat maintained steady-state 
Figure 11 - Cell concentrations predicted by the growth model for diffusivities of (a) $40 \mathrm{~cm}^{2} \mathrm{~s}^{-1}$, (b) $80 \mathrm{~cm}^{2} \mathrm{~s}^{-1}$, (c) $300 \mathrm{~cm}^{2} \mathrm{~s}^{-1}$ and (d) $600 \mathrm{~cm}^{2} \mathrm{~s}^{-1}$. Lines represent cell quotas of $1.7 \times 10^{-16} \mathrm{~mol} \mathrm{~N}_{\text {cell }}{ }^{-1}$ (solid), $4.5 \times 10^{-16} \mathrm{~mol} \mathrm{~N}^{-1 l^{-1}}$ (long dash) and $7.2 \times 10^{-16}$ mol $\mathrm{N} \mathrm{cell}^{-1}$ (short dash). Lines were not shown if cell quotas were too large for incoming nutrient concentrations to support cell concentrations observed in the unscreened bottle in the corresponding mixostat experiment. Symbols are timeaveraged concentrations from the mixostat observations (Fig. 2). 
Quota:

$\left(\mathrm{mol} \mathrm{N} \mathrm{cell}{ }^{-1}\right)$

$-1.7 \times 10^{-16}$

$---4.5 \times 10^{-16}$

-..-- $7.2 \times 10^{-16}$

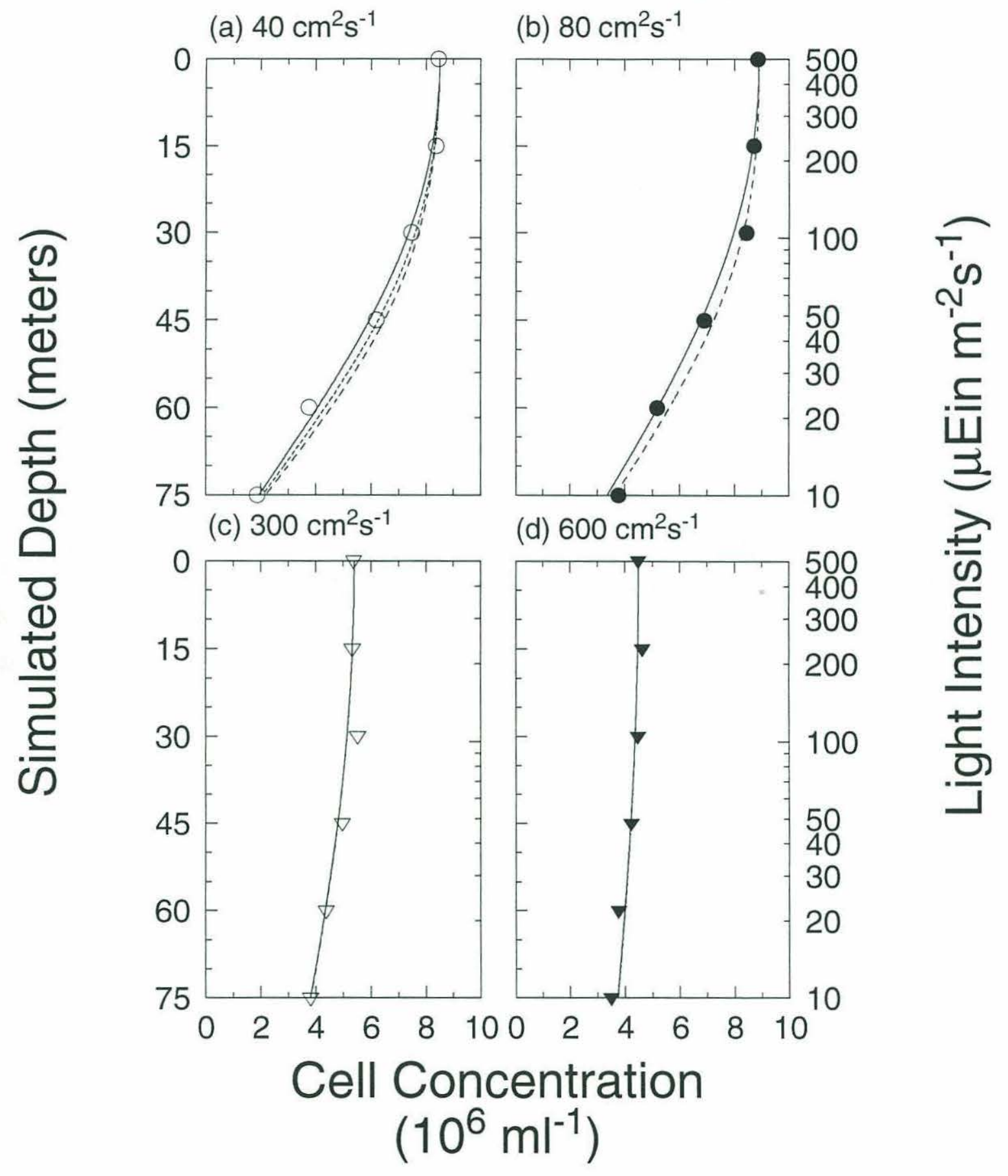


Figure 12 - Substrate (nitrogen) concentrations predicted by the growth model (as in figure 11) for diffusivities of (a) $40 \mathrm{~cm}^{2} \mathrm{~s}^{-1}$, (b) $80 \mathrm{~cm}^{2} \mathrm{~s}^{-1}$, (c) $300 \mathrm{~cm}^{2} \mathrm{~s}^{-1}$ and (d) $600 \mathrm{~cm}^{2} \mathrm{~s}^{-1}$. Lines represent cell quotas of $1.7 \times 10^{-16} \mathrm{~mol} \mathrm{~N}^{-1 l^{-1}}$ (solid), $4.5 \times 10^{-16}$ mol N cell ${ }^{-1}$ (long dash) and $7.2 \times 10^{-16} \mathrm{~mol} \mathrm{~N} \mathrm{cell}^{-1}$ (short dash). 
Quota:

(mol N cell ${ }^{-1}$ )

$-1.7 \times 10^{-16}$

$---4.5 \times 10^{-16}$

-..-- $7.2 \times 10^{-16}$

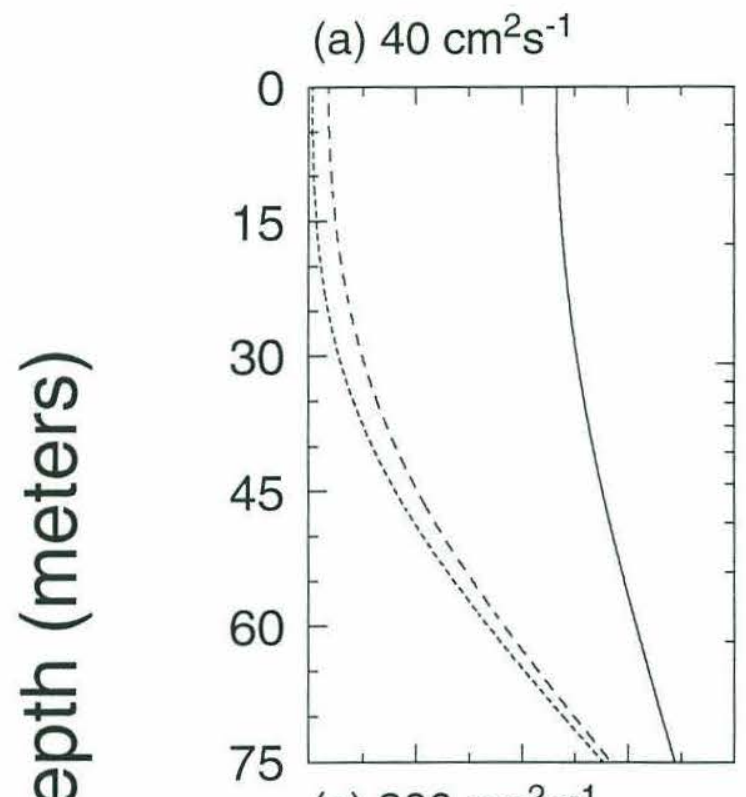

(b) $80 \mathrm{~cm}^{2} \mathrm{~s}^{-1}$

ด
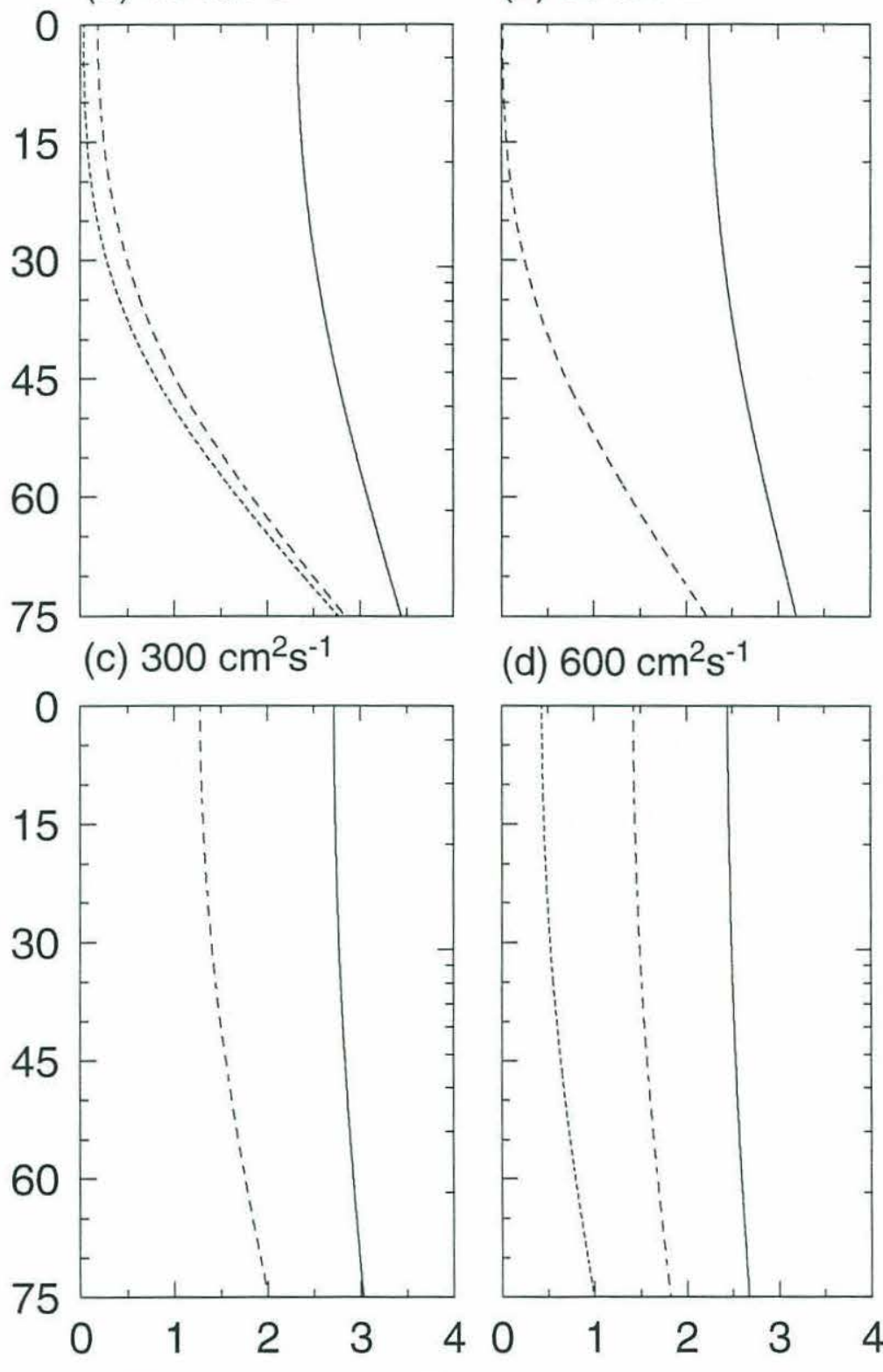

500

300

200

ర

(1)

元

है

(d) $600 \mathrm{~cm}^{2} \mathrm{~s}^{-1}$

100

T)

50

40

30

20

10

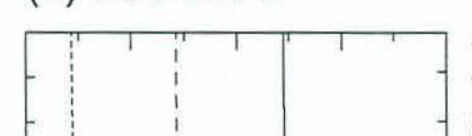

500

N

'E

들

Nitrogen Concentration

\section{$(\mu \mathrm{M})$}


Figure 13 - Growth rates predicted by the growth model (as in figure 11) for diffusivities of (a) $40 \mathrm{~cm}^{2} \mathrm{~s}^{-1}$, (b) $80 \mathrm{~cm}^{2} \mathrm{~s}^{-1}$, (c) $300 \mathrm{~cm}^{2} \mathrm{~s}^{-1}$ and (d) $600 \mathrm{~cm}^{2} \mathrm{~s}^{-1}$. Lines represent cell quotas of $1.7 \times 10^{-16} \mathrm{~mol} \mathrm{~N}$ cell $^{-1}$ (solid), $4.5 \times 10^{-16} \mathrm{~mol} \mathrm{~N}$ cell $^{-1}$ (long dash) and $7.2 \times 10^{-16} \mathrm{~mol} \mathrm{~N}^{-1 l^{-1}}$ (short dash). Light limited growth rates (based on Moore et al., 1995) are indicated. In (c) and (d), all simulations yielded growth rates that closely approximated the light limited growth rate. 


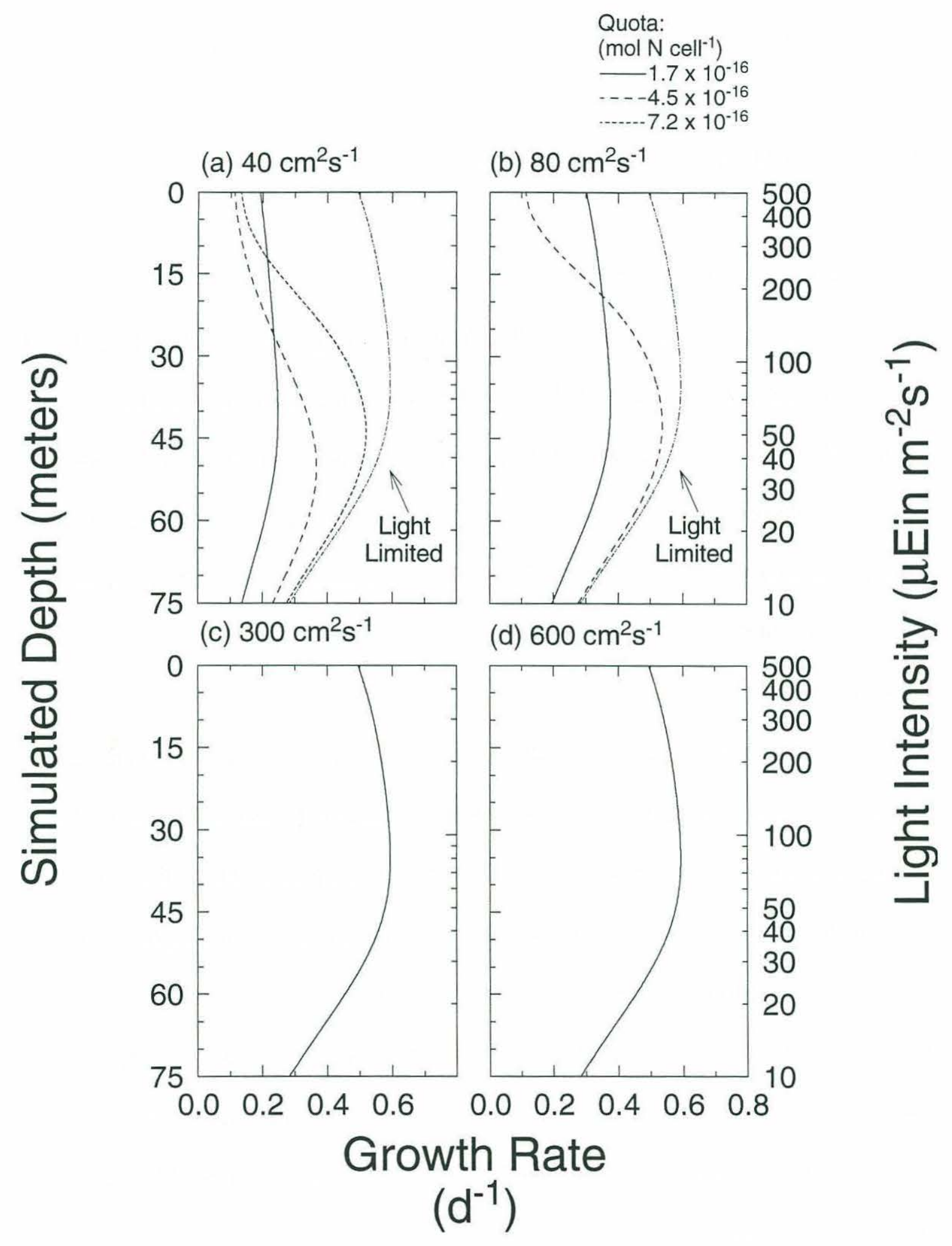


cell concentrations during these two simulations (no washout), this indicates a

maximum growth rate in the mixostat greater than the $0.62 \mathrm{~d}^{-1}$ (estimated from batch culture experiments) used here. There is no reason, a priori, to expect cultures under fluctuating light regimes to exhibit growth rates equivalent to those in steady light.

\section{Model Results: Photoacclimation-Diffusion Model}

Similar trends are evident in all four of the mixing rates modelled (Fig. 14-17). In each, a gradient in the mean value develops during the day as a result of photoacclimation; this gradient begins to break down immediately upon darkness, with the highest mixing rate $\left(600 \mathrm{~cm}^{2} \mathrm{~s}^{-1}\right)$ achieving homogeneity within the first few hours of darkness, similar to the results seen in the mixostat. Also as seen in the mixostat, the slower mixing rates were unable to attain homogeneity during the dark phase as modelled.

The variance further reflects the mixing dynamics. The nighttime variance decreases with increasing mixing rates (within the range explored here), due to the homogenization of a weaker gradient in $\Gamma$. Higher mixing rates during the day prevent the development of a strong gradient in $\Gamma$, mixing during the night simply homogenizes an already more nearly homogeneous mixed layer. In addition, patterns of change in the variance in $\Gamma$ during the light period show an initial tightening of the variance in all four mixing rates studied. This tightening is significantly faster than the change in the mean values, in agreement with Lande and Lewis's (1988) finding that the variance responds at a time scale of $2 \gamma^{-1}$. 
At the higher mixing rates, the variance begins to increase after this initial tightening. This is analogous to Lande and Lewis' (1988) finding that the variance was proportional to $\mathrm{K}_{\mathrm{v}} \mathrm{b}^{2} \gamma^{-1}$ (at steady state, in the absence of boundary effects), where b was the gradient $\left(\partial \Gamma_{\infty} / \partial z\right)$ in the fully acclimated photoacclimative property. Here, in a time-dependent model, the development of a gradient in the mean must precede the increase in variance. This increase in variance at the end of the light period is not as pronounced in the slower mixing rates modelled (Fig. 14-15), showing that both sufficient mixing and a gradient in the mean of the photoacclimative property are necessary to increase the variance in a photoacclimative property.

The third moment, an indicator of the skewness of the distribution, shows positive values at the surface boundary and negative values at the lower boundary as would be expected from boundary effects (Fig. 14-17c) (see also Chapter IV). This skewing shows a maxima and minima away from the boundaries rather than at the boundaries, similar to results seen in stationary model simulations (Chapter IV, Fig. 4). These maxima and minima correspond to a transition between the near boundary homogeneity seen in the mean and the sharper gradient seen in the interior. It thus gives a direct indication of boundary effects. The mixostat shows a slight, but rather limited semblance to these patterns (Fig. 7-10c).

The "corrected" fourth moment (Fig. 14-17d) shows patterns that complement those seen in the third moment. The interior region shows more negative corrected fourth moment, suggesting flattened distributions. This is expected from the interior gradient in the mean values coupled with the reflective boundary effects. The 
Figure 14 - Model simulations (Eq. 7 and 8) of the mean and higher moments of a photoacclimative property, $\Gamma$, in a mixed layer with a diffusivity of $40 \mathrm{~cm}^{2} \mathrm{~s}^{-1}$, and a photoacclimative rate, $\gamma$, of $3.5 \mathrm{~d}^{-1}$. Plots show the (a) mean, (b) variance, (c) third moment, and (d) fourth moment less three times the standard deviation raised to the fourth power. A 10:14 light-dark cycle was used, with the black boxes representing the period when the lights are "off" in the model. The photoacclimation rate was assumed to be zero during this dark period. Units are a non-dimensional log-scaling of the ratio between the photoacclimative optimum, $\Gamma_{\infty}$, at the base of the mixed layer to that at the surface. 


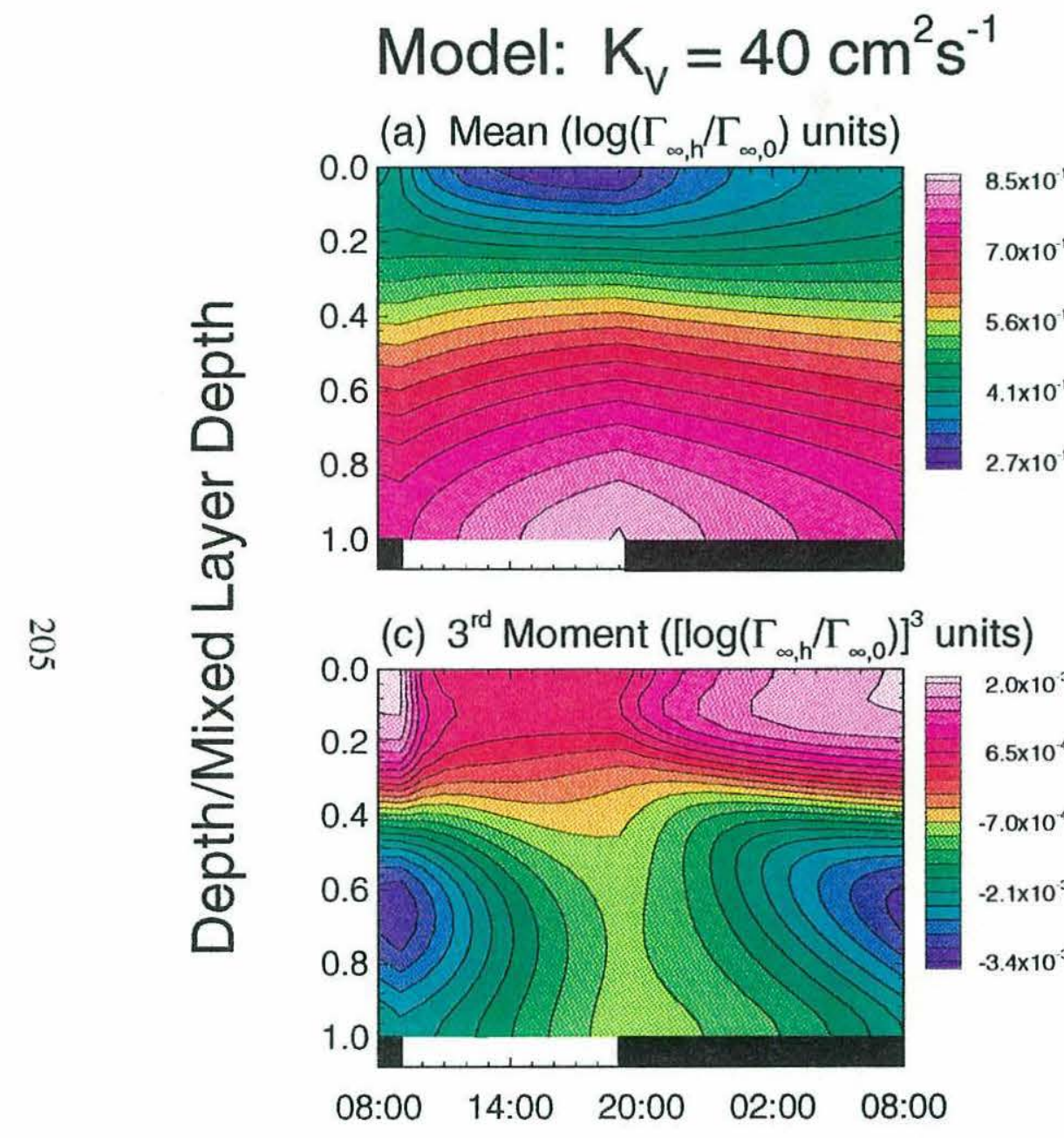

(b) Variance $\left(\left[\log \left(\Gamma_{\infty, h} / \Gamma_{\infty, 0}\right)\right]^{2}\right.$ units $)$

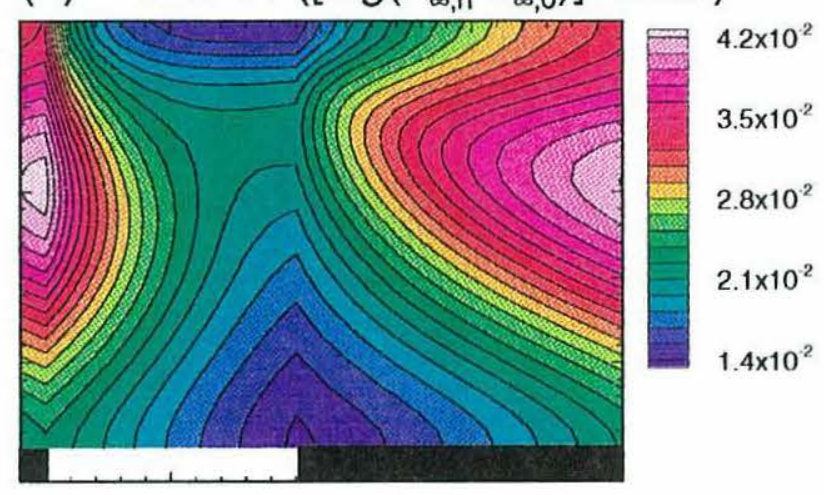

(d) $4^{\text {th }}$ Moment $-3 s^{4}\left(\left[\log \left(\Gamma_{\infty, \mathrm{h}} / \Gamma_{\infty, 0}\right)\right]^{4}\right.$ units $)$

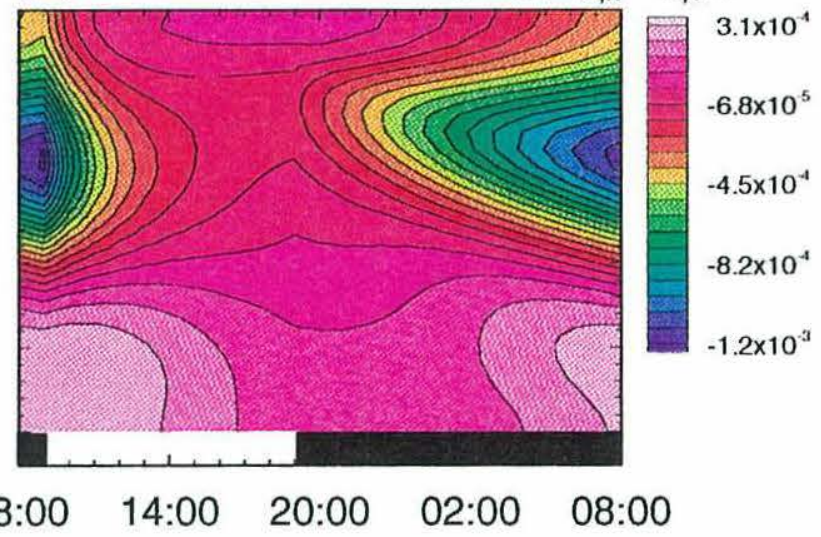

Time of Day (hours) 
Figure 15 - Model simulations (Eq. 7 and 8) of the mean and higher moments of a photoacclimative property, $\Gamma$, in a mixed layer with a diffusivity of $80 \mathrm{~cm}^{2} \mathrm{~s}^{-1}$, and a photoacclimative rate, $\gamma$, of $3.5 \mathrm{~d}^{-1}$. Plots show the (a) mean, (b) variance, (c) third moment, and (d) fourth moment less three times the standard deviation raised to the fourth power. A 10:14 light-dark cycle was used, with the black boxes representing the period when the lights are "off" in the model. The photoacclimation rate was assumed to be zero during this dark period. Units are a non-dimensional log-scaling of the ratio between the photoacclimative optimum, $\Gamma_{\infty}$, at the base of the mixed layer to that at the surface. 


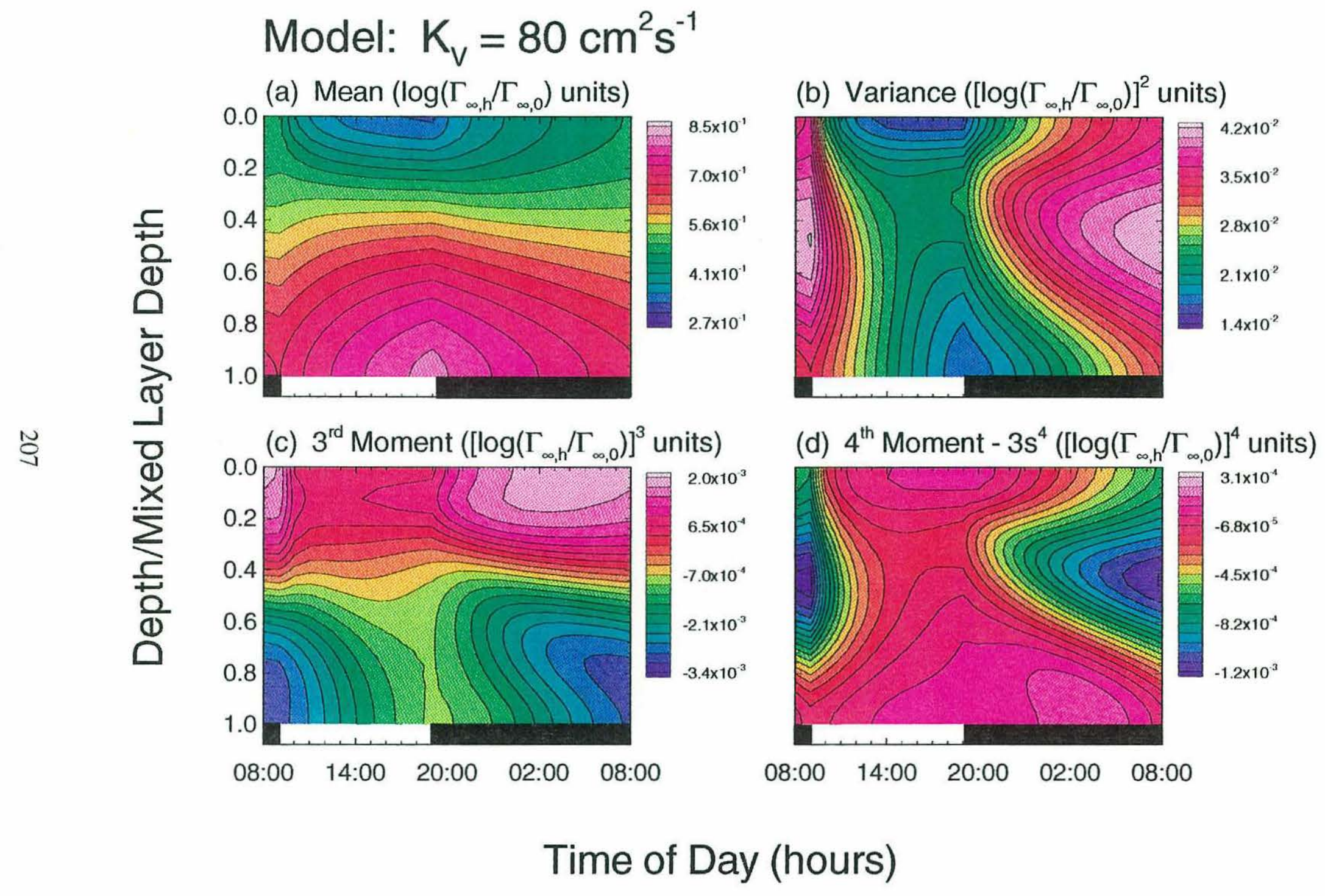


Figure 16 - Model simulations (Eq. 7 and 8) of the mean and higher moments of a photoacclimative property, $\Gamma$, in a mixed layer with a diffusivity of $300 \mathrm{~cm}^{2} \mathrm{~s}^{-1}$, and a photoacclimative rate, $\gamma$, of $3.5 \mathrm{~d}^{-1}$. Plots show the (a) mean, (b) variance, (c) third moment, and (d) fourth moment less three times the standard deviation raised to the fourth power. A 10:14 light-dark cycle was used, with the black boxes representing the period when the lights are "off" in the model. The photoacclimation rate was assumed to be zero during this dark period. Units are a non-dimensional log-scaling of the ratio between the photoacclimative optimum, $\Gamma_{\infty}$, at the base of the mixed layer to that at the surface. 


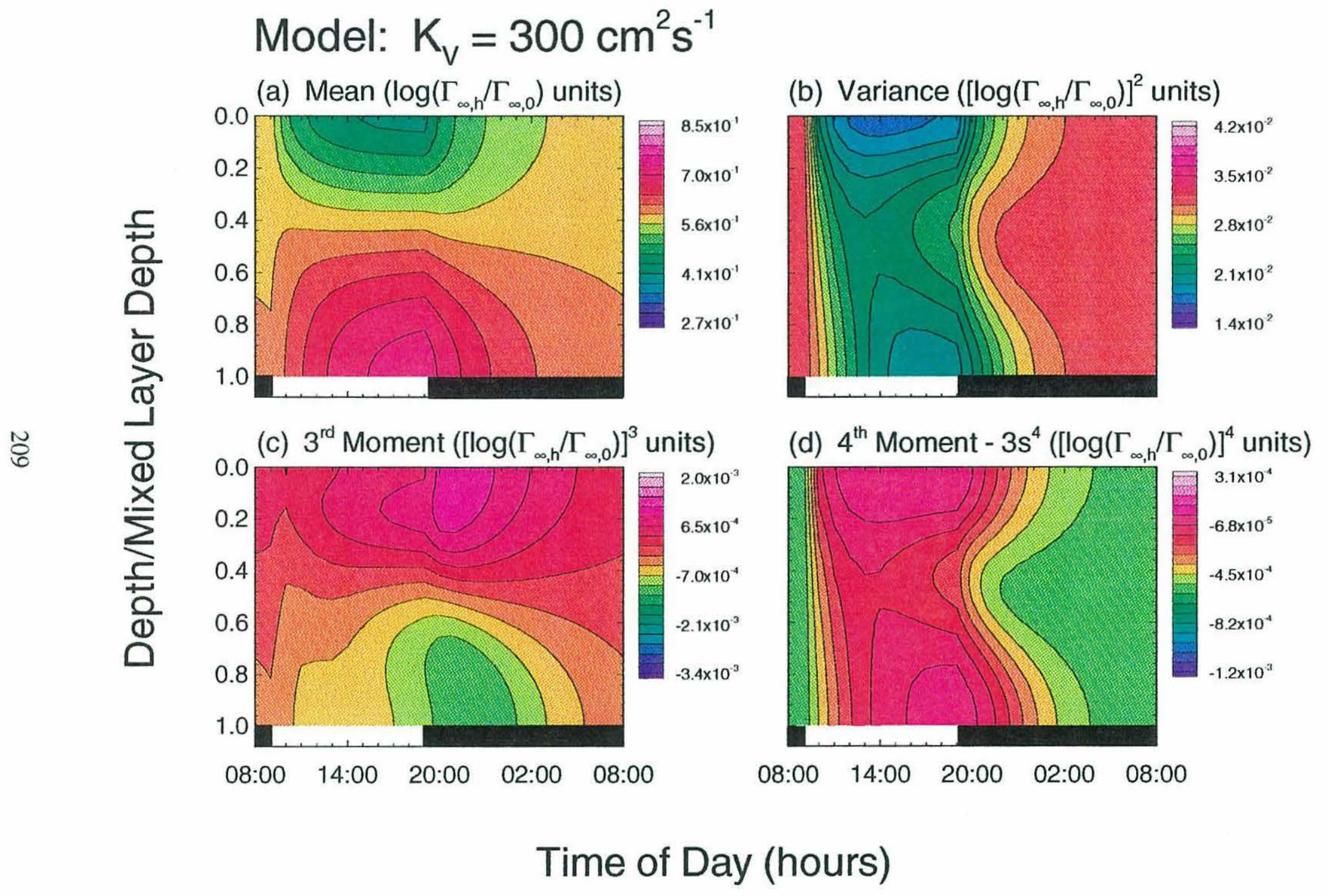


Figure 17 - Model simulations (Eq. 7 and 8) of the mean and higher moments of a photoacclimative property, $\Gamma$, in a mixed layer with a diffusivity of $600 \mathrm{~cm}^{2} \mathrm{~s}^{-1}$, and a photoacclimative rate, $\gamma$, of $3.5 \mathrm{~d}^{-1}$. Plots show the (a) mean, (b) variance, (c) third moment, and (d) fourth moment less three times the standard deviation raised to the fourth power. A 10:14 light-dark cycle was used, with the black boxes representing the period when the lights are "off" in the model. The photoacclimation rate was assumed to be zero during this dark period. Units are a non-dimensional log-scaling of the ratio between the photoacclimative optimum, $\Gamma_{\infty}$, at the base of the mixed layer to that at the surface. 


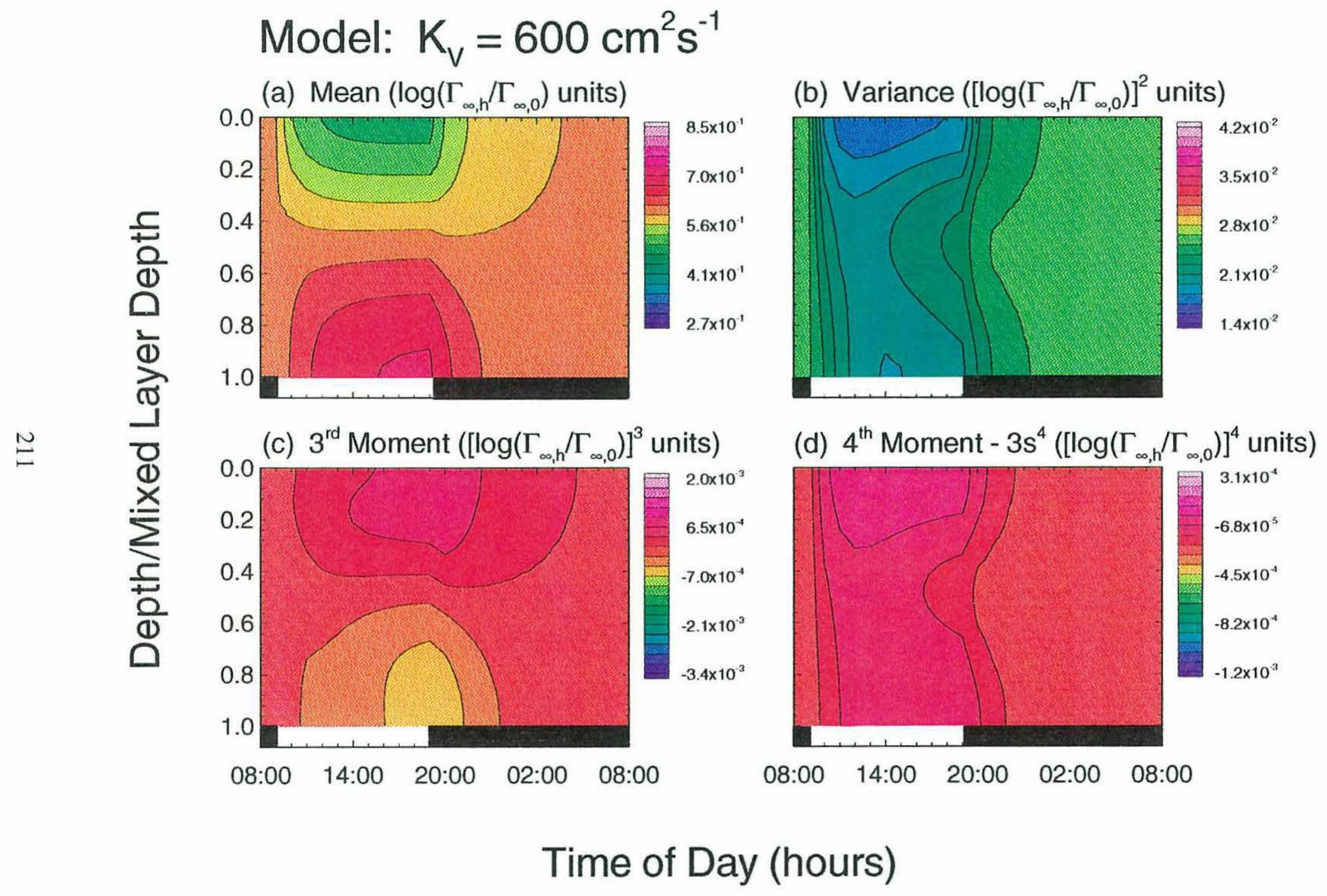


boundaries effectively limit contributions at the tails of the interior distributions.

Both the mean and higher moments show attenuated gradients with increasing mixing. This seems to be a result of the range of values chosen to be modelled here. Stationary model results (Chapter IV, Fig. 3-5) show maxima and minima for the higher moments (as a function of the ratio of photoacclimation and mixing time scales) in a region of intermediate mixing rates. The lowest diffusivity modelled here, $40 \mathrm{~cm}^{2} \mathrm{~s}^{-1}$, corresponds to a value for the ratio of the photoacclimative time scale to the mixing time scale, $\mathrm{K}_{\mathrm{v}} \gamma^{-1} \mathrm{~h}^{-2}$, of $1.8 \times 10^{-2}$, which is near the region of maxima and minima in the stationary model (Chapter IV, Fig. 3-5). I would therefore expect that higher mixing rates should result in weaker gradients in the higher moments with time and depth as seen here. I would further expect that slower mixing rates than the 40 $\mathrm{cm}^{2} \mathrm{~s}^{-1}$ modelled here should yield a similar response (i.e. weaker gradients with decreasing mixing rates). 


\section{Discussion}

Using a variation of the standard cyclostat and the SEDA apparatus of Gallegos and Platt (1982), a system was developed which can be used to simulate the effects of a random walk among individual phytoplankton cells. Nutrient supply, light levels and light gradient, and mixing rates can all be regulated independently, simulating differing mixing environments. The system can simulate the random walk, and produces picoplankton fluorescence distributions in P. marinus strain Med4 which have characteristics consistent with both model and field observations.

Model analysis suggests that gradients in cell concentrations in the laboratory experiment are primarily influenced by mixing rates, and relatively insensitive to nutrient uptake kinetics. This system shows how we might expect a nutrient that is supplied from below the mixed layer (or perhaps from above - through the air-sea interface) to affect growth within the mixed layer. Picoplankton cell concentrations in the field tend to be homogeneous (in our observations) throughout the mixed layer, indicating either rapid mixing at some point during the day to reestablish homogeneity or that (net) growth rates in the field show insufficient gradient with depth to drive a gradient in cell number.

Mixing rates and photoacclimation have a significant effect on picoplankton single cell light scatter and fluorescence properties and their distributions. This effect can be predicted using a simple single cell one-dimensional photoacclimation-diffusion model. The laboratory, model, and field data show similarities, particularly in the variance of the photoacclimative parameter. All show tightening of distributions 
(decreased variance) during the daytime due to photoacclimation and homogenization of these distributions with resultant increase in variance during the nighttime due to mixing in the absence of photoacclimation. A cruise to the Sargasso Sea time-series shows a region of relatively high variance in Prochlorococcus spp. normalized red fluorescence at the end of the day (Chapter II, Fig. 8b, 20 m). This effect is also predicted by the quasi-steady model presented here, with increasing variance in the photoacclimative parameter following the development of a gradient in the mean (see Model Results: Photoacclimation-Diffusion Model above).

\section{Acknowledgments}

I thank Zackary Johnson and Jim Falter for technical assistance in building the mixostat; Sheila Frankel, Erin Graham, Zackary Johnson, Liz Mann, Sebastién Morel, Nicole Poulton, Charu Puri, Laurel Schaider, Ena Urbach and Alex Worden for assistance with operation and experimental data collection; and Lisa Moore for providing the starting culture of $P$. marinus strain Med4. I thank Daniel Vaulot for the use of CYTOPC. I thank Rob Olson and Penny Chisholm for helpful discussions.

This work was supported by ONR (N00014-87-K-0007 to S. W. Chisholm and R. J. Olson), NSF (BSR 90-20254 and OCE 90-00043 to S. W. C., OCE 90-12117, OCE 90-22285, and DIR 91-01361 to S. W. C. and R. J. O.), M.I.T Sloan Funds and M.I.T. Department of Civil and Environmental Engineering funds (both to S. W. C.). J. A. D. was supported in part by an NSF graduate fellowship and a Rockwell fellowship. 


\section{References}

Bazin, M. J. 1981. Theory of continuous culture. in: Continuous Cultures of Cells Volume I. P. H. Calcott (ed.). CRC Press. Boca Raton, Florida. 27-62.

Chisholm, S. W. and others. 1992. Prochlorococcus marinus nov. gen. nov. sp.: An oxyphototrophic marine prokaryote containing divinyl chlorophyll $a$ and $b$. Arch. Microbiol. 157:297-300.

Chisholm, S. W., R. J. Olson, E. R. Zettler, R. Goericke, J. B. Waterbury and N. A. Welschmeyer. 1988. A novel free-living prochlorophyte abundant in the oceanic euphotic zone. Nature. 334:340-343.

Cullen, J. J. and M. R. Lewis. 1988. The kinetics of algal photoadaptation in the context of vertical mixing. J. Plankton Res. 10:1039-1063.

Dusenberry, J. A. and S. L. Frankel. 1994. Increasing the sensitivity of a FACScan flow cytometer to study oceanic picoplankton. Limnol. Oceanogr. 39:206-209.

Falkowski, P. G. 1983. Light-shade adaptation and vertical mixing of marine phytoplankton: A comparative field study. J. Mar. Res. 41:215-237.

Falkowski, P. G. and C. D. Wirick. 1981. A simulation model of the effects of vertical mixing on primary productivity. Mar. Biol. 65:69-75.

Gallegos, C. L. and T. Platt. 1982. Phytoplankton production and water motion in surface mixed layers. Deep-Sea Res. 29:65-76.

Geider, R. J. and T. Platt. 1986. A mechanistic model of photoadaptation in microalgae. Mar. Ecol. Prog. Ser. 30:85-92.

Jandel Scientific. 1992. Sigmaplot Scientific Graph System. Jandel Corporation. San Rafael, CA.

Kirkpatrick, G. J., T. B. Curtin, D. Kamykowski, M. D. Feezor, M. D. Sartin and R. E. Reed. 1990. Measurement of photosynthetic response to euphotic zone physical forcing. Oceanography. 3:18-22.

Laws, E. A. and T. T. Bannister. 1980. Nutrient- and light-limited growth of Thalassiosira fluviatilis in continuous culture, with implications for phytoplankton growth in the ocean. Limnol. Oceanogr. 25:457-473.

Lewis, M. R., J. J. Cullen and T. Platt. 1984. Relationships between vertical mixing and photoadaptation of phytoplankton: Similarity criteria. Mar. Ecol. Prog. Ser. 


\section{5:141-149.}

Lewis, M. R. and J. C. Smith. 1983. A small volume, short-incubation-time method for measurement of photosynthesis as a function of incident irradiance. Mar. Ecol. Prog. Ser. 13:99-102.

Marra, J. 1978a. Effect of short-term variations in light intensity on photosynthesis of a marine phytoplankter: A laboratory simulation study. Mar. Biol. 46:191-202.

Marra, J. 1978b. Phytoplankton photosynthetic response to vertical movement in a mixed layer. Mar. Biol. 46:203-208.

Moore, L. R., R. Goericke and S. W. Chisholm. 1995. The comparative physiology of Synechococcus and Prochlorococcus: Influence of light and temperature on growth, pigments, fluorescence and absorptive properties. Mar. Ecol. Prog. Ser. (in press).

Rivkin, R. B. 1990. Photoadaptation in marine phytoplankton: Variations in ribulose 1,5-bisphosphate activity. Mar. Ecol. Prog. Ser. 62:61-72.

Sokal, R. R. and F. J. Rohlf. 1981. Biometry, Second Edition. W. H. Freeman and Company. New York.

Therriault, J.-C., D. Booth, L. Legendre and S. Demers. 1990. Phytoplankton photoadaptation to vertical excursion as estimated by an in vivo fluorescence ratio. Mar. Ecol. Prog. Ser. 60:97-111.

Waterbury, J. B., S. W. Watson, F. W. Valois and D. G. Franks. 1986. Biological and ecological characterization of the marine unicellular cyanobacterium Synechococcus. in: Photosynthetic Picoplankton. T. Platt and W. K. W. Li (eds.). Can. Bull. Fish. Aquatic Sci. 71-120. 
Chapter VI

\section{Future Directions}




\section{Future Directions}

I present in this thesis a framework for investigating the implications of vertical mixing on phytoplankton physiology and also the potential for the use of physiological properties measured at the individual cell level to infer mixing processes. This thesis presents several avenues for future research, in each of the modes used in this work: field, laboratory, and modelling efforts.

\section{Field}

Field observations of picophytoplankton single cell light scatter and fluorescence properties coupled directly with microstructure measurements of mixing dynamics should facilitate calibration and validation of modelling efforts. Calibration and validation efforts are currently limited to laboratory experiments under controlled mixing rates.

Another interesting aspect of field studies is the characterization of Synechococcus spp. light scatter and fluorescence properties. Because of the limited sample volumes analyzed for the purposes of this research, Synechococcus spp. population data is sparse. Prochlorococcus spp. generally outnumber the Synechococcus spp. by a factor of 3-10 in the locales sampled here. Use of faster sample flow rates on the flow cytometer would allow quantification of sufficient numbers of Synechococcus spp. to obtain accurate estimates of the distribution of optical properties within a sample population. The benefits of looking at Synechococcus spp. data are two-fold: it allows validation of model efforts with a 
second, independent organism, and it facilitates physiological comparisons of Synechococcus spp. and Prochlorococcus spp.

Field time-series observations from mixing environments not presented here would also help round out the field picture. Unfortunately, it is difficult to plan what will happen in the field before beginning a sampling program. One interesting situation for study would be a deep-mixed layer without diurnal stratification.

However, such mixed layers are typically found under conditions unfavorable for overthe-side shipboard research (high winds, high seas). An additional situation which should lead to a better understanding of high light photoacclimation kinetics is to study a well stratified surface layer (i.e. shallow seasonal mixed layer) (see Appendix A). In the past, such systems have been difficult to study due to a lack of necessary sensitivity in instrumentation to study the dim surface cells. Improvements in instrument sensitivity (Olson et al., 1990; Dusenberry and Frankel, 1994) should make dim Prochlorococcus spp. from stratified surface waters easier to detect and quantify.

\section{Laboratory}

As discussed in Chapter III, acclimation to high light levels appears to be fundamentally different than acclimation to "intermediate" light levels, even if cells were previously acclimated to a low light level. This is especially evident in the apparent increase in normalized fluorescence during the nighttime for the high-light shifted cells in the experiment presented in Chapter III. At intermediate intensities, the dominant mechanism appears to be more of a dilution effect (increase in forward 
angle light scatter or size) rather than a degradation effect (decrease in red autofluorescence) as seen at higher light levels. In order to fully understand the kinetics of acclimation to a fluctuating light environment, these processes need further quantification.

The mixostat apparatus has several extensions into future research. It is an ideal tool for studying the effects of continuous random movements through a light gradient on any number of phytoplankton physiological properties or productivity. Of particular interest is the kinetics of change in pigment concentrations in a dynamic environment, and the relationship between these changes and productivity.

Because the mixostat is a continuous culture system and can generate simultaneous light and nutrient gradients, ecological studies can be conducted involving the coexistence of two or more types or species of organisms. With slight modifications, is should also be possible to incorporate temperature gradients, further increasing the usefulness of the system. As an example, the coexistence of several strains of Prochlorococcus marinus or of Prochlorococcus spp. and Synechococcus spp. can be explored under conditions of different nutrient and light levels. If appropriate organisms are selected, it is conceivable that both should be able to occupy the apparatus at steady-state, with each organism in its own "niche" within the mixostat.

\section{Modelling}

The modelling efforts presented in this thesis can be improved upon in several 
ways. The stationary model presented in Chapter IV could be extended to a time dependent model. Given some initial conditions, one could thus track the change in distributions of photoacclimative properties with time. In addition, a depth and time dependence of the diffusivity, $\mathrm{K}_{\mathrm{V}}$, can be incorporated. Both of these changes allow for a more realistic representation of the physical dynamics of the open ocean.

Another aspect of future model efforts is the inclusion of different eddy sizes into the model instead of using the simple parameterization of a diffusivity. This would allow separation of the length and time scales for mixing. 


\section{References}

Dusenberry, J. A. and S. L. Frankel. 1994. Increasing the sensitivity of a FACScan flow cytometer to study oceanic picoplankton. Limnol. Oceanogr. 39:206-209.

Olson, R. J., S. W. Chisholm, E. R. Zettler, M. A. Altabet and J. A. Dusenberry. 1990. Spatial and temporal distributions of prochlorophyte picoplankton in the North Atlantic Ocean. Deep-Sea Res. 37:1033-1051. 
Appendix A

Chapter II Ancillary Data 


\section{Chapter II Ancillary Data}

Sargasso Sea, Oligotrophic, January 1992

I present here raw data for Prochlorococcus spp. light scatter and fluorescence from a time-series of samples taken from the Sargasso Sea $\left(26^{\circ} 51^{\prime} \mathrm{N}, 67^{\circ} 44^{\prime} \mathrm{W}\right)$ in January 1992. The sample collection and data analysis methods are the same as in Chapter II for the deep-mixed layer time series. These results are from a well stratified oligotrophic region (Fig. 1), and were included as an appendix rather than in Chapter II because the FACScan was not sufficiently sensitive to detect all of the extremely dim Prochlorococcus spp. from the near surface samples. However, these populations exhibit interesting patterns in light scatter and fluorescence that are worth noting for their similarities to laboratory results (see below).

This time-series shows a markedly different diel pattern in Prochlorococcus spp. mean forward angle light scatter and red fluorescence (Fig. 2). Because part of the surface populations (during the day, Fig. 2) were not detected during flow cytometric analysis, surface cell concentrations will be underestimated while red fluorescence will be overestimated. Prochlorococcus spp. forward angle light scatter remains essentially constant, unlike the strong patterns seen during the time-series presented in Chapter II (Chapter II, Fig. 5, 7). These cells display more than a factor of two larger signal in forward angle light scatter than those in the October Sargasso Sea time-series (Chapter II, Fig. 5). In this larger forward scatter region, the forward scatter signal may respond less strongly to cell size (Appendix B). As a result, 
Figure 1 - Density (sigma-theta) measurements from a time-series of profiles taken in the Sargasso Sea $\left(26^{\circ} 51^{\prime} \mathrm{N}, 67^{\circ} 44^{\prime} \mathrm{W}\right)$ in January 1992. Near surface values were unreliable. However, there is a suggestion of near homogeneity in the upper $20 \mathrm{~m}$ during the first day, with a thermocline immediately below. The second day has a deeper seasonal thermocline, indicating a change in water mass. During this second day, there is also an indication of surface warming during the day, resulting in a shoaling of the mixed layer. 


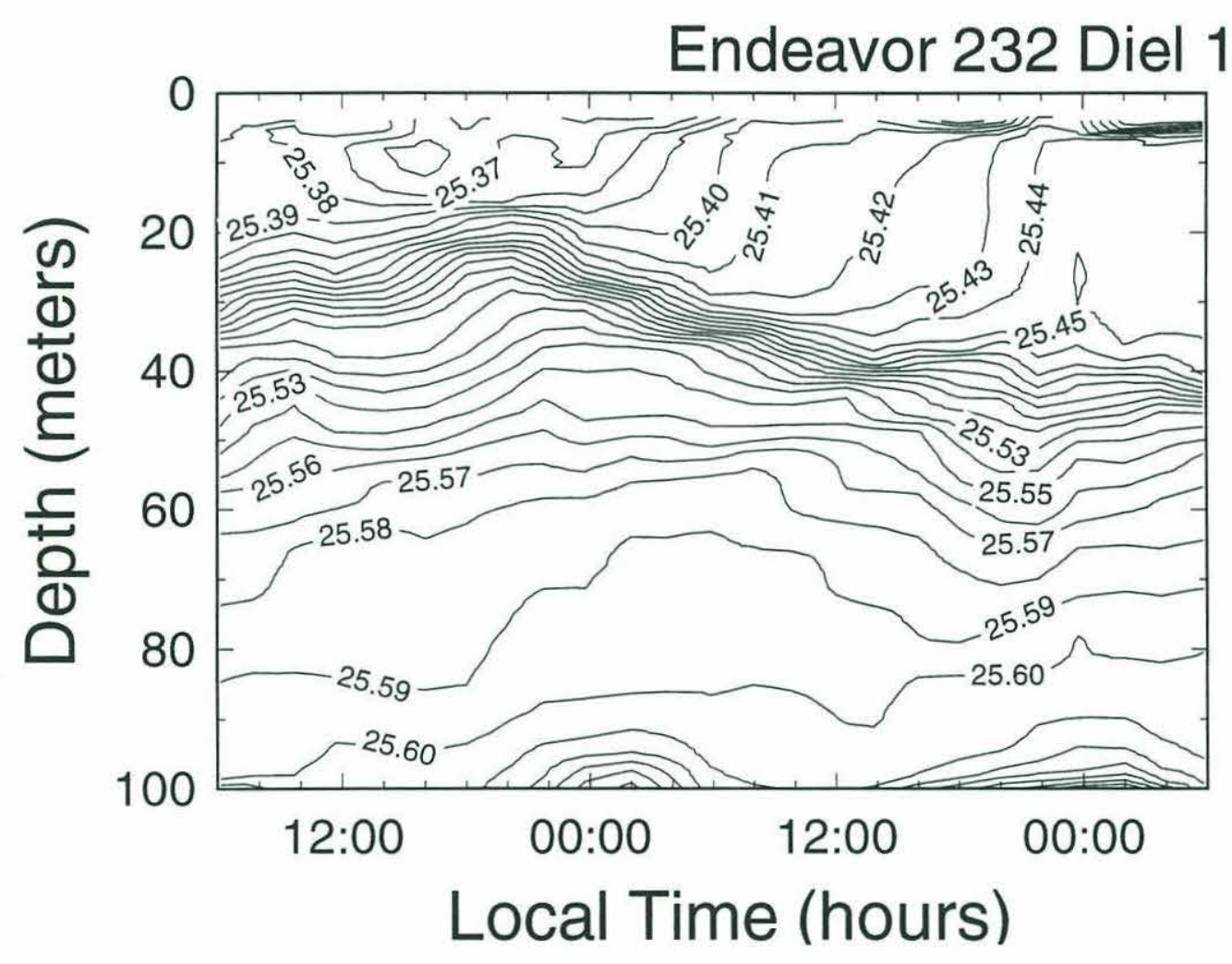


Figure 2 - Flow cytometric observations of Prochlorococcus spp. for the upper $50 \mathrm{~m}$ from the same time-series of figure 1. Cell concentration (a), mean forward angle light scatter (b), mean red autofluorescence (c), and the mean red fluorescence normalized to the cube root of the mean forward angle light scatter (d) were determined using a FACScan flow cytometer. Fluorescence and scatter measurements are all relative to $0.57-\mu \mathrm{m}$ microspheres ("beads"). 
Endeavor 232 Diel 1
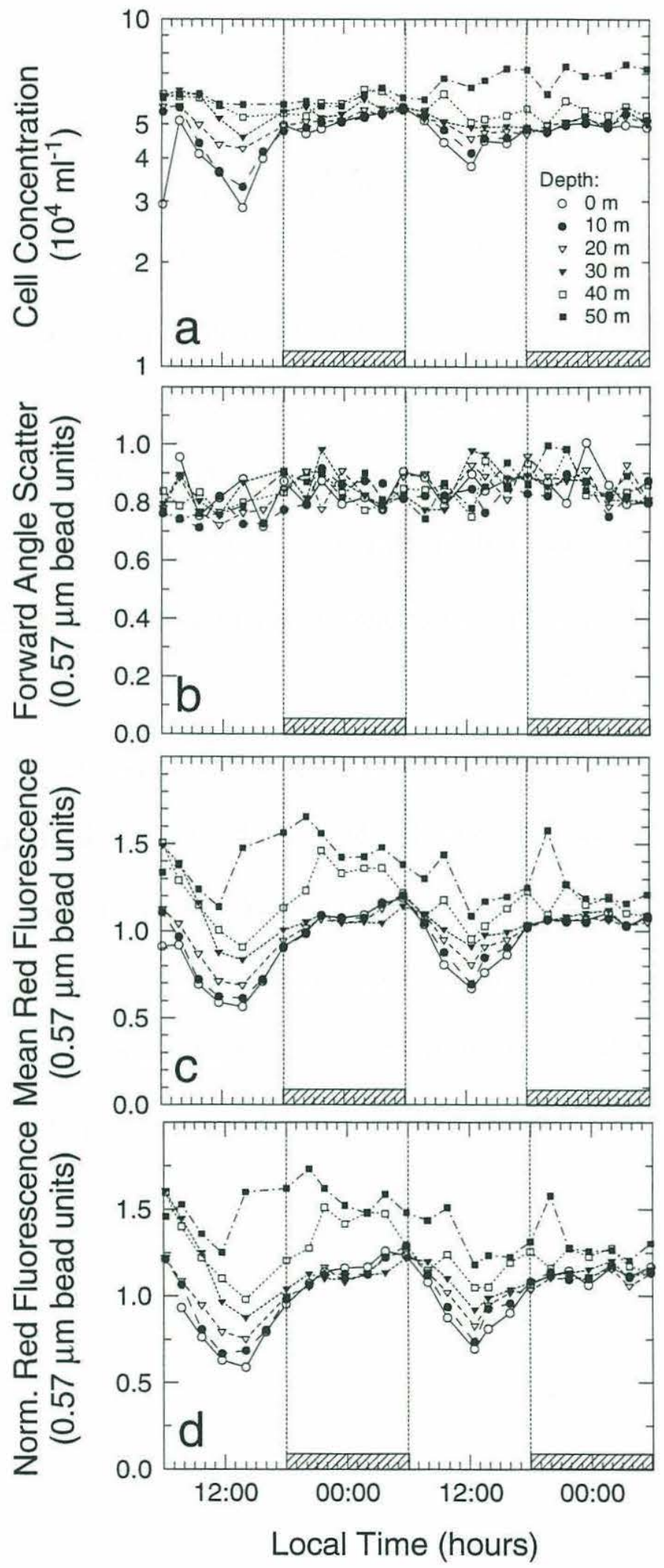
changes in forward scatter corresponding to cell division could be significantly less strong. Cell division may also not be phased or the growth rate may be insufficiently large to cause a detectable pattern in forward angle light scatter (Appendix B).

Because of the lack of change in the forward angle light scatter signal, the normalized red fluorescence (Fig. 2d) shows essentially the same patterns as the mean non-normalized red fluorescence (Fig. 2c). Both show a depression in fluorescence beginning at dawn and continuing until early afternoon on both days. This depression is similar to that seen in the laboratory in batch cultures of Prochlorococcus marinus strain Med4 grown at high light intensities ( $>320 \mu \mathrm{E} \mathrm{m} \mathrm{m}^{2} \mathrm{~s}^{-1}$ or about $40-50 \mathrm{~m}$ here) (Chapter III, Fig. 2, 5) and in field bottle incubations at near surface intensities (Chapter III, Fig. 16, 17).

The water column during the first day of this time-series is more strongly stratified than that seen in the October Sargasso Sea time-series discussed in Chapter II. Cells near the surface would thus be expected to spend more time at (or be "trapped" at) high light intensities. These observations seem to indicate that this strong depression followed by an increase in red fluorescence occurs when cells are "trapped" at high light intensities, either in bottles or due to stratified conditions. 


\section{Appendix B}

\section{Use of Forward Angle Light Scatter as a Proxy for Size in Prochlorococcus marinus Strain Med4}




\section{Use of Forward Angle Light Scatter as a Proxy for Size in Prochlorococcus marinus Strain Med4}

I present here an indirect method to determine the relationship between forward angle light scatter as measured on a modified FACScan flow cytometer (Dusenberry and Frankel, 1994) and relative cell volume. While the relationship presented here applies only to Prochlorococcus marinus strain Med4 measured with the FACScan in our laboratory, the method should be applicable for other strains of picoplankton and instruments as well.

\section{Methods}

This method is based on the dynamics of a population of cells undergoing phased division, on a one burst per day cycle. This population shortly before division can be divided into two cohorts, cohort 1 and cohort 2, representing those that will and will not divide, respectively. The relative numbers in each of these cohorts is represented by $n_{1}$ and $n_{2}$, respectively, with $N_{0}=n_{1}+n_{2}$ being the total number of cells before division and $\mathrm{N}_{\mathrm{t}}=2 \mathrm{n}_{1}+\mathrm{n}_{2}$ the number of cells after division. The underlying assumption is that total cell volume is conserved during the division process. Assuming a power relationship such that the volume, $\mathrm{V}$, is proportional to some power of forward angle light scatter, FSC:

$$
V \propto F S C^{y}
$$

discussion is facilitated by the use of geometric mean values as opposed to arithmetic 
mean values. All mean values here represented by the overbar indicate geometric mean values. The (geometric) mean volume, $\overline{\mathrm{V}}_{0}$, before division is given by:

$$
N_{0} \ln \overline{V_{0}}=\sum_{i=1}^{n_{1}} \ln V_{1 i}+\sum_{j=1}^{n_{2}} \ln V_{2 j}
$$

Assuming that the each cell in the first cohort divides exactly in half, the mean volume after division, $\overline{\mathrm{V}}_{\mathrm{t}}$, is given by:

$$
N_{t} \ln \bar{V}_{t}=2 \sum_{i=1}^{n_{1}} \ln \frac{1}{2} V_{1 i}+\sum_{j=1}^{n_{2}} \ln V_{2 j}
$$

Now, we want to derive a relationship between the mean volume (i.e. mean forward angle light scatter) and change in cell number. For simplification, I assume that the mean volume of the first cohort is proportional to the mean volume of the second:

$$
\overline{V_{1}}=\alpha \overline{V_{2}}
$$

where $\alpha$ is the proportionality constant. An $\alpha$ value equal to 1 indicates that the dividing cells represent a random subset (volume-wise) of the population, while an $\alpha$ value greater than 1 suggests that larger cells are preferentially dividing. From (4), it follows that

$$
\frac{1}{n_{1}} \sum_{i=1}^{n_{1}} \ln V_{1 i}=\alpha \frac{1}{n_{2} j=1} \sum_{2}^{n_{2}} \ln V_{2 j}
$$

Substituting (5) into equations (2) and (3), respectively and rearranging yields: 


$$
\begin{gathered}
N_{0} \ln \bar{V}_{0}=\frac{\alpha n_{1}+n_{2}}{n_{2}} \sum_{j=1}^{n_{2}} \ln V_{2 j} \text {, and } \\
N_{t} \ln \bar{V}_{t}=\frac{2 \alpha n_{1}+n_{2}}{n_{2}} \sum_{j=1}^{n_{2}} \ln V_{2 j}+2 n_{1} \ln \frac{1}{2} .
\end{gathered}
$$

Combining equations (6) and (7) gives:

$$
N_{t} \ln \bar{V}_{t}=\frac{2 \alpha n_{1}+n_{2}}{\alpha n_{1}+n_{2}} N_{0} \ln \bar{V}_{0}+2 n_{1} \ln \frac{1}{2} .
$$

Let

$$
A=\frac{2 \alpha n_{1}+n_{2}}{\alpha n_{1}+n_{2}} \cdot \frac{N_{0}}{N_{t}},
$$

substituting into (8) and rearranging yields:

$$
\ln \left(\overline{V_{t}} \bar{V}_{0}^{A}\right)=\frac{2\left(N_{t}-N_{0}\right)}{N_{t}} \ln \frac{1}{2},
$$

which gives the desired relationship between the mean volume and cell number, for phased cells undergoing a division burst. This can be rewritten with forward scatter (Eq. 2) as:

$$
\ln \left(\frac{\overline{F S C_{t}^{y}}}{{\overline{F S C_{0}^{A y}}}^{A y}}\right)=\frac{2\left(N_{t}-N_{0}\right)}{N_{t}} \ln \frac{1}{2}
$$


The experimental methods for both the laboratory and field experiments discussed below are explained in detail in Chapter III.

\section{Results}

In the course of a laboratory batch culture light shift experiment carried out to characterize the photoacclimative properties of $P$. marinus (Chapter III), strong phasing of division was observed, with up to $75 \%$ of the cells dividing within the first several hours of darkness (Fig. 1). Corresponding to the division burst, mean cell forward angle light scatter shows a decrease due to the change in cell size upon division (Fig. 2).

The experiment lasted 48 hours and two division bursts were recorded. For both of these bursts, the values of $\mathrm{A}$ and $\mathrm{y}$ in equation (11) were determined using a commercially available non-linear least squares fit (Jandel Scientific, 1992). In order to minimize potential cell shrinkage due to respiration, I tried to keep the window of time over which A and y were determined to a minimum. For the two lower light levels (54 and $110 \mu \mathrm{E} \mathrm{m}^{-2} \mathrm{~s}^{-1}$ ) the division burst starts at approximately 18:00 and ends at about 02:00 the following day (Fig. 1). For the two higher light levels (320 and $\left.620 \mu \mathrm{E} \mathrm{m}^{-2} \mathrm{~s}^{-1}\right)$, this burst starts later, at approximately 20:00 and also lasts until about 02:00 the following day. The forward angle light scatter corresponding to these intervals was used in the determination of $\mathrm{A}$ and $\mathrm{y}$. The least squares fit yields values of $\mathrm{A}=0.99 \pm 0.15$ and $\mathrm{y}=0.53 \pm 0.05$.

The value of $\mathrm{A}$ of approximately 1 suggests that the dividing and non-dividing 
cohorts of the initial population have essentially the same mean volume. We note that this only applies to the populations immediately before division, suggesting that divided cells can "catch up" to their undivided cohorts during the light (growth) phase. This parameter makes no inferences regarding the age structure of the population, or the probability of division as a function of cell age.

The y value suggests a relationship between forward angle light scatter, cell volume, or the radius of the cells, r:

$$
F S C \propto V^{1.9} \propto r^{5.7}
$$

This relationship is similar to relationships found by a similar time-course (dawn and dusk only) method (Binder et al., 1995) or other methods such as sizing using microspheres of a known volume (Binder, personal communication; Dusenberry unpublished data; Steen, 1991) or by measuring the volume of cells using electron microscopy or coulter volume (DuRand, personal communication; Roberts, personal communication). The constant of proportionality could be obtained, if needed, by obtaining an estimate of the appropriate size using electron microscopy and running the same cells on the flow cytometer.

Growth rates of field populations could be measured with this method by assuming that there is no differential net growth related to cell size within the range of interest (i.e. larger picoplankton in a given population aren't preferentially eaten, or growing faster or slower, etc.). The specific growth rate, $\mu$, is given by:

$$
\mu=\frac{1}{\Delta t} \ln \left(\frac{N}{N_{0}}\right)
$$


Figure 1 - Time-series measurements of cell concentration for P. marinus strain Med4 during the laboratory reciprocal light shift experiment discussed in Chapter III. Cells acclimated to light intensities of $620 \mu \mathrm{E} \mathrm{m}^{-2} \mathrm{~s}^{-1}$ (open circles), $320 \mu \mathrm{E} \mathrm{m}^{-2} \mathrm{~s}^{-1}$ (closed circles), $110 \mu \mathrm{E} \mathrm{m}^{-2} \mathrm{~s}^{-1}$ (open triangles) and $54 \mu \mathrm{E} \mathrm{m}^{-2} \mathrm{~s}^{-1}$ (closed triangles) were shifted to (a) $620 \mu \mathrm{E} \mathrm{m}^{-2} \mathrm{~s}^{-1}$, (b) $320 \mu \mathrm{E} \mathrm{m}^{-2} \mathrm{~s}^{-1}$, (c) $110 \mu \mathrm{E} \mathrm{m}^{-2} \mathrm{~s}^{-1}$ and (d) $54 \mu \mathrm{E} \mathrm{m}^{-2} \mathrm{~s}^{-1}$. Error bars not shown. 


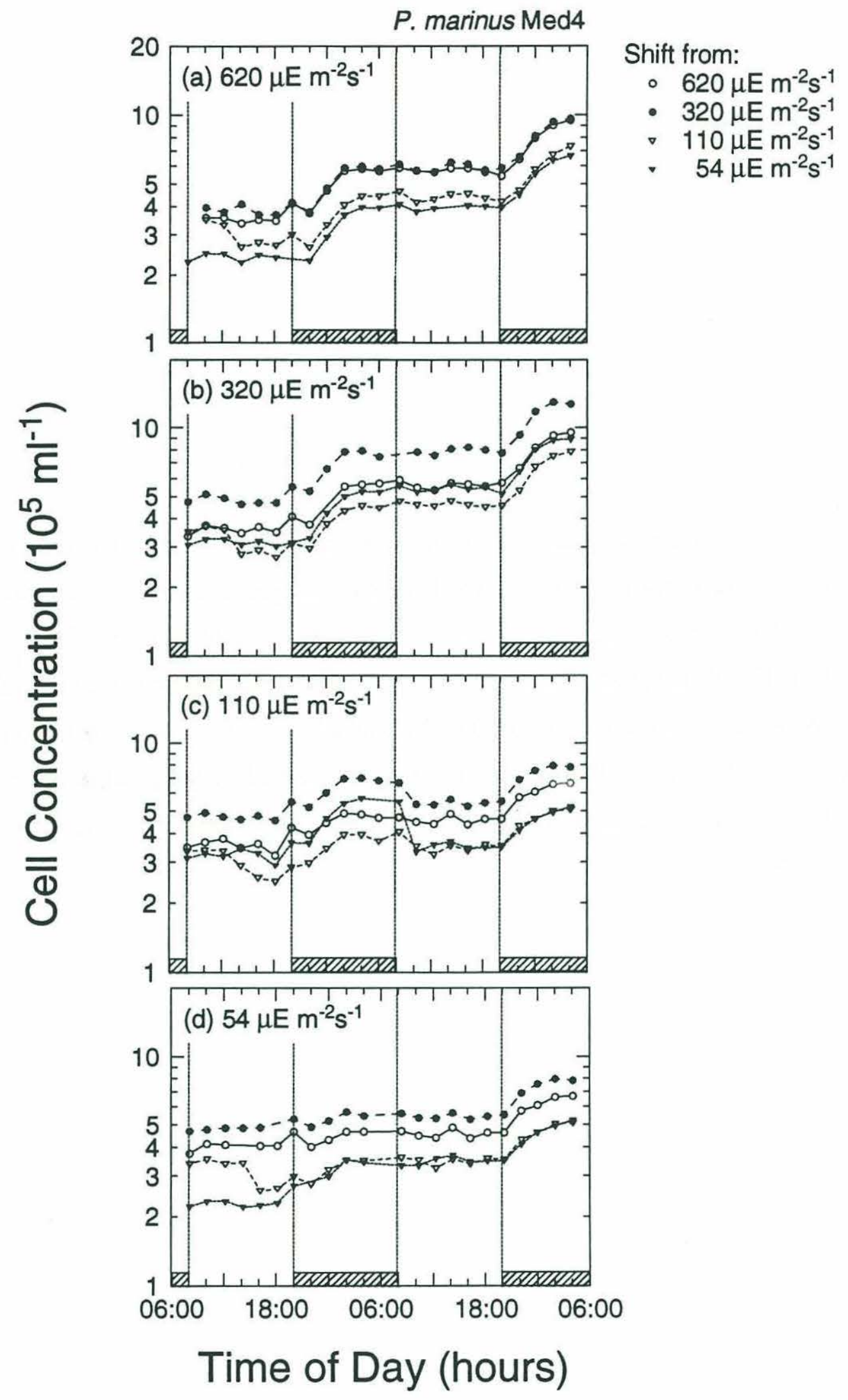


Figure 2 - Time-series measurements of mean (geometric) forward angle light scatter for $P$. marinus strain Med4 during the laboratory reciprocal light shift experiment presented in figure 1. Cells acclimated to light intensities of $620 \mu \mathrm{E} \mathrm{m}^{-2} \mathrm{~s}^{-1}$ (open circles), $320 \mu \mathrm{E} \mathrm{m}^{-2} \mathrm{~s}^{-1}$ (closed circles), $110 \mu \mathrm{E} \mathrm{m}^{-2} \mathrm{~s}^{-1}$ (open triangles) and $54 \mu \mathrm{E} \mathrm{m} \mathrm{m}^{-2} \mathrm{~s}^{-1}$ (closed triangles) were shifted to (a) $620 \mu \mathrm{E} \mathrm{m}^{-2} \mathrm{~s}^{-1}$, (b) $320 \mu \mathrm{E} \mathrm{m}^{-2} \mathrm{~s}^{-1}$, (c) $110 \mu \mathrm{E} \mathrm{m}^{-2} \mathrm{~s}^{-1}$ and (d) $54 \mu \mathrm{E} \mathrm{m}^{-2} \mathrm{~s}^{-1}$. All values are relative, determined by assigning a value of 1 to the lowest channel acquired during analysis. Error bars represent one standard deviation. 


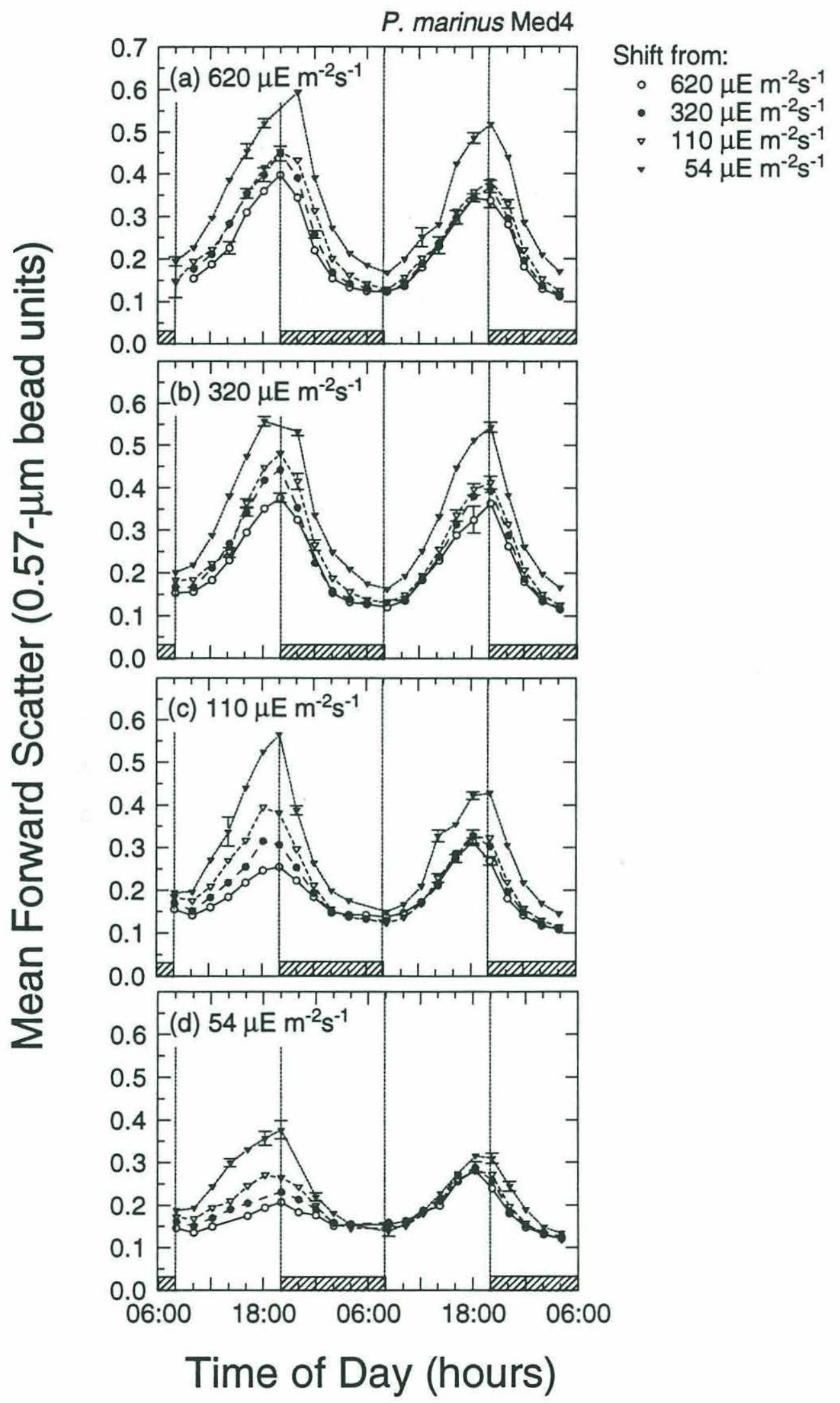


where $\Delta t$ is 1 day. Rearranging equation (11) and substituting into (13) yields:

$$
\mu\left(d^{-1}\right)=-\ln \left[1-\frac{y}{2 \ln \frac{1}{2}} \ln \left(\frac{\overline{F S C_{t}}}{\overline{F S C_{0}}{ }^{A}}\right)\right]
$$

One can use equation (14) to estimate growth rates in field bottle incubations, where the presence of grazers may affect the cell densities making growth rate determination via cell numbers difficult. For example, during an October 1989 cruise to the Sargasso Sea populations of both Prochlorococcus spp. and Synechococcus spp. from reciprocal light shift bottle incubations were analyzed (Fig. 3-4) (see also Chapter III). Two other field simulated in-situ bottle incubations, one from the Sargasso Sea in July 1990 (Fig. 5-6) and the other from the Equatorial Pacific in August 1991 (Fig. 7-8), have been analyzed using a similar procedure to that outlined here (except in reverse), to determine the growth rates of the population (Table 1).

Synechococcus spp. growth rates were calculated by assuming a value of $\mathrm{y}=$ 0.75. This corresponds to FSC $\propto \mathrm{r}^{4}$ and was used because a y-value of 0.53 tended to underestimate $\mu$ compared to estimates of $\mu$ based on changes in cell concentration. Mie theory and experimental evidence shows that as diameter increases, the r-exponent changes from 6 to 4 and then to 2 (see Steen, 1991). These results suggest that an rexponent near 4 may be appropriate for Synechococcus spp. 
Table 1 - Growth rates estimated from time-series of on-deck bottle incubations for cruises discussed in Chapter III. Results are shown here for samples taken from depths corresponding to $50 \%, 10 \%$, and $3 \%$ surface irradiance $\left(\mathrm{I}_{0}\right)$ and incubated at $50 \% \mathrm{I}_{0}$. Growth rates were calculated based on both the change in forward angle light scatter during the early part of the night $\left(\mu_{\mathrm{FSC}}\right)$ or the corresponding change in cell number $\left(\mu_{\mathrm{NUM}}\right)$ assuming division is limited to the division burst.

\begin{tabular}{|c|c|c|c|c|c|c|}
\hline \multirow[b]{2}{*}{ Cruise } & \multirow{2}{*}{$\begin{array}{l}\text { Location } \\
\text { Date }\end{array}$} & \multirow{2}{*}{$\begin{array}{l}\text { Depth } \\
\text { Sampled } \\
\text { (m) }\end{array}$} & \multicolumn{2}{|c|}{ Prochlorococcus spp. } & \multicolumn{2}{|c|}{ Synechococcus spp. } \\
\hline & & & $\mu_{\mathrm{FSC}}\left(\mathrm{d}^{-1}\right)$ & $\mu_{\mathrm{NUM}}\left(\mathrm{d}^{-1}\right)$ & $\mu_{\mathrm{FSC}}\left(\mathrm{d}^{-1}\right)$ & $\mu_{\mathrm{NUM}}\left(\mathrm{d}^{-1}\right)$ \\
\hline \multirow{3}{*}{$\begin{array}{l}\text { Oceanus } 214 \\
\text { day } 1\end{array}$} & Sargasso Sea & 15 & 0.36 & 0.50 & 0.57 & 0.60 \\
\hline & $\left(33^{\circ} \mathrm{N}, 66^{\circ} \mathrm{W}\right)$ & 48 & 0.39 & 0.59 & 0.62 & 0.62 \\
\hline & October 1989 & 77 & 0.40 & 0.70 & 1.08 & 1.03 \\
\hline \multirow{3}{*}{$\begin{array}{l}\text { Oceanus } 221 \\
\text { day } 1\end{array}$} & Sargasso Sea & 25 & 0.18 & 0.17 & 0.17 & 0.16 \\
\hline & $\left(34^{\circ} \mathrm{N}, 61^{\circ} \mathrm{W}\right)$ & 55 & 0.16 & 0.04 & 0.31 & 0.18 \\
\hline & July 1990 & 70 & 0.11 & 0.02 & 0.25 & 0.17 \\
\hline \multirow{3}{*}{$\begin{array}{l}\text { Oceanus } 221 \\
\text { day } 2\end{array}$} & Sargasso Sea & 25 & 0.13 & 0.11 & 0.60 & 0.59 \\
\hline & $\left(34^{\circ} \mathrm{N}, 61^{\circ} \mathrm{W}\right)$ & 55 & 0.12 & 0.13 & 0.33 & 0.40 \\
\hline & July 1990 & 70 & 0.07 & -0.11 & 0.38 & 0.46 \\
\hline \multirow{3}{*}{$\begin{array}{l}\text { Moana Wave } \\
91-010\end{array}$} & Eq. Pacific & 10 & 0.06 & 0.39 & 0.18 & 0.43 \\
\hline & $\left(0^{\circ} \mathrm{N}, 140^{\circ} \mathrm{W}\right)$ & 40 & 0.04 & 0.51 & 0.16 & 0.69 \\
\hline & August 1991 & 60 & 0.09 & 0.59 & 0.20 & 0.84 \\
\hline
\end{tabular}

\section{Discussion}

I have shown here a preliminary method by which growth rates can be estimated using flow cytometric forward angle light scatter measurements. Calibration of the method was obtained using laboratory cultures of $P$. marinus. The method was then tested by extending it to simulated in-situ bottle incubations done in the field. This testing reveals several limitations of the method. In two experiments, the October 1989 Sargasso Sea experiment and the August 1991 Equatorial Pacific experiment, the forward angle light scatter method tends to underestimate growth rates when compared to changes in cell concentration. In the Sargasso Sea experiment, this 
Figure 3 - Time-series measurements of (a) forward angle light scatter and (b) cell concentration for Prochlorococcus spp. during a simulated in-situ reciprocal light shift experiment carried out during the October 1989 Sargasso Sea cruise (see also Chapter III). Populations collected from $15 \mathrm{~m}$ (open circles), $48 \mathrm{~m}$ (closed circles) and $77 \mathrm{~m}$ (open triangles) were incubated on-deck in a neutral density screened incubator. Light levels were at $50 \%$ of incident irradiance $\left(\mathrm{I}_{0}\right)$. Forward angle light scatter values are relative to $0.57-\mu \mathrm{m}$ microspheres (beads) which were used as an internal standard. Error bars represent one standard deviation. 


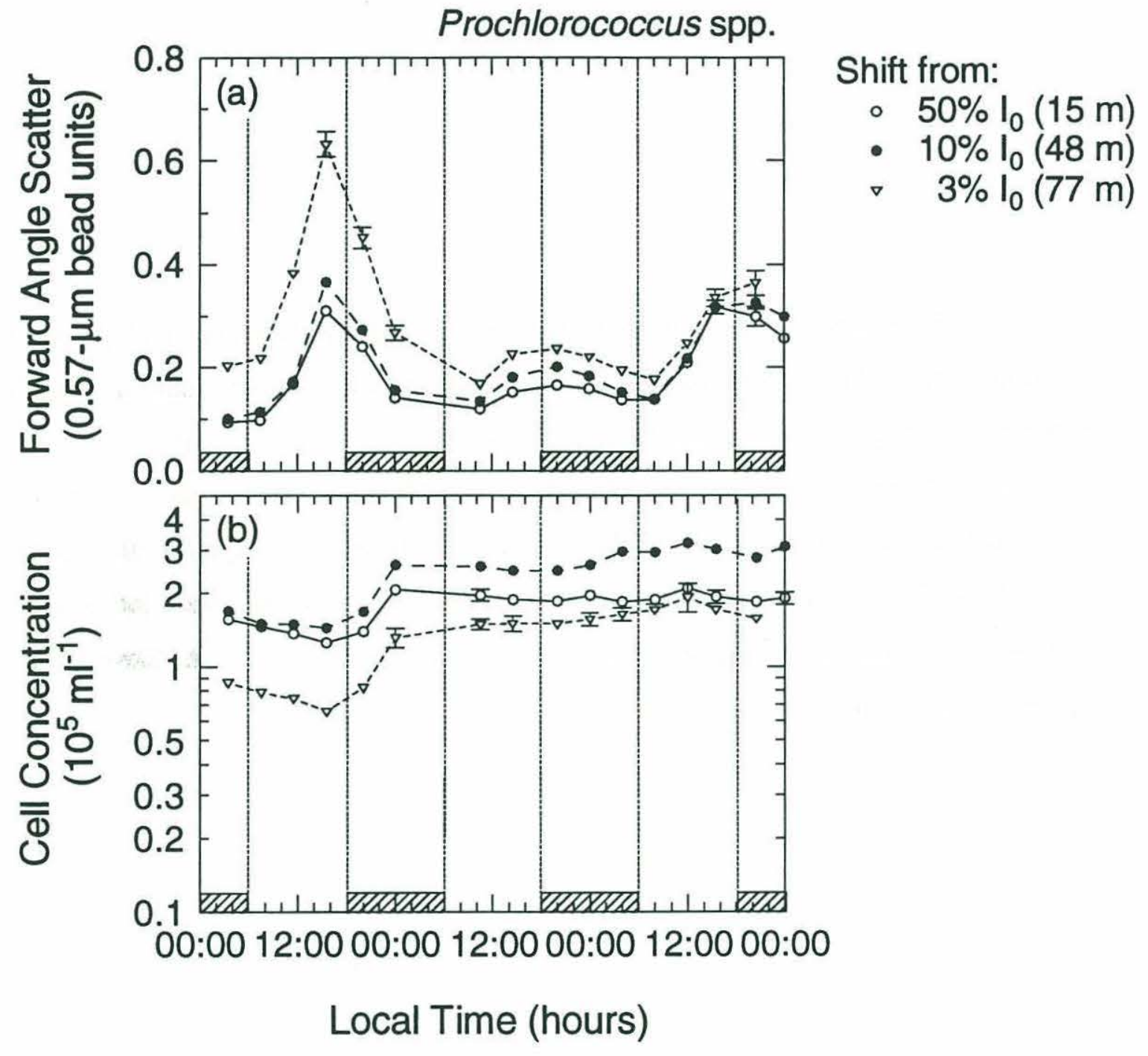


Figure 4 - Time-series measurements of (a) forward angle light scatter and (b) cell concentration for Synechococcus spp. during a simulated in-situ reciprocal light shift experiment carried out during the October 1989 Sargasso Sea cruise. Populations collected from $15 \mathrm{~m}$ (open circles), $48 \mathrm{~m}$ (closed circles) and $77 \mathrm{~m}$ (open triangles) were incubated on-deck in a neutral density screened incubator. Light levels were at $50 \%$ of incident irradiance $\left(\mathrm{I}_{0}\right)$. Forward angle light scatter values are relative to $0.57-\mu \mathrm{m}$ microspheres (beads) which were used as an internal standard. Error bars represent one standard deviation. 


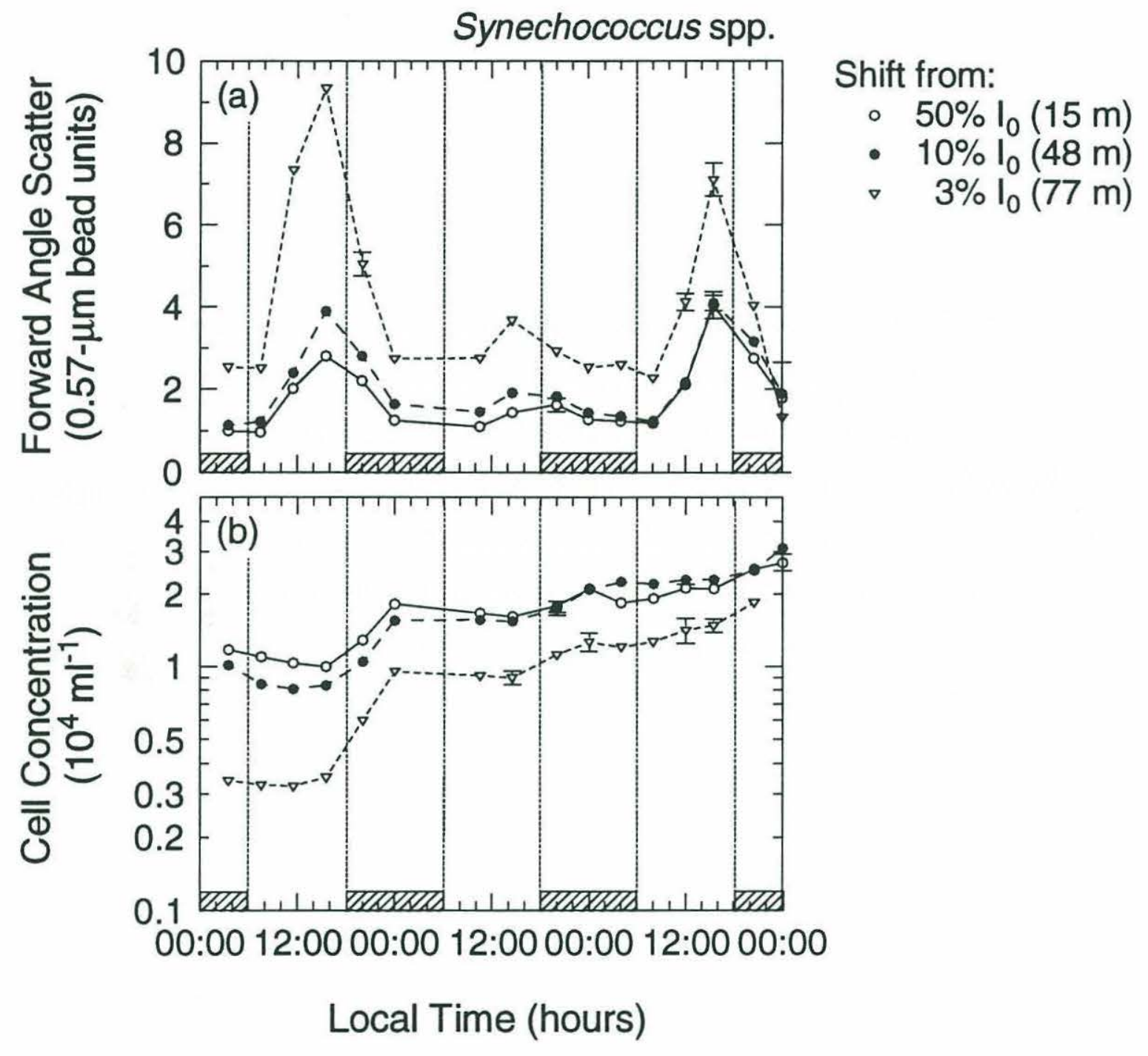


Figure 5 - Time-series measurements of (a) forward angle light scatter and (b) cell concentration for Prochlorococcus spp. during a simulated in-situ reciprocal light shift experiment carried out during the July 1990 Sargasso Sea cruise. Populations collected from $25 \mathrm{~m}$ (open circles), $55 \mathrm{~m}$ (closed circles) and $70 \mathrm{~m}$ (open triangles) were incubated on-deck in a neutral density screened incubator. Light levels were at $50 \%$ of incident irradiance $\left(\mathrm{I}_{0}\right)$. Forward angle light scatter values are relative to $0.57-\mu \mathrm{m}$ microspheres (beads) which were used as an internal standard. Error bars represent one standard deviation. 


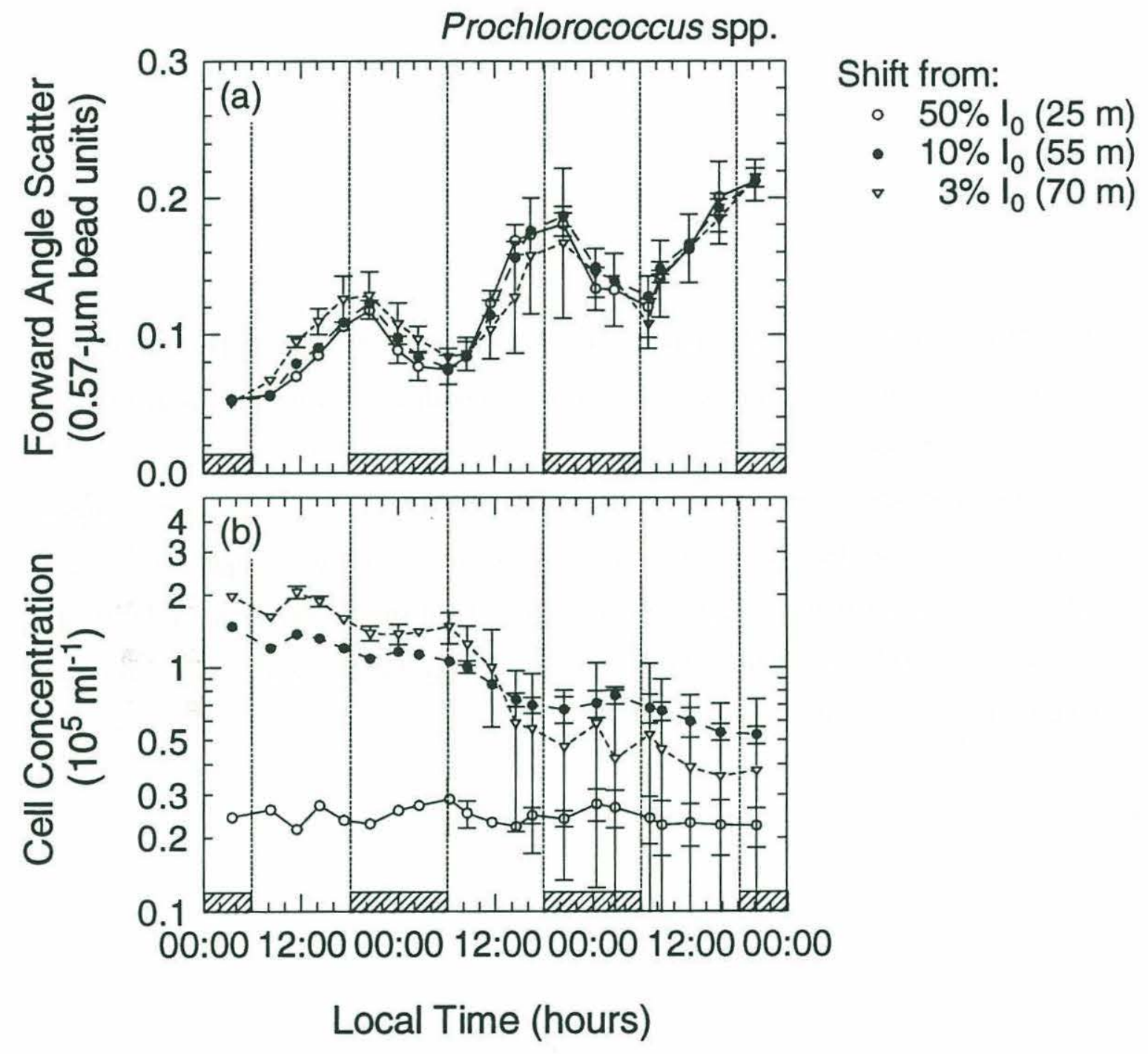


Figure 6 - Time-series measurements of (a) forward angle light scatter and (b) cell concentration for Synechococcus spp. during a simulated in-situ reciprocal light shift experiment carried out during the July 1990 Sargasso Sea cruise. Populations collected from $25 \mathrm{~m}$ (open circles), $55 \mathrm{~m}$ (closed circles) and $70 \mathrm{~m}$ (open triangles) were incubated on-deck in a neutral density screened incubator. Light levels were at $50 \%$ of incident irradiance $\left(\mathrm{I}_{0}\right)$. Forward angle light scatter values are relative to $0.57-\mu \mathrm{m}$ microspheres (beads) which were used as an internal standard. Error bars represent one standard deviation. 


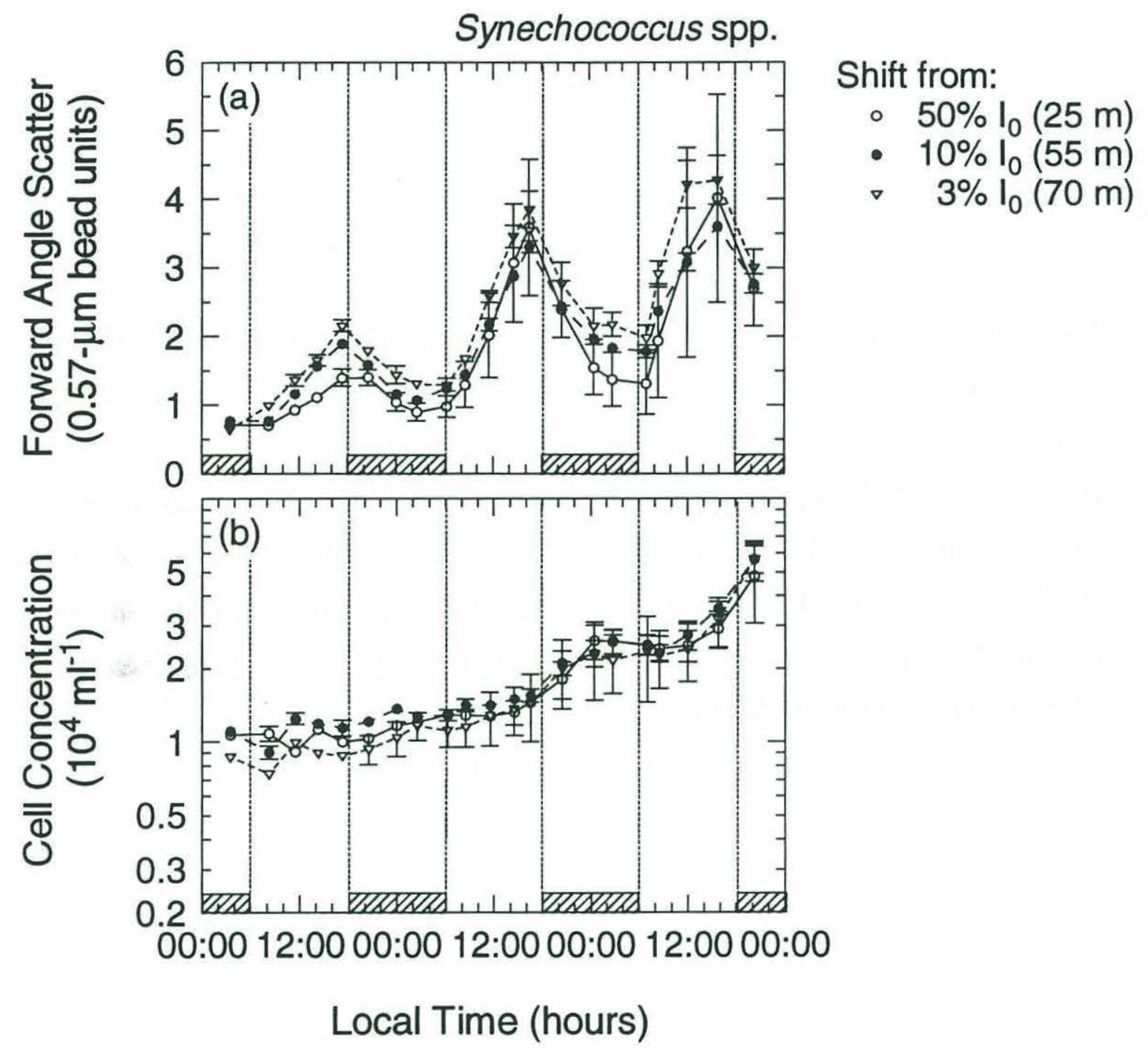


Figure 7 - Time-series measurements of (a) forward angle light scatter and (b) cell concentration for Prochlorococcus spp. during a simulated in-situ reciprocal light shift experiment carried out during the August 1991 equatorial Pacific cruise. Populations collected from $10 \mathrm{~m}$ (open circles), $40 \mathrm{~m}$ (closed circles) and $60 \mathrm{~m}$ (open triangles) were incubated on-deck in a neutral density screened incubator. Light levels were at $50 \%$ of incident irradiance $\left(\mathrm{I}_{0}\right)$. Forward angle light scatter values are relative to $0.57-\mu \mathrm{m}$ microspheres (beads) which were used as an internal standard. Error bars represent one standard deviation. 


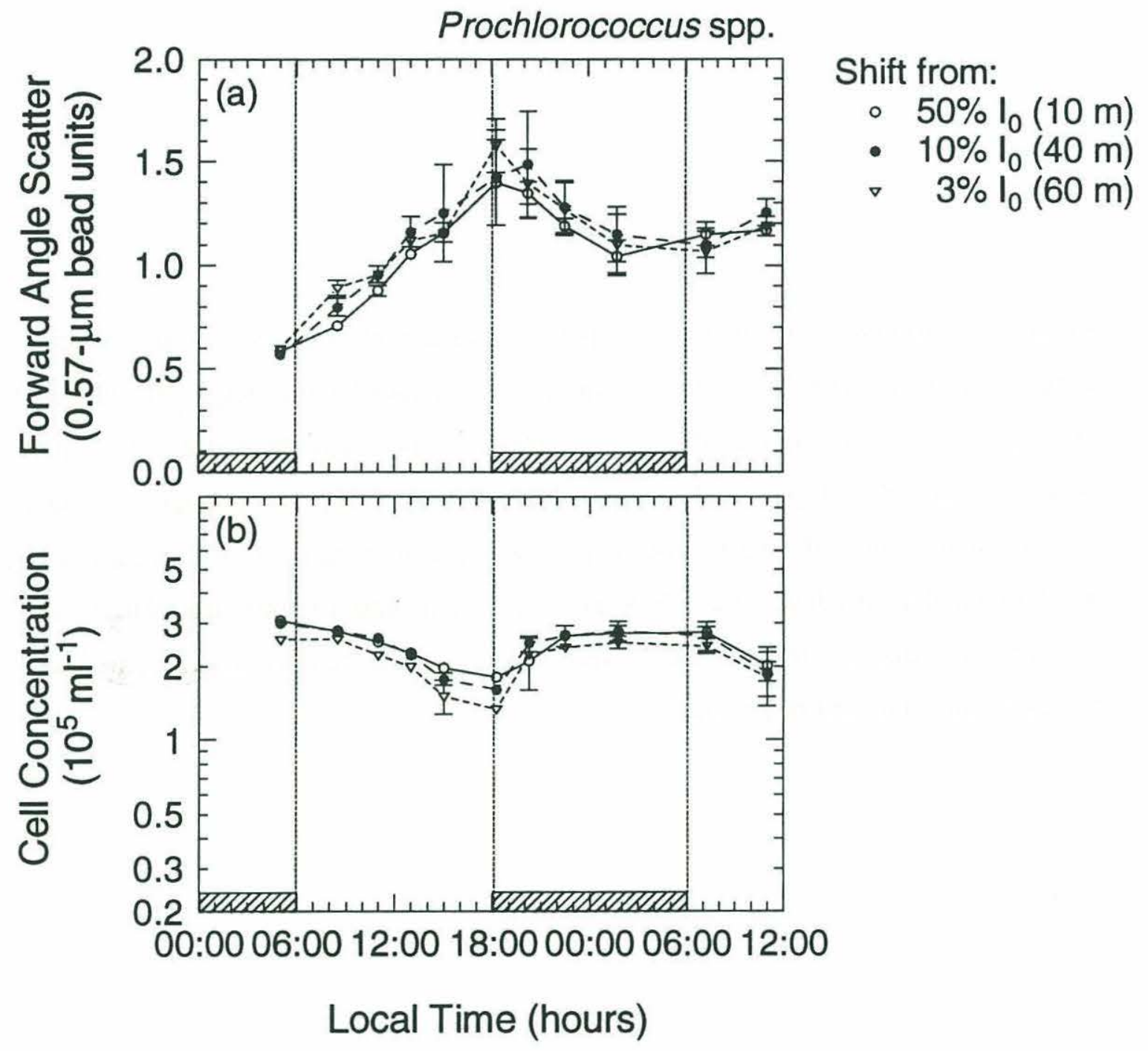


Figure 8 - Time-series measurements of (a) forward angle light scatter and (b) cell concentration for Synechococcus spp. during a simulated in-situ reciprocal light shift experiment carried out during the August 1991 equatorial Pacific cruise. Populations collected from $10 \mathrm{~m}$ (open circles), $40 \mathrm{~m}$ (closed circles) and $60 \mathrm{~m}$ (open triangles) were incubated on-deck in a neutral density screened incubator. Light levels were at $50 \%$ of incident irradiance $\left(\mathrm{I}_{0}\right)$. Forward angle light scatter values are relative to $0.57-\mu \mathrm{m}$ microspheres (beads) which were used as an internal standard. Error bars represent one standard deviation. 


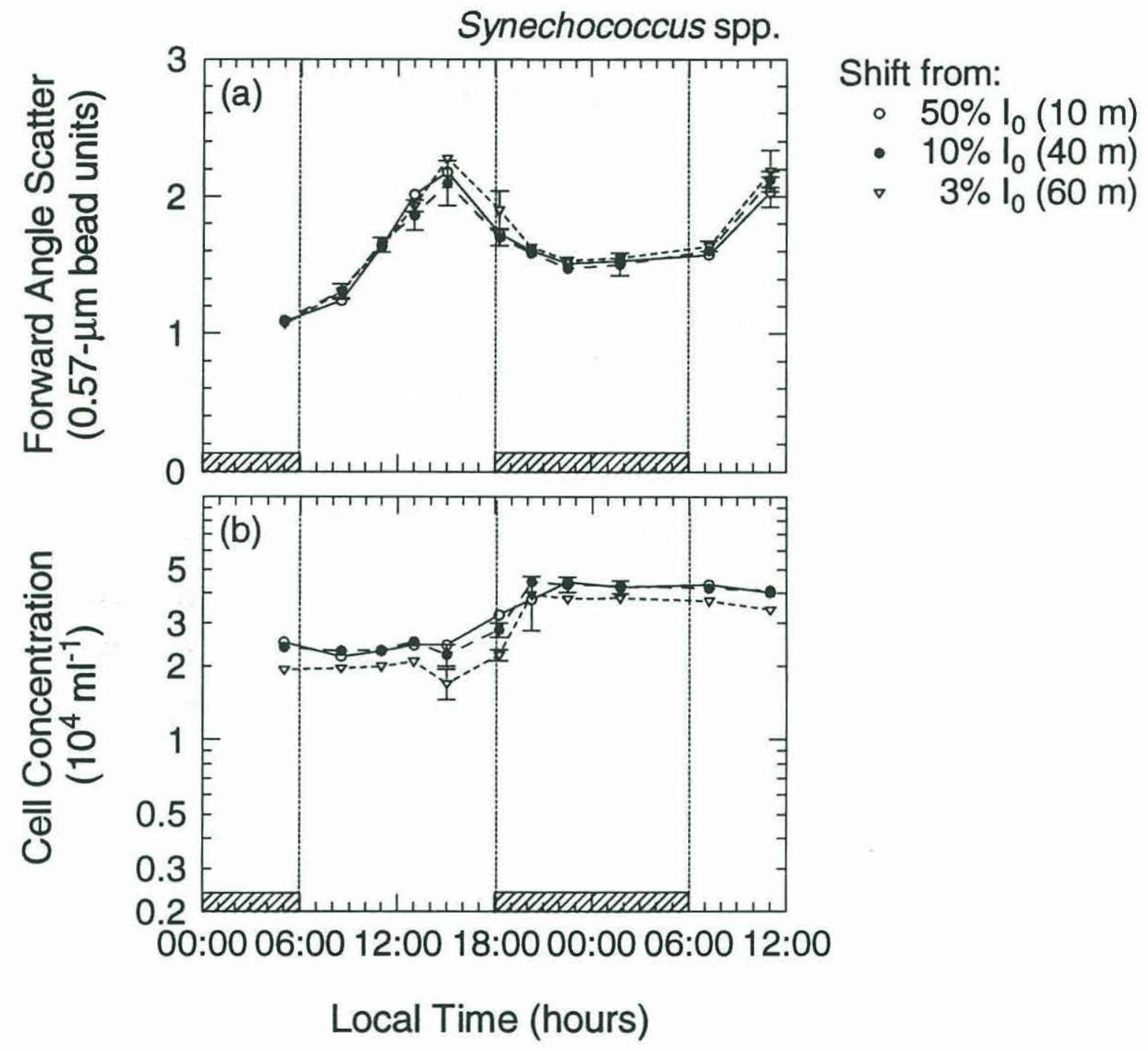


appears to be a result of an inadequate sampling frequency, yielding an underestimate of the difference in forward angle light scatter during the division burst. This method requires accurate determination of the maxima in forward angle light scatter, which is expected to occur at the beginning of the division burst.

There appear to be two other factors contributing to the discrepancy between estimates of $\mu$ obtained by forward angle light scatter changes and by cell concentration changes in the equatorial Pacific experiment. These cells show larger forward scatter signals than those seen in other field experiments and in the lab, suggesting that these cells are larger. These cells may therefore exhibit a less steep forward scatter to radius relationship with an r-exponent of approximately 4 or less, which would serve to increase the estimates of growth rates by this method by about $50 \%$. However, this is still a factor of 4 less than growth rates obtained through the corresponding changes in cell concentration. It appears that an increase in cell size during the division burst is contributing to the discrepancy as well. These cells show an increase in mean red fluorescence (Chapter III, Fig. 16) during the division burst, an unexpected result which indicates that cellular pigment (or more exactly, fluorescence) is not simply being divided in half between the progeny cells. If a similar effect is occurring in forward scatter signals, resulting in an increase in total cell volume during the division burst, the magnitude of the change in forward scatter signals before and after the burst will be reduced, thus yielding an underestimate of the growth rate. Flow cytometric DNA measurements and independent estimates of cell size coupled with similar data to that obtained here should help to resolve this 
issue.

Synechococcus spp. growth rates were obtained by assuming a y-value of 0.75 . Further laboratory experiments are needed to determine the y-value as a function of cell size, in order to extend this method to Synechococcus spp. and even the larger Prochlorococcus spp. Larger strains of Prochlorococcus spp. are now in culture (Moore, personal communication), so such results should be readily obtainable.

Growth rates for Prochlorococcus spp. in these bottle experiments vary widely from overall net negative growth rates to growth rates approaching 1 doubling $\mathrm{d}^{-1}(\mu=$ $\left.0.69 \mathrm{~d}^{-1}\right)$. Synechococcus spp., in contrast, shows growth rates predicted by both forward angle scatter and cell number in excess of one doubling during the division burst.

This method should be readily extended to in-situ field observations such as those presented in Chapter II. By quantifying the change in cell number during the day and comparing to forward angle light scatter patterns, it should be possible to estimate growth and loss (i.e. grazing) rates for picophytoplankton in-situ. In addition, a thorough understanding of the relationship between optical properties such as forward angle light scatter and fluorescence and cell growth and division should facilitate the development of an appropriate parameter or combination of parameters to represent the photoacclimative status of the cells. It is desirable to find a parameter which shows maximum response to changes in light intensity, but is relatively unaffected by other factors, such as cell growth. 


\section{References}

Binder, B. J., S. W. Chisholm, S. L. Frankel and R. J. Olson. 1995. (in prep.).

Dusenberry, J. A. and S. L. Frankel. 1994. Increasing the sensitivity of a FACScan flow cytometer to study oceanic picoplankton. Limnol. Oceanogr. 39:206-209.

Jandel Scientific. 1992. Sigmaplot Scientific Graph System. Jandel Corporation. San Rafael, CA.

Steen, H. B. 1991. Flow cytometry instrumentation. in: Particle Analysis in Oceanography. S. Demers (ed.). Springer-Verlag. New York. 
Appendix C

\section{Chapter III Ancillary Data}




\section{Chapter III Ancillary Data}

I present here the fits of the logistic equation for photoacclimation (Chapter III, Eq. 2) to the normalized fluorescence data from the laboratory light shift experiment (Chapter III, Fig. 1-5) that were used to define the photoacclimation kinetics for the model presented in Chapter V. Due to the difficulty in fitting the logistic model to the high light treatments (Chapter III, Fig. 5), I had previously fitted this data to the curve

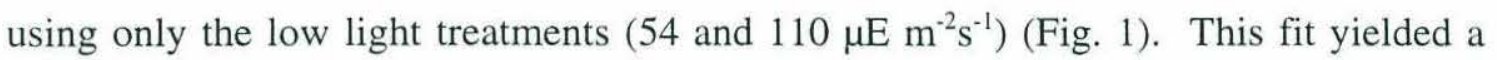
photoacclimative rate of $3.5 \mathrm{~d}^{-1}$ and fully acclimated normalized fluorescence, $\Gamma_{\infty}$, as shown (Fig. 1).

With the exception of the unscreened bottle, the mixostat (Chapter V), was

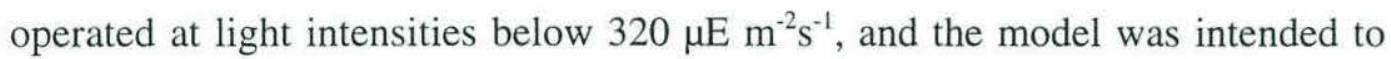
simulate the dynamics in the mixostat. Thus the fit presented here seemed reasonable, as it provides a better fit to the low light treatments. 
Figure 1 - Time-series of mean red fluorescence normalized to the cube root of the mean forward angle light scatter signal for $P$. marinus strain Med4 during the laboratory based reciprocal light shift experiment presented in Chapter III (Chapter III, Fig. 1-5). Cells acclimated to light intensities of $620 \mu \mathrm{E} \mathrm{m}^{-2} \mathrm{~s}^{-1}$ (open circles), $320 \mu \mathrm{E} \mathrm{m}^{-2} \mathrm{~s}^{-1}$ (closed circles), $110 \mu \mathrm{E} \mathrm{m}^{-2} \mathrm{~s}^{-1}$ (open triangles) and $54 \mu \mathrm{E} \mathrm{m}^{-2} \mathrm{~s}^{-1}$ (closed triangles) were shifted to (a) $620 \mu \mathrm{E} \mathrm{m}^{-2} \mathrm{~s}^{-1}$, (b) $320 \mu \mathrm{E} \mathrm{m}^{-2} \mathrm{~s}^{-1}$, (c) $110 \mu \mathrm{E} \mathrm{m}^{-2} \mathrm{~s}^{-1}$ and (d) $54 \mu \mathrm{E} \mathrm{m}^{-2} \mathrm{~s}^{-1}$. All values are relative to $0.57-\mu \mathrm{m}$ microspheres (beads) which were used as an internal standard. Error bars represent one standard deviation. Solid lines are a least-squares fit to the logistic formula for photoacclimation (Chapter III, Eq. 2), which yields a photoacclimative rate, $\gamma$, of $3.5 \mathrm{~d}^{-1}$, and fully acclimated values, $\Gamma_{\infty}$, as shown. 


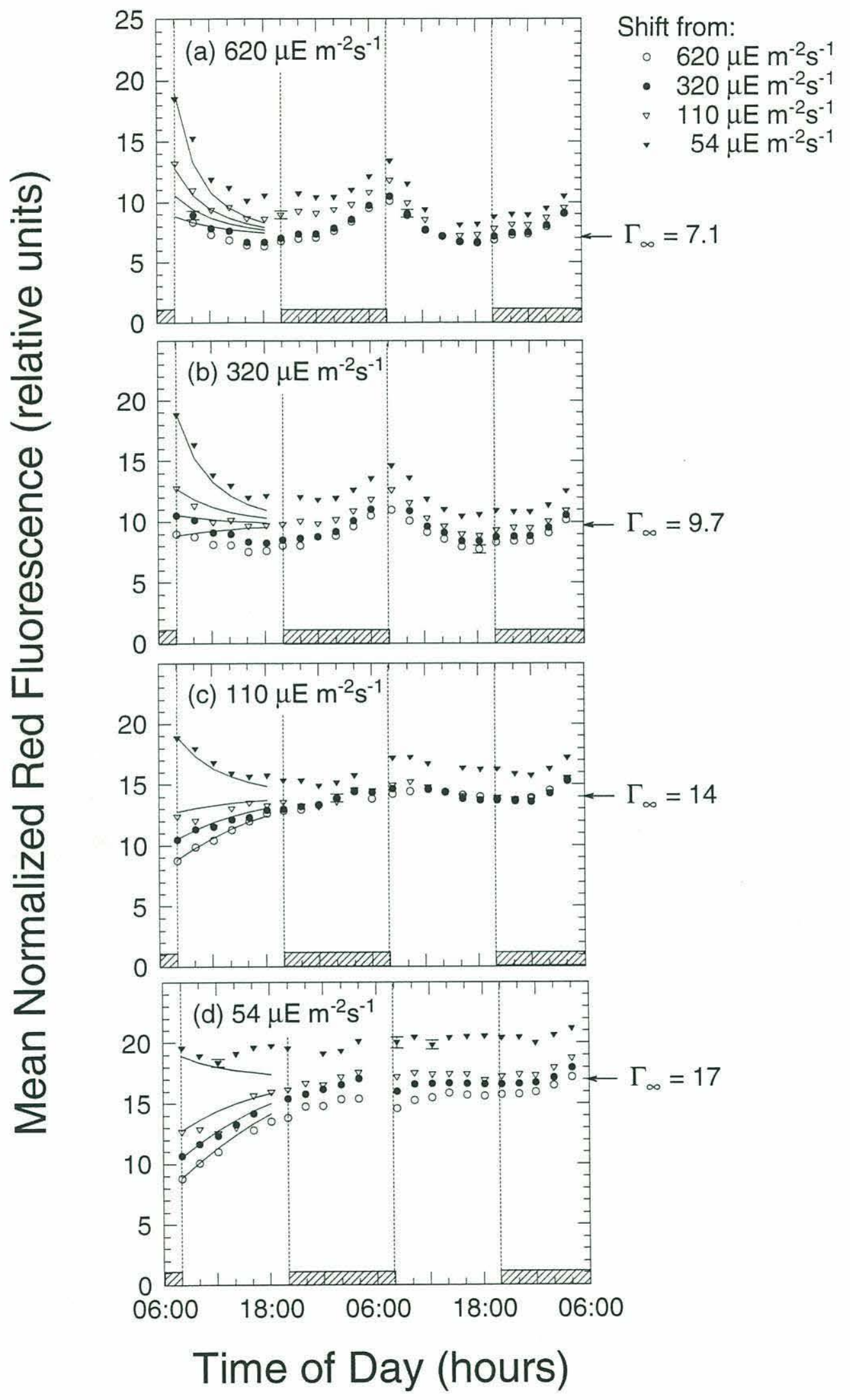


Appendix D

\section{Numerical Algorithm for the Steady State Model of Chapter IV}




\section{Numerical Algorithm for the Steady State Model of Chapter IV}

I present here the algorithm by which the stationary Fokker-Planck equation for a first-order photoacclimation process coupled with turbulent mixing (Chapter IV, Eq.

10):

$$
-\frac{1}{\ln 10} \frac{\partial}{\partial \Gamma^{*}}\left(N \gamma\left[\frac{\Gamma_{\infty}}{10^{\Gamma^{*}}}-1\right]\right)+K_{v} \frac{\partial^{2} N}{\partial z^{2}}=0
$$

was solved. For simplicity, let

$$
A=-\frac{1}{\ln 10} \gamma\left[\frac{\Gamma_{\infty}}{10^{\Gamma^{*}}}-1\right]
$$

so that equation (1) becomes

$$
\frac{\partial}{\partial \Gamma^{*}}(N A)+K_{v} \frac{\partial^{2} N}{\partial z^{2}}=0 .
$$

\section{Model Definition}

A finite difference method was used, with direct solution of the resultant set of linear equations. A set of regularly spaced nodes were defined over the region from the smallest possible value of the photoacclimative parameter, here at the surface $(\Gamma=$

$\left.\Gamma_{0, \infty}^{*}\right)$, to the largest $\left(\Gamma=\Gamma_{\mathrm{h}, \infty}^{*}\right)$, and from the surface $(\mathrm{z}=0)$ to the base of the mixed 
layer $(\mathrm{z}=\mathrm{h})($ Fig. 1). The $\mathrm{z}$-derivative in the above equations was approximated with a centered approximation:

$$
\left.\frac{\partial^{2} N}{\partial z^{2}}\right|_{i j} \approx \frac{N_{i-1, j}-2 N_{i j}+N_{i+1, j}}{(\Delta z)^{2}}
$$

The $\Gamma^{*}$-derivative was approximated with either a forward or backward difference. If $\Gamma_{\mathrm{ij}}^{*}<\Gamma_{\mathrm{i}, \infty}^{*}$ the backward difference:

$$
\left.\frac{\partial N A}{\partial \Gamma^{*}}\right|_{i j} \approx \frac{3 N_{i j} A_{i j}-4 N_{i, j-1} A_{i, j-1}+N_{i, j-2} A_{i, j-2}}{2 \Delta \Gamma^{*}}
$$

was used. Similarly, the forward difference:

$$
\left.\frac{\partial N A}{\partial \Gamma^{*}}\right|_{i j} \approx \frac{-3 N_{i j} A_{i j}+4 N_{i, j+1} A_{i, j+1}-N_{i, j+2} A_{i, j+2}}{2 \Delta \Gamma^{*}}
$$

was used to approximate the derivative if $\Gamma_{\mathrm{ij}}^{*}>\Gamma_{\mathrm{i}, \infty}^{*}$. These approximations were chosen instead of a centered difference to reduce the oscillations produced when the centered difference was used. The use of both forward and backward differences facillitates the incorporation of boundary effects (see below). At the cross-over point between the forward and backward difference approximations, where $\Gamma_{\mathrm{ij}}^{*}=\Gamma_{\mathrm{i}, \infty}^{*}$, a centered difference was used:

$$
\left.\frac{\partial N A}{\partial \Gamma^{*}}\right|_{i j} \approx \frac{N_{i, j-2} A_{i, j-2}-8 N_{i, j-1} A_{i, j-1}+8 N_{i, j+1} A_{i, j+1}-N_{i, j+2} A_{i, j+2}}{12 \Delta \Gamma^{*}}
$$


The choice of the cross-over point was found to not affect the solution; $\Gamma_{\mathrm{i}, \infty}^{*}$ was chosen for simplicity.

For each interior node with $\Gamma_{\mathrm{ij}}^{*}<\Gamma_{\mathrm{i}, \infty}^{*}$, combining equations (4) and (5) yields an approximation to equation (1):

$$
\frac{3 N_{i j} A_{i j}-4 N_{i, j-1} A_{i, j-1}+N_{i, j-2} A_{i, j-2}}{2 \Delta \Gamma^{*}}+K_{\eta}\left(\frac{N_{i-1, j}-2 N_{i j}+N_{i+1, j}}{(\Delta z)^{2}}\right)=0
$$

In a similar manner, approximations for $\Gamma_{\mathrm{ij}}^{*}>\Gamma_{\mathrm{i}, \infty}^{*}$ :

$$
\frac{-3 N_{i f} A_{i j}+4 N_{i, j+1} A_{i, j+1}-N_{i, j+2} A_{i, j+2}}{2 \Delta \Gamma^{*}}+K_{V}\left(\frac{N_{i-1, j}-2 N_{i j}+N_{i+1, j}}{(\Delta z)^{2}}\right)=0
$$

and $\Gamma_{\mathrm{ij}}^{*}=\Gamma_{\mathrm{i}, \infty}^{*}$ :

$$
\begin{array}{r}
\frac{N_{i, j-2} A_{i, j-2}-8 N_{i, j-1} A_{i, j-1}+8 N_{i, j+1} A_{i, j+1}-N_{i, j+2} A_{i, j+2}}{12 \Delta \Gamma^{*}}+ \\
K_{V}\left(\frac{N_{i-1, j}-2 N_{i j}+N_{i+1, j}}{(\Delta z)^{2}}\right)=0
\end{array}
$$

can be derived.

\section{Boundary Conditions}

The boundary conditions in the $\Gamma^{*}$ dimension were incorporated by simply using the above equations for the interior nodes, and taking $\mathrm{N}_{\mathrm{ij}}=0$ for all $\mathrm{j}<1$ or 
Figure 1 - Definition schematic for the finite-difference approximation discussed in the text. $\mathrm{N}_{\mathrm{ij}}$ represents the marginal probability of a cell at a depth, $\mathrm{z}$, corresponding to the $\mathrm{j}^{\text {th }}$ row, having a photoacclimative state, $\Gamma$, corresponding to the $\mathrm{i}^{\text {th }}$ column. 


\section{Photoacclimative Parameter $\left(\Gamma^{*}\right)$}

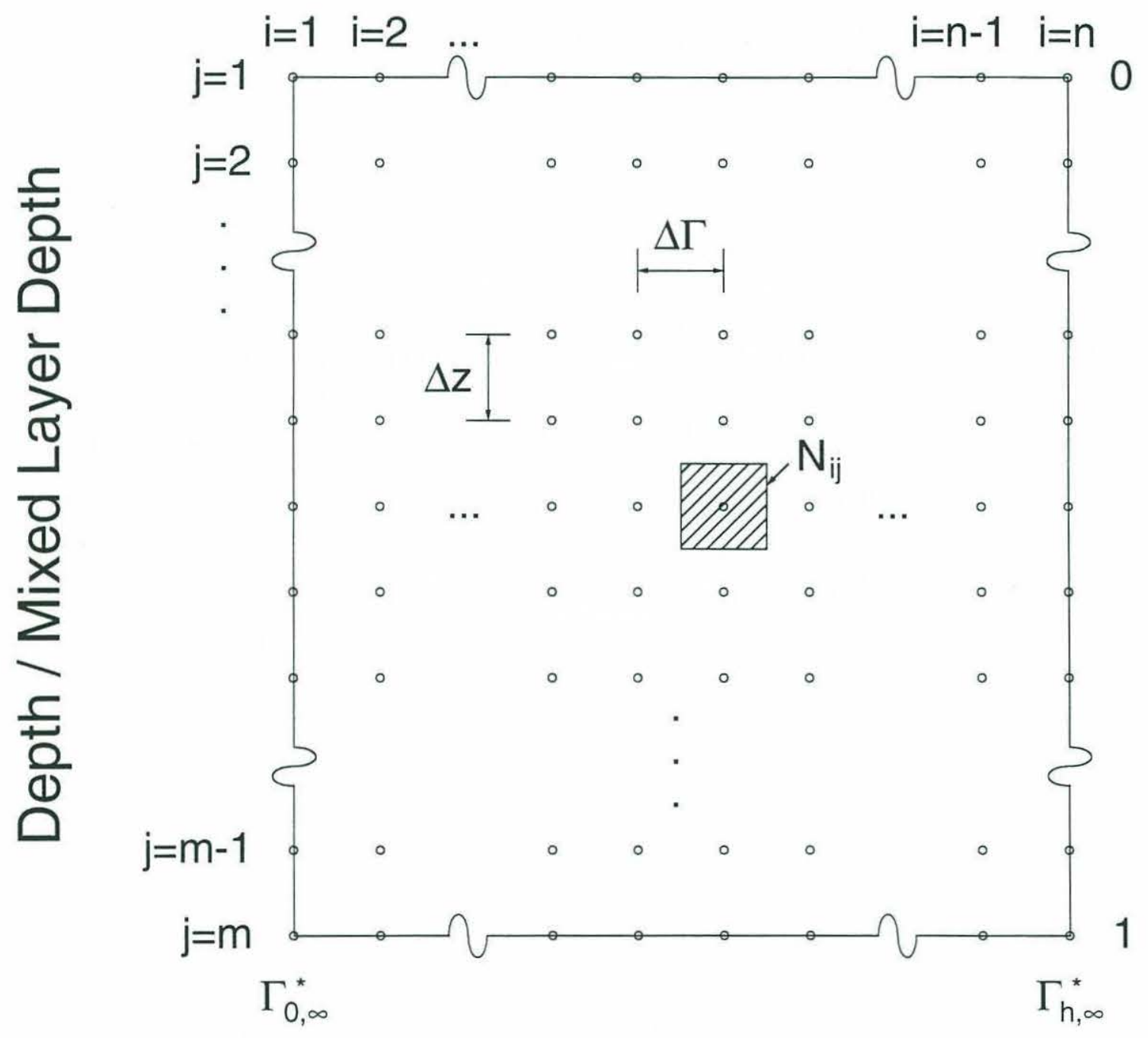


$\mathrm{j}>\mathrm{m}$. Thus, for the $\mathrm{N}_{\mathrm{i}, 0}$ nodes, the difference approximation becomes:

$$
\frac{3 N_{i 0} A_{i 0}}{2 \Delta \Gamma^{*}}+K_{V}\left(\frac{N_{i-1,0}-2 N_{i, 0}+N_{i+1,0}}{(\Delta z)^{2}}\right)=0
$$

Similar equations can be obtained from the $\mathrm{N}_{\mathrm{i} 1}, \mathrm{~N}_{\mathrm{i}, \mathrm{m}-\mathrm{l}}$ and $\mathrm{N}_{\mathrm{im}}$ nodes.

Reflective boundaries were imposed at the "upper" $(\mathrm{z}=0)$ and "lower" $(\mathrm{z}=\mathrm{h}$, the mixed layer depth) boundaries, so that:

$$
\frac{\partial N}{\partial z}=0
$$

at these boundaries. This was incorporated into the difference approximations by "mirroring" the nodes within the boundary across the boundary. Thus " $\mathrm{N}_{-1, \mathrm{j}}$ " (a nonexistent node) was taken as equal to $\mathrm{N}_{1, \mathrm{j}}$ and the approximations developed for the interior can be rewritten using this substitution (for $\mathrm{i}=0$ ):

$$
\frac{3 N_{0, f} A_{0, j}-4 N_{0, j-1} A_{0, j-1}+N_{0, j-2} A_{0, j-2}}{2 \Delta \Gamma^{*}}+K_{V}\left(\frac{-2 N_{0, j}+2 N_{1, j}}{(\Delta z)^{2}}\right)=0
$$

A similar approximation holds for the nodes at $\mathrm{i}=\mathrm{n}$. The corner nodes, where both boundary effects occur, were written using the appropriate combination of the above boundary approximations.

One additional constaint was imposed upon the system. The integral over $\Gamma^{*}$ at each depth was taken to be one, thus yielding a probability density function. Therefore, for each i, 


$$
\sum_{j=1}^{m} N_{i j}=1
$$

This equation was substituted, with replacement, at an interior node, generally near the mode of the density function. This choice of nodes seems to yield a smaller error in the approximation.

The logistic model from Chapter IV:

$$
-\frac{1}{\ln 10} \frac{\partial}{\partial \Gamma^{*}}\left(N \gamma\left[\frac{\Gamma_{\infty}-10^{\Gamma^{*}}}{\Gamma_{\infty}}\right]\right)+K_{V} \frac{\partial^{2} N}{\partial z^{2}}=0 .
$$

can be approximated in a similar manner by replacing A (Eq. 2) with:

$$
A=-\frac{N \gamma}{\ln 10}\left(\frac{\Gamma_{\infty}-10^{\Gamma^{*}}}{\Gamma_{\infty}}\right)
$$

\section{Matrix Formulation and Solution}

Using the difference approximations above to derive the coefficients of the

$\mathrm{N}_{\mathrm{ij}}$ 's, an equation was created for each node point in the ar'ay (Fig. 1). This yields a system of $n * m$ equations, with $n * m$ unknowns. These were written in matrix form and solved directly using gaussian elimination. The code is available from the author. 
Appendix E

Numerical Algorithm for the Quasi-Steady State Photoacclimation-Diffusion Model of Chapter V 


\section{Numerical Algorithm for the Quasi-Steady State Photoacclimation-Diffusion Model of Chapter V}

I present here the numerical algorithm by which the logistic photoacclimation diffusion equation:

$$
\frac{\partial \Gamma}{\partial t}=K_{V} \frac{\partial^{2} \Gamma}{\partial z^{2}}+\gamma \Gamma_{\infty}\left(\frac{\Gamma_{\infty}-\Gamma}{\Gamma_{\infty}}\right)
$$

was solved. A quasi-steady state was assumed, with each 24-hour photoperiod identical to the previous 24-hours.

\section{Model Definition}

A discretized random walk model was used to characterize the distributions of a photoaccliative parameter, $\Gamma$, as a function of time and depth. The model was set up as an initial value problem, and allowed to run until a quasi-steady state was reached.

A regular rectangular array of nodes (or "bins") was defined (Fig. 1) between the boundaries of the surface and the base of the mixed layer and the maximum and minimum possible values of the photoacclimative parameter.

\section{Initial Conditions}

The initial conditions chosen represent a non-mixed, fully acclimated water 
Figure 1 - Definition schematic for the finite-difference approximation discussed in the text. $\mathrm{N}_{\mathrm{ij}}$ represents the marginal probability of a cell at a depth, $\mathrm{z}$, corresponding to the $\mathrm{j}^{\text {th }}$ row, having a photoacclimative state, $\Gamma$, corresponding to the $\mathrm{i}^{\text {th }}$ column. 


\section{Photoacclimative Parameter $\left(\Gamma^{*}\right)$}

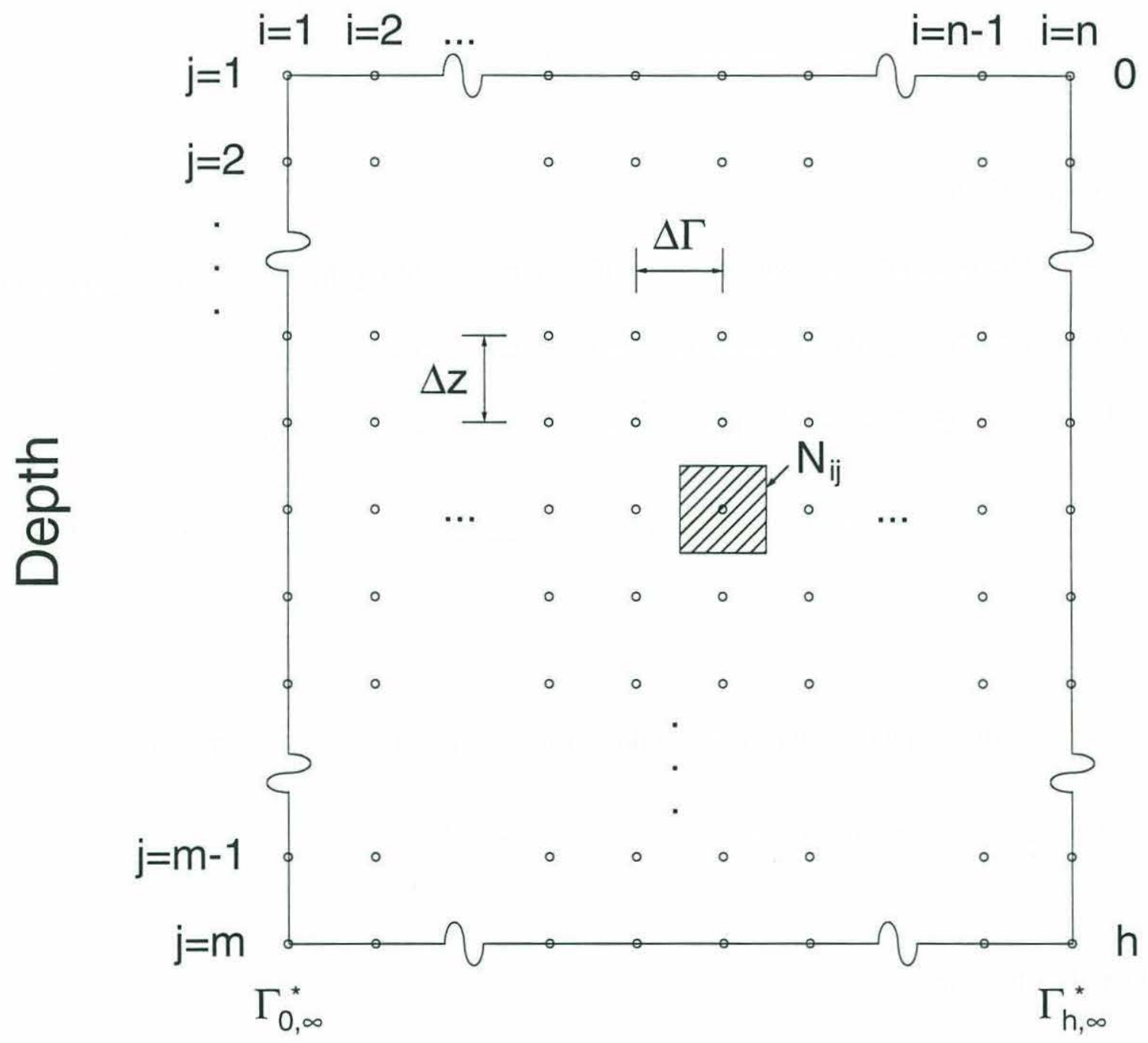


column. Thus, $\mathrm{N}_{\mathrm{ij}}=0$ for all ij where $\Gamma_{\mathrm{ij}} \neq \Gamma_{\mathrm{i}, \infty}$. The value of $\mathrm{N}_{\mathrm{ij}}$ where $\Gamma_{\mathrm{ij}}=\Gamma_{\mathrm{i}, \infty}$ was set to 1 .

\section{Temporal Propagation}

The system was propagated through time using a discretized random walk to approximate the mixing term, coupled with photoacclimation.

\section{Random Walk}

The random walk was incorporated by redistributing the node values according to a normal probability distribution with a variance equal to $2 \mathrm{~K}_{\mathrm{v}} \Delta \mathrm{t}$. Thus the value (due to the mixing term) at a given node point $\mathrm{N}_{\mathrm{ij}}$ at time $\mathrm{t}+\Delta \mathrm{t}$ is:

$$
N_{i j}(t+\Delta t)=\sum_{k} N_{k j}(t) \cdot \frac{1}{\sqrt{2 \pi} \sqrt{2 K_{V} \Delta t}} e^{-[(k-i) \Delta z]^{2} / 4 K_{\downarrow} \Delta t}
$$

The range of summation was $\mathrm{i} \pm 3$ standard deviations (i $\pm 3 \Delta z \sqrt{2 K_{V} \Delta t}$ ), thus including $99.7 \%$ of the contribution of cells from adjacent depths.

\section{Photoacclimation}

The photoacclimation term in equation (1) was integrated to yield (Cullen and Lewis, 1988): 


$$
\Gamma(t+\Delta t)=\frac{\Gamma_{\infty}}{1+\left[\left(\Gamma_{\infty}-\Gamma(t)\right) / \Gamma(t)\right] e^{-\gamma \Delta t}}
$$

which can be solved for $\Gamma(\mathrm{t})$ :

$$
\Gamma(t)=\frac{\Gamma_{\infty}}{1+\left[\left(\Gamma_{\infty}-\Gamma(t+\Delta t)\right) / \Gamma(t+\Delta t)\right] e^{\gamma \Delta t}}
$$

During each time step, the values of $\Gamma(\mathrm{t})$ was determined for each value of $\Gamma(\mathrm{t}+\Delta \mathrm{t})$ correponding to the left and right boundaries of each node bin (Fig. 1). I define these values as $\Gamma_{\mathrm{i}, \mathrm{j}-1 / 2}(\mathrm{t})$ and $\Gamma_{\mathrm{i}, \mathrm{j}+1 / 2}(\mathrm{t})$, respectively, and they define the limits of the region in $\Gamma$-space which contains cells that will acclimate sufficiently during time $\Delta \mathrm{t}$ to be contained within the node $\mathrm{N}_{\mathrm{ij}}(\mathrm{t}+\Delta \mathrm{t})$. The value of $\mathrm{N}_{\mathrm{ij}}(\mathrm{t}+\Delta \mathrm{t})$ can be computed from:

$$
N_{i j}(t+\Delta t)=\sum_{\Gamma_{i, j-1 / k}(t)}^{\Gamma_{i, j+1}(t)} N_{i j}(t)
$$

Values of $\Gamma_{\mathrm{i}, \mathrm{j}-1 / 2}(\mathrm{t})$ and $\Gamma_{\mathrm{i}, \mathrm{j}+1 / 2}(\mathrm{t})$ which were between node boundaries were linearly interpolated in the above summation.

\section{Growth}

Cell growth was considered in a separate model ${ }^{1}$ and incorporated here by

${ }^{\mathrm{I}}$ The growth model is similar to the photoacclimation-diffusion model except that the integrated photoacclimation term was replaced with the integrated cell concentration and 
simply forcing

$$
\sum_{j} N_{i j}=C_{i}
$$

where $\mathrm{C}_{\mathrm{i}}$ is the concentration predicted by the growth model at the depth corresponding to $\mathrm{N}_{\mathrm{ij}}$. Each $\mathrm{N}_{\mathrm{ij}}$ was corrected by the factor $\mathrm{C}_{\mathrm{i}} / \Sigma_{\mathrm{ij}} \mathrm{N}_{\mathrm{ij}}$ in order to satisfy equation (6).

\section{Boundary Conditions}

Boundaries at the minimum and maximum values of $\Gamma$ were incorporated by simply setting any contributions (during the photoacclimation step) from nodes outside this range to zero. Reflective boundaries at the surface $(z=0)$ and the base of the mixed layer $\left(\mathrm{z}=\mathrm{h}\right.$ ) were incorporated by mirroring the $\mathrm{N}_{\mathrm{ij}}$ to a virtual array either above or below the $\mathrm{N}_{\mathrm{ij}}$ array. The summation in equation (2) will thus reflect the contributions from the virtual array.

\section{Solution}

The system was propagated through time assuming a 10:14 light:dark photoperiod, with the lights "on" from 09:00 to 19:00. The rate constant used for photoacclimation was $3.5 \mathrm{~d}^{-1}$ during the light period and zero otherwise. Mixing was constant throughout, with diffusivities as presented in Chapter V. The model was run

substrate equations (Chapter V, Eq. 2-4). Diel patterns were not considered as they were not expected to significantly affect the gradient in cell number. 
for several "days" (simulated) until the daily pattern repeated itself, thus establishing the quasi-steady state dynamics. The time-step was constrained so that the standard deviation of the diffusing distribution was greater than the depth interval sampled $\left(\sqrt{2 K_{V} \Delta t}>\Delta z\right)$. Memory limitations on the workstation used constrained $\Delta \mathrm{z}$ to a minimum value of $4 \mathrm{~cm}$. The simulation was repeated at increasingly smaller time steps until convergence (defined as $<1 \%$ change) was attained or until the above limit was reached. These simulations generally either satisfied this convergence at the limit or were demonstrating approximately $3 \%$ differences between node values at the limit. 


\section{Reference}

Cullen, J. J. and M. R. Lewis. 1988. The kinetics of algal photoadaptation in the context of vertical mixing. J. Plankton Res. 10:1039-1063. 
Appendix F

\section{Increasing the Sensitivity of a FACScan Flow Cytometer to Study Oceanic Picoplankton}

Reprinted with permission from Limnology and Oceanography 


\title{
Increasing the sensitivity of a FACScan flow cytometer to study oceanic picoplankton
}

Jeffrey A. Dusenberry and Sheila L. Frankel

Ralph M. Parsons Laboratory, Department of Civil and Environ. Engineering, Massachusetts Institute of Technology, Cambridge, 02139

\begin{abstract}
Existing limitations on the sensitivity of commercially available flow cytometers do not permit the detection of extremely dim picoplankton cells, particularly Prochlorococcus marinus in near surface oligotrophic ocean waters. This problem was overcome by making some simple modifications to a FACScan (Becton Dickinson) flow cytometer to increase its sensitivity by about fivefold. The fluorescence and side scatter sensitivity was increased by replacing the existing focusing lens and beam steering mirror with a $3 \times$ expansion telescope and a slightly shorter focusing lens, resulting in a smaller laser spot size at the interrogation point. Forward scatter sensitivity was increased by replacing the existing photodiode with a photomultiplier tube, which has a background noise level about an order of magnitude lower. The fluorescence sensitivity of the modified instrument, measured with a quantitative fluorescence microbead standards kit, is 74 molecules of equivalent soluble fluorochrome for fluorescein. The instrument can now detect extremely dim P. marinus from open-ocean surface waters.
\end{abstract}


Sea-going flow cytometry has been used to study oceanic picoplankton for some time (Yentsch et al. 1983; Olson et al. 1985; Li and Wood 1988). These measurements have been made almost exclusively with the use of commercial instruments designed for biomedical use. High sensitivity measurements (needed to detect low fluorescence picoplankton such as Prochlorococcus marinus) typically require large instruments that use high-power water-cooled lasers (e.g. Epics V, Coulter Corp.), making shipboard use inconvenient. Even these instruments require modifications to enable them to detect dimly fluorescent picoplankton (Olson et al. 1990). Smaller air-cooled "clinical" instruments typically lack the flexibility and sensitivity needed for oceanographic use, although their relative portability and ease of use would otherwise make them ideal. For example, the FACScan (Becton Dickinson) is quite sensitive, but it cannot always detect $P$. marinus in near-surface oligotrophic waters, where cellular fluorescence can be quite low.

The unmodified FACScan uses a $15-\mathrm{mW}$ argon ion laser, a set of prisms to expand the beam in the vertical dimension, a $68-\mathrm{mm}$ plano-convex lens to focus the laser beam down to a spot size of $\sim 20 \mu \mathrm{m}$ (vertical) $\times 60 \mu \mathrm{m}$ (horizontal), and a beam steering plate to fine tune the position of the spot (Fig. 1). Five signal parameters are collected as cells pass through the laser beam: forward light scatter, right-angle light scatter, and green $(530 \mathrm{~nm}$, bandwidth at half-maximum of $30 \mathrm{~nm})$, orange $(585 \mathrm{~nm}$, bandwidth at half-maximum of $42 \mathrm{~nm}$ ), and red (> $650 \mathrm{~nm}$ ) fluorescence. For studying picoplankton, only the two scatter parameters, the orange (phycoerythrin) and the red (chlorophyll) fluorescence channels are typically used. The green channel 
(generally used for the detection of FITC-stained cells) is not used. Right-angle light scatter and the three fluorescence channels are measured via photomultiplier tubes positioned behind a collection lens situated at right angles to the flow cell, while forward light scatter is measured with a photodiode.

One approach to improving the sensitivity of a flow cytometer is to increase the intensity of the laser light incident on the interrogation point; the spot intensity can be increased by increasing the laser power, decreasing spot size at the interrogation point, or both. Because installing a more powerful laser is difficult in a FACScan, we increased the laser intensity by decreasing spot size. In a diffractionlimited system (a system in which aberration is negligible), the spot size depends upon the incoming beam geometry and optics according to

$$
2 \mathrm{w}_{0}=(4 \lambda / \pi)(\mathrm{F} / \mathrm{D}) .
$$

$2 \mathrm{w}_{0}$ is the spot diameter, $\lambda$ the wavelength of the laser light, $\mathrm{F}$ the focal length of the focusing lens, and D the diameter of the collimated laser beam. Although the FACScan is not strictly a diffraction-limited system, it behaves essentially as such; it follows that an increase in the diameter of the incoming laser beam would result in a decrease in the spot size.

The diameter of the laser beam was expanded by placing a $3 \times$ expansion telescope between the prisms and the focusing lens. The expanded laser beam allowed for a threefold decrease in the linear dimensions of the diffraction-limited spot size to $\sim 7 \mu \mathrm{m}$ (vertical) $\times 20 \mu \mathrm{m}$ (horizontal), resulting in a ninefold decrease in the crosssectional area of the spot. These changes should yield a maximum ninefold increase 
Figure 1 - Schematic of FACScan excitation optics before and after modifications. 


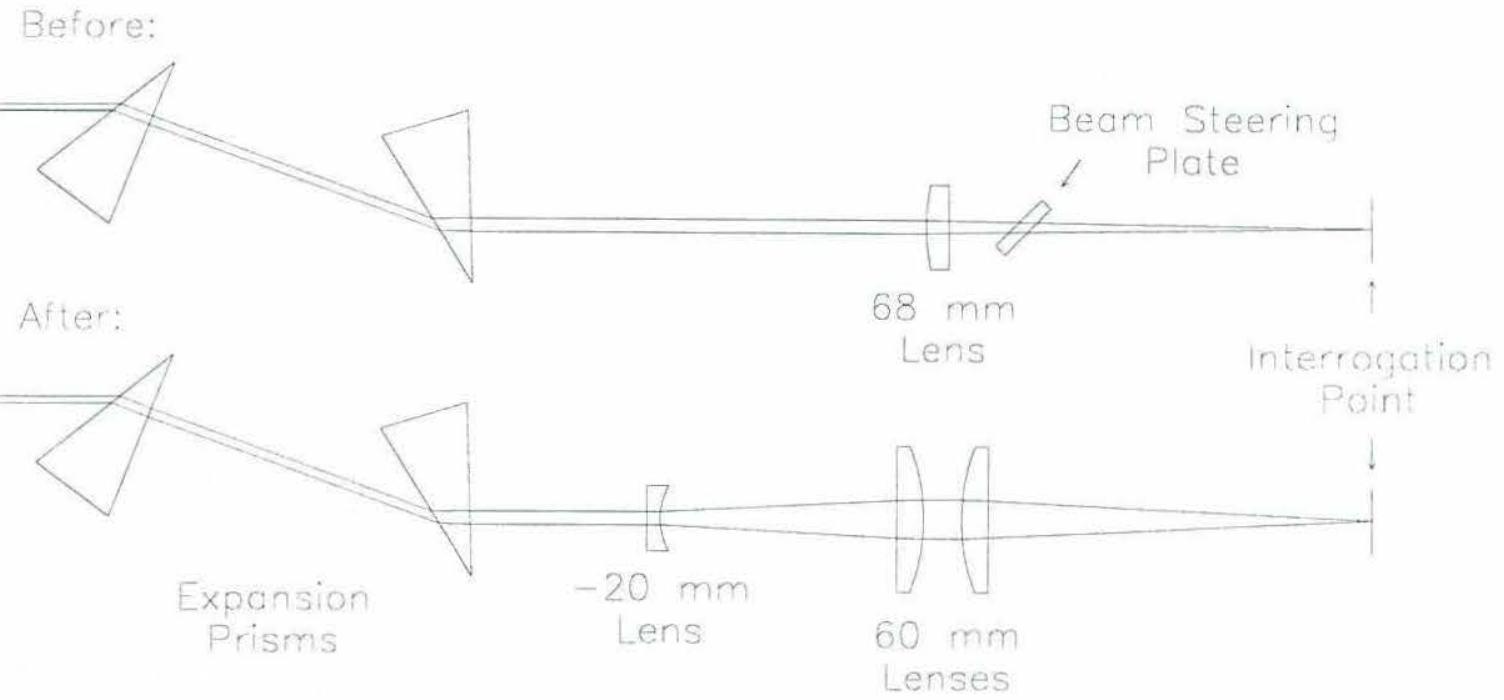


(less any decrease due to aberration) in intensity of the laser beam incident on the particle. A plano-concave lens of 20-mm focal length and a plano-convex lens of 60$\mathrm{mm}$ focal length (lenses from CVI Lasers) were used to expand the beam threefold (Fig. 1). We also replaced the existing focusing lens with another plano-convex 60$\mathrm{mm}$ focal length lens as these lenses were ground to fit into a single barrel mount (22.4-mm i.d.) (Spindler/Hoyer). The barrel was mounted on a three-axis translation stage fitted with a kinematic mirror mount (Newport Corp.) which provided five degrees of movement (three translational, two rotational). This positioning stage allowed accurate positioning of the lenses in the laser beam, which was already aligned to the interrogation point. The negative lens was mounted with the flat surface towards the laser, which generates more negative (spherical) aberration to counteract some of the positive aberration produced by the positive lenses (which are in their minimum aberration configuration with their curved surfaces oriented towards the collimated part of the beam).

Due to the noise associated with the photodiode detector, forward scatter sensitivity in the original FACScan was barely sufficient to detect the largest P. marinus cells and the $0.57-\mu \mathrm{m}$ microspheres (Polysciences, Inc.) that we use as an internal standard. To improve forward scatter sensitivity, we replaced this photodiode with a head-on type photomultiplier tube from an Ortho flow cytometer (similar tubes are available from Hamamatsu Corp.), which has a much higher signal-to-noise ratio. We used a standard photomultiplier housing (Thorn-EMI) with a simple custom-made fitting to allow the housing to attach directly to the existing photodiode mount. The 
built-in power supply and amplifier for the green fluorescence channel was used to power the new forward scatter photomultiplier tube, and the forward scatter obscuration bar (which blocks direct laser light from reaching the detector) was replaced with a larger one. The latter was necessary because expanding the laser beam and using a shorter focusing lens results in increased divergence of direct laser light at the forward scatter collection lens.

Because of the smaller spot size, the amount of time that particles were excited by the laser beam was reduced. Unfortunately, the resulting decreased signal pulse width exceeded the bandwidth of the FACScan's amplifiers. To compensate for this, we decreased the sample velocity through the interrogation point by reducing the sheath pressure to $12 \mathrm{kPa}$ (from $31 \mathrm{kPa}$ ). The slower sample velocity coupled with the increased spot intensity yields a fivefold increase in sensitivity, but necessitates slower sample throughput. The sheath pressure cannot be decreased much more, as the FACScan incorporates a built-in override which shuts down the sample flow and the laser when the sheath pressure drops too low. One could conceivably override this mechanism, but the above sample throughput and sensitivity combination proved to be a good compromise for our purposes. In addition, the alignment of the new lens system was very temperature sensitive and required an hour of warm up time.

The threshold sensitivity of the modified instrument was established using a mixture of fluorescein calibration beads and unstained reference beads (Flow Cytometry Standards Corp.). These beads are used to measure the noise level of an instrument as indicated by the signal measured from the unstained beads relative to the 
stained calibration beads. Noise levels can thus be expressed in terms of molecules of equivalent soluble fluorochrome (MESF), which can be used to compare different machines or configurations. Because the calibration beads were designed to fluoresce green, the green channel was used for this calibration. The increase in sensitivity of the green channel was representative of that of all the fluorescence channels (see below). The sensitivity threshold of 74 MESF was substantially better than 480 MESF obtained with the unmodified system.

The increased sensitivity of the instrument makes it possible to quantify surface (low pigment) picoplankton samples from the Sargasso Sea which were not readily detectable and not well resolved with the standard configuration. Before the modifications, the surface population of $P$. marinus was not completely separable from the noise, whereas after the modifications $P$. marinus was distinct from background noise (Fig. 2), permitting quantification of cell number as well as the distribution of fluorescence for this population. The relative increase in fluorescence of the cells was less than that of the beads (Fig. 2) probably as a result of the close proximity of the signal from $P$. marinus cells to the noise in the unmodified instrument (causing the signal from the cells to reflect the influence of baseline noise). In addition, P. marinus and Synechococcus spp. fluorescence relative to that of the $0.57-\mu \mathrm{m}$ microspheres decreases (even though absolute fluorescence increases) with increasing laser intensity (data not shown), suggesting a decrease in fluorescence yield for these cells with increasing laser intensity.

The change in fluorescence and scatter signals from the $0.57-\mu \mathrm{m}$ microspheres 
was used to quantify the change in sensitivity of the other fluorescence and scatter channels. The high voltage settings on the fluorescence power supplies were kept the same and the amplifiers kept in log mode to avoid any artifacts due to changes in signal amplification. However, it was necessary to decrease the high voltage setting on the right-angle scatter photomultiplier tube in order to keep the signals on-scale. The right-angle scatter values obtained after the modifications were corrected to the previous setting by multiplying by the ratio of the right-angle scatter of the microspheres at the two settings. The threshold noise level (arbitrarily defined here as the threshold level where the noise rate exceeds $150 \mathrm{cps}$ ) on right-angle light scatter, orange fluorescence, and red fluorescence did not change as a result of the modifications. The signal from the $0.57-\mu \mathrm{m}$ microspheres was almost fivefold greater on the fluorescence channels and almost eightfold greater on right-angle light scatter (Table 1). We cannot compare the forward scatter signals in this manner since we changed the detection system. However, we note that before the modifications the scatter signal from $0.57-\mu \mathrm{m}$ microspheres was not distinctly different from the noise; after the modifications, the $0.57-\mu \mathrm{m}$ microspheres exhibited a signal more than a decade greater than the noise threshold (Table 1). P. marinus populations that had not previously been separable from the noise in forward scatter also exhibited forward scatter signals that were mostly above the noise threshold.

Operation of the FACScan is much the same as before modification. The alignment needs only to be adjusted once every week or so during heavy use; the day-to-day consistency of our measurements is therefore quite good. The net result is 
Figure 2 - Single-parameter histograms for red (chlorophyll) fluorescence for the same sample presented in Table 1. The $0.57-\mu \mathrm{m}$ microspheres and the cells were identified with multiparameter data analysis and the single-parameter histograms for both were replotted. Sample run before (a) and after (b) modifications to the flow cytometer. 


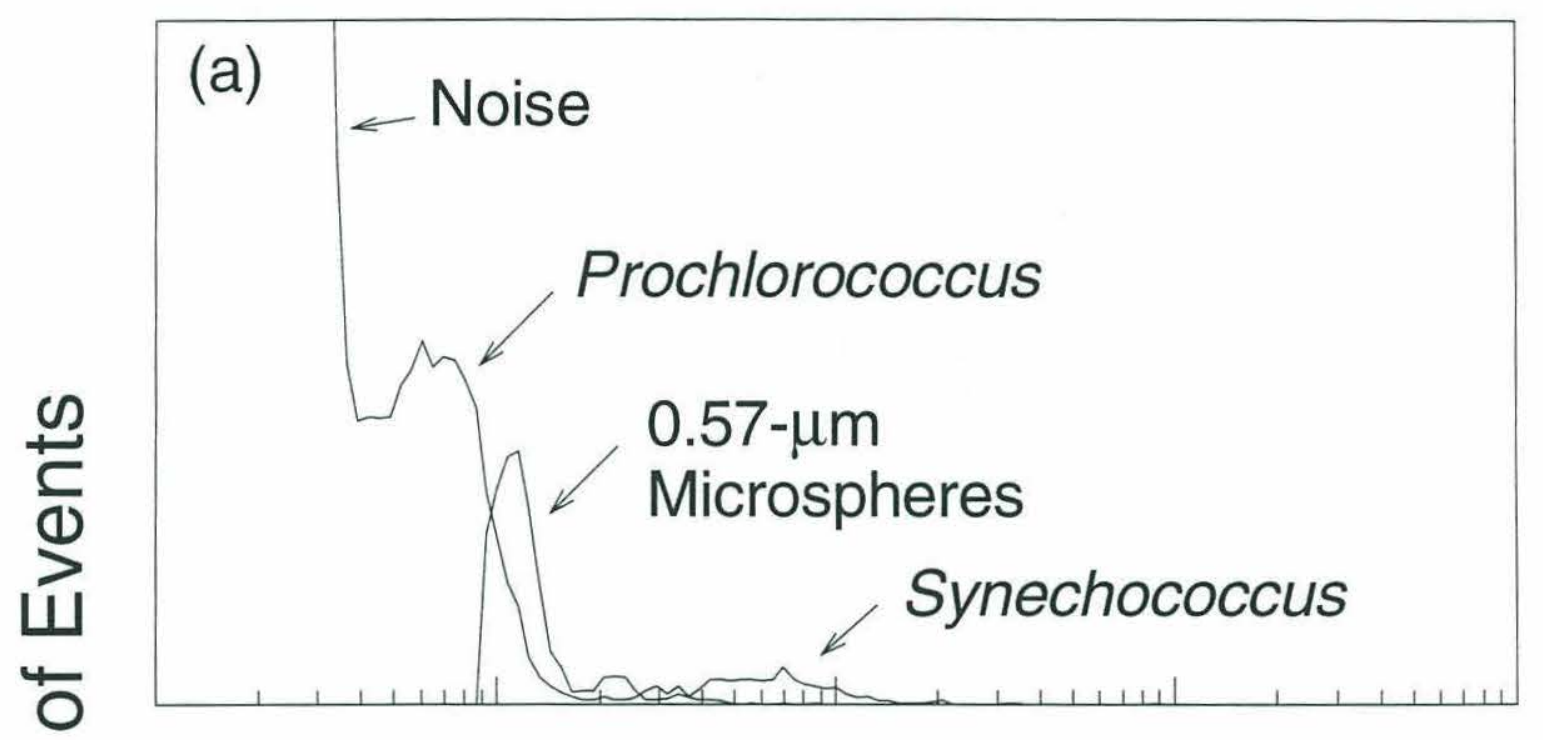

$\frac{\grave{\searrow}}{\text { है }}$

(b)

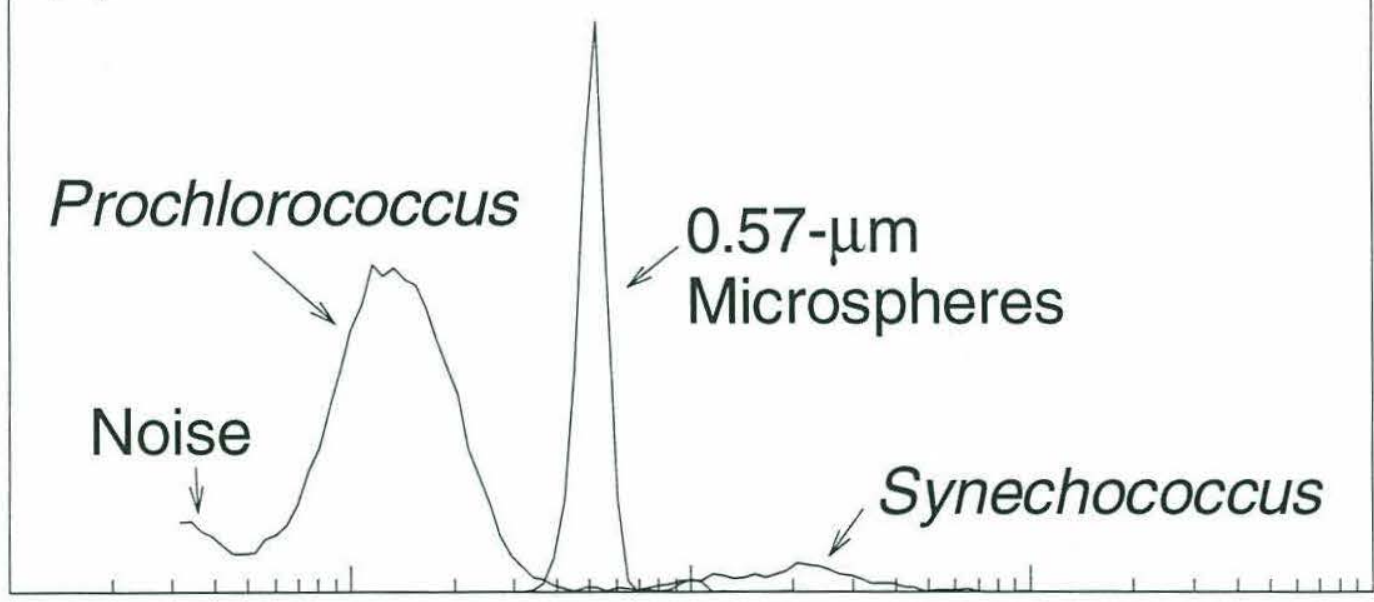

Relative Red Fluorescence 
Table 1 - Results of flow cytometric analyses of a sample from $10 \mathrm{~m}$ in the Sargasso Sea, October 1989 which was preserved by fixation with $0.1 \%$ glutaraldehyde followed by storage in liquid nitrogen. All results are given in linear values of relative fluorescence or scatter, arbitrarily assigning a value of 1 to the lowest channel.

\begin{tabular}{|c|c|c|c|}
\hline \multirow[b]{2}{*}{ Population } & \multirow[b]{2}{*}{ Parameter } & Before & After \\
\hline & & \multicolumn{2}{|c|}{ (relative units) } \\
\hline \multirow{4}{*}{$0.57 \mu \mathrm{m}$ microspheres } & Right-angle scatter & 182.3 & $1,622.0$ \\
\hline & Orange fluorescence & 36.5 & 167.4 \\
\hline & Red fluorescence & 10.6 & 50.0 \\
\hline & Forward scatter signal:noise & $<2.0$ & 37.2 \\
\hline \multirow[t]{3}{*}{ Synechococcus } & Right-angle scatter & 44.0 & 417.9 \\
\hline & Orange fluorescence & 57.2 & 139.3 \\
\hline & Red fluorescence & 63.0 & 218.8 \\
\hline \multirow[t]{2}{*}{ Prochlorococcus } & Right-angle scatter & 14.2 & 107.8 \\
\hline & Red fluorescence & 6.3 & 13.9 \\
\hline
\end{tabular}

a fairly sensitive, stable and relatively portable instrument that is well suited to oceanographic studies of picoplankton.

\section{Acknowledgments}

We thank Bob Hoffman, Rob Olson, Brian Binder and Penny Chisholm for helpful discussions, and the captain and crew of the RV Oceanus.

This work was supported by NSF (BSR 90-20254, OCE 90-00043 to S. W. Chisholm, OCE 90-12117, OCE 90-22285, and DIR 91-01361 to S. W. C. and R. J. Olson), ONR (N00014-87-K-0007 to S. W. C. and R. J. Olson), and M.I.T. Sloan Funds (to S. W. C.). J. A. D. was supported in part by an NSF graduate student fellowship. 


\section{References}

Li, W. K., and A. M. Wood. 1988. Vertical distribution of North Atlantic ultraphytoplankton: analysis by flow cytometry and epifluorescence microscopy. Deep-Sea Res. 35:1615-1638.

Olson, R. J., S. W. Chisholm, E. R. Zettler, M. A. Altabet, and J. A. Dusenberry. 1990. Spatial and temporal distributions of prochlorophyte picoplankton in the North Atlantic Ocean. Deep-Sea Res. 37:1033-1051.

Olson, R. J., D. Vaulot, and S. W. Chisholm. 1985. Marine phytoplankton distributions measured using shipboard flow cytometry. Deep-Sea Res. 32:12731280.

Yentsch, C.M., and others. 1983. Flow cytometry and sorting: A powerful technique with potential applications in aquatic sciences. Limnol. Oceanogr. 28:1275-1280. 